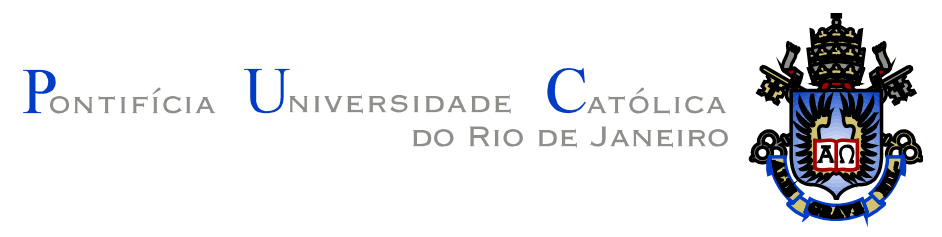

JORGE LUCAS FERREIRA

\begin{abstract}
Proposta de Metodologia para Determinação Do Alinhamento de Lagoas Urbanas Utilizando Tecnologias CAD/SIG/WEB: O Caso da Lagoa Rodrigo de Freitas - Rio de Janeiro
\end{abstract}

Dissertação de Mestrado

Dissertação apresentada ao Programa de Pós-Graduação em Engenharia Urbana e Ambiental da PUC-Rio como requisito parcial para obtenção do Título de Mestre em Engenharia Urbana e Ambiental (opção profissional).

Orientador: Prof. Antônio Roberto Martins Barboza de Oliveira Coorientador: Prof. Luiz Felipe Guanaes Rego 


\section{Proposta de Metodologia para Determinação Do Alinhamento de Lagoas Urbanas Utilizando Tecnologias CAD/SIG/WEB: O Caso da Lagoa Rodrigo de Freitas - Rio de Janeiro}

Dissertação apresentada como requisito parcial para obtenção do grau de Mestre em Engenharia Urbana e Ambiental pelo Programa de Pós-Graduação da PUC-Rio. Aprovada pela Comissão Examinadora abaixo assinada.

Antônio Roberto Martins Barboza de Oliveira Presidente / Orientador Departamento de Engenharia Civil - PUC-Rio

Profa. Maria Cláudia Barbosa UFRJ

Prof. Celso Romanel Departamento de Engenharia Civil - PUC-Rio

Prof. José Eugenio Leal Coordenador Setorial de Pós-Graduação do Centro Técnico Científico - PUC-Rio 
Todos os direitos reservados. É proibida a reprodução total ou parcial deste trabalho de pesquisa sem a autorização prévia da Universidade PUC-Rio, do autor e dos orientadores.

Jorge Lucas Ferreira

Formado em Engenharia Civil pela FTESM - Faculdade de Engenharia, Jorge Lucas Ferreira foi funcionário e Engenheiro da LIGHT S.E.S.A. de 1977 a 2013, onde ocupou vários cargos trabalhando em diversos projetos e obras do setor elétrico, como Reservatórios e Usinas Geradoras de Energia; Linhas de Transmissão/Distribuição; Estações Rurais/Urbanas; Manutenção/Construção Predial, Complexos de Escritórios/Agências Comerciais.

Informatizou e Automatizou a Topografia/Desenho da Engenharia da LIGHT, foi Coordenador de Projetos e Engenharia de Obras Civis, quando também informatizou os Serviços de Orçamento, Planejamento e Controle de Obras, implantando o Software Volare e Base de Dados TCPO/PINI, também atuando em Perícias Judiciais e Engenharia Patrimonial para expansão do Setor Elétrico, Escolhas de Alternativas e Estudos de Viabilidade Técnica de Projeto/Obra em áreas Rurais/Urbanas, em toda área de concessão da cia.

Atuando também como Professor na PUC-Rio desde 1997, nos Cursos de Engenharia Civil/Ambiental e Arquitetura e Urbanismo, sendo responsável pela Disciplina de Topografia, implantou o módulo informatizado e automatizado com aulas em laboratórios de computação, criando o Laboratório de Topografia com novos equipamentos e dinâmicas de campo.

Ficha Catalográfica

Ferreira, Jorge Lucas

Proposta de metodologia para determinação do alinhamento de lagoas urbanas utilizando tecnologias CAD/SIG/WEB : o caso da Lagoa Rodrigo de Freitas - Rio de Janeiro / Jorge Lucas Ferreira ; orientador: Antônio Roberto Martins Barboza de Oliveira ; co-orientador: Luiz Felipe Guanaes Rego. - 2014.

181 f. : il. (color.) ; $30 \mathrm{~cm}$

Dissertação (mestrado)-Pontifícia Universidade Católica do Rio de Janeiro, Departamento de Engenharia Civil, 2014.

Inclui bibliografia

1. Engenharia civil - Teses. 2. Engenharia urbana e ambiental.

3. Urbano-ambiental. 4. Fauna-flora. 5. Legislação urbana e uso do solo. 6. Alinhamento e as margens das lagoas urbanas. 7. Ecossistemas lagunares. 8. Mapeamento georreferenciado. 9. Relevo. 10. Hidrografia. 11. Tecnologias CAD/SIG/WEB. 12. Portais na internet. I. Oliveira, Antônio Roberto Martins Barboza de. II. Rego, Luiz Felipe Guanaes. III. Pontifícia Universidade Católica do Rio de Janeiro. Departamento de Engenharia Civil. Programa de Pós-Graduação em Engenharia Urbana e Ambiental. IV. Título. 


\section{Agradecimentos}

Em 2011 ao encerrar mais um período letivo conduzindo a Disciplina de Topografia na PUC-RIO, em conversa com o então Diretor do DEC, Prof. Raul Rosas, recebi a sugestão do mesmo de ingressar no Curso de Mestrado Profissional em Engenharia Urbana e Ambiental - DEC-PUC-RIO. Como já tinha planos de avançar nas especializações Urbano-Ambientais em função das minhas atividades profissionais e acadêmicas, a sugestão foi a alavanca para a decisão e o meu empenho e dedicação em realizar esse Mestrado Profissional.

Agradeço muito ao Prof. Raul Rosas por sua sugestão e motivação. Agradeço também a todos os colegas de turma pela participação e colaboração durante o curso.

Agradeço a todos os professores que deram ideias e orientações para a escolha e elaboração deste estudo e dissertação, que realizei com interesse, principalmente pelo emprego de tecnologia digital e acesso aos portais de órgãos públicos e privados, que hoje se constituem uma realidade na vida profissional. Agradeço aos meus orientadores Prof. Antônio Roberto Martins Barboza de Oliveira e Prof. Luiz Felipe Guanaes Rego pelas ideias, acolhida e liberdade de atuação, bem como em especial também agradeço ao Prof. Celso Romanel sempre presente e atuante.

Um especial agradecimento em memória do engenheiro Theo Ramos Martha, companheiro de trabalho na LIGHT S.E.S.A. no final dos anos 80 e início dos anos 90, na equipe de Engenheiros de Patrimônio daquela empresa, onde elaboramos diversos e bons trabalhos. Agradeço muito o convívio, a amizade, o exemplo de pessoa e a inspiração. 


\section{Resumo}

Ferreira, Jorge Lucas; de Oliveira, Antônio Roberto Martins Barbosa (Orientador); Rego, Luiz Felipe Guanaes (Coorientador). Proposta de Metodologia para Determinação do Alinhamento de Lagoas Urbanas Utilizando Tecnologias CAD/SIG/WEB: O Caso da Lagoa Rodrigo de Freitas - Ri de Janeiro. Rio de Janeiro, 2014, 181p Dissertação de Mestrado - Departamento de Engenharia Civil - Pontifícia Universidade Católica do Rio de Janeiro.

A determinação do Alinhamento das Lagoas Urbanas é hoje no contexto das grandes cidades, uma questão complexa e polêmica, iniciada pela necessidade de Manutenção Ambiental daqueles espelhos d'água, suas margens e características paisagísticas, considerando todo o manancial hidráulico e biológico envolvido (ecossistema), mas ao mesmo tempo atendendo a premente necessidade e determinação do Uso do Solo Urbano, com as diversas necessidades de ocupação e expansão, que encontram nas margens e adjacências dessas lagoas, uma válvula de escape oportuna e atraente, principalmente por suas características naturais, que acabam por oferecer paisagens belas e prazerosas, remetendo inclusive e principalmente a Valorização Imobiliária. Observa-se em diversas cidades, o quanto é atraente e interessante sobre o Aspecto Urbanístico e Paisagístico, os bairros, regiões e ocupações adjacentes a esses espelhos d'água. Considerando a complexidade e motivação do assunto, inserido no Contexto Social, Ambiental, Urbano e Tecnológico atual, o Estudo das Condicionantes que venham a definir e implantar o Alinhamento das Lagoas Urbanas, de modo a preservar as melhores condições ambientais da região, utilizando tecnologias digitais de Sistemas de Desenho em CAD e Sistemas de Informação Geográfica SIG, para a montagem, estruturação, comparação e análises dos dados envolvidos e pesquisados na Web, motivou a escolha e objetivos desta dissertação.

\section{Palavras-Chave}

Urbano-Ambiental; Fauna-Flora; Legislação Urbana e Uso do Solo; Alinhamentos e as Margens das Lagoas Urbanas; Ecossistemas Lagunares; Mapeamento Georreferenciado; Relevo; Hidrologia; Tecnologias CAD/SIG/WEB; Portais na Internet. 


\section{Abstract}

Ferreira, Jorge Lucas; de Oliveira, Antônio Roberto Martins Barbosa (Advisor); Rego, Luiz Felipe Guanaes (Co-Advisor). Proposed Methodology for Determination the Urban Lagoons Alignment Using Technology CAD/GIS/WEB: The Case of Lagoon Rodrigo de Freitas Rio de Janeiro. Rio de Janeiro, 2014, 181p. Master's thesis - Departamento de Engenharia Civil, Pontifícia Universidade Católica do Rio de Janeiro.

In various cities is observed how much is attractive and interesting about the urban and landscape aspect, neighborhoods, regions and occupations adjacent the Urban Lagoons.

Considering the complexity of the subject, the objective of this work is to propose methodology for the study of conditioning factors that can influence the determination of the limits of the alignment of urban lagoons in order to preserve the best conditions and environmental characteristics of the region, using CAD technology and GIS for the analysis and selection of such conditions.

\section{Introdution}

The choice of this theme was motivated by the desire for plan the use of urban land on the banks of the Urban Lagoons, in order to respect the environment and preserve its natural resources, as subject in evidence today.

Due to population growth that has taken place in various urban centers, the need for densification and expansion of its boundaries, is invariably associated with a planning and redesign pathways to enable and enhance the urban mobility. The margins and adjacent area to the lagoons, just turning into alternative occupation, which undermines the conservation of natural areas, as seen in Figure 01 . 


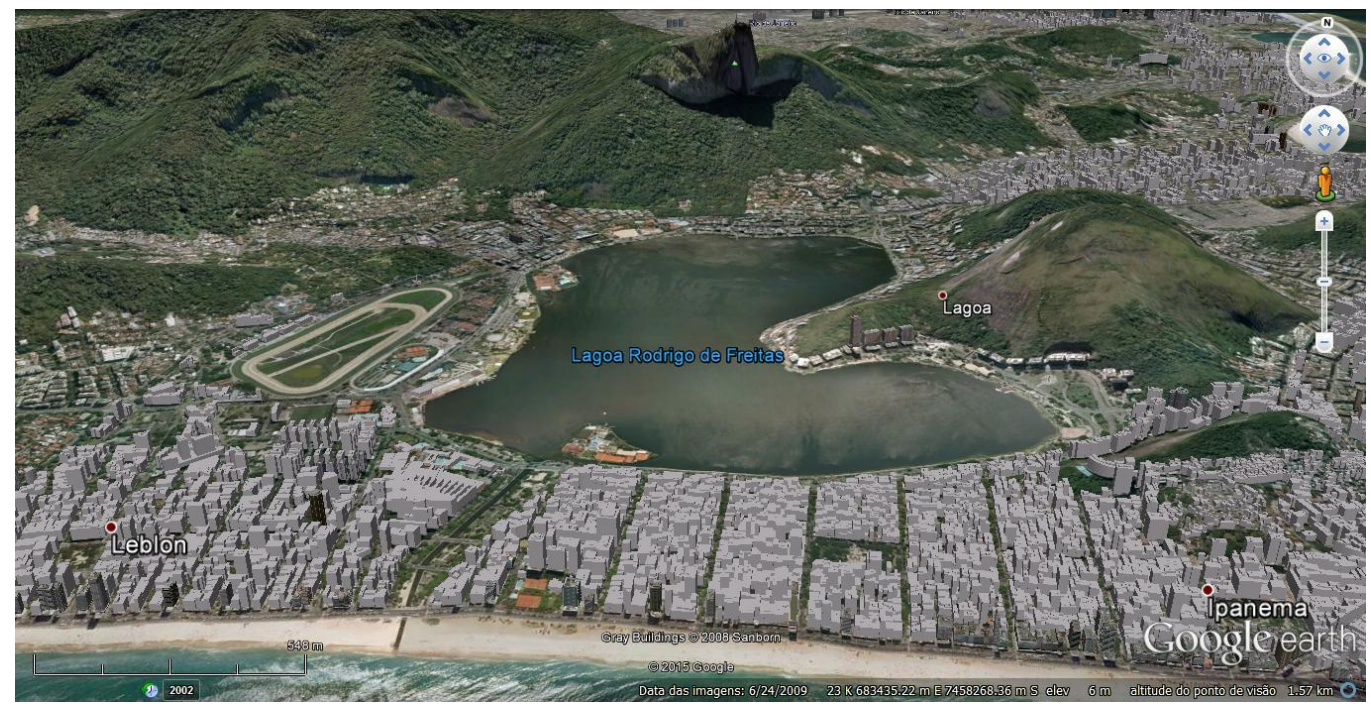

Figure 01 - View of the Rodrigo de Freitas Lagoon

Thus, determine a limit to these urban occupations in the margins of the

Lagoons is essential to the necessary preservation of the nature of the lagoon systems.

Finally, take the Rodrigo de Freitas Lagoon as "Case Study", was due to its location and importance in relation to our city, and especially the exemplary and historical dualism of its Urban-Environmental context and the strong real estate appeal.

\section{Factors Conditioning}

With the purpose to confirm and consolidate the knowledge and use of technological tools (CAD / GIS) and consultation with existing database, this study established the idea of electing comparative parameters, possible conditioning factors involved in defining the limits of alignment of urban lagoons. Based on a concept map as can be seen in Figure 02, we analyzed the natural environmental conditions inherent in the region, as well as urban interventions already made, picturing quantitative and qualitative parameters, organized into two groups, according to their characteristics of influence. 


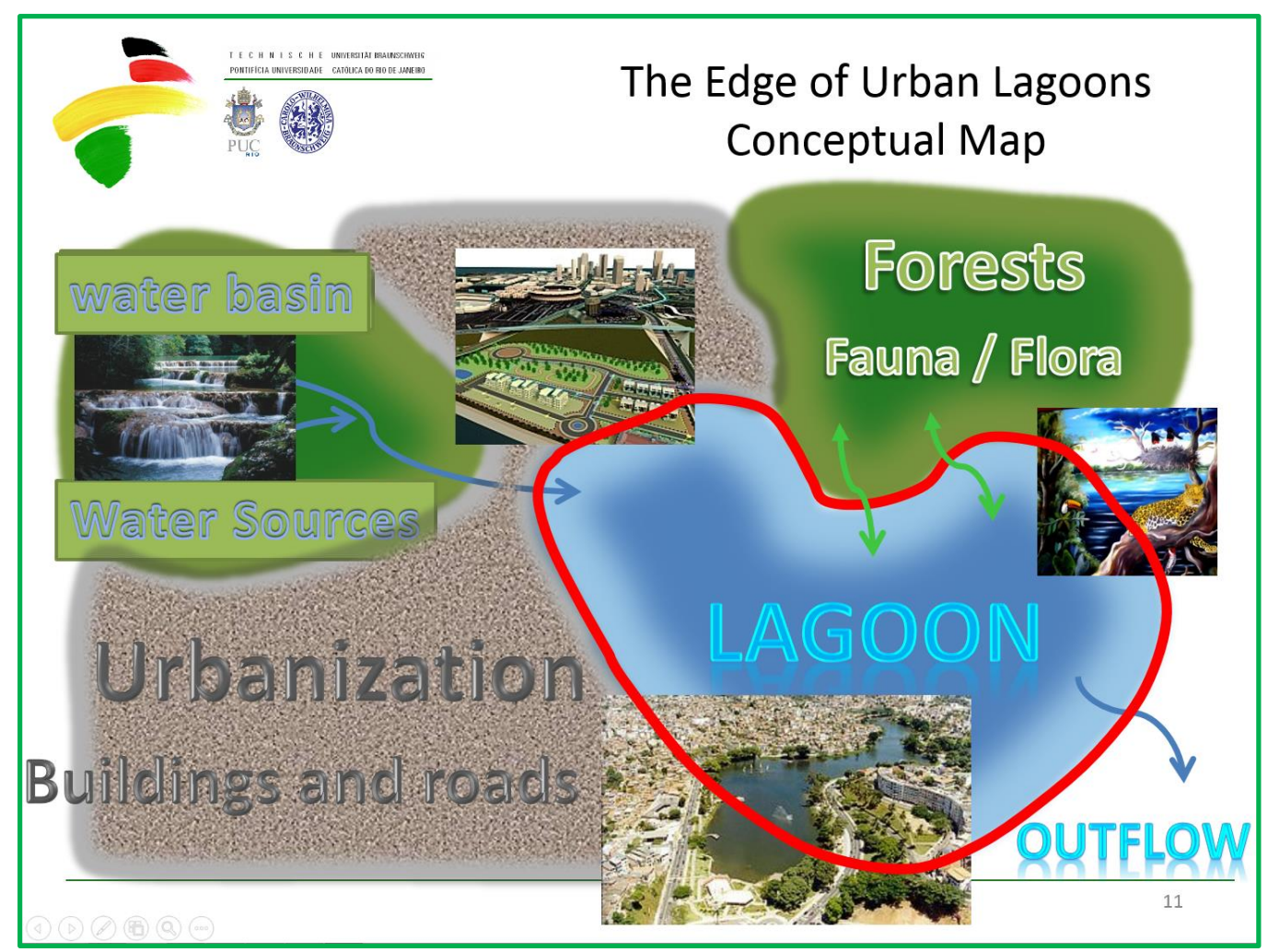

Figure 02 - Conceptual map of the edge of lagoons - With Urbanization

In a first level of classification, were designed two groups:

\section{$\underline{\text { Environmental Factors }}$ and $\underline{\text { Urban Factors. }}$}

Then in each of these groups were identified conceptually other levels now more specific, forming a structure as shown in Figure 03.

\begin{tabular}{|c|c|c|c|c|c|c|c|c|}
\hline \multicolumn{7}{|c|}{ FACTORS CONDITIONING } \\
\hline \multicolumn{3}{|c|}{ ENVIRONMENTAL } & \multicolumn{3}{c|}{ URBAN } \\
\hline FAUNA & FLORA & GEOLOGICAL & TOPOGRAPHIC & HYDROLOGICAL & ALIGNMENTS & INFRASTRUCTURE & REGULAR & IRREGULAR \\
\hline
\end{tabular}

Figure 03 - Factors Conditionings Structure

Therefore, considering this fundamental structure, we designed study these conditioning factors, using a process to determine a relationship of influence and balance guided by the objectives of this thesis. 


\section{Methodology and Query Tools}

The Obtaining of technical material to form the Geographic Base Georeferenced and Technical Documentation and Specific, was carried out through consultation and access to portals Official Certificates, published and made available online by the various organs and Public and Private Entities involved and responsible for each specific subject, such as the example in Figure 04 - Charter Geological-Geotechnical. This research is to enable the analysis of the geological characteristics of the region, and with the use of the concepts of Geotechnics, will measure and parameterize this conditioning factor.

This is done for all the other defined conditioning factors, will possible the development of a specific diagnosis to define the limits of the alignment of the lagoon Urban studied.

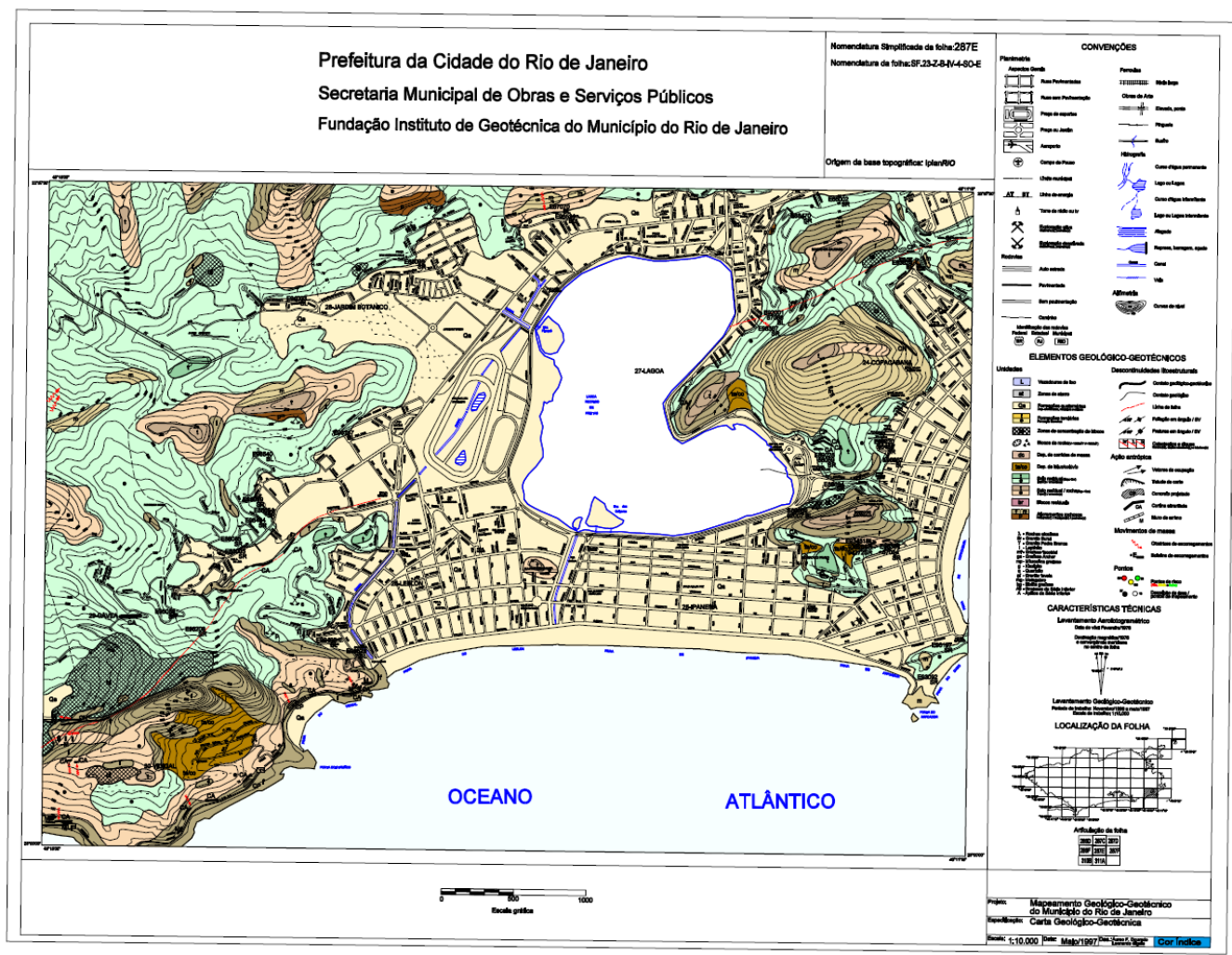

Figure 04 - Charter Geological-Geotechnical, leaf 287e 


\section{Development - Production of Maps}

After the research phase we investigate the information in database interpreting the existing maps, and developing others in the various disciplines and conditions involved, as shown in Figures 05 and Figure 06, in order to measure its importance and interference in the context of the defining limits the alignment of Urban Lagoon in study, thus creating a parameterized value system.

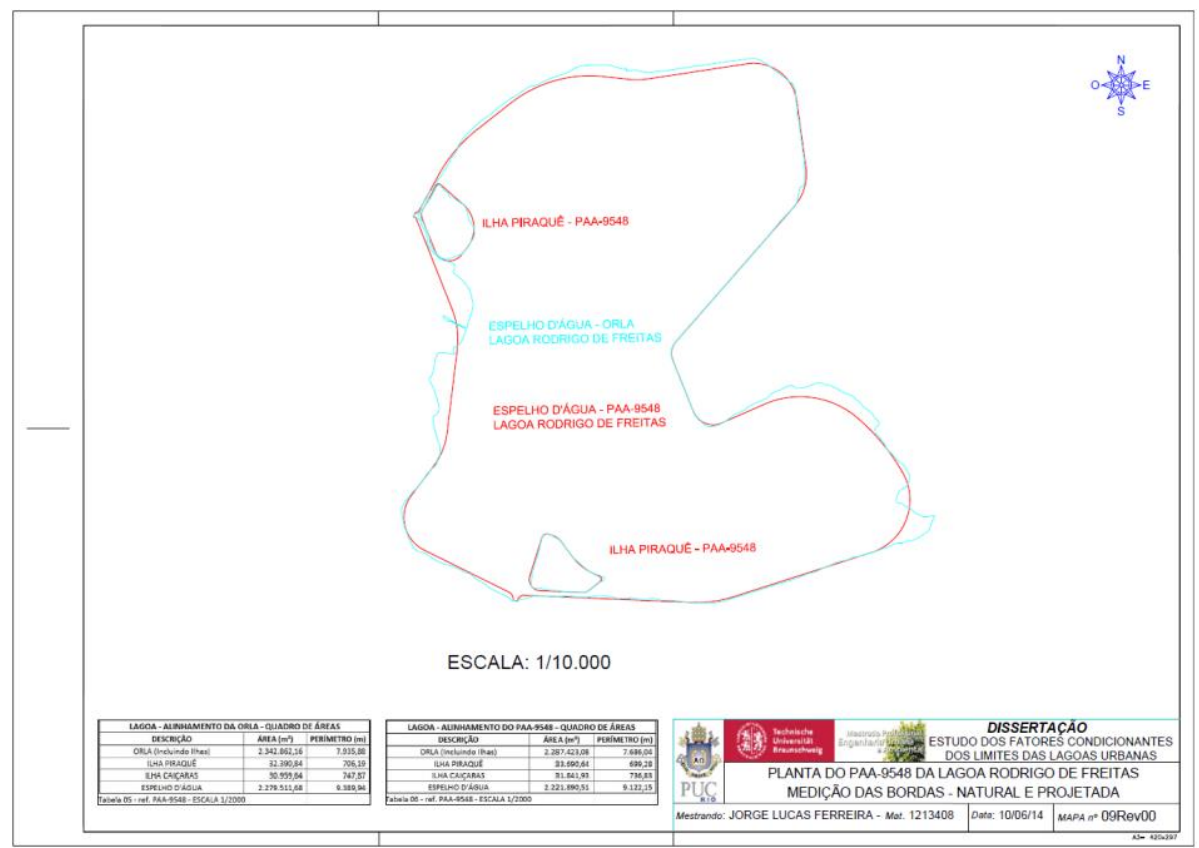

Figure 05 - Map Measurement of Borders LRF - Natural and Projected

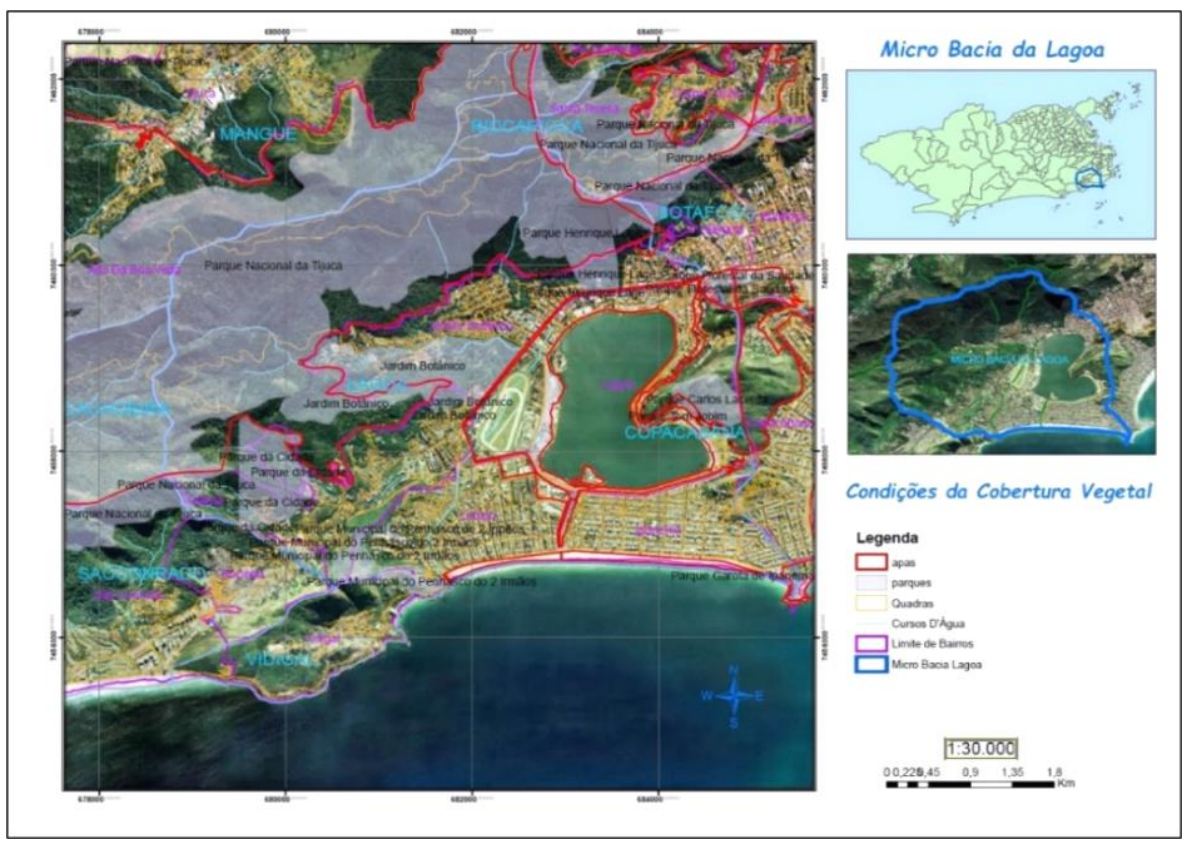

Figure 06 - Map of the Conditions of Vegetation Cover of the Lagoon Region 
Finally, we plan a means of consolidating all the conditioning factors, now parameterized, using comparative graphics, as the examples detailed in Figures 07 and 08 , showing conclusively the degree of urban interference compared to the degree of environmental preservation, signaled by these indicators.

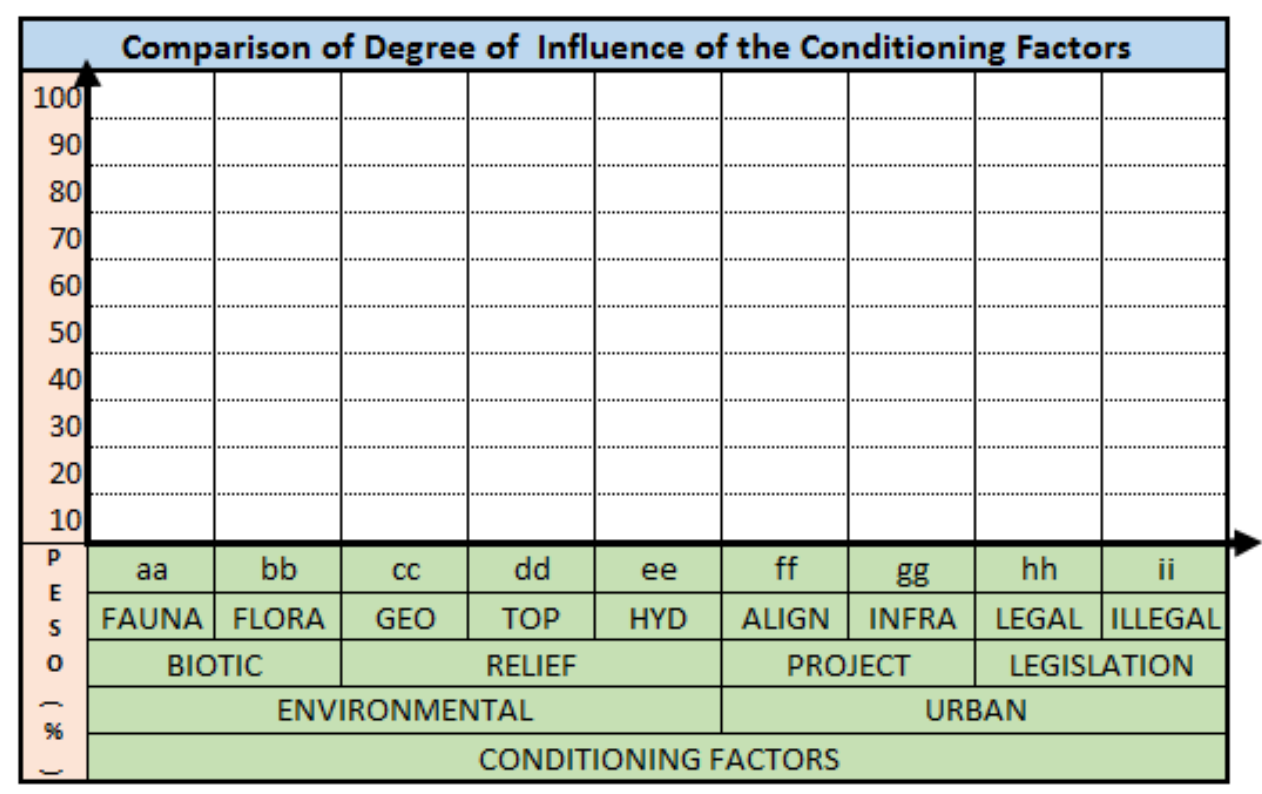

Figure 07 - Bar Chart

\section{CONDITIONING FACTORS}

Graph Polar Directional

\section{ENVIRONMENTAL}

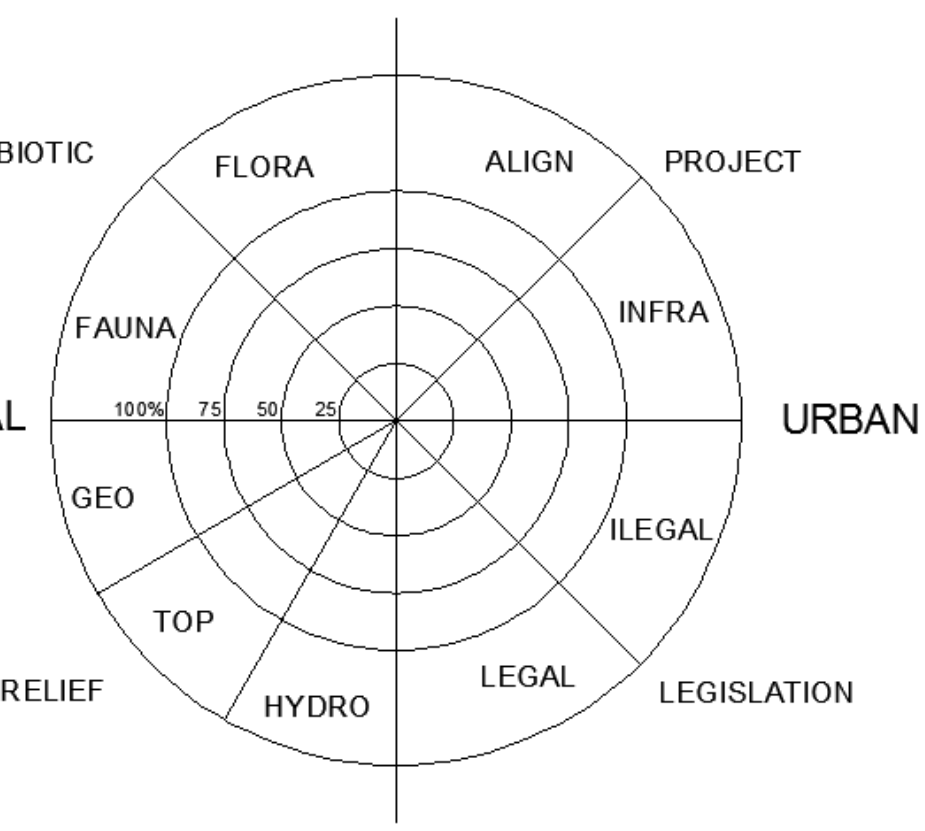

Figure 08 - Graph Polar Directional 


\section{Conclusion}

We understand that this study achieved its objectives, experiencing a line of research that used modern and current tools for collecting and processing of data (CAD / GIS / WEB), to research and propose a methodology for the definition of Conditioning Factors highly, creating a relative scale of values, able to signal and measure the anthropic interventions and the environmental conditions of Urban Lagoons.

A summary of the evolution of the actions developed in the methodology is found in the context shown in Figure 09, forming a conceptual notion of the procedures adopted in this study.

\begin{tabular}{|c|c|}
\hline \multicolumn{2}{|c|}{ EVOLUTION OF THE ACTIONS OF THE METHODOLOGY } \\
\hline AÇÃO & CARACTERIZAÇÃO \\
\hline ALIGNMENT OF THE URBAN LAGOON & STUDY OBJECT \\
\hline DATA BASE MOUNTING AND ACCESS TO INFORMATION & QUANTITY \\
\hline RESEARCH AND ANALYSIS & QUALITY \\
\hline CONCEPTS AND CORRELATIONS / CONCLUSIONS & INTELLIGENCE \\
\hline DECISION MAKING / PROJECTS AND WORKS & MANAGEMENT AND ACTIONS \\
\hline
\end{tabular}

Figure 09 - Table of Evolution of The Actions of The Methodology

\section{Keywords}

Environmental-Urban; Fauna-Flora; Legislation Urban and Land Use; Alignments and margins of Urban Lagoons; Lagoon ecosystems; Georeferenced mapping; Relief; Hydrology; Technology CAD/GIS/WEB; Web Portals. 


\section{Sumário}

1. Introdução 20

1.1 O Problema 32

1.2 Justificativa 36

2. Condicionantes 38

2.1 Objetivos do Estudo e Fundamentação 38

2.2 Objetivo Final e Intermediários 39

2.3 Linha de Pesquisa e Suposição $\quad 40$

2.4 Delimitações do Estudo e Aplicativos 41

2.5 Termos e Assuntos a Serem Abordados 42

2.6 Referencial Teórico e Base de Dados 42

2.7 Modelo de Análise 42

2.8 Determinação dos Fatores Condicionantes 45

2.9 Modelagem de Condicionantes Urbano/Ambientais $\quad 47$

2.10 Metodologia de Modelagem $\quad 50$

2.10.1 Gráfico de Barras $\quad 51$

2.10.2 Gráfico Polar Direcional 52

3. Metodologia com Ferramentas de Consulta 54

3.1 Obtenção de Dados e Documentação 55

3.2 Estruturação do Projeto de Estudo 55

3.3 Google Earth $\quad 56$

3.4 Embrapa $\quad 62$

3.5 Portal do Exército Brasileiro $\quad 65$

3.6 Portal do DNIT 68

$\begin{array}{ll}\text { 3.7 Portal do DER } & 70\end{array}$

3.8 Portal da Prefeitura Municipal da Cidade do Rio de Janeiro 71

3.9 CPRM - Dados Geológicos da Região 89

3.10 Infraestrutura Urbana $\quad 92$

3.10.1 Controle das Galerias de Águas Pluviais 92

3.10.2 Centro de Controle Operacional de Esgoto - CCOE 93

3.11 Carta Náutica da Lagoa 97

3.12 Urbanização, Adensamento e Expansão 98

3.13 Estudos e Mapeamento com Ortofotografia 105

4. Desenvolvimento - Mapas Produzidos e Análises 110

4.1 Utilização e Aplicação dos Recursos de CAD/SIG 110

$\begin{array}{ll}4.2 \text { Relevo } & 110\end{array}$

$\begin{array}{ll}4.3 \text { Hidrologia } & 116\end{array}$

4.4 Projeto de Alinhamento Aprovado - PAA-9548 124

4.5 Ecossistema e Cobertura Vegetal 135

$\begin{array}{ll}4.6 \text { Tecnologia SIG } & 137\end{array}$ 
4.6.1 Padrão Geomorfológico da Bacia 138

4.6.2 Padrão de Ocupação da Região 138

4.6.3 Condições da Cobertura Vegetal 139

4.6.4 Caracterização Bacia Relação com Distribuição Serviços 140

4.6.5 Comparativo dos Mapas do ExB e DNIT 140

5. Conclusões e Sugestões 141

$\begin{array}{ll}\text { Referências Bibliográficas } & 144\end{array}$

$\begin{array}{ll}\text { Portais Internet Consultados } & 147\end{array}$

Anexos 149

Anexo 01 - Banco de Dados Clima BR - Embrapa - RJ/RJ 149

Anexo 02 - Manual do Usuário - Legislação Urbana On-Line 151

Anexo 03 - Certidão de Informações - trecho Av. B. de Medeiros 157

Anexo 03a - Certidão de Informações - Av. Eptácio Pessoa 158

Anexo 03b - Certidão de Informações - R Tabatinguera 159

Anexo 04 - Decreto IPHAN 130 - PAA-9548_10-09-75 160

Anexo 05 - D9396M Tombamento Def. - PAA-9548_13-06-90 162

Anexo 06 - Uso do Solo 2012 - Critérios de Mapeamento 166

\section{Lista de Tabelas}

Tabela 01 - Comparação Grau Influência - Fator Condicionante 51

Tabela 02 - Dados do Bairro da Lagoa 80

Tabela 03 - Dados do Bairro de Ipanema $\quad 80$

Tabela 04 - Dados do Bairro do Jardim Botânico 80

Tabela 05 - Dados do Bairro da Gávea $\quad 80$

Tabela 06 - Dados do Bairro do Humaitá $\quad 81$

Tabela 07 - Dados do Bairro de Copacabana 81

Tabela 08 - Dados do Bairro do Leblon 81

Tabela 09 - Hidrologia - Quadro de Rios - Mapa 1/50.000 119

Tabela 10 - Hidrologia - Bacia Hidrográfica - Mapa 1/50.000 120

Tabela 11 - Quadro de Áreas - Mapa 1/50.000 124

Tabela 12 - Quadro de Áreas - Mapa 1/2.000 124

Tabela 13 - Cálculo de Elementos da Curva Circular 128

Tabela 14 - Quadro de Áreas e Perímetro - Borda Natural 133

Tabela 15 - Quadro de Áreas e Perímetro - Borda Projetada 134

Tabela 16 - Quadro Comparativo de Áreas de Preservação 137

Tabela 17 - Evolução das Ações da Metodologia 141 


\section{Lista de Gráficos}

Gráfico 01 - Árvore de Fatores Condicionantes - AFC 47

Gráfico 02 - de Barras Comparativo - Fatores Condicionantes 52

Gráfico 03 - Polar Vetorial Comparativo - Fatores Condicionantes 53

Gráfico 04 - Visualização da Evolução das Ações da Metodologia 142

\section{Lista de Figuras}

Figura 01 - Mapa Plano da LRF (1809) - Foto R. Lima, Acervo JB 22

Figura 02 - Vista Panorâmica - LRF Século IX 23

Figura 03 - Vista Panorâmica - LRF Atualmente 23

Figura 04 - Evolução do Traçado Orla da LRF - Renato Carvalho 24

Figura 05 - Planta LRF Ano 1880 - Barão de Teffé (Calixto, 1990) 25

Figura 06 - Planta LRF Ano 1990 - Carta Náutica (Calixto, 1990) 26

Figura 07 - Mapa Comparativo - LRF 880x1990 (Calixto, 1990) 27

Figura 08 - Panorâmica M. Imperador - Foto Fialdini, Acervo JB 28

Figura 09 - Quadro Pintura N. - Museu M. Procópio, Acervo JB 28

Figura 10 - Implantação Infraest. Acesso, Inst. M. S., Acervo JB 29

Figura 11 - F. Cia Fiação/T. Corcovado, Col. G. Ferrez, Acervo JB 30

Figura 12 - Extrato Mapa Mun. RJ/RJ - Escala 1/50.000, LRF 30

Figura 13 - PAA-1386/Orla LRF - Proj. Av. E. Pessoa, M. do Pires 31

Figura 14 - PAA-1386/Orla LRF - outro trecho Av. B. de Medeiros 31

Figura 15 - PAA-1454A - Canal. Rio Rainha, demais alinhamentos 32

Figura 16 - Lagoa da Pampulha - Belo Horizonte - MG 33

Figura 17 - Lagoa Central - Sete Lagoas - MG 33

Figura 18 - Lagoa dos Patos - Porto Alegre RS 33

Figura 19 - Lago Paranoá - Brasília - GO 34

Figura 20 - Lagoa da Prata - MG 34

Figura 21 - Lagoa Santa - MG 34

Figura 22 - Lagoa Rodrigo de Freitas, Rio de Janeiro - RJ 35

Figura 23 - Vista em Perspectiva da Lagoa, Rio de Janeiro - RJ 35

Figura 24 - PAL-47945 Rem. Terrenos, Vista Google Earth - LRF 36

Figura 25 - Detalhe das margens e adjacências da Lagoa 41

Figura 26 - Modelo de Análise 43

Figura 27 - Mapa Conceitual só natureza 44

Figura 28 - Mapa Conceitual com urbanização 44

Figura 29 - Representação do Primeiro Nível de Análise 45

Figura 30 - Montagem da Base de Dados e Informações 54

Figura 31 - Organograma / Fluxograma do Estudo 56

Figura 32 - Google Earth - SIG 57

Figura 33 - Google Earth - Perspectiva em 3D da llha Caiçaras 57

Figura 34 - Google Earth - Perspectiva em 3D da llha Piraquê 57 
Figura 35 - Google Earth - Perspectiva em 3D Bairro da Gávea 58

Figura 36 - Google Earth - Perspectiva em 3D Bairro do Humaitá 58

Figura 37 - Arquivo kmz - Delimitação dos Municípios, Est. do RJ 59

Figura 38 - Arquivo kmz - Delimitação dos Bairros, Munic. do RJ 60

Figura 39 - Arquivo kmz - Delimitação Reg. Hidrográficas, INEA 59

Figura 40 - Coleção de Imagens e Fotos do Google Earth 61

Figura 41 - Livro "Geotecnologias e Geoinformação" 62

Figura 42 - Dados e Gráficos Climáticos, Embrapa, Anexo 01

Figura 43 - Carta SF-23Z-B-IV-4-SO - MDT 64

Figura 44 - Carta SF-23Z-B-IV-4-SO - FSR 65

Figura 45 - Geoportal do Exército Brasileiro 65

Figura 46 - Folha Baía da Guanabara 66

Figura 47 - Detalhe da LRF 66

Figura 48 - Mapa E01 Folhas V. Militar, B. de Guanabara e TMR 67

Figura 49 - Portal do DNIT 68

Figura 50 - Extrato do Mapa Multimodal RJ - RJ071 68

Figura 51 - Mapa E02 Extrato M. Rodoviário, Trecho RJ-071/LRF 69

Figura 52 - Portal do DER $\quad 70$

Figura 53 - Mapa da RMRJ - DER $\quad 70$

Figura 54 - Mapa de Helipontos no Estado do RJ 71

Figura 55 - Portal da SMU on line - Rio de Janeiro 71

Figura 56 - Item MA.4 - Monitoramento Ambiental 72

Figura 57 - Legislação Bairro a Bairro - RJ 72

Figura 58 - Legislação Bairro a Bairro - RJ - SIG 73

Figura 59 - Trecho selecionado na Av. Borges de Medeiros 73

Figura 60 - Portal do Acervo de Imagens - PAA-PAL - RJ 75

Figura 61 - Imagem do PAA-9548 - Orla da Lagoa 76

Figura 62 - Armazém de Dados - Instituto Pereira Passos 76

Figura 63 - Portal Sigweb - Bairros Cariocas $\quad 79$

Figura 64 - Bairro selecionado - Lagoa $\quad 80$

Figura 65 - Mapa Digital do Rio de Janeiro - BaseGeo WEB 82

Figura 66 - Mapa Digital RJ - Suscetibilidade a Escorregamento 83

Figura 67 - Detalhamento da Lagoa e Adjacências $\quad 84$

Figura 68 - Suscetibilidade Perfil 1

Figura 69 - Suscetibilidade Perfil $2 \quad 84$

Figura 70 - Suscetibilidade Perfil 3

Figura 71 - Portal do Armazém de Dados - Opção Mapas Digitais 85

Figura 72 - Mosaico da região da Lagoa 86

Figura 73 - Extrato do Mapa Detalhe Diretriz Geradora de Perfil $\quad 90$

Figura 74 - Extrato do Mapa com o Perfil 91

Figura 75 - Extrato Perfil O. Oceânica, LRF e Morro Corcovado 91

Figura 76 - Morros Seriados - Gustavo Nunes Pereira, 2009

Figura 77 - Extrato Planta Topográfica Cadastral - 287-E-II-1 - IPP 105

Figura 78 - Fotografia Aérea $\mathrm{n} . \stackrel{2166}{106}$ 
Figura 79 - Fotografia Aérea ․ํ2160 106

Figura 80 - Foto - Trecho do Mosaico da área em estudo da LRF 106

Figura 81 - Foto - Detalhe do Heliponto e Adjacências 106

Figura 82 - Foto - Detalhe do Parque e Ocupações no entorno 107

Figura 83 - Foto - Detalhe da Ortofotocarta Digital - Fonte IPP 108

Figura 84 - Extrato Ortofotomosaico - Detalhe LRF, Fonte IBGE 109

Figura 85 - Extrato de Planta Topográfica no ArcGIS 112

Figura 86 - Extrato Mosaico Planta Cadastral Base de Dados, IPP 112

Figura 87 - Planta Topográfica Cadastral Aerofoto, 1/2000, IPP-RJ 114

Figura 88 - Ciclo Hidrológico Global (fonte: Tucci, 2006) 116

Figura 89 - Extrato do Mapa Estudo da Bacia/Malha Hidrográfica 118

Figura 90 - Espelho D'Água, Rios e Bacia Hidrográfica 119

Figura 91 - Extrato do Mapa Amplitude da Média de Sizígia, IBGE 120

Figura 92 - Extrato da pág. 3, Relatório de Chuvas 2009, GeoRio 122

Figura 93 - Extrato pág. 4, Relatório de Chuvas 2009, GeoRio 123

Figura 94 - Elementos Geométrico da Curva Circular 125

Figura 95 - PAA-9548 - Espelho D'água Natural e Projetado 127

Figura 96 - PAA-9548 - Alinhamento Natural/Projetado e CC's 128

\section{Lista de Mapas Pesquisados - Mapa}

Mapa 01 - Uso do Solo - Áreas Urbanizadas, 2012, Fonte IPP 46 Mapa 02 - P. V. T. : Rodov./Ferrovi./Metrov., 2004, Fonte IPP 78 Mapa 03 - Altimetria e traçado viário 2004, Fonte IPP 79 Mapa 04 - População Total Urbana por Bairro 2010, Fonte IPP 81 Mapa 05 - Dinâmica da População por RA 2010, Fonte IPP 82 Mapa 06 - Carta Geológica-Geotécnica, GeoRio, Folha 287e 86 Mapa 07 - Carta Geológica-Geotécnica, GeoRio, Folha 286d 87 Mapa 08 - Carta Geológica-Geotécnica, GeoRio, Folha 286f 88 Mapa 09 - Carta Geológica-Geotécnica, GeoRio, Folha 287c 88 Mapa 10 - Geologia - 2004 - Fonte IPP 89

Mapa 11 - Mapa Geológico, CPRM B. Guanabara (SF23-Z-B-IV) 90 Mapa 12 - Sistemas de Galerias Águas Pluviais, LAGOA LIMPA 92 Mapa 13 - Sistema de Controle Op. Esgoto,LAGOA LIMPA 93 Mapa 14 - Espelho D'água da Lagoa, LAGOA LIMPA $\quad 94$ Mapa 15 - Áreas de Dragagem da Lagoa, LAGOA LIMPA 94 Mapa 16 - Sistema Esgoto Sanitário Bacia Lagoa, LAGOA LIMPA 95 Mapa 17 - Bacia Hidrográfica da Lagoa, Fonte LAGOA LIMPA 95 Mapa 18 - Batimetria da Lagoa - Fonte LAGOA LIMPA 96 Mapa 19 - Bairros da Bacia da Lagoa - Fonte LAGOA LIMPA 96 Mapa 20 - Carta Náutica da Lagoa Rodrigo de Freitas $\quad 97$ Mapa 21 - Planta Topográfica com a delimitação da VI-RA Lagoa 98 Mapa 22 - Planta Topográfica com a delimitação APA2 98 
Mapa 23 - AP 1 e AP 2 - Fonte IPP 99

Mapa 24 - Região de Planejamento e Bairros, 2014, Fonte IPP 100

Mapa 25 - IAT - Plano Diretor - Fonte IPP 101

Mapa 26 - Planta Topográfica Cadastral, 287-E-IV-1, Fonte IPP 102

Mapa 27 - Planta Topográfica Cadastral, 287-E-II-4, Fonte IPP 103

Mapa 28 - Planta Topográfica Cadastral, 287-E-II-1, Fonte IPP 104

Mapa 29 - Ortofotocarta Digital, Fonte IPP 107

Mapa 30 - Mapa Ortofotomosaico Baía Guanabara, Fonte IBGE 108

Mapa 31 - Planta Cadastral Aerofotogramétricas, Escala 1/10.000 109

Mapa 32 - Bacias e sub-bacias hidrográficas, 2004, Fonte IPP 117

Mapa 33 - Mapa do Município do Rio de Janeiro, Escala 1/50.000 118

Mapa 34 - Chuva Média Anual (1997/1998), Fonte IPP 121

Mapa 35 - Visão Urbano / Ambiental, 2014 Guia Ruas NOKIA/MS 135

\section{Lista de Mapas Elaborados - Mapa Enn}

Mapa E01 - Folhas Vila Militar, Baía de Guanabara e TMR 67

Mapa E02 - Extrato Mapa Rodoviário - Trecho RJ-071 - Orla LRF 69

Mapa E03 - Planta da LRF, Extraída do Google Earth 111

Mapa E04 - Planta Cadastral, Montagem 1/2000 - Detalhe Lagoa 115

Mapa E05 - Estudo da Bacia e Malha Hidrográfica da Lagoa 118

Mapa E06 - Espelho D'Água, Rios e Bacia Hidrográfica 119

Mapa E07 - Projeto Alinhamento Aprovado - PAA-9548 - LRF 124

Mapa E08 - Mapa da Digitalização e Cálculo do PAA-9548 133

Mapa E09 - Mapa da Medição das Bordas - Natural e Projetada 134

Mapa E10 - Áreas de Proteção Ambiental, Parques e Orla da LRF 136

Mapa E11 - Padrão Geomorfológico da Bacia da LRF 138

Mapa E12 - Padrão de Ocupação da Região da LRF 139

Mapa E13 - Condições da Cobertura Vegetal da Região da LRF 139

Mapa E14 - Caracterização/Relação c/ Distribuição de Serviços 140

\section{Lista de Abreviaturas}

ABNT - Associação Brasileira de Normas Técnicas;

AFC - Árvore de Fatores Condicionantes

ANOED - Alinhamento Natural da Orla do Espelho D'água

AP - Área de Planejamento;

APA - Área de Proteção Ambiental;

APARU - Área de Proteção Ambiental e Recuperação Urbana;

APOED - Alinhamento Projetado da Orla do Espelho D'água

BDG - Banco de Dados Geográficos; 
BDGex - Banco de Dados Geográficos do Exército Brasileiro;

CAD - Computer Aided Design (Desenho Assistido por Computador);

CC - Curva Circular

$\mathrm{Cl}$ - Certidão de Informações;

CCOE - Centro de Controle Operacional de Esgoto

DCT - Departamento de Ciências e Tecnologia;

DER - Departamento de Estrada de Rodagens;

DF - Decreto Federal

DM - Decreto Municipal

DNIT - Departamento Nacional de Infraestrutura de Transportes;

DSG - Diretoria de Serviços Geográficos;

DXF - Drawing Exchange Format

EGT - Erro Gráfico Tolerável

FSR - Fotografia de Sensoriamento Remoto

GIS - Geographic Information System;

IBGE - Instituto Brasileiro de Geografia e Estatística;

IPP - Instituto Pereira Passos;

JB - Jardim Botânico

LRF - Lagoa Rodrigo de Freitas;

Mapa - Mapas Pesquisados

Mapa_E - Mapas Elaborados

MDT - Modelo Digital do Terreno

PAA - Projeto Aprovado de Alinhamento;

PAL - Projeto Aprovado de Loteamento;

PAO - Projeto Aprovado da Orla;

PAOLU - Projeto de Alinhamento da Orla das Lagoas Urbanas

PHNA - Processos Hidrológicos Naturais e Antrópicos

POL - Alinhamento da Orla Lagunar

PRPAO - Padrão Resultante do PAO

PUC-RIO - Pontifícia Universidade Católica do Rio de Janeiro;

RMRJ - Região Metropolitana do Rio de Janeiro

SIG - Sistema de Informações Geográficas ou;

SMAC - Secretaria Municipal de Meio Ambiente;

SMU - Secretaria Municipal de Urbanismo;

TCF - Tree of Conditionings Factors

TD - Tecnologia Digital;

TI - Tecnologia da Informação;

TMR - Traçado da Malha Rodoviária

WEB - Rede de conexão formada por sistema de informações disponível em hipermídia; 


\section{Introdução}

Ao longo da nossa carreira profissional na LIGHT S.E.S.A., participando das equipes multidisciplinares, desenvolvendo e implantando projetos do setor elétrico inerentes a geração, transmissão e distribuição de energia elétrica, convivíamos com a realidade de dois territórios distintos e opostos; as Áreas Rurais e as Áreas Urbanas.

Com a responsabilidade de fornecer Energia Elétrica ao consumidor final, seja ele residencial rural ou residencial urbano, comercial, industrial, etc., participamos da implantação e crescimento de núcleos e áreas urbanas, em seu planejamento e implantação, observando as transformações ambientais e urbanas a eles inerentes.

Na prestação deste serviço, nossa documentação básica de trabalho para os estudos, planejamento, elaboração de projetos e execução das obras, sempre foi a Planta Topográfica (em várias escalas), das diversas regiões envolvidas, prérequisito para todas as etapas, tarefas e procedimentos de engenharia.

Assim, acabamos por nos especializar dentre outras atividades, na obtenção, produção, e/ou interpretação de todo material topográfico básico e avançado; dados técnicos gerais e específicos inerentes, necessários e indispensáveis.

Participamos da revolução tecnológica com a informatização e automação dos processos, sistemas e atividades, e da formatação de dados e de sua disponibilização via Portais na Internet, por diversos órgãos públicos e privados.

Quando da decisão pela realização do Curso de Mestrado Profissional em Engenharia Urbana e Ambiental na PUC-RIO, houve a constatação do quanto seria importante e oportuna esta pós-graduação tão abrangente e ao mesmo tempo específica, tirando proveito da nossa experiência profissional.

Em diversas cidades observa-se o quanto é interessante sobre o aspecto urbanístico/paisagístico, os bairros e regiões adjacentes as Lagoas Urbanas.

Considerando a complexidade do assunto, o objetivo desta dissertação é propor metodologia para estudo das condicionantes que venham a definir o Alinhamento da Orla de Lagoas Urbanas, de modo a preservar as melhores condições ambientais e características da região, utilizando tecnologia digital de 
Sistemas CAD e Sistemas de Informação Geográfica - SIG, para a comparação e análises dos dados envolvidos.

A escolha do estudo do alinhamento de Lagoas Urbanas para a elaboração desta Dissertação, veio ao encontro do sentimento e desejo de planejar as necessárias transformações do uso do solo, respeitando o meio ambiente e suas características naturais e paisagísticas, assunto tão em evidência nos dias de hoje.

Especificamente a definição do Alinhamento da Orla das Lagoas Urbanas, que acaba por se caracterizar como linha limite entre o que é possível “transformar e ocupar”, e o que é necessário “manter e preservar”, considerando como fundamento o ecossistema inerente às lagoas.

Por fim, adotar a Lagoa Rodrigo de Freitas como "Estudo de Caso", deveuse pela sua localização e importância em relação à nossa cidade, e principalmente pelo dualismo exemplar e histórico do seu contexto Urbano-Ambiental e o forte apelo imobiliário.

O Engenheiro Flavio Miguez de Mello, em seu livro "Episódios da Engenharia no Brasil - 2014”, no capítulo “A LINGUA TUPI”, cita que o padre Anchieta no intuito de ajudar os jesuítas na evangelização dos índios que habitavam o litoral da Região Sudeste, fez um dicionário da língua tupi. Algumas localidades possuíam nomes indígenas que indicavam suas propriedades e assim, quando da realização de obras nesses locais, isso deveria ser levado em consideração.

Como exemplo, continua sua narrativa no livro, citando dentre outras a região de Ipanema, onde o Engenheiro Vieira Souto encontrou dificuldades para urbanizar a área, que até hoje vem sofrendo periodicamente com a dificuldade de renovação das águas da Lagoa. Ipanema na língua tupi significa "água suja”. Este episódio nos remete a imaginar como eram as características ambientais dessa região em estudo, e como elas podem ter evoluído ao longo dos anos até os dias de hoje. 


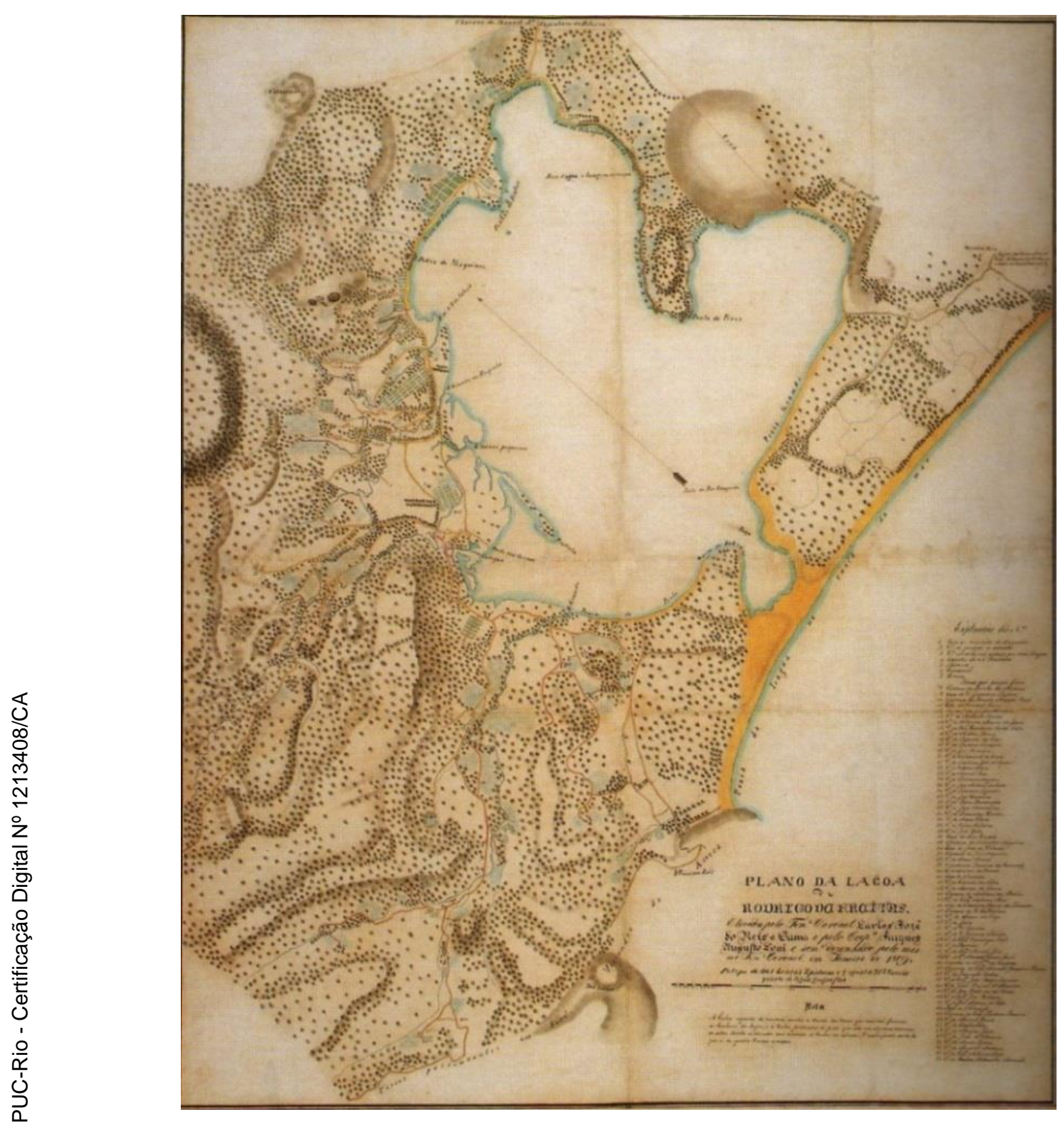

Figura 01 - Mapa do Plano da LRF (1809) - Foto Raul Lima - Acervo JB

Podemos observar neste mapa representado na Figura 01, elaborado em 1809 por oficiais do exército brasileiro, o quanto naquela época era amplo e tipicamente natural o espelho d'água da Lagoa e os seus arredores.

Trata-se de Planta da Lagoa levantada e desenhada pelo Tenente Coronel Carlos José dos Reis e Gama (1809), por ocasião da desapropriação da Fazenda da Lagoa de Rodrigo de Freitas, contendo um índice com números remissivos de todos os moradores que pagavam foro, constando também estradas, caminhos, terras, rios, fortes, engenhos, praias, a Capela de N. Senhora, Canavial, Casa da Vivenda do Engenho, Ermida de N. Sra. Da Cabeça e Forte de São Clemente. 
Nesta planta também podemos observar a existência de duas praias no interior da Lagoa, ambas se desenvolvem nas margens voltadas para o lado do mar (presença de areia). São elas a Praia do Pinto e a Praia Guandu.

Entre essas duas praias, havia a ocorrência de uma cavidade (na planta denominada Poço), avançando na direção no mar, que pela convenção cartográfica utilizada, apresenta-se como a formação de uma praia, cuja porção de areia se estende interligando o interior da Lagoa até a Orla Oceânica.

A orla hoje denominada Praia de Ipanema, na época era denominada "Praia da Lagoa na Costa do Mar", denotando assim a proximidade e até mesmo a interligação entre as duas orlas (lagunar e oceânica).

Pela sua conformação e localização, podemos sugerir que este detalhe do relevo deu origem ao hoje Canal do Jardim de Alah.

Reforçando essa ideia, pesquisamos no Portal "Projeto Ambiental Lagoa Limpa", duas imagens que em termos de comparação, comprovam esta e outras diversas transformações.

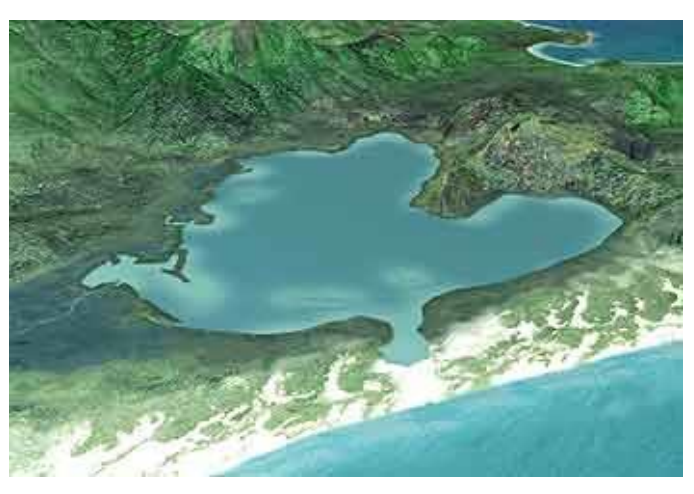

Figura 02 - Vista Panorâmica - LRF Século IX

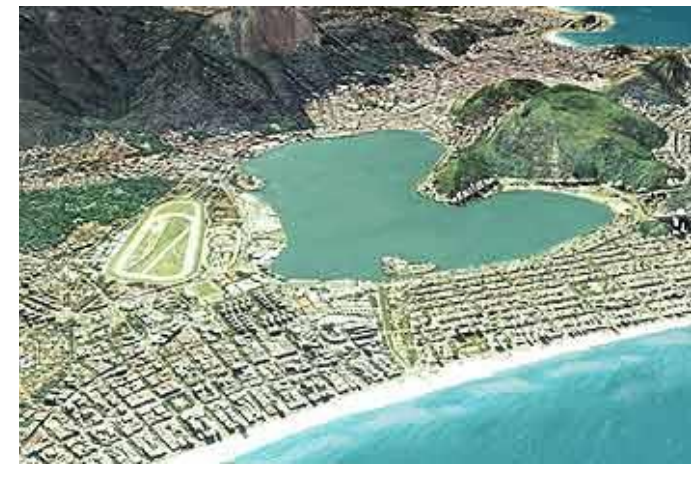

Figura 03 - Vista Panorâmica - LRF Atualmente

$\mathrm{Na}$ Figura 02 podemos observar uma paisagem de época, que coincide e retrata o traçado da Orla da Lagoa constante no mapa de 1809, já visto na Figura 01, em comparação com a Figura 03 ao seu lado, que retrata e nos dá uma perfeita visão da situação hoje.

Segundo Claudio Belmonte de Athayde Bohrer, no livro "Guia de História Natural do Rio de Janeiro - 2012", nos últimos 100 anos, a Lagoa Rodrigo de Freitas foi objeto de sucessivos aterros, que com o tempo acarretaram em uma redução de cerca de 50\% do seu espelho d'água, conforme demonstrado na Figura 04 extraída do citado livro. 
Essas ações acabaram por impactar de tal forma a região e adjacências, que hoje se apresenta e se caracteriza com um ecossistema em alto nível de artificialidade, devido às grandes transformações.

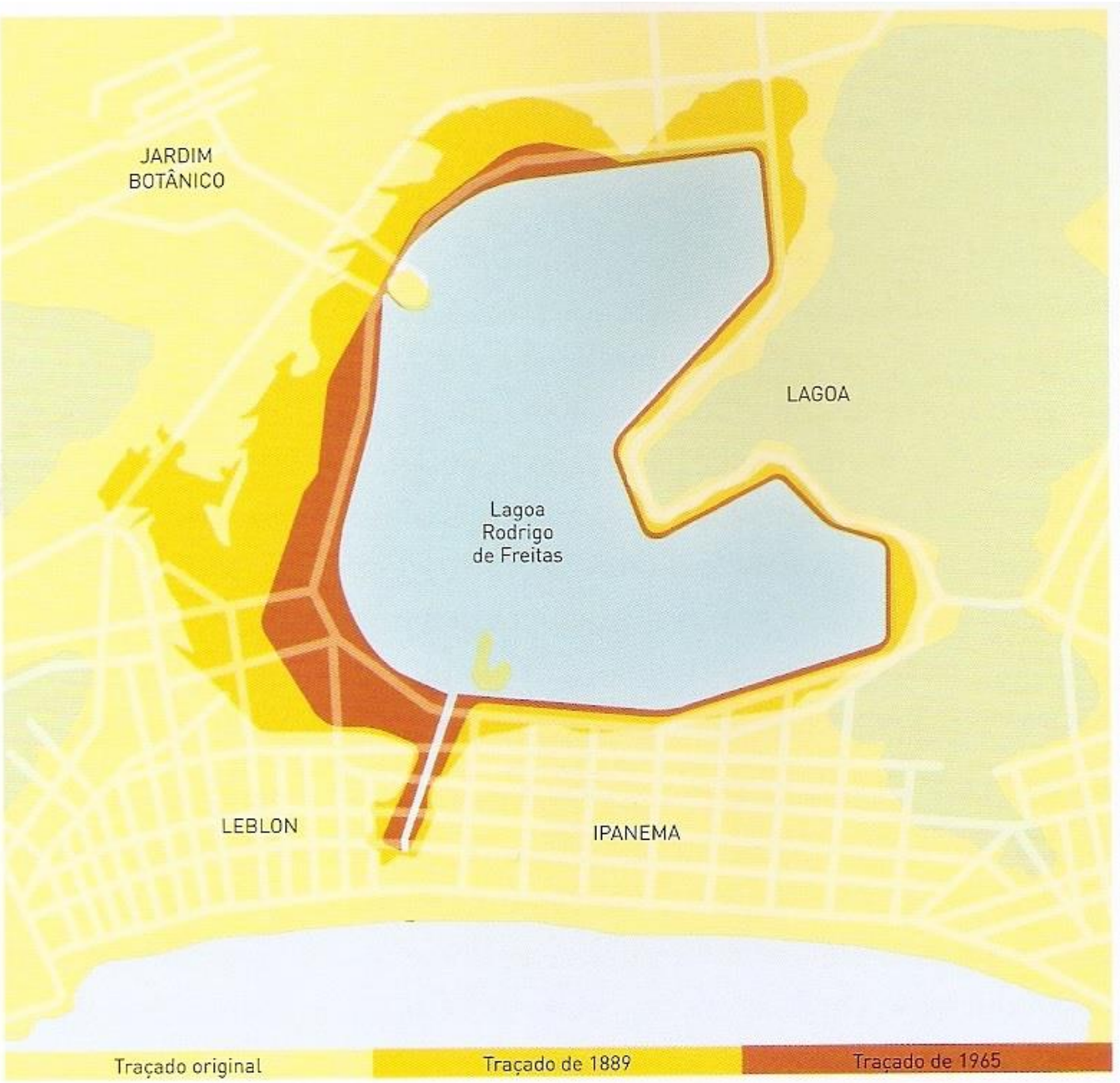

Figura 04 - Evolução do Traçado da Orla da LRF - Ilustração Renato Carvalho

Continua sua narrativa no livro, afirmando que isto se deve ao processo de urbanização de sua bacia de drenagem e do seu entorno, a deposição de sedimentos e efluentes e a construção de canais de ligação com o mar no Jardim de Alah e na Avenida Visconde de Albuquerque, no bairro do Leblon.

Afirma também que neste processo, foram alterados em muito os padrões de circulação das águas da região e que foi perdida parte considerável da vegetação original de suas margens, transformando os habitats de uma fauna que foi também com o tempo desaparecendo.

Segundo Calixto (1990), após estudos sobre o Canal de Jardim de Alah, cuja construção visava solucionar um problema secular de qualidade de água e mortandade de peixes na LRF, e que face a não ter sido alcançado esse objetivo, 
conclui que um novo canal deveria ser construído, com o estabelecimento de uma área crítica bem maior que a dimensão atual.

Nesse seu estudo, comparando uma planta elaborada em 1880 levantada pelo Barão de Teffé e representada na Figura 05, com outra planta elaborada em 1990, designada Carta Náutica n. 1511 - DNH, representada na Figura 06, Calixto elaborou um Mapa Comparativo visto na Figura 07, demonstrando a Noção Evolutiva da LRF,

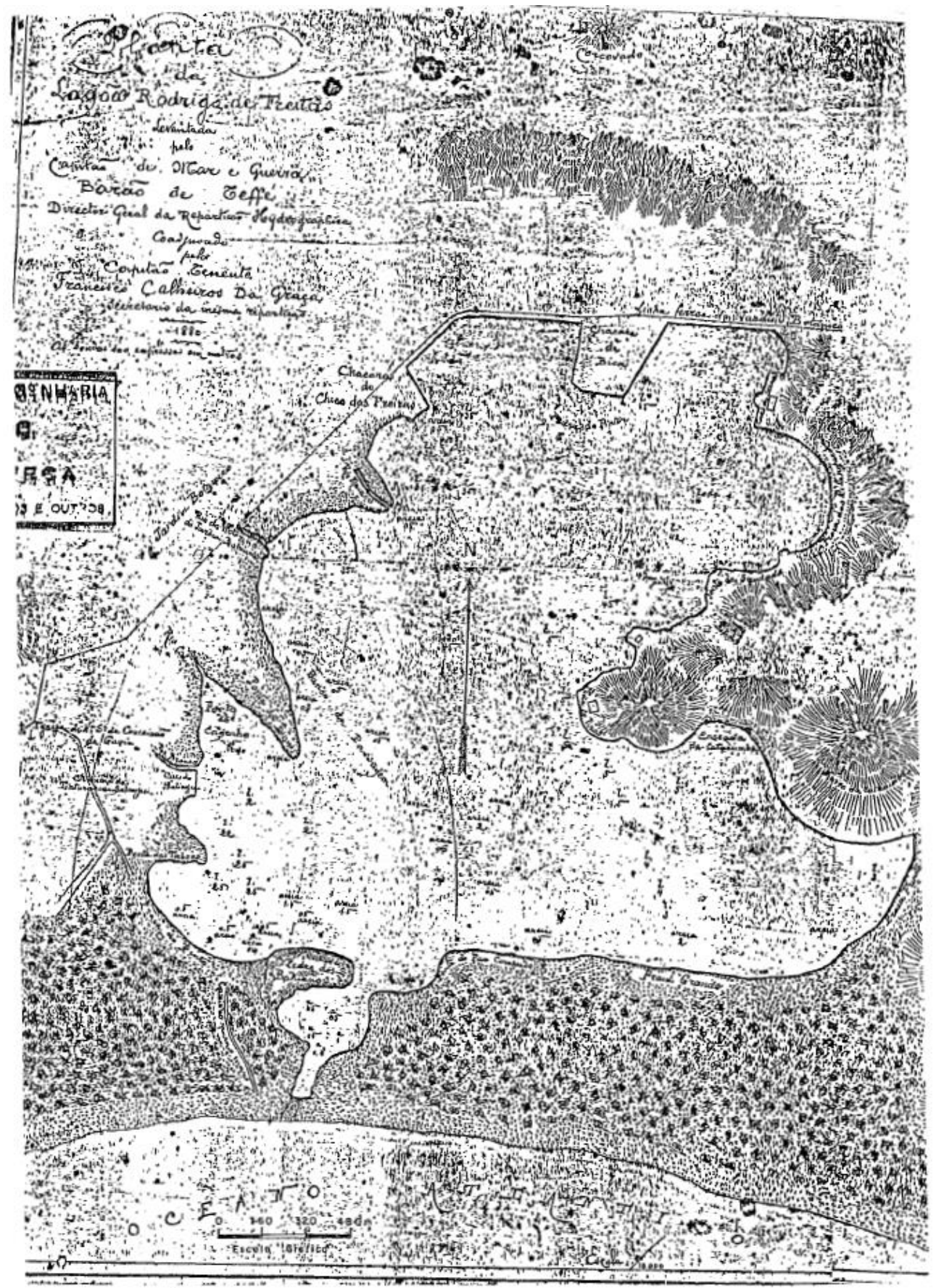

Figura 05 - Planta da LRF no ano de 1880 (Fonte: Calixto, 1990) 


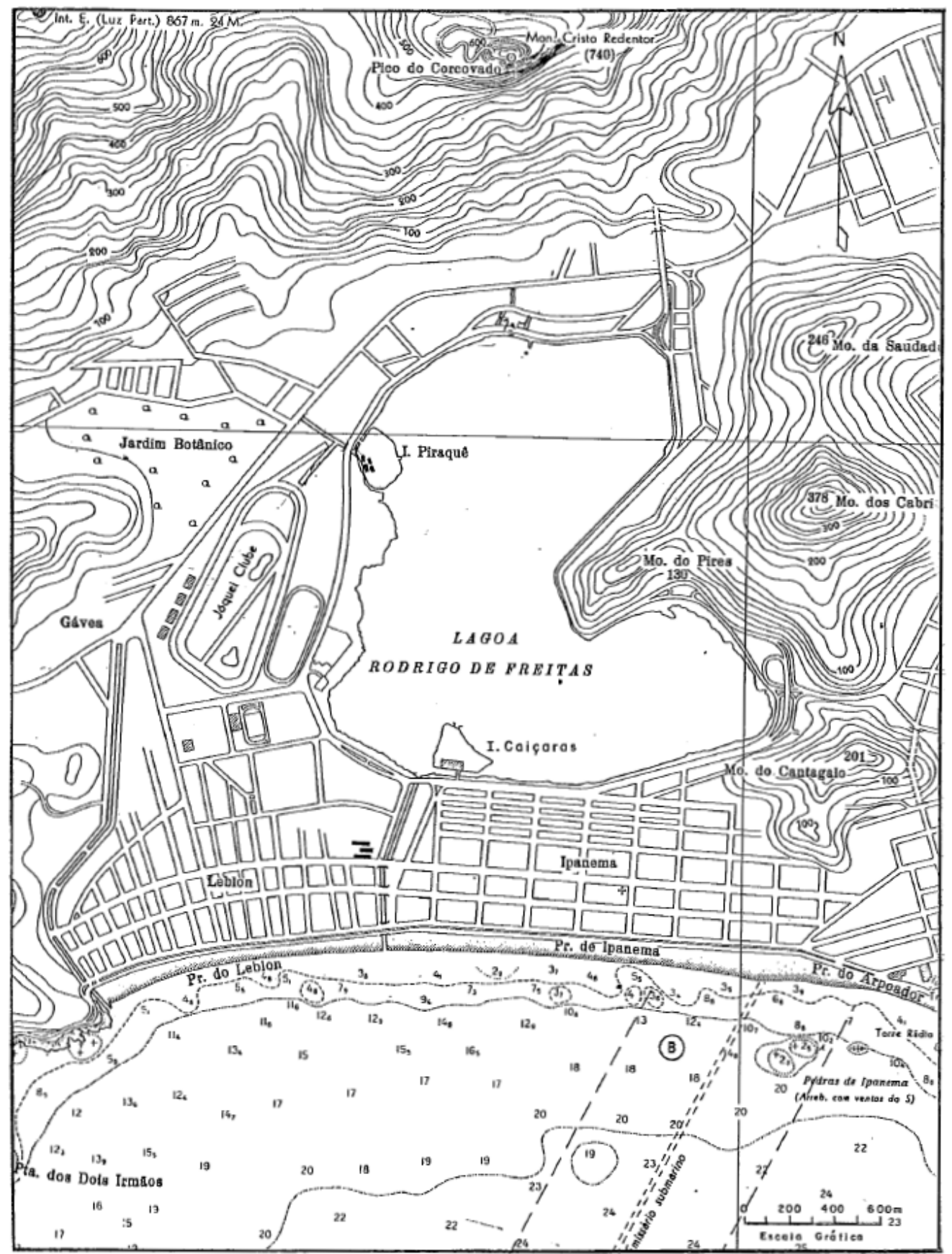

Figura 06 - Planta da LRF Ano 1990 - Carta Náutica (Fonte: Calixto, 1990) 


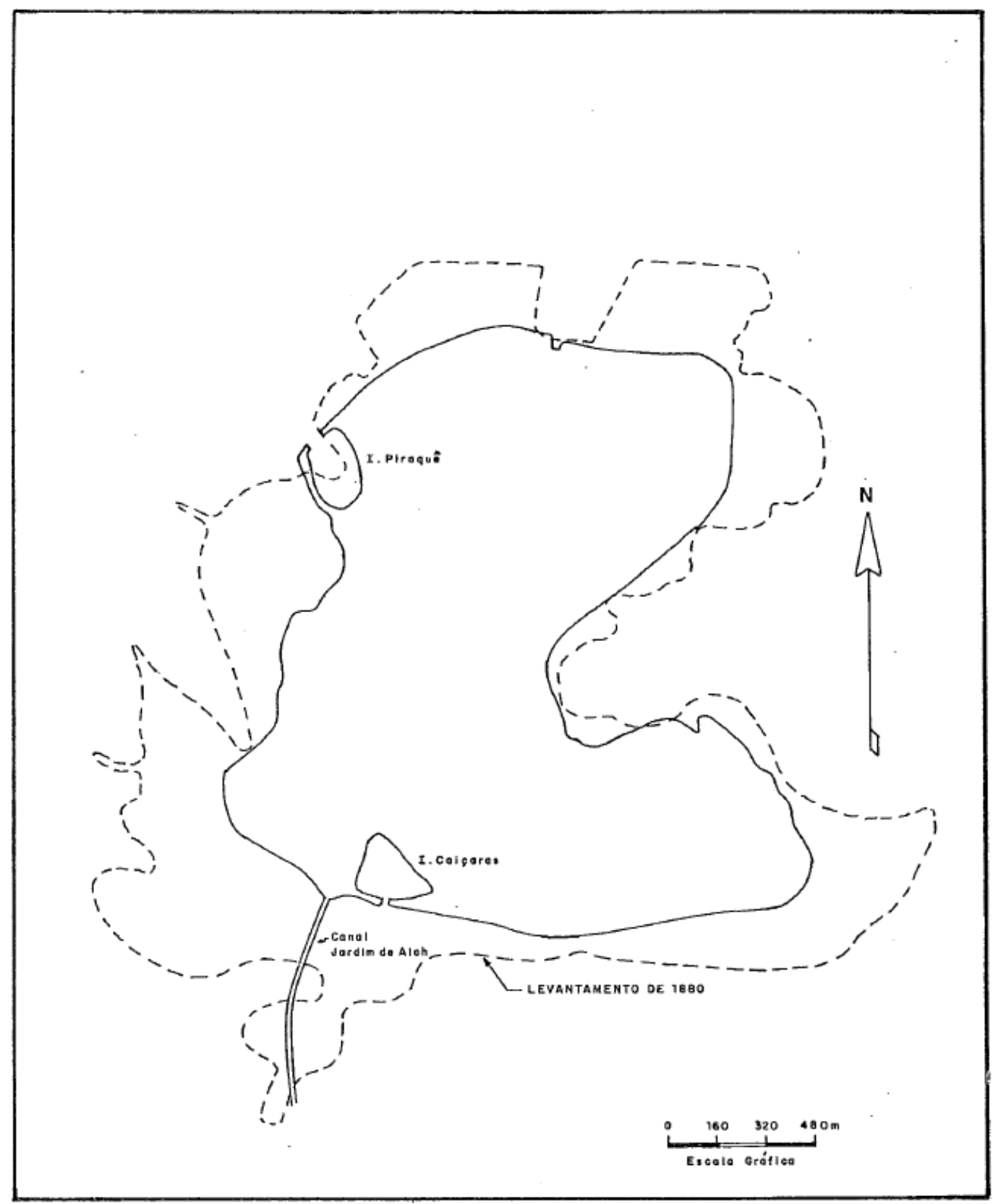

Figura 07 - Mapa Comparativo - Noção Evolutiva da LRF - 1880 x 1990 (Calixto, 1990)

Tal redução do espelho d'água da LRF deveu-se a sucessivas obras de aterro e urbanização das margens e do seu entorno, que alteraram em muito sua orla, incluindo o próprio Canal de Jardim de Alah que na década de 40 foi estreitado e alongado, passando o seu comprimento de 140 para 835 metros.

Restando-se assim, a constatação do alto grau de transformação e modificação que foi imposto para o ecossistema. 
Ainda no acervo fotográfico do Jardim Botânico, buscando caracterizar as condições ambientais originais da LRF, podemos observar imagens que ilustram bem a região e suas adjacências.

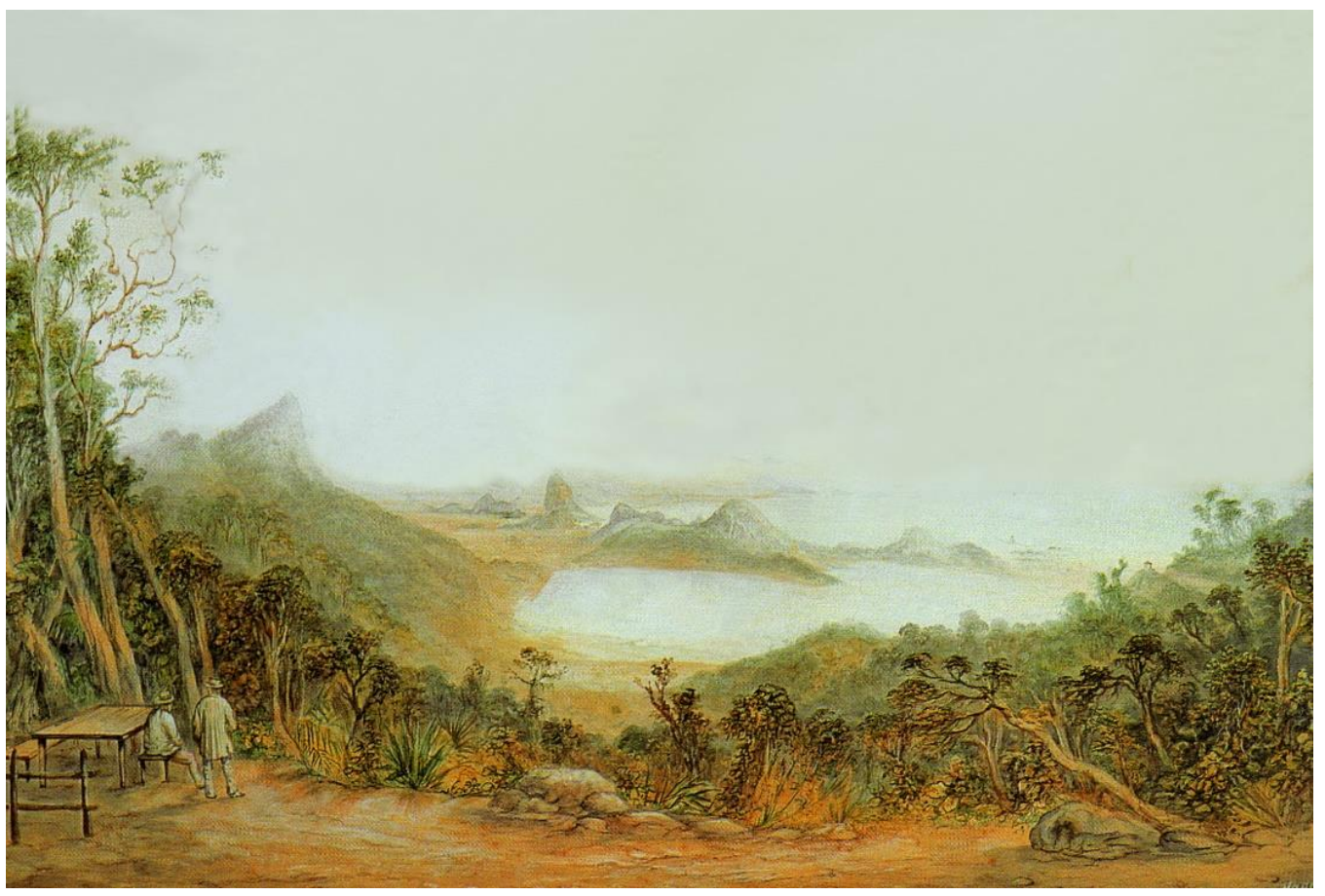

Figura 08 - Panorâmica da Mesa do Imperador - Foto Rômulo Fialdini - Acervo JB

Na Figura 08, da esquerda para a direita: o Corcovado, a Lagoa, Morros de São João e Cabrito, ao fundo o Pão de Açúcar.

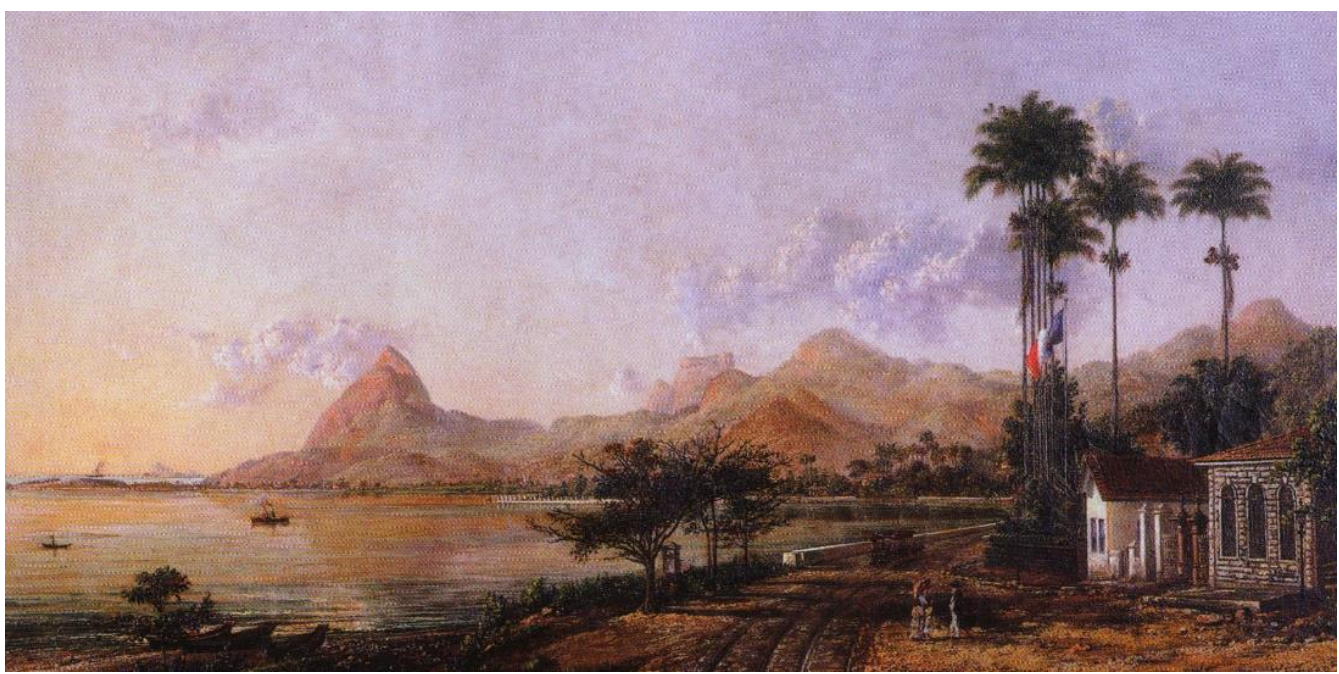

Figura 09 - Quadro pintura natural - Museu Mariano Procópio / Juiz de Fora Acervo JB 
Na Figura 09 tem-se uma vista à margem da Lagoa Rodrigo de Freitas, onde se vê o Morro Dois Irmãos, Pedra da Gávea e umas palmeiras enfileiradas, possivelmente do Jardim Botânico, além de uma construção. Em primeiro plano aparece uma linha de trem e uma residência ostentando a bandeira da França.

Avançando um pouco mais na cronologia (final do século XIX e início do século XX), podemos observar obras de infraestrutura de urbanização e acessos, bem como ocupações, que já começam a transformar em definitivo as características e paisagismo da região.

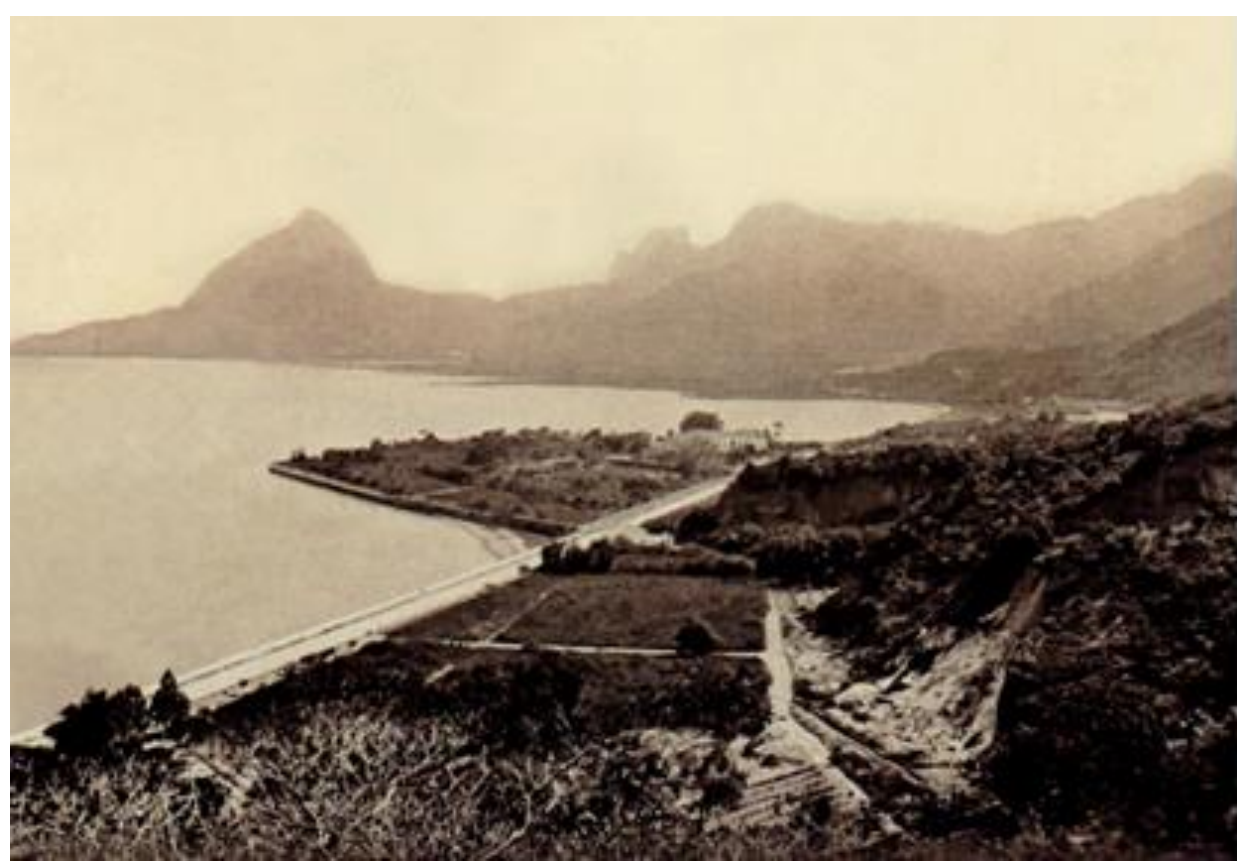

Figura 10 - Implantação Infraestrutura de Acesso / Instituto M. Salles - Acervo JB

Na Figura 10, avista-se o Morro Dois Irmãos e a Pedra da Gávea. Ao fundo, a direita com dificuldade vê-se as palmeiras do Jardim Botânico. 


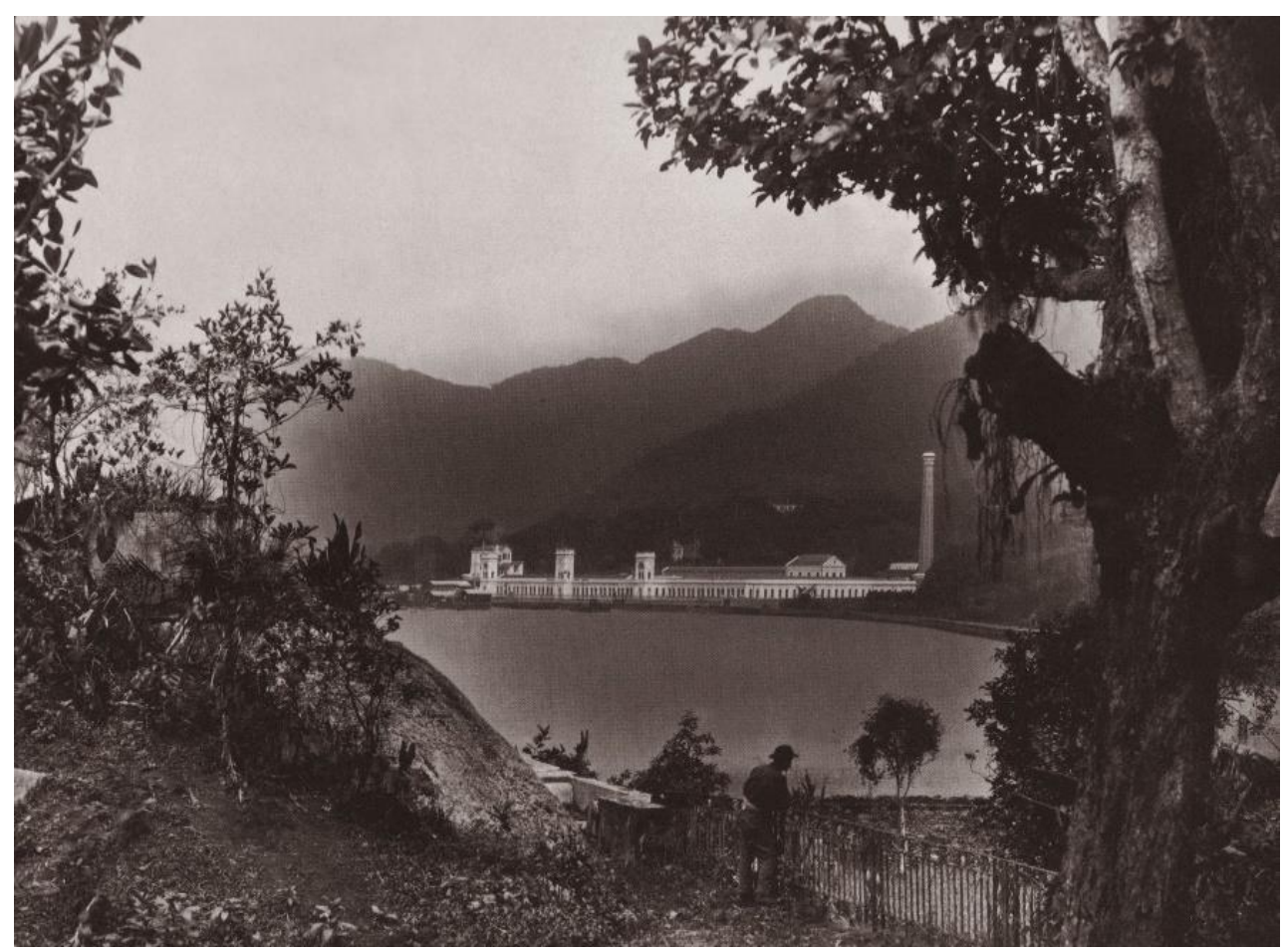

Figura 11 - Fábrica Cia Fiação/Tecidos Corcovado - Coleção G. Ferrez - Acervo JB

Já na Figura 11, observa-se a Lagoa e ao fundo a Fábrica da Cia de Fiação e Tecidos Corcovado, fundada em 1889, vista das proximidades da Fonte da Saudade.

Com o passar dos anos, a região da Lagoa e adjacências teve na sua localização ilustrada na Figura 12, uma grande importância no contexto da cidade, que acabou por motivar questões urbanas de infraestrutura para interligação, mobilidade e apelo para saneamento, gerando estudos, projetos e obras de grande relevância, tendo como consequência a modificação de sua topologia original.

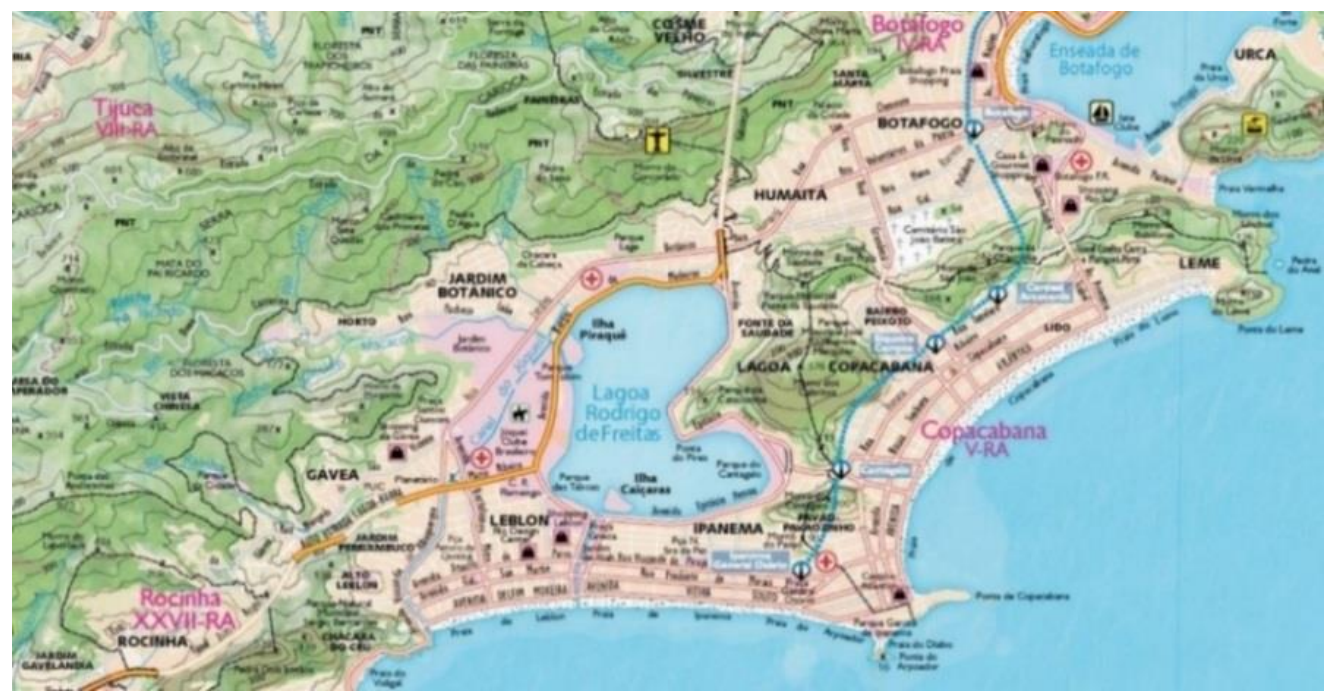

Figura 12 - Extrato do Mapa Município RJ / Escala 1/50.000 / Lagoa R de Freitas 
No contexto histórico da cidade, destacam-se obras como o projeto da Avenida Borges de Medeiros (década de 20); implantação da Avenida Epitácio Pessoa (década de 30); Corte do Cantagalo (década de 50), Túnel Rebouças (década de 60), etc., que causaram grandes modificações e transformações sob todos os aspectos.

Durante a gestão do Prefeito Carlos Sampaio foram desenvolvidos os primeiros projetos de melhoramentos e saneamento da Lagoa Rodrigo de Freitas.

O PAA-1386 de 1921 conforme Figura 13, projeta ruas e avenida ao longo das margens da Lagoa, bem como canalização/retificação do Rio Rainha, e alinhamento da Av. Borges de Medeiros (figura 14).

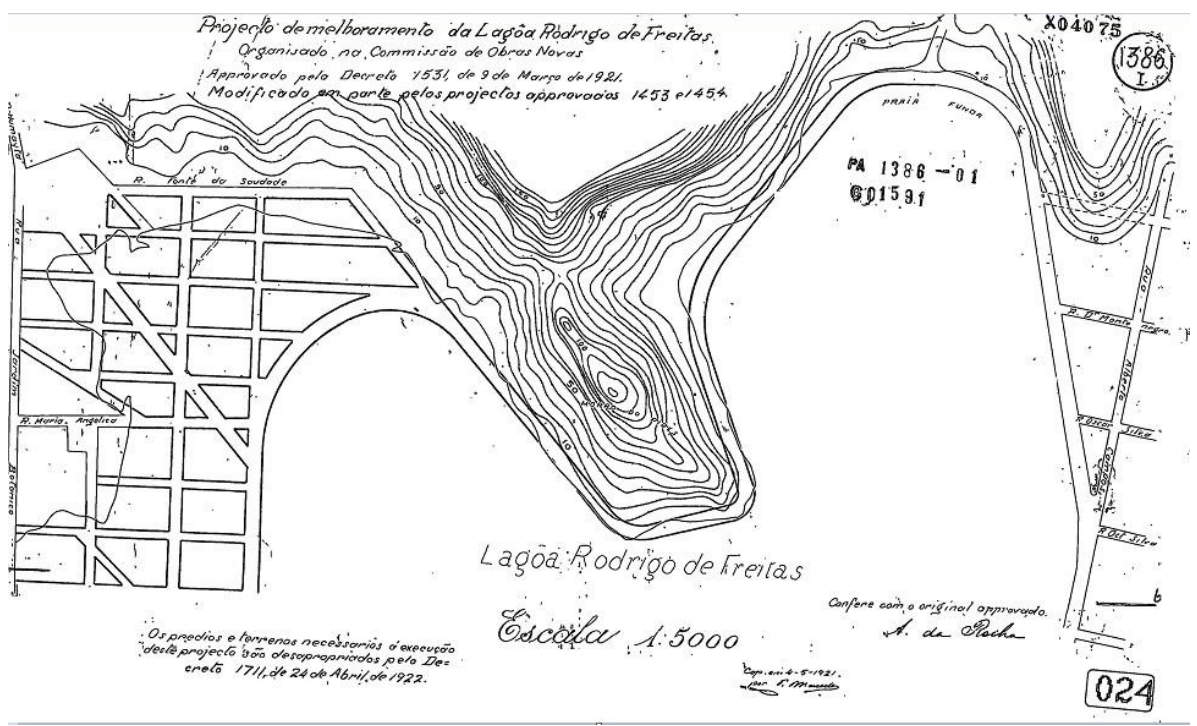

Figura 13 - PAA-1386/Orla Lagoa - Projeto Av. Epitácio Pessoa contorno M. do Pires

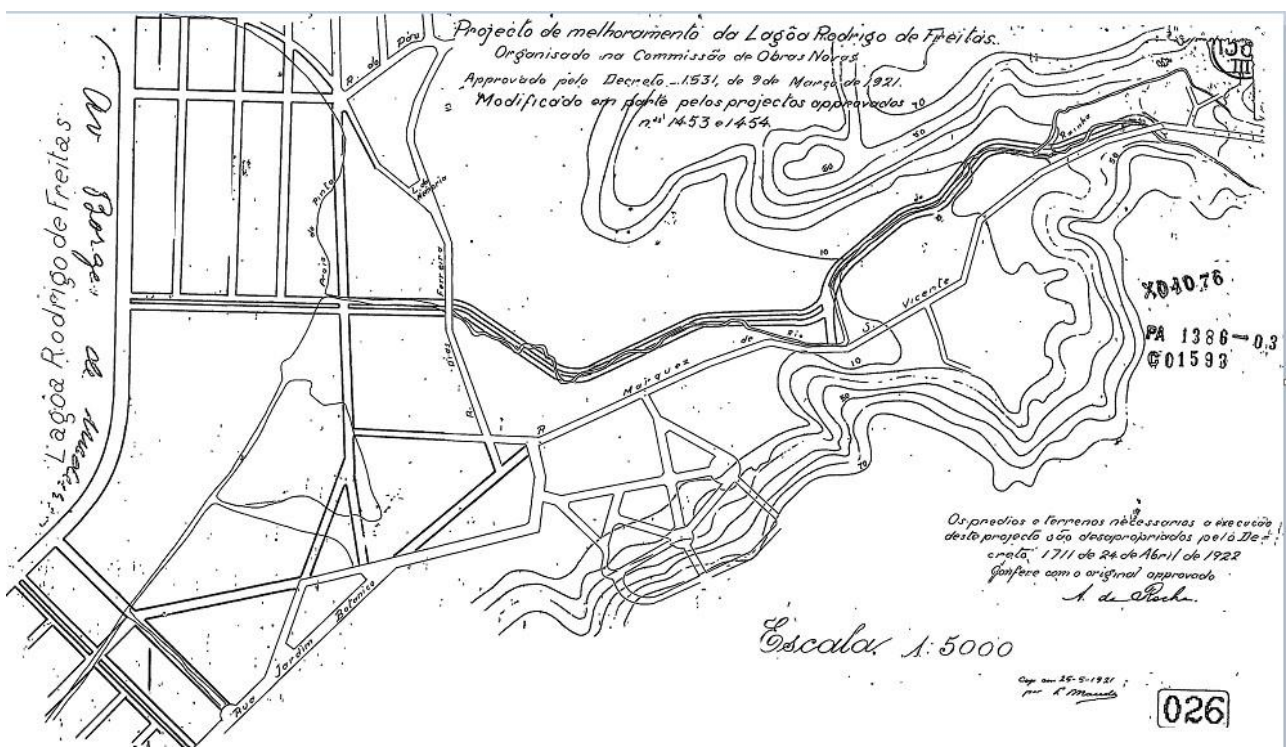

Figura 14 - PAA-1386/Orla Lagoa - Na sequência outro trecho (Av. Borges de Medeiros) 
Já o PAA-1454A de 1922 representado na Figura 15 a seguir, projeta parte da Av. Epitácio Pessoa, Canal Visconde de Albuquerque e Canal da Lagoa, (o que seria a canalização do Rio Rainha).

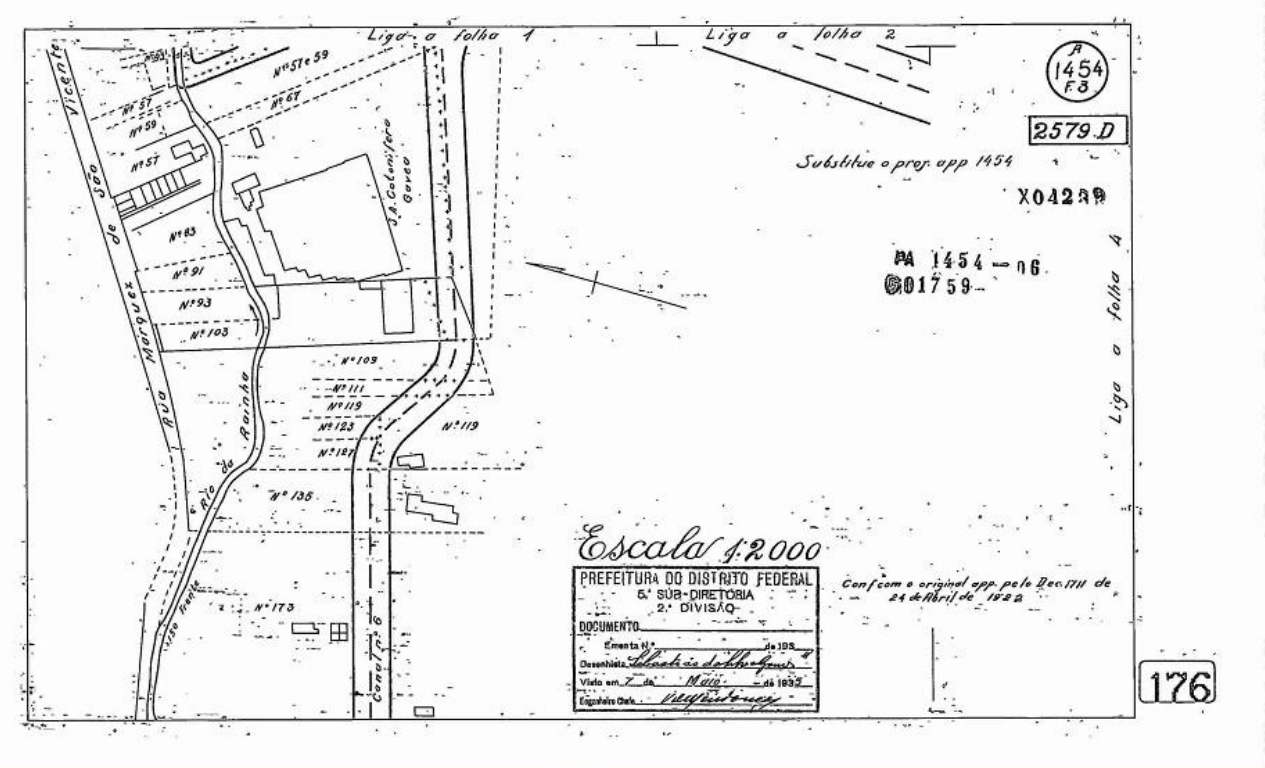

Figura 15 - PAA-1454A - Canalização do Rio Rainha e demais alinhamentos adjacentes

\section{1}

\section{O Problema}

Definir e implantar o Alinhamento de Lagoas Urbanas, de modo a preservar as melhores condições ambientais da região, utilizando para a montagem, estruturação, comparação e análises dos dados envolvidos, tecnologia digital de Sistemas CAD e Sistema de Informação Geográfica - SIG.

Nas cidades, a determinação do Alinhamento da Orla das Lagoas Urbanas deveria observar as condições Geomorfológicas e Ambientais de cada região envolvida, e não somente aspectos urbanos e imobiliários.

Cidades como Belo Horizonte - MG (Lagoa da Pampulha - Figura 16); Sete Lagoas - MG (Lagoa Central - Figura 17); Porto Alegre - RS (Lagoa dos Patos - Figura 18); Brasília - DF (Lago Paranoá - Figura 19); Lagoa da Prata - MG (Lagoa da Prata Figura 20); Lagoa Santa - MG (Lagoa Santa - Figura 21); Rio de Janeiro - RJ (Lagoa Figura 22), são alguns exemplos dentro de um sem número de cidades que têm a responsabilidade de definir a ocupação, utilização e alinhamento das margens de suas lagoas urbanas, encontrando um consenso com apelo cada vez mais ambiental, face aos impactos resultantes. 


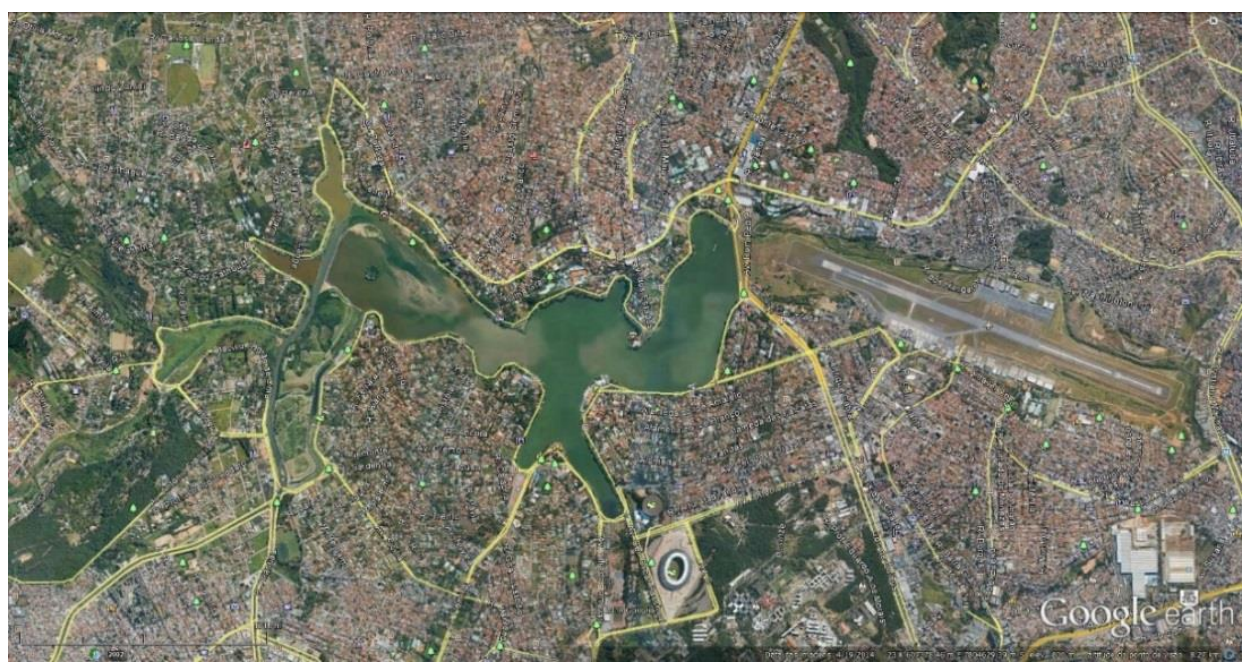

Figura 16 - Lagoa da Pampulha - Belo Horizonte - MG

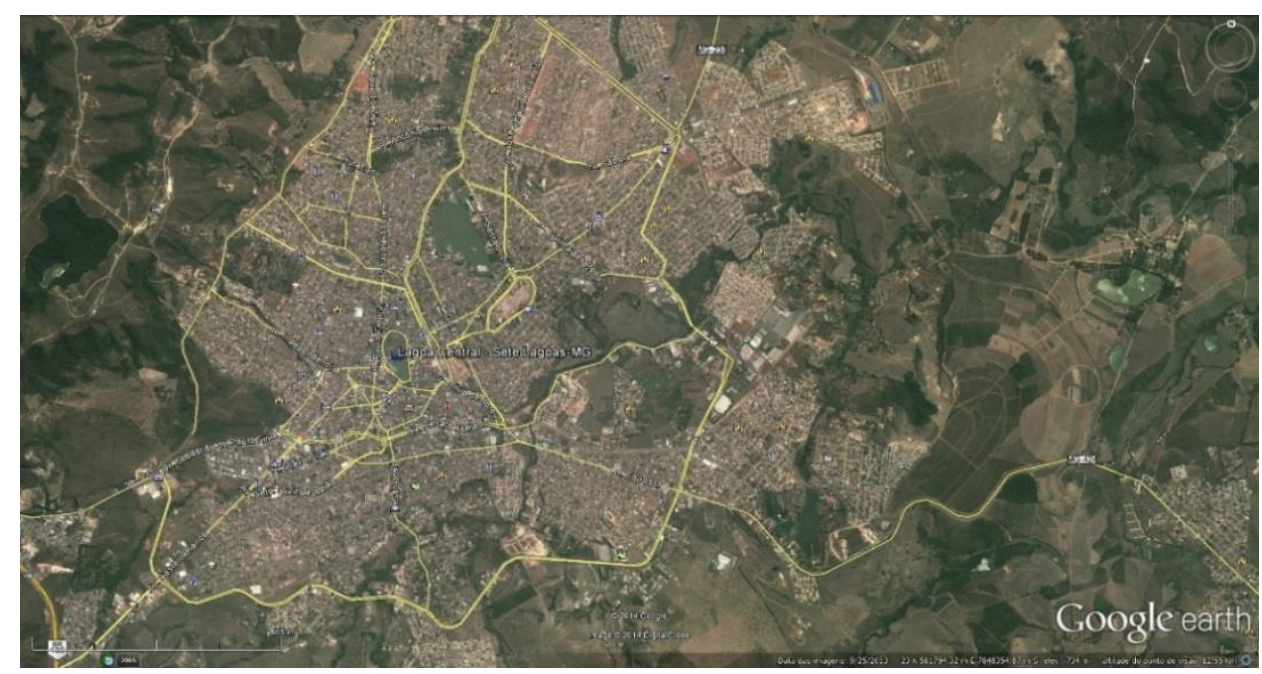

Figura 17 - Lagoa Central - Sete Lagoas - MG

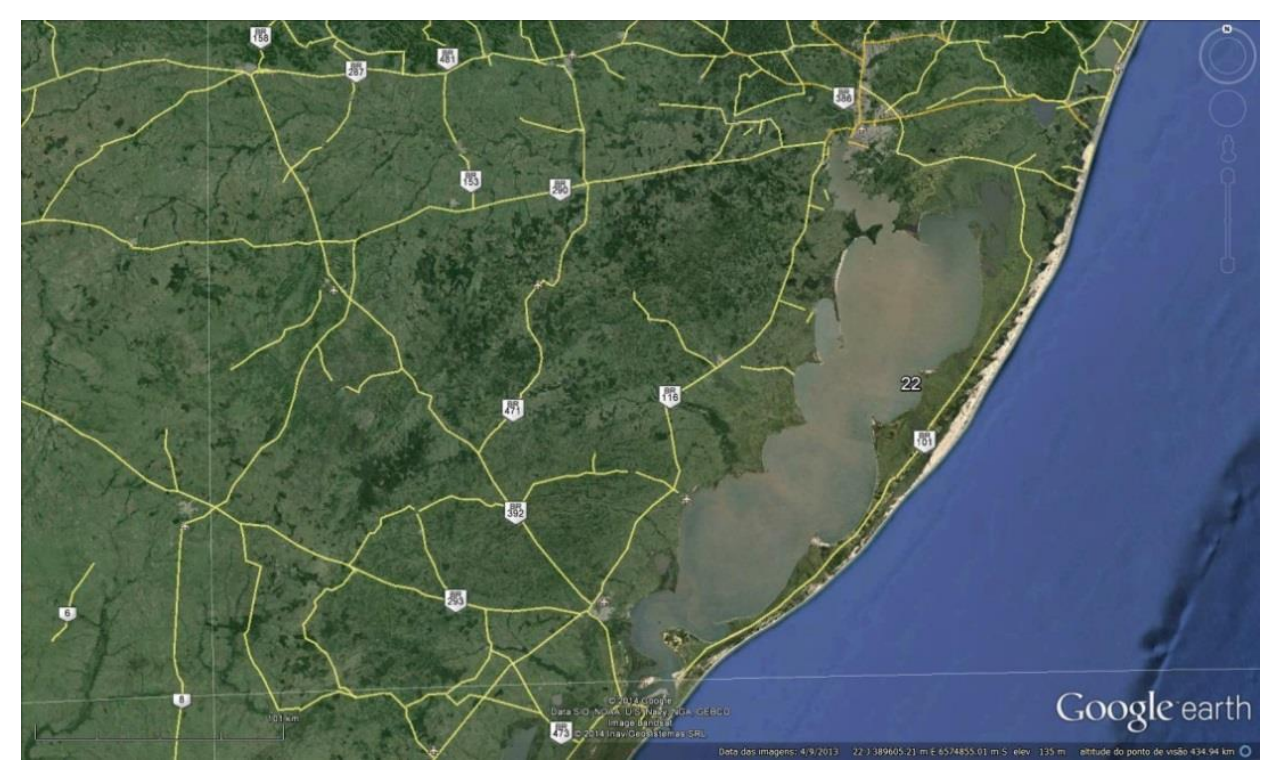

Figura 18 - Lagoa dos Patos - Porto Alegre RS 


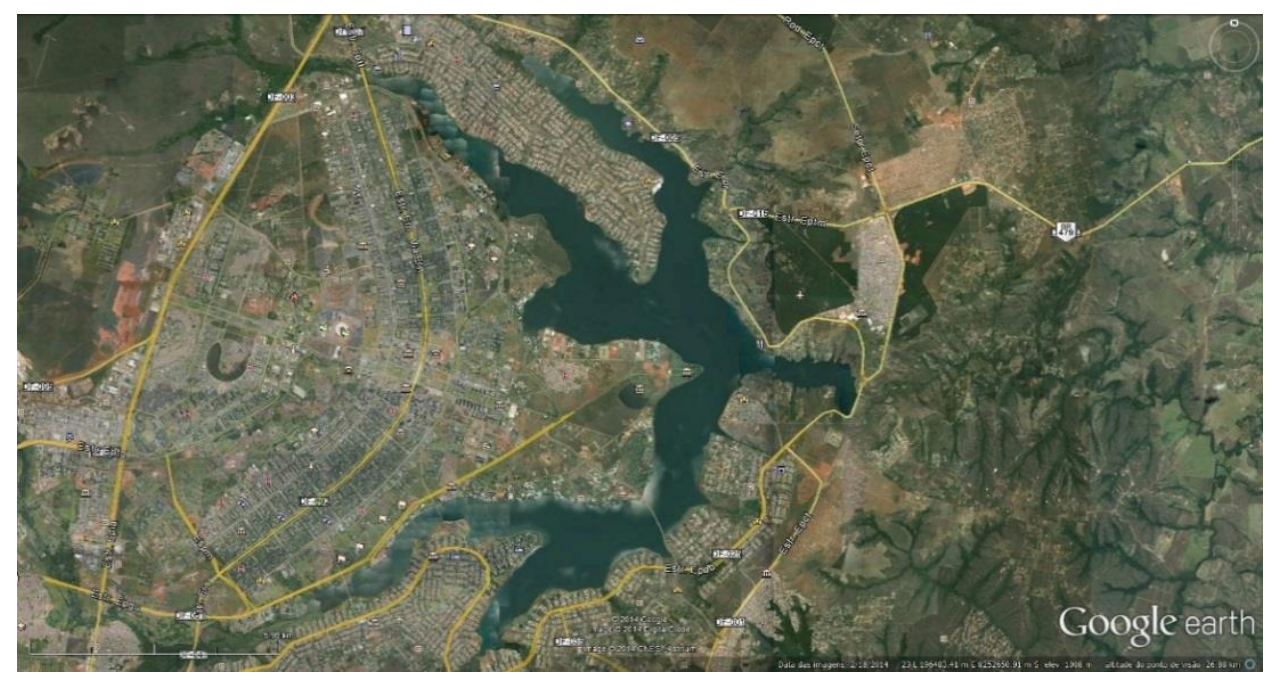

Figura 19 - Lago Paranoá - Brasília - GO

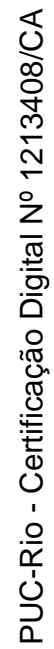

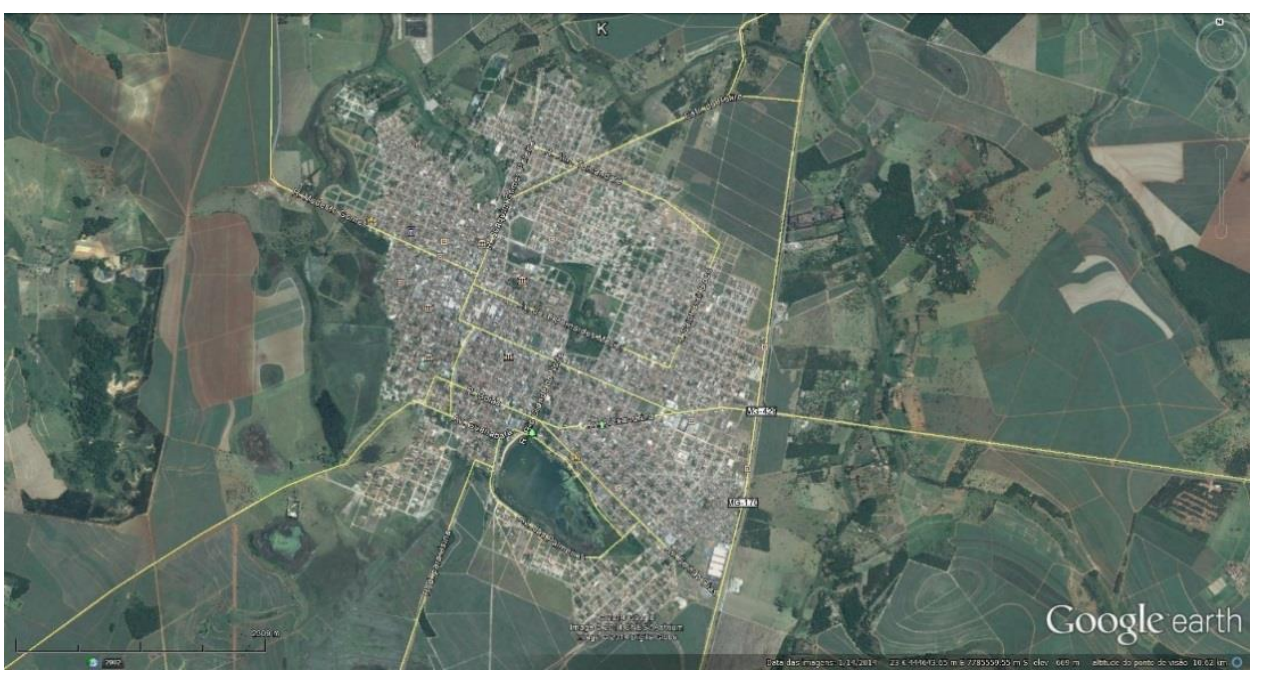

Figura 20 - Lagoa da Prata - MG

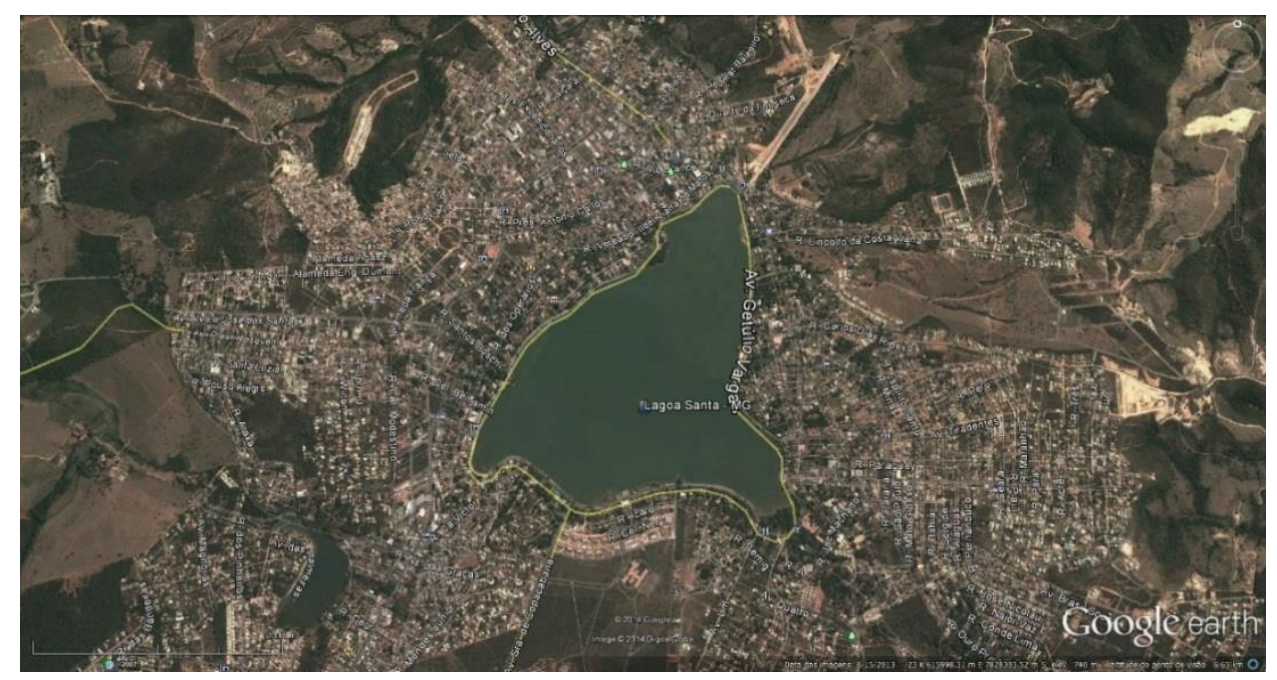

Figura 21 - Lagoa Santa - MG 


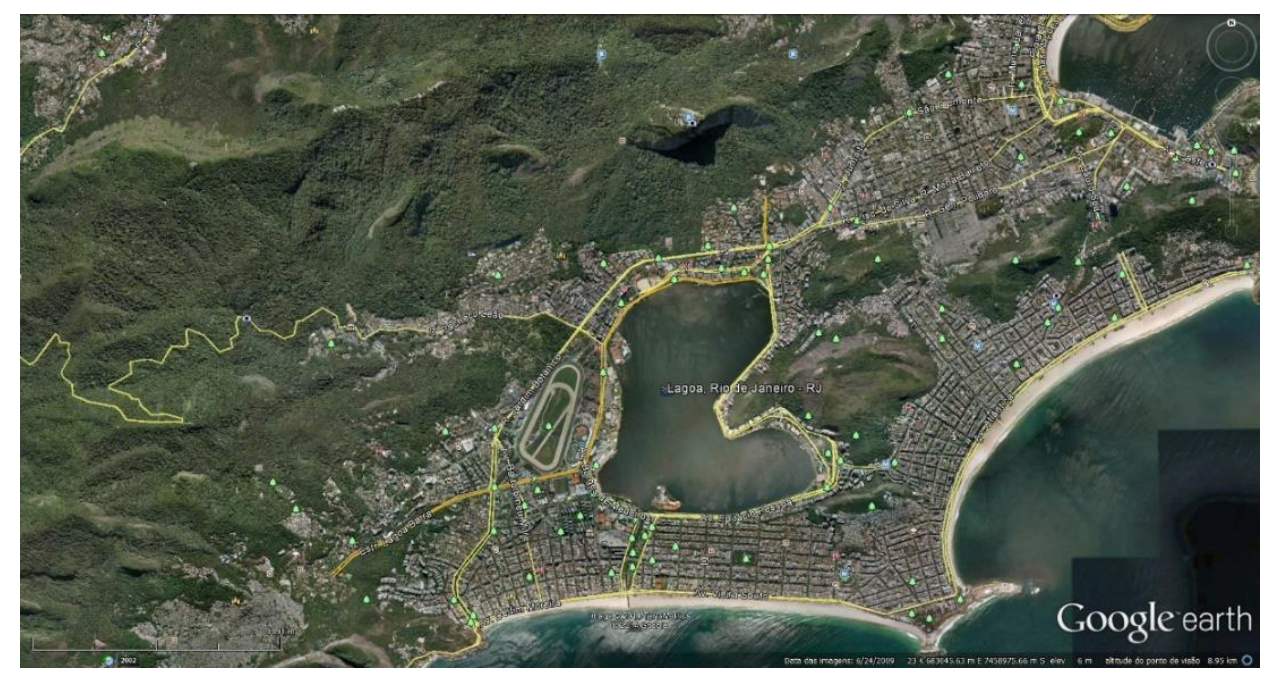

Figura 22 - Lagoa Rodrigo de Freitas, Rio de Janeiro - RJ

O estudo do relevo, hidrologia, cobertura vegetal e espécies animais (fauna e flora), em conjunto com o estudo da Ocupação e Uso do Solo Urbano,

Paisagismo e suas necessidades de aprimoramento, acabam por caracterizar a importância de se preservar o Ecossistema e o Sistema Lagunar, em contraposição ao também importante planejamento e ocupações urbanas no seu entorno e adjacências, com suas necessidades e características observadas na Figura 23.

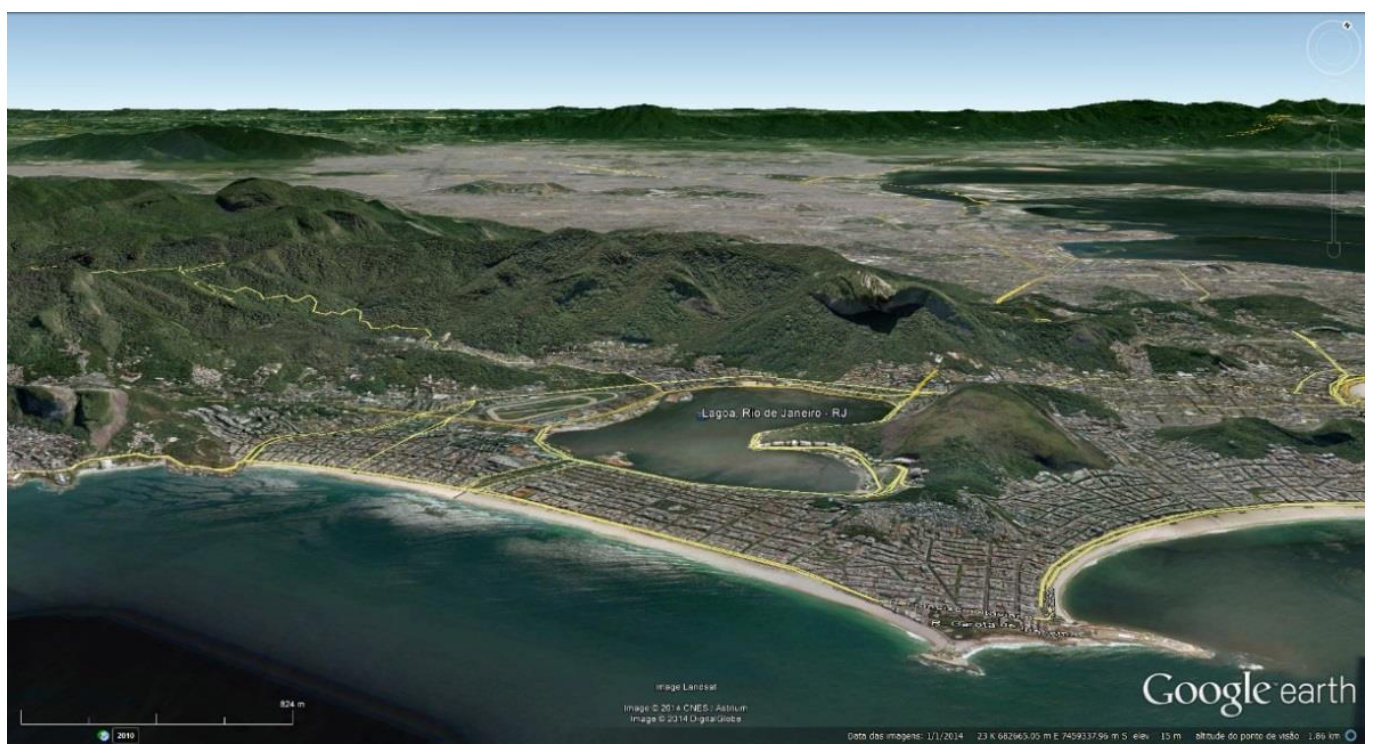

Figura 23 - Vista em Perspectiva da Lagoa, Rio de Janeiro - RJ

Assim, o Planejamento das Cidades objetivando sempre preservar as condições ambientais naturais, mantendo-se o equilíbrio, e dando sustentabilidade as ocupações e expansões, determinam regras e condutas em uma sociedade moderna e consciente. 


\section{2}

\section{Justificativa}

Nos estudos e planejamento do crescimento e desenvolvimento urbano, observa-se que a necessidade de novos espaços e áreas para empreendimentos, com novas ocupações e expansões em quadras e quarteirões, são muito frequentes.

$\mathrm{Na}$ figura 24 temos um típico exemplo de projeto urbano, cujo objetivo é o remembramento de terrenos situados na Av. Epitácio Pessoa, com outro terreno situado na Rua Quitéria, permitindo uma readequação e uso do solo, criando uma nova dinâmica imobiliária.

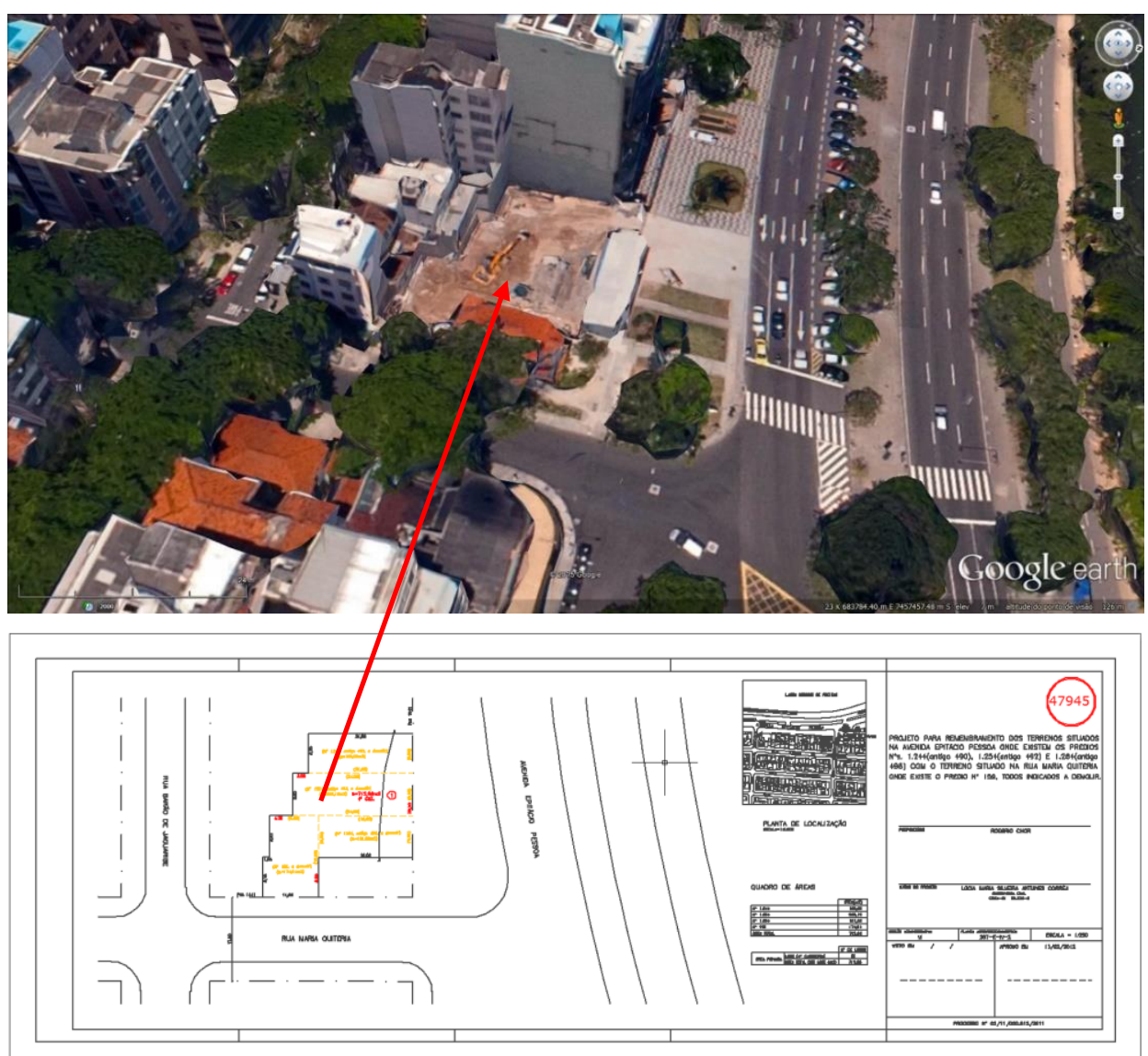

Figura 24 - PAL-47945 (Remembramento de Terrenos) e Vista no Google Earth - Lagoa

Mas quando da necessidade de adequação e criação de novas áreas e/ou novos logradouros e vias expressas que permitem mobilidade urbana, áreas verdes nas faixas de córregos e rios e no entorno de margens de áreas alagadas e de espelhos d'água de lagoas, acabam constituindo-se como válvula de escape, concorrendo com a manutenção e preservação dos espaços livres naturais de cada região. 
É de domínio público o histórico de que várias dessas áreas vêm perdendo nas últimas décadas seus espaços naturais, e acabam por ceder um razoável percentual do seu entorno em função desse crescimento e expansão urbana, pois o apelo dessas áreas, cujas paisagens e iteração com a natureza funcionam como atrativo, gerando uma demanda que resulta em notória valorização imobiliária.

No caso particular da existência de Lagoas Urbanas a situação se torna ainda mais complexa, visto que por consequência do relevo, cobertura vegetal, formações geológicas e clima, as condições físicas do meio ambiente existente (ecossistema/sistema lagunar), acabam por configurar um desdobramento e ambientação próprios, servindo para captação, retenção, absorção, drenagem e vazão das águas das chuvas, formando um equilíbrio natural, propiciando a existência e permanência de variedade de espécies na fauna e na flora.

O entendimento do fluxo hídrico nos diversos compartimentos ambientais é essencial na gestão de recursos hídricos e no dimensionamento de obras hidráulicas, no entanto, a quantificação desses diversos fluxos in-loco é muito difícil devido à grande variedade de fatores ambientais e extensão das áreas a serem estudadas. Diante disso, a modelagem hidrológica se apresenta como um instrumento fundamental nessas quantificações (Filho, 2012).

Assim considerando, a utilização dessa modelagem hidrológica requer a medição da variação do nível d'água de rios e lagoas em diferentes épocas; levantamento da forma topográfica de suas margens e do seu entorno; caracterização da hidrologia da região; adicionando-se ao modelo o estudo da cobertura vegetal, matas e florestas existentes, que contribuem para a preservação e manutenção do fluxo e espelhos d'água, absorção de vazões das águas superficiais; além de estudos dos impactos causados por consequência da urbanização de áreas.

Para tanto, o levantamento de todos esses dados considerando o envolvimento e articulação de diversas disciplinas, acaba por promover uma maior complexidade, principalmente na análise e ponderação dos seus resultados, o que vem justificar a ideia e objetivo deste estudo em pesquisar e propor a utilização de Sistemas CAD; Sistema de Informações Geográficas - SIG; e $\underline{\text { Base }}$ de Dados Georreferenciados em Portais Web, disponibilizados pelos diversos órgãos públicos e privados envolvidos. 


\section{CONDICIONANTES}

Esperando confirmar e consolidar o conhecimento e emprego de ferramentas tecnológicas e uso de base de dados, desenvolveu-se neste estudo a ideia de eleger parâmetros comparativos, quantitativos e qualitativos, dos possíveis fatores condicionantes envolvidos na definição do alinhamento das lagoas urbanas. De modo organizado, sistemático e claro, tirando partido dos diversos recursos e características desses sistemas informatizados, modernos e ágeis, que vem a cada dia sendo mais utilizados e consolidados nas decisões e planejamento urbano-ambientais.

\section{1}

\section{Objetivos do Estudo e Fundamentação}

Propor metodologia para a determinação do alinhamento das lagoas urbanas, utilizando tecnologias CAD/SIG/WEB, utilizando bancos de dados disponibilizados por órgãos públicos e privados, de modo a propiciar o crescimento e expansão urbana, mas preservando as condições ambientais e naturais de cada região.

É necessário e fundamental o emprego de mapeamento topográfico sistemático de toda a região envolvida, que servirá de base sólida para a indicação e tratamento dos diversos fatores envolvidos. Isto se faz necessário por trata-se de assunto que requer análise multidisciplinar, com pesquisa, estudos, e ponderações envolvendo a definição e determinação de vários fatores condicionantes representativos do ecossistema (em específico o sistema lagunar da região), e das características e necessidades de adensamento e expansão urbana do seu entorno (planejamento das cidades e bairros),

Esse mapeamento topográfico servirá de base para os estudos, indicações e lançamento das características e dos fatores definidores das condicionantes envolvidas, procede-se enfim aos estudos, análises, planejamento e determinação do Alinhamento das Lagoas Urbanas 
Tratar o assunto analisando os diversos fatores condicionantes, aplicando os recursos de Desenho Assistido por Computador - CAD (AutoCAD), para tratamento inicial de dados e informações; e Sistema de Informação Geográfica SIG (ArcGis), para consolidação de Base de Dados em Mapas Temáticos Georreferênciados, obtidos junto a órgãos públicos e entidades afins via Portais WEB, propondo uma forma mais ágil e ponderada para a abordagem do problema, facilitando as análises e conclusões.

\section{2}

\section{Objetivo Final e Intermediários}

\section{Final:}

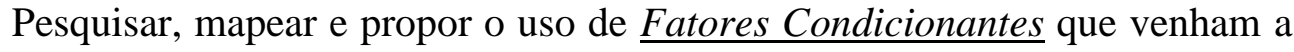
interferir na definição do Alinhamento das Lagoas Urbanas, de modo a propiciar as ocupações e expansões urbanas, mas preservando as melhores condições ambientais da região, utilizando Tecnologia Digital (CAD/SIG/BDG-WEB).

\section{Intermediários:}

- Consolidar o emprego de Levantamento Topográfico (Planialtimétrico Cadastral Georreferênciado) nos estudos de interferências e ocorrências urbano-ambientais;

- Percepção, registro e Estudo das Relações dos fatores condicionantes urbanoambientais nos alinhamentos da Lagoas (Planejamento/Ocupações Urbanas x Iterações com Ecossistemas/Sistemas Lagunares);

- Mapear e eleger essas condicionantes de modo a construir um Modelo Teórico de Análise e ponderações inerentes;

- Construir referencial teórico sobre a aplicação e utilização de Tecnologia Digital nos estudos dessas condicionantes urbanas e ambientais;

- Contribuir para a Gestão de Conhecimento Multidisciplinar, nos modelos de estudos urbano-ambientais;

- Organizar Fluxos de Procedimentos nas Análises Multidisciplinares, nos modelos de gestão urbana-ambiental. 


\section{3}

\section{Linha de Pesquisa e Suposição}

Conforme a Estrutura Acadêmica proposta pela PUC-Rio e a TU Braunshweig da Alemanha, disponível no Portal do Curso de Mestrado, a Linha de Pesquisa para este trabalho é a seguinte:

\section{- Planejamento Urbano e Sustentabilidade}

Destina-se à investigação dos modelos de planejamento e soluções para as cidades brasileiras, procurando desenvolver propostas e alternativas tecnológicas para minorar os impactos das atividades urbanas sobre o meio ambiente e no processo de mudanças climáticas.

Supõe-se que com o uso de Tecnologia Digital - CAD/SIG nestes estudos, utilizando Base de Dados Geográficos - BDG via WEB existentes e disponibilizados pelos diversos Órgãos Públicos Federais, Estaduais e Municipais inerentes a cada região; e com base nas várias disciplinas envolvidas (assunto tipicamente multidisciplinar), a saber:

1. Topografia - Planialtimetria com estudo do Relevo;

2. Aerofotogrametria - Emprego de fotografia aérea para a elaboração do Mapeamento Sistemático;

3. Cadastramento (coleta de dados físico-legais da região);

4. Georreferenciamento;

5. Clima e Histórico de Chuvas;

6. Hidrologia - Traçado dos Rios, Divisores de Águas, Talvegues e Bacias de Contribuição);

7. Engenharia Urbana e Ambiental (Biologia; Fauna-Flora);

8. Planejamento Urbano - Projetos de Alinhamento e Loteamento Urbanos;

9. Legislação Urbana e Ambiental;

Seja possível melhorar a pesquisa, mapeamento e análise dos "fatores condicionantes" que definem e/ou interferem na escolha do Alinhamento de Lagoas Urbanas, de modo a preservar as melhores condições ambientais da região. 


\section{4}

\section{Delimitação do Estudo e Aplicativos}

Este estudo pretende observar as vantagens em utilizar Tecnologia Digital (CAD/SIG), pretende também aplicar o conhecimento de disciplinas e teorias já consolidadas, revisando legislação inerente e bibliográficas específicas; elaborando pesquisas; estudos de projetos; consultas em órgãos públicos e privados, e análise multidisciplinar.

A pesquisa foca o assunto delimitando-se ao caso da Lagoa Rodrigo de Freitas: Estudo de Caso - Ilustrado na Figura 25, objetivando simplificar ações e demandas, bem como otimizar recursos e prazos, considerando que as diversas outras lagoas urbanas existentes, podem estar inseridas num outro contexto particular e específico, claramente inerentes a cada sistema ambiental e urbano envolvidos.

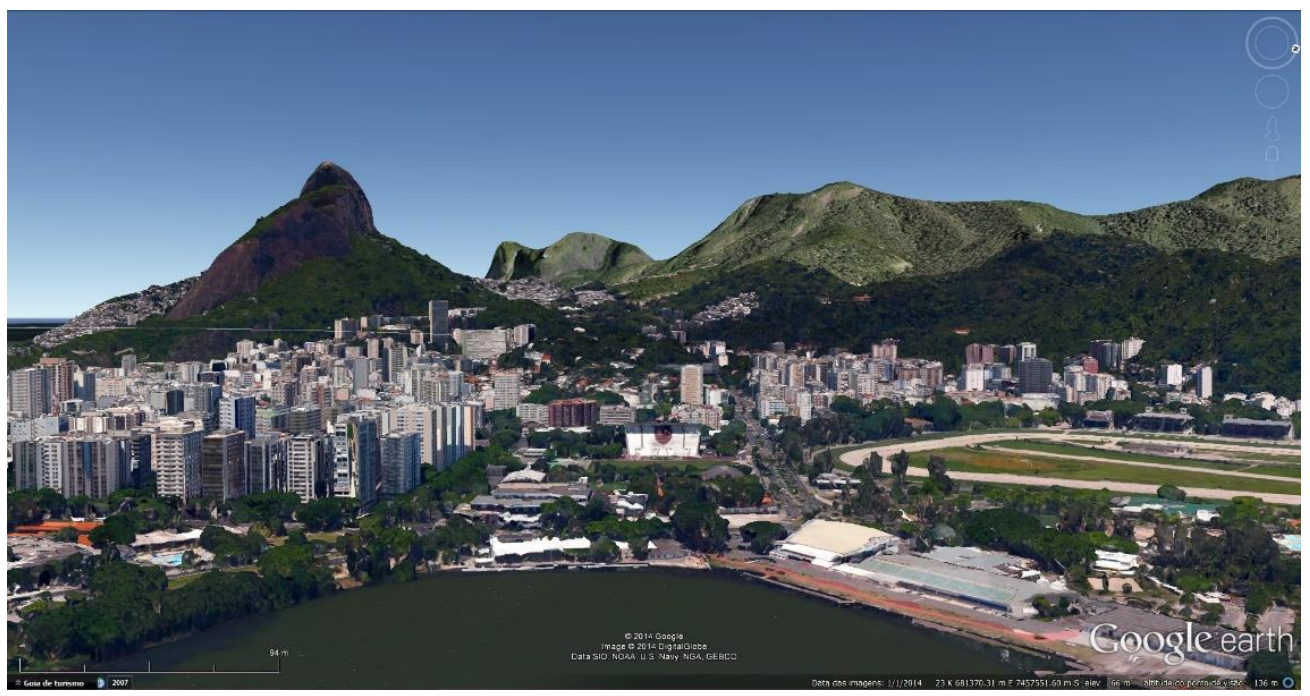

Figura 25 - Detalhe das margens e adjacências da Lagoa com suas particularidades

Os aplicativos escolhidos para emprego e utilização dentre outros foram:

O sistema Windows e seus acessórios e recursos; Pacote Office; AutoCAD; ArcGIS, e Navegadores web, considerando suas características, qualificações, disponibilidade e adoção no escopo curricular do Curso de Mestrado da PUC-Rio, além da navegação pelos Portais de Órgãos Públicos e Privados para obtenção da Base de Dados. 


\section{5}

\section{Termos e Assuntos a Serem Abordados}

Levantamento Topográfico / Cadastramento / Georreferenciamento;

Relevo / Divisor de Águas / Talvegue / Vertente / etc;

Base de Dados / Atributos / Tecnologia Digital (CAD / SIG);

Rio / Bacia Hidrográfica; / Mananciais; Lagos e Lagoas / Sistema Lagunar Espelho D’água / Batimetria; Lençol Freático / Águas Subterrâneas / Águas Superficiais;

Hidrologia / Micro e Macro Drenagem; Clima e Regime de Chuvas;

Ecossistema / Vegetação Ciliar / Fauna / Flora; Floresta Urbana;

Planejamento Urbano (Certidão de Informações da Prefeitura);

Plano diretor (Legislação Urbana e Legislação Ambiental);

Situação Fundiária / Registro de Imóveis / Valor Imobiliário;

Infraestrutura Urbana Ocupação e Expansão Urbana;

Projeto Aprovado de Alinhamento; Projeto Aprovado de Loteamento;

Projeto Aprovado de Orla.

\section{6}

\section{Referencial Teórico e Base de Dados}

Para o desenvolvimento deste estudo com suas conceituações e suposições, este trabalho de pesquisa lança mão de ideias de natureza criativa, buscando inspiração nas diversas disciplinas curriculares estudadas ao longo do curso de Mestrado de Engenharia Urbana e Ambiental da PUC-RIO, partindo-se do contexto do ambiental sofrendo interferências urbanas, empregando e adotando um conjunto de hipóteses e um universo de informações conforme segue:

\section{7}

\section{Modelo de Análise}

Objetivando montar e configurar um Modelo de Análise das iterações entre o Meio Ambiente Natural das Lagoas e o Meio Urbano com suas ocupações e necessidades de expansão, elegendo e associando Fatores Condicionantes que 
possam vir a influenciar na determinação do Alinhamento Lagunar, de modo a manter as melhores condições ambientais naturais da região, criamos e adotamos inicialmente o modelo demonstrado na Figura 26 a seguir:

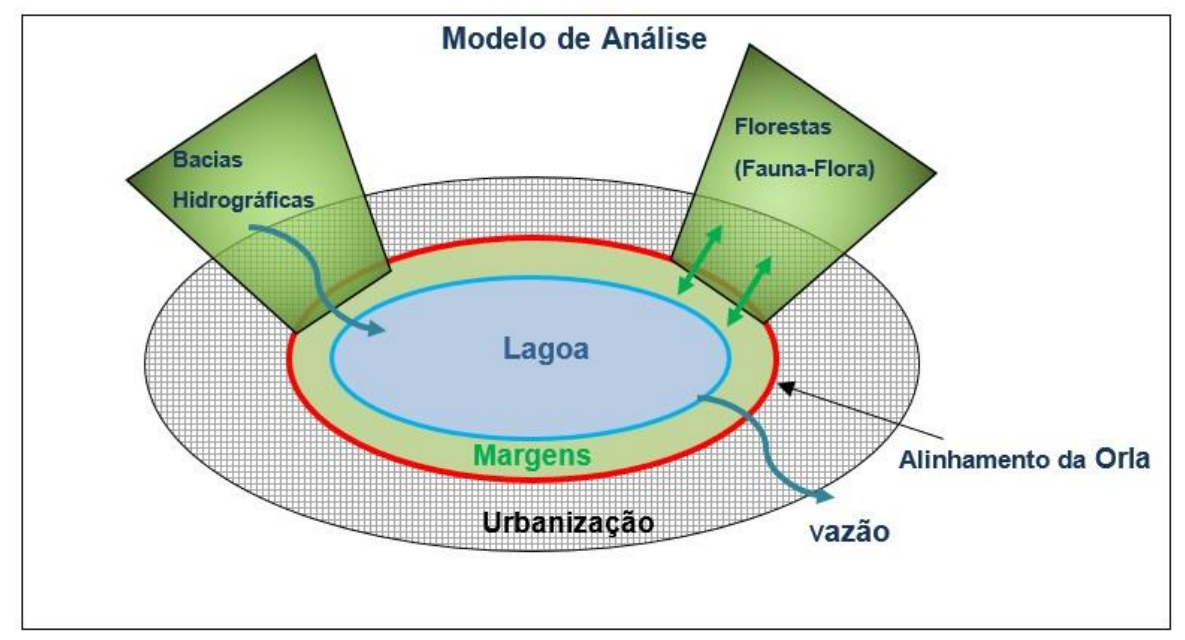

Figura 26 - Modelo de Análise

Conceitualmente, conforme ilustrado, podemos entender que as lagoas em seu estado natural possuam além do espelho d'água (Lagoa), perímetro compostos por vegetação ciliar que funcionam como proteção contra erosões e instabilidades do solo (Margens), e que possuam também afluência de águas captadas e conduzidas através da topografia da região (Bacias Hidrográficas), formadas e definidas por suas vertentes e talvegues, com rios e córregos; todos estes associados direta ou indiretamente a uma cobertura vegetal, constituída por áreas florestadas (Florestas) e consequentemente vida animal compondo a fauna-flora da região. 


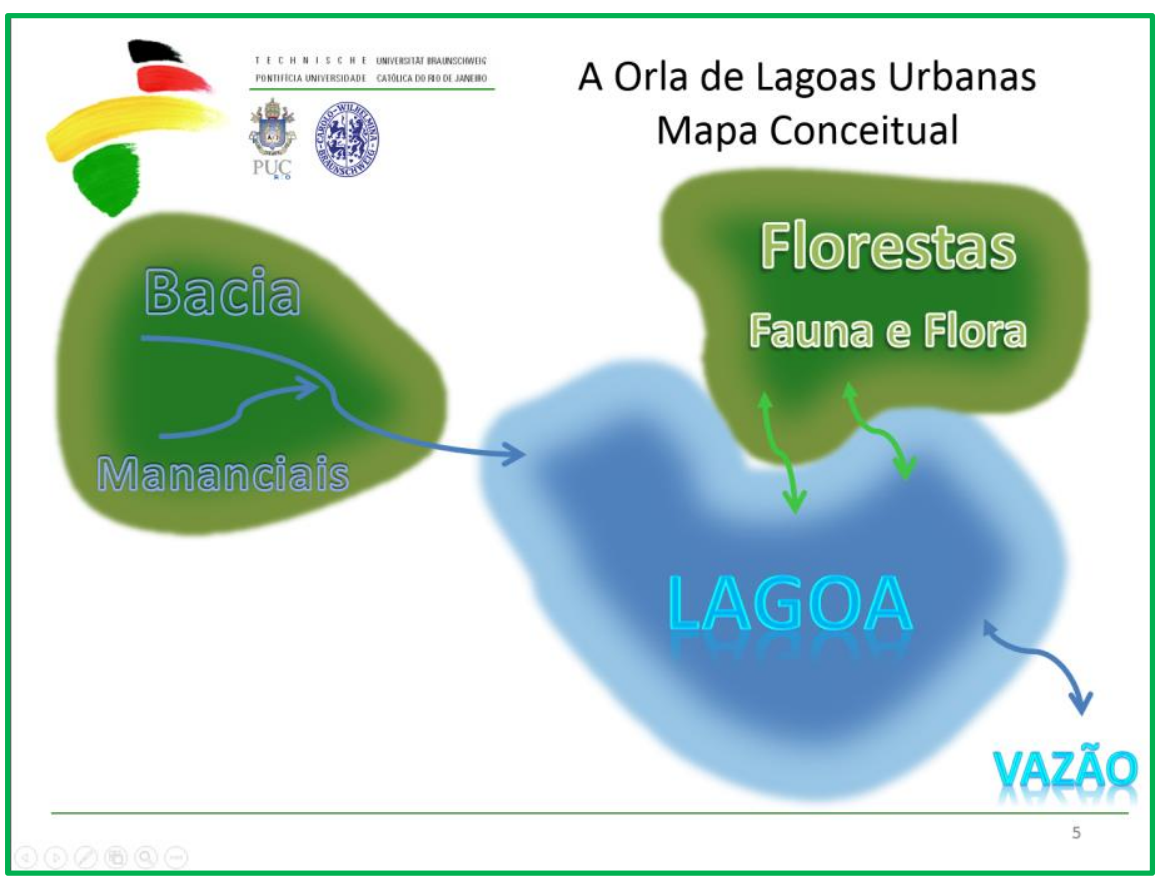

Figura 27 - Mapa Conceitual só natureza

Criamos e ilustramos a ideia da lagoa no seu estado natural, no mapa conceitual representado na Figura 27. No entanto, no desenvolvimento das ações antrópicas, vão surgindo ocupações e transformações do uso do solo, formando as áreas urbanizadas que acabam por alcançar e interagir com as margens das Lagoas, sem uma definição exata de seus limites. Esta ideia está representada no Mapa Conceitual apresentado na Figura 28 a seguir.

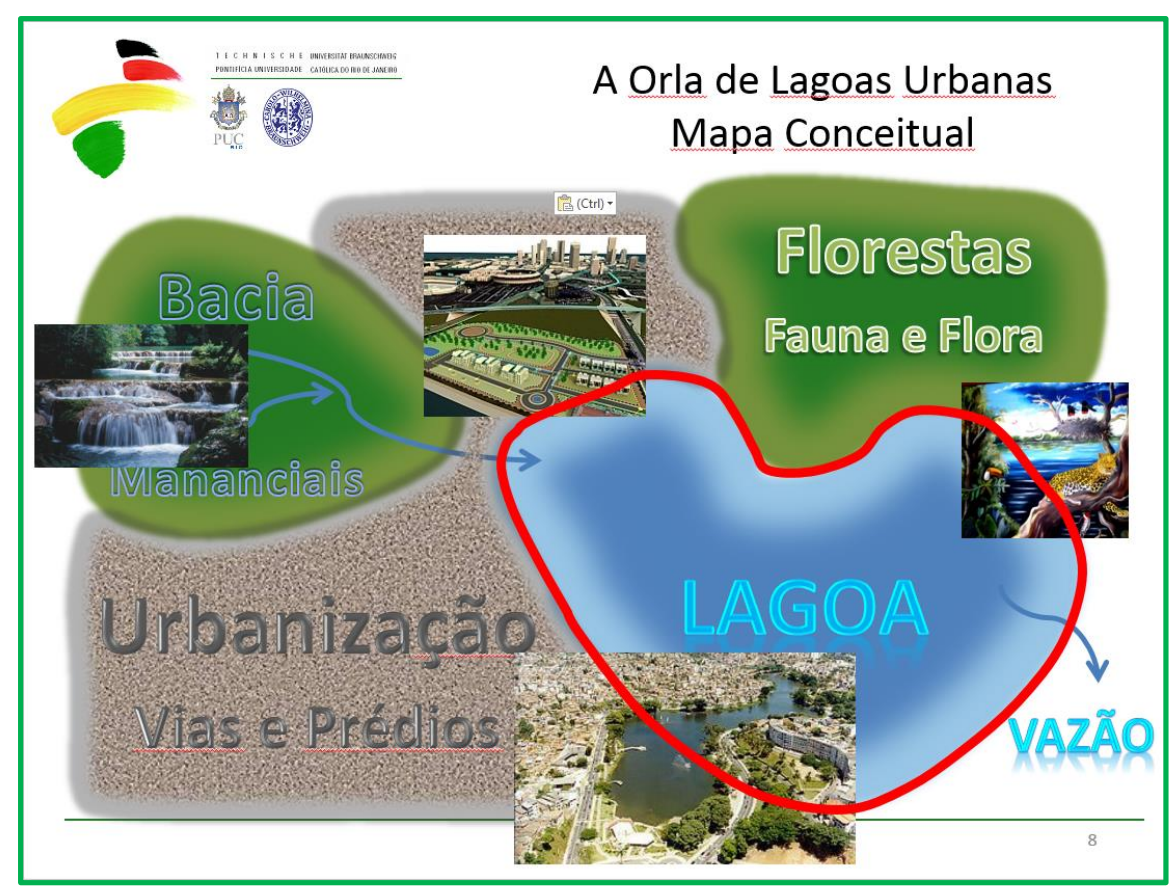

Figura 28 - Mapa Conceitual com urbanização 
Deste modo, busca-se entender como seria o posicionamento desse limite, elegendo-se parâmetros que possam vir a indicar e associar um alinhamento que propicie manter as condições naturais de preservação da integridade peculiar da Lagoa, definindo-se assim, o Projeto de Alinhamento da Orla das Lagoas Urbanas - PAOLU.

\section{8}

\section{Determinação dos Fatores Condicionantes}

Num primeiro nível de análise, depuramos dois aspectos de fatores $\underline{\text { condicionantes }}$, cujo desdobramento vem descrito abaixo e representado na Figura 29:

- Fatores Ambientais $(\boldsymbol{F A}):$ Condições e fatores naturais predominantemente existentes na região de ocorrência da lagoa, que fazem parte do seu contexto e que agrupam peculiaridades de influência e oscilação do espelho d'água da LRF; e

- Fatores Urbanos (FU): Condições e fatores antrópicos resultantes das necessidades de ocupação e expansão das cidades, que acabam por interferir de modo forçado e artificial nas condições natural da LRF.

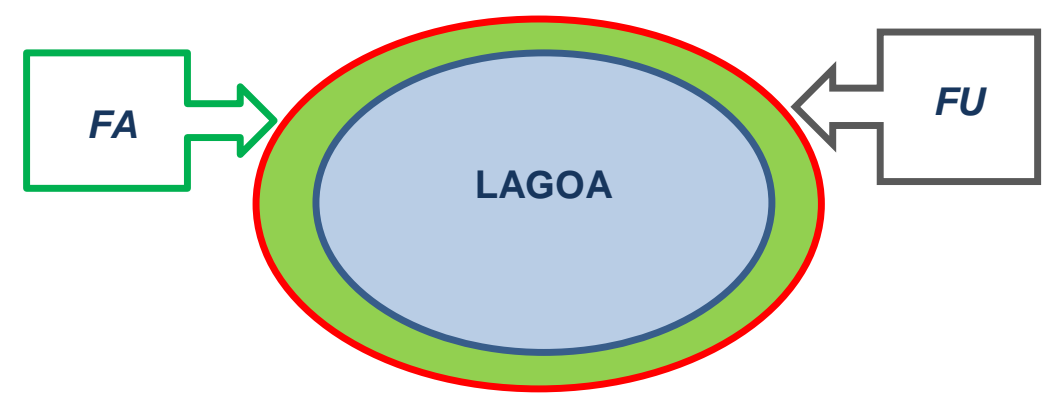

Figura 29 - Representação do Primeiro Nível de Análise

No próximo item iremos prosseguir com esse conceito e raciocínio estruturado, avançando com mais desdobramentos de níveis em cada um dos dois grupos de fatores.

No Mapa 01, podemos ter uma boa noção das questões de uso do solo, destacando-se as áreas não urbanizadas e as urbanizadas com classificação de uso. 


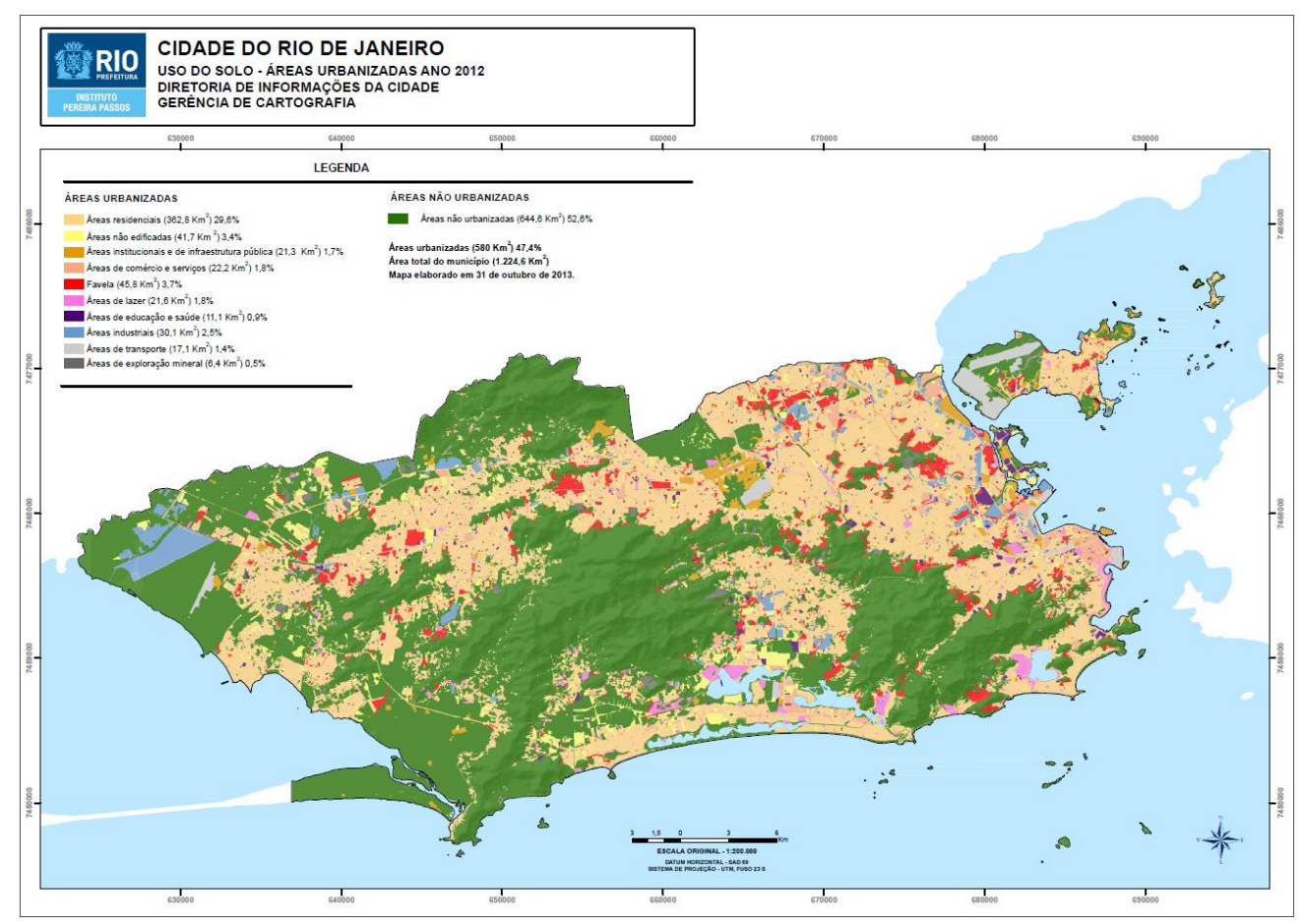

Mapa 01 - Uso do Solo - Áreas Urbanizadas - 2012 - Fonte IPP 


\section{9}

\section{Modelagem de Condicionantes Urbano/Ambientais}

Para a modelagem e conceituação dos Fatores Condicionantes em estudo, buscamos e criamos um raciocínio de análise utilizando uma escala de níveis em hierarquia no formato de árvore, cuja denominação adotada neste trabalho foi de

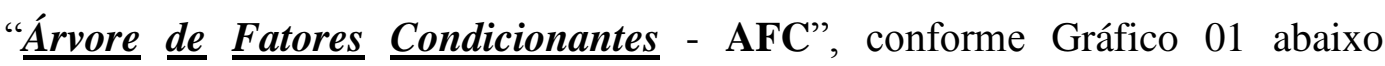
detalhado.

Partindo-se do objetivo de determinação do Projeto de Alinhamento da Orla das Lagoas Urbanas - PAOLU, num primeiro nível de detalhamento, conforme já abordado no item anterior, analisamos dois aspectos de fatores, cujo desdobramento levou em consideração a sua natureza, conforme justificado abaixo:

- Fatores Ambientais: Condições e fatores predominantemente naturais existem na região de ocorrência da lagoa, que fazem parte do meio ambiente e que são peculiares e de influência ao nível e superfície da água; e

- Fatores Urbanos: Condições e fatores antrópicos decorrentes das necessidades de ocupação e expansão das cidades, e que acabam por forçar e interferir nas condições naturais da lagoa.

Neste sentido, seguindo a conceituação e desenvolvimento de níveis subsequentes, concebemos que para cada um dos fatores podemos subdividi-los sucessivamente, até chegar aos níveis indicados no Gráfico 01 abaixo.

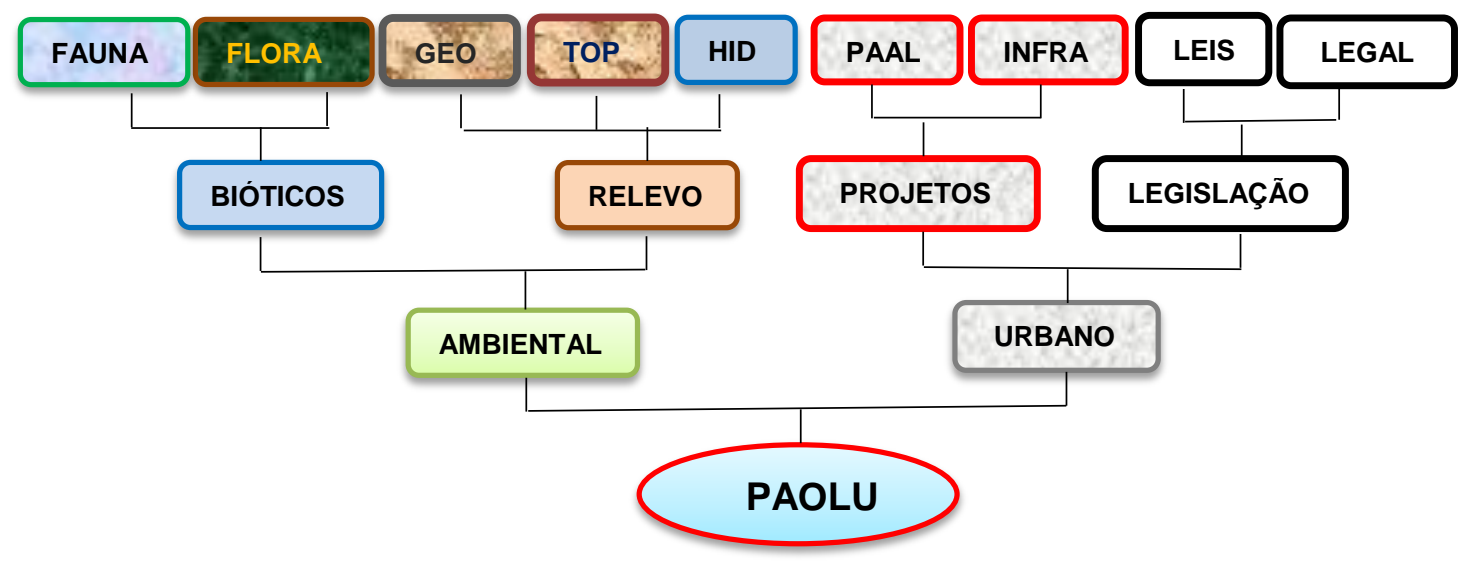


Assim, nesse gráfico elencamos os Fatores Condicionantes para a determinação do PAOLU, organizados em formato de Árvore, cujo gráfico mostrou-se interessante e eficaz na representação das ideias de abrangência e abordagem, concatenando as diversas questões envolvidas (multidisciplinaridade) com clareza e senso de organização, partindo-se de uma divisão inicial primária, até alcançar o desdobramento de elementos mais específicos e complexos. Neste sentido, demonstrando a linha de raciocínio e avançando com a conceituação e desenvolvendo dos níveis subsequentes temos que:

Os $\underline{\text { Fatores }} \underline{\text { Ambientais }}$ podem ser subdivididos em Bióticos e Relevo:

- Bióticos (seres vivos): Seres animais, vegetais, fungos, protozoários e bactérias que predominam na região, que por sua vez podem ser desdobrados e classificados em Fauna e Flora:

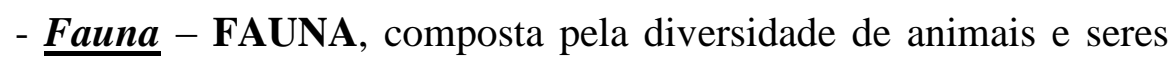
que habitam a região, e

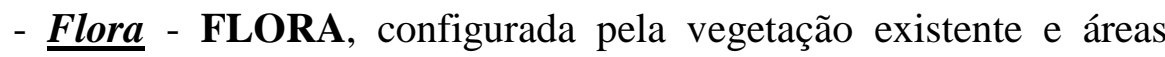
naturais densas ou não de vegetação.

- $\underline{\text { Relevo }}$ (abióticos): Superfície física que, apresentando irregularidades e formas específicas, empresta e impõe determinadas características à região; podendo seu desdobramento ser considerado como de formação Geológica, Topográfica e Hidrológica:

- Geológica - GEO, a conformação e caracterização do solo e sua origem, resulta em maiores desdobramentos e influências depurados em geotecnia;

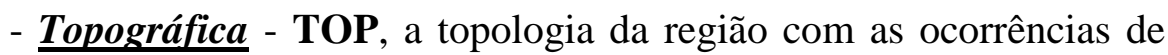
elevações, depressões, linhas de cumeadas e talvegues, resultam em características de influência e condições de contorno; e

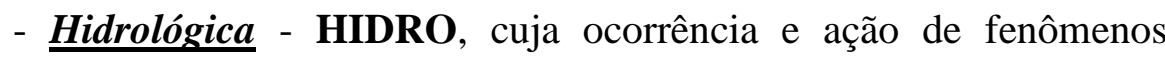
atmosféricos, associados a forma e abrangência da bacia e sub-bacias da região, com quantidade e volume das águas dos rios principais, afluentes e sub-afluentes, também interferem diretamente no equilíbrio das condições da Lagoa. 
Já os Fatores $\underline{\text { Urbanos, }}$ podem ser divididos em:

- Projetos: Projetos de Urbanização e/ou Modificação do uso do solo, que seguindo a mesma linha de análise também podem ser divididos e classificados como:

- Projeto Aprovado de Alinhamento e Loteamento - PAAL que projetam ou modificam o traçado de ruas, avenidas e até mesmo estradas (PAA), e que projetam ou modificam área, lotes e quadras (PAL); e

- Projetos e Obras de Infraestrutura Urbana - INFRA, que representam a quantidade e qualidade destes aparelhos urbanos (calçamento, pavimentação, águas pluviais, esgoto, água potável, serviços públicos) no contexto da região em estudo.

- Legislacão, Definido inicialmente pelo Plano Piloto da Cidade e demais questões de Zoneamento e Regulação de Ocupação e Uso do Solo, e questões de ocupações e ações urbanas ilegais não permitidas e/ou não autorizadas, tidas como irregulares, perfazendo um contexto de subdivisão tal como:

- Decretos e Leis - LEIS, conjunto de Decretos e Leis que na prática são detalhados no Código de Obras da Cidade, com o sistema de aprovação e licenciamento de obras e concessão de alvará e habite-se.

- Áreas e Acões Legais - ILEGAL, e enfim a Legalidade das ações e ocupações, que representa as possíveis ações legais ou ilegais (regulares ou irregulares), considerando itens como área total edificável, recuos, faixas "non aedificand", gabaritos, etc., todos regidos, regulamentados e publicados por Decretos na Legislação Urbana.

É certo que o nível de desdobramento alcançado, ainda não representa totalmente a complexidade contida nos sistemas lagunares urbanos. Podemos ainda desenvolver mais análises e decomposições dos fatores condicionantes encontrados, buscando uma melhor representação ainda mais complexa, das condições ambientais e urbanas envolvidas.

Citamos abaixo alguns exemplos:

- Da formação Hidrológica - HIDRO:

Bacia Hidrográfica; 
Rio A; Vazão A; Rio B; Vazão B;

Afluentes e Sub-afluentes; e

Quantidade de Chuvas.

- Da formação Geológica - GEO:

$\mathrm{Na}$ Geologia, os principais fatores como constituição mineral, matéria orgânica, umidade e granulometria (textura e estrutura) são exemplo de detalhamento a ser levado em consideração na análise:

Geologia da Lagoa e suas margens; e

Geologia da Bacia Hidrográfica.

- Dos Projetos Aprovados de Alinhamento e Loteamento - PAAL:

Previsão de Canteiro Central Arborizado; e

Projeto de Praças e Parques (áreas Verdes).

- Das Leis e Decretos - LEIS:

Taxa de Ocupação;

Faixas de Recuo; e

Gabarito.

Assim, presumimos que a cada desdobramento de níveis estaremos melhor representando as verdadeiras condições Ambientais e Urbanas envolvidas, mas aumentando em muito a complexidade do assunto.

\subsection{0}

\section{Metodologia de Modelagem}

Objetivando representar matematicamente as ações antrópicas que acabam por interferir e alterar o ecossistema das Lagoas Urbanas, pensamos em formatar uma escala comparativa de valores dos Fatores Condicionantes, considerando sua representação em gráficos, buscando uma visualização e correlação entre as ações e reações com equilíbrios e desequilíbrios; tendências de comportamento e consequências, buscando uma modelagem e comparação.

Para tanto, entendemos que cada um dos Fatores Condicionantes devem ser estudados e analisados em suas características e padrões, de modo a serem representados e expressos em termos de parâmetros, ou seja realizar uma 
parametrização de cada um deles, que pode vir a ser representada resumidamente em escala mensural comparativa, conforme sugerido na Tabela 01 abaixo.

Tabela 01 - Comparação do Grau de Influência de cada Fator Condicionante

\begin{tabular}{|c|c|c|c|c|c|c|c|c|c|}
\hline \multicolumn{8}{|c|}{ Comparativo do Grau de Influência dos Fatores Condicionantes na Determinação do PAOLU } \\
\hline \multirow{3}{*}{ FATORES CONDICIONANTES } & \multicolumn{4}{|c|}{ AMBIENTAIS } & \multicolumn{4}{c|}{ URBANOS } \\
\cline { 2 - 10 } & \multicolumn{2}{|c|}{ BIÓTICOS } & \multicolumn{3}{|c|}{ RELEVO } & PROJETOS & \multicolumn{2}{c|}{ LEGISLAÇÃO } \\
\cline { 2 - 10 } & FAUNA & FLORA & GEO & TOP & HID & PAAL & INFRA & LEIS & ILEGAL \\
\hline Grau de Influência (\%) & aa & bb & cc & dd & ee & ff & gg & hh & ii \\
\hline
\end{tabular}

Considerando a complexidade desta questão de parametrização, que acabaria por envolver diversas outras ações e experimentos, e que consequentemente estenderia em demasia este trabalho e estudo, buscamos apenas esboçar e formatar a ideia com hipóteses e formas de representação gráfica simplificada.

Para o caso desta etapa de detalhamento de parametrização vir a ser desenvolvida, entendemos que dentro de um conjunto de ferramentas e aplicativos a serem utilizados, a tecnologia SIG - Sistemas de Informações Geográficas, venha a ser a mais indicada para análises e conclusões finais, devido as suas características e recursos de demonstração dos resultados, pois este aplicativo dentre outros recursos, vincula mapas vetoriais/matriciais a um banco de dados estruturado.

Esse banco de dados estruturado sendo formado e alimentado pelos parâmetros obtidos para cada um dos fatores condicionantes, evidenciará e demonstrará melhor os resultados, através da produção de mapeamento temático georreferenciado.

\subsection{1}

\section{Gráfico de Barras}

Num primeiro exercício simples de avaliação da interferência e correlação desses fatores, idealizamos um gráfico de barras representativo e comparativo, cuja visualização venha a fornecer intuitivamente um padrão de qualidade para o PAOLU, onde os valores aa, bb, ....ii apurados, sejam indicados e assinalados conforme a escala gráfica em forma de barras, estruturada no Gráfico 02 a seguir. 


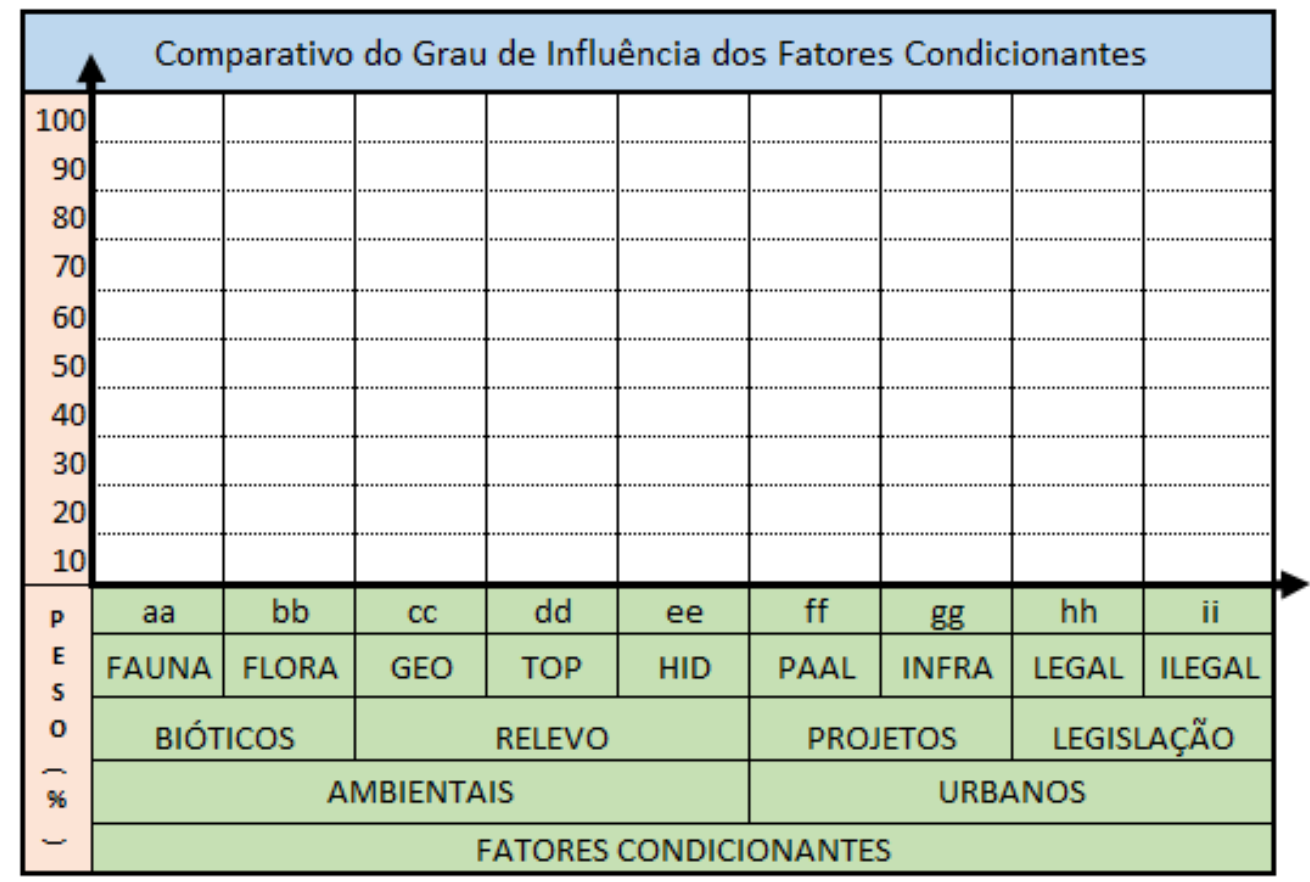

Gráfico 02 - Gráfico de Barras Comparativo dos Fatores Condicionantes do PAOLU

\subsection{0 .2}

\section{Gráfico Polar Direcional}

Num segundo exercício de comparação da parametrização, agora buscando desenvolver uma ideia de escala de valores que englobe todos os Fatores Condicionantes conceituados num só resultado, buscamos na representação de "Gráfico Polar Direcional”, um processo comparativo que permita visualização de um vetor resultante, cuja intensidade e direção podem indicar o quanto os fatores Urbanos interferem nos fatores Ambientais e vice-versa, permitindo categorizar e classificar o estado das Lagoas Urbanas (Naturais; Poucas Interferências; Medianas Interferências; Muitas Interferências; Total Interferência; etc.), conforme o Gráfico 03 a seguir. 
FATORES CONDICIONANTES - PAOLU Gráfico Polar Direcional

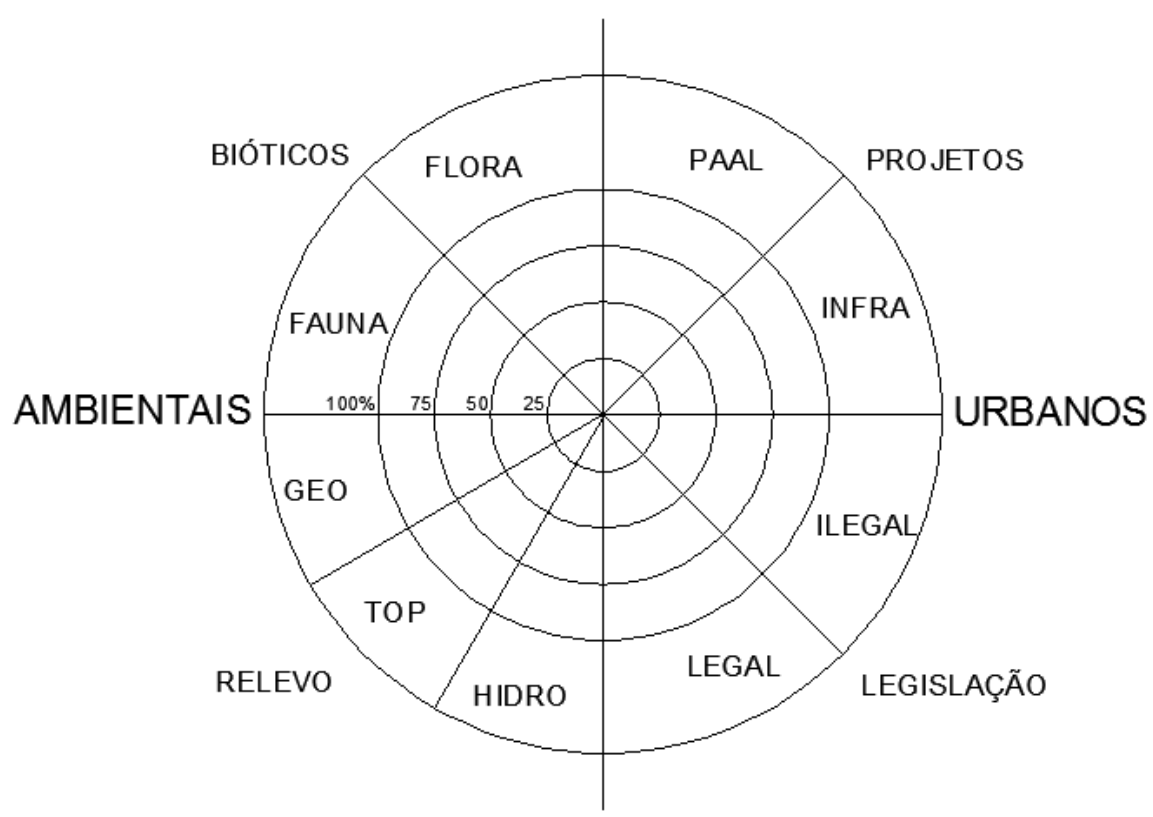




\section{3}

\section{Metodologia e Ferramentas de Consulta}

A pesquisa, obtenção e estudo de material técnico inerente (Base de Dados Geográficos e Documentação), foram realizados através de consultas e acessos a Portais Oficiais Certificados, publicados e disponibilizados na Internet (web), pelos diversos Órgãos e Entidades Públicas e Privadas, envolvidas e responsáveis por cada assunto específico, criando-se um conjunto de informações organizadas conforme indicado na Figura 30.

\section{Base de Dados Geográficos e Informações}

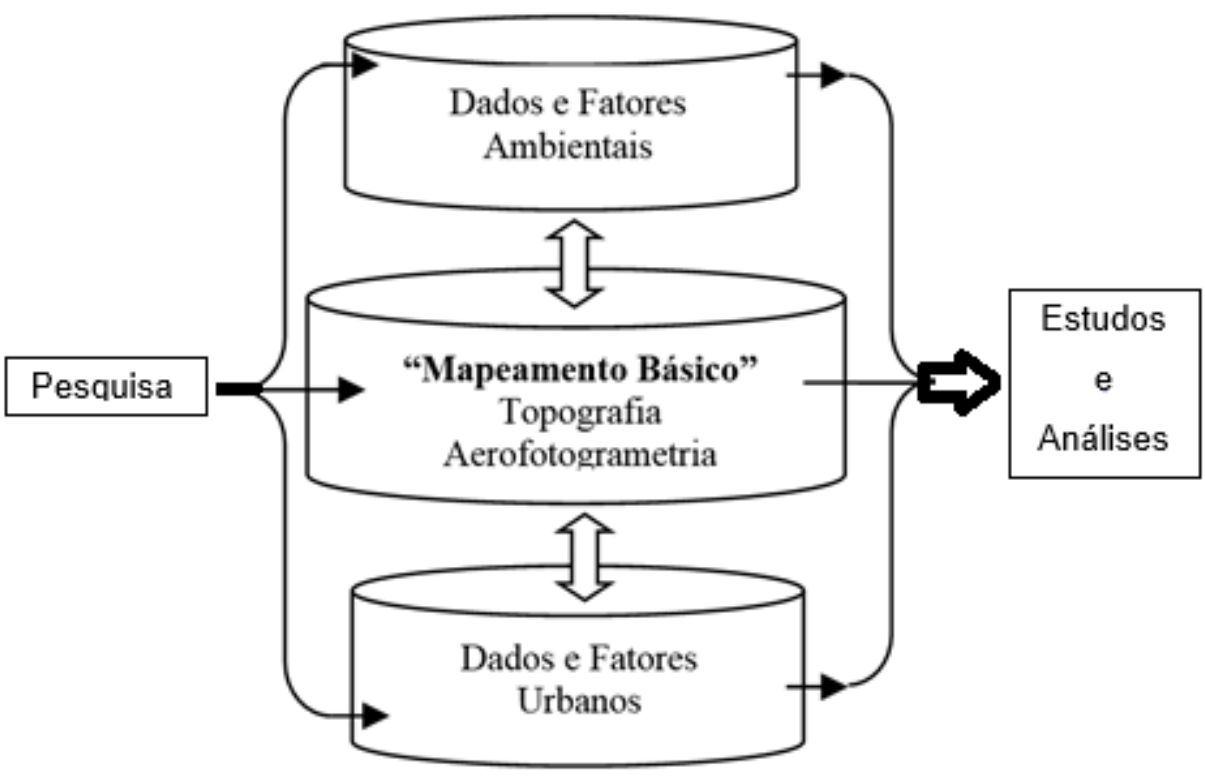

Figura 30 - Montagem da Base de Dados e Informações

Observa-se que a pesquisa foi desenvolvida baseada principalmente na nossa experiência profissional em obtenção de informações, e por leitura e acompanhamento de Livros, Revistas, Periódicos e Portais que divulgam os diversos assuntos técnicos e novidades nas áreas Ambientais, Urbanas, da Informação e de Tecnologia.

Destaca-se a importância de sempre verificar e assegurar a confiabilidade e integridade das fontes utilizadas, cuja representação legal e formal seja regida por legislação própria. 


\section{1}

\section{Obtenção de Dados e Documentação}

Com a navegação na rede da internet utilizando-se ferramentas de hipermídias, desenvolveu-se uma linha de trabalho com procedimentos de obtenção de dados e informações, que já a algum tempo vem sendo utilizado profissionalmente, substituindo antigos procedimentos de busca e pesquisa física, que passavam por visitas formais em expediente aos locais determinados e disponibilizados para o público em geral. Esta substituição vem ocorrendo em grande intensidade e volume pelo acesso via portais na rede web, desburocratizando, agilizando e democratizando a informação e obtenção de dados, tornando-os muito mais abrangentes e sofisticados.

Neste sentido desenvolveu-se a base desta dissertação, consolidando esse canal de informações e serviços, que revolucionou e vem cada vez mais revolucionando ações de estudos, pesquisa, serviços acadêmicos e até mesmo trabalhos e projetos profissionais, bem como demais necessidades e procedimentos do dia-a-dia da sociedade como um todo e até mesmo no lazer.

\section{2}

\section{Estruturação do Projeto de Estudo}

A Estruturação do Projeto de Estudo conforme representado na Figura 31, foi planejada configurando-se a utilização de Tecnologias Digitais (Sistemas CAD / SIG), nas quais foram inseridos os dados e informações obtidas (Portais Web), propiciando estudos, análises e definições, que em conjunto com o conteúdo teórico adquirido no Mestrado de Engenharia Urbana e Ambiental cursado na Puc-rio, e também embasamento em bibliografias específicas e complementares, propiciou o alcance dos objetivos propostos. 


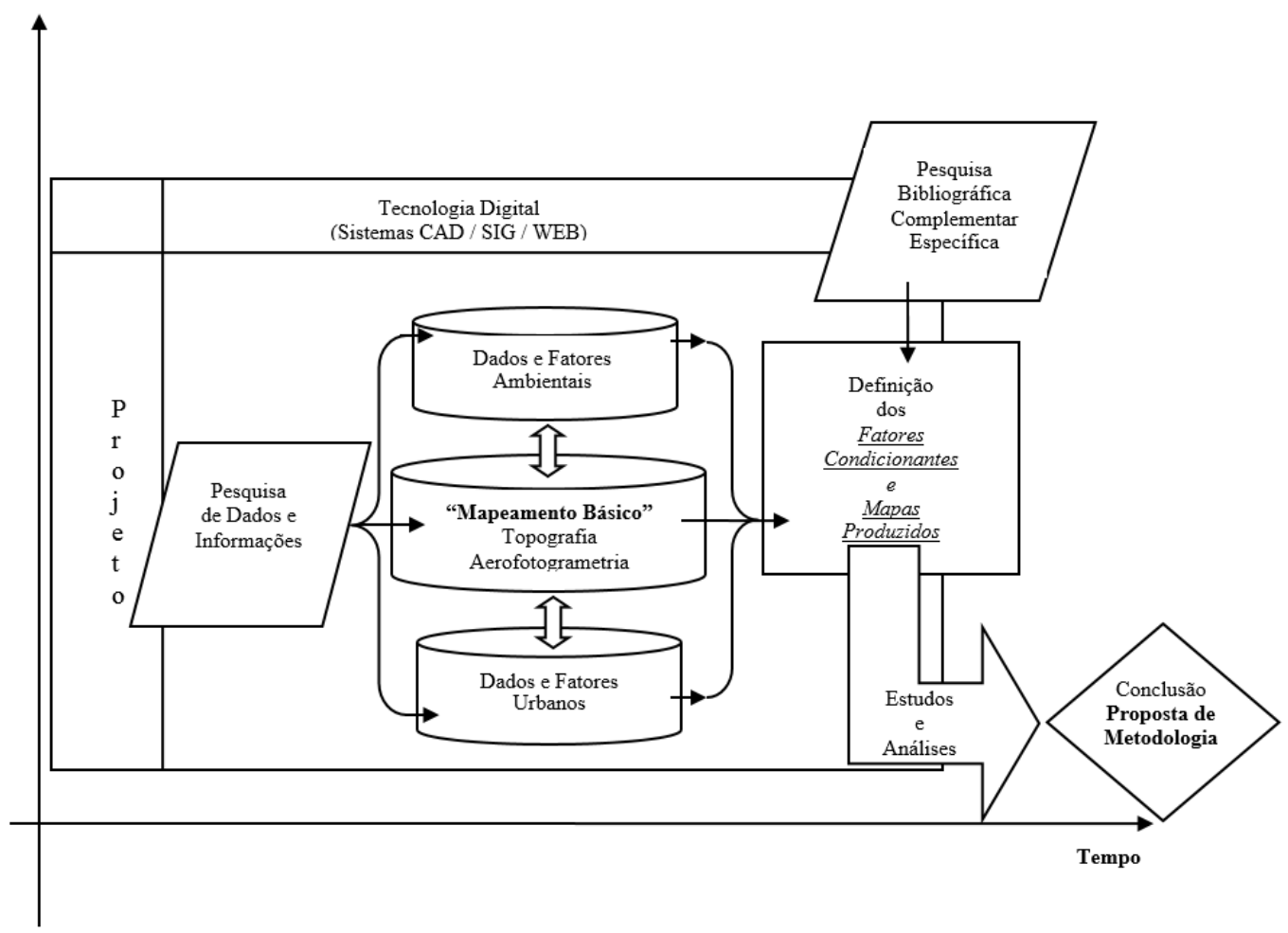

Figura 31 - Organograma / Fluxograma do Estudo

\section{3}

\section{Google Earth:}

Há bastante tempo em diversas situações e etapas dos serviços de Engenharia por nós realizados, utilizamos com bastante êxito o "Google Earth", que é um aplicativo disponibilizado pela empresa Google em duas versões; grátis com algumas limitações; e profissional paga, destinada a uso comercial, e que foi lançado pela Keyhole, Inc nos EUA.

Este aplicativo disponibiliza imagens aéreas georreferenciadas, observadas por Satélites Imageadores, Aerofotogrametria e Fotografias Terrestres (Google Street View), obtidas junto a diversas fontes de geração. Com essas imagens que são organizadas e dispostas em mosaico, formando um modelo dimensional de superfície, cuja visualização no formato de um "elipsoide terrestre georreferenciado", se apresenta de modo muito amigável, fácil de usar, prático e atraente como se apresenta na Figura 38, até mesmo com inserção de modelos em 3D (Maquetes, etc.), com excelente resultado e realismo demonstrado nas Figuras 32 a 36. 


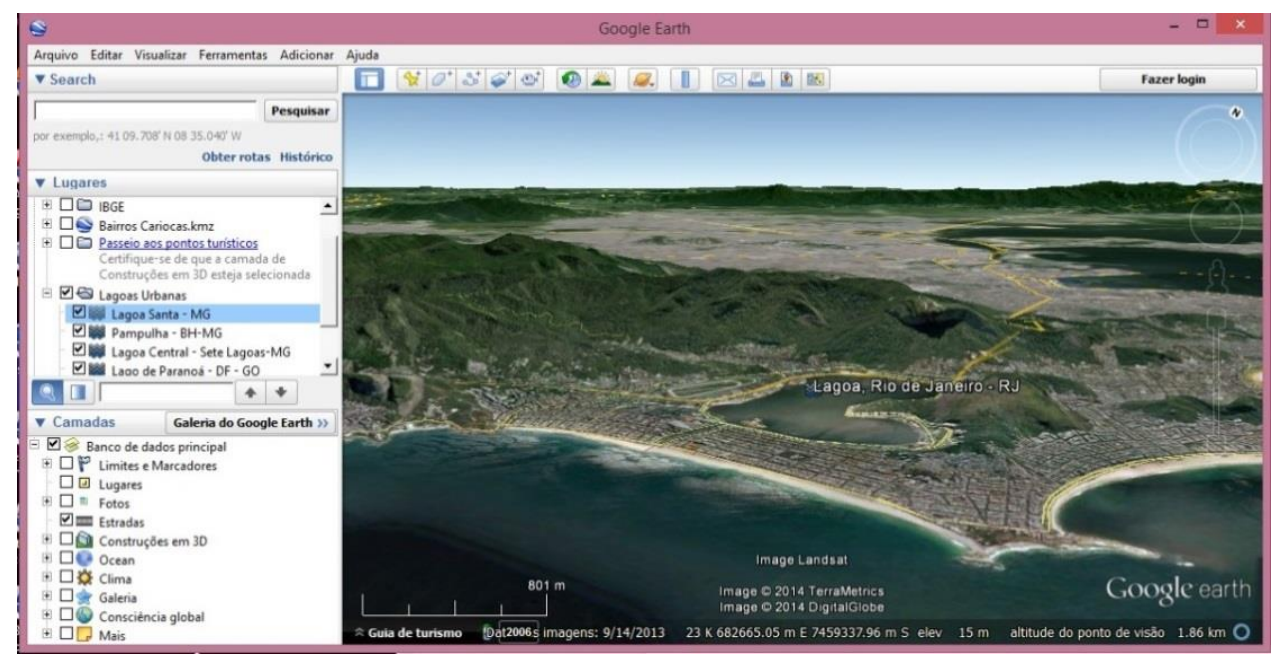

Figura 32 - Google Earth - SIG

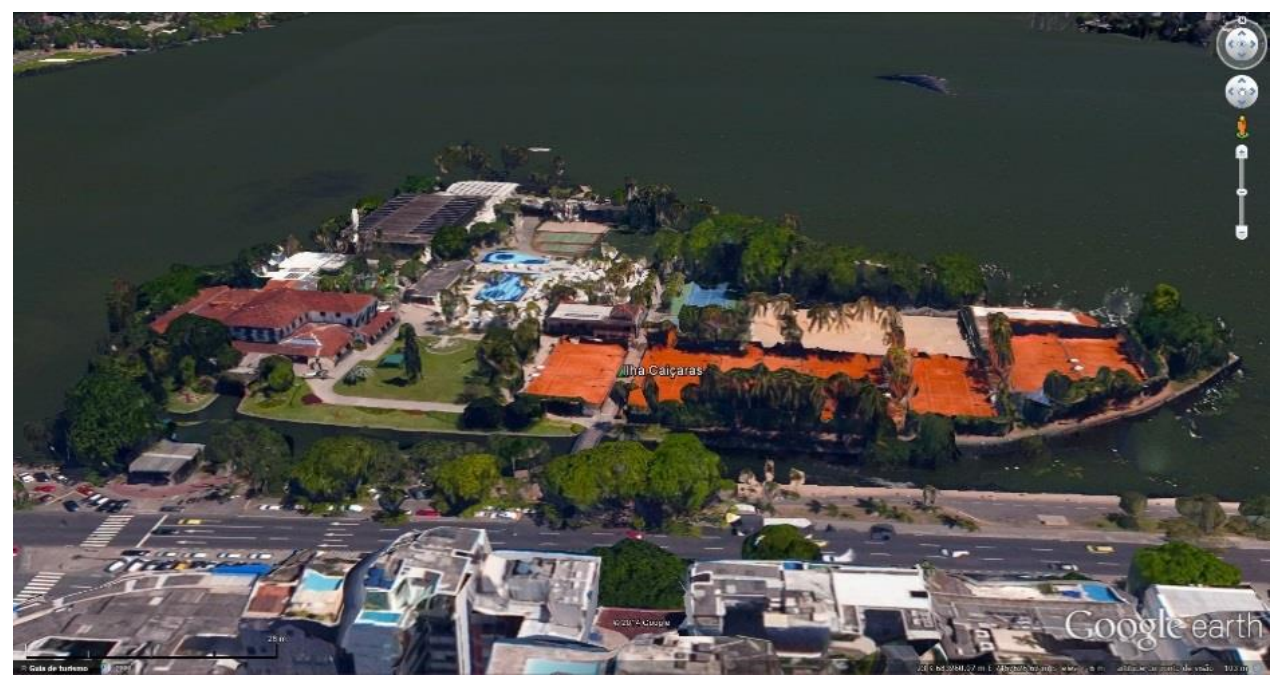

Figura 33 - Google Earth - Perspectiva em 3D da Ilha Caiçaras

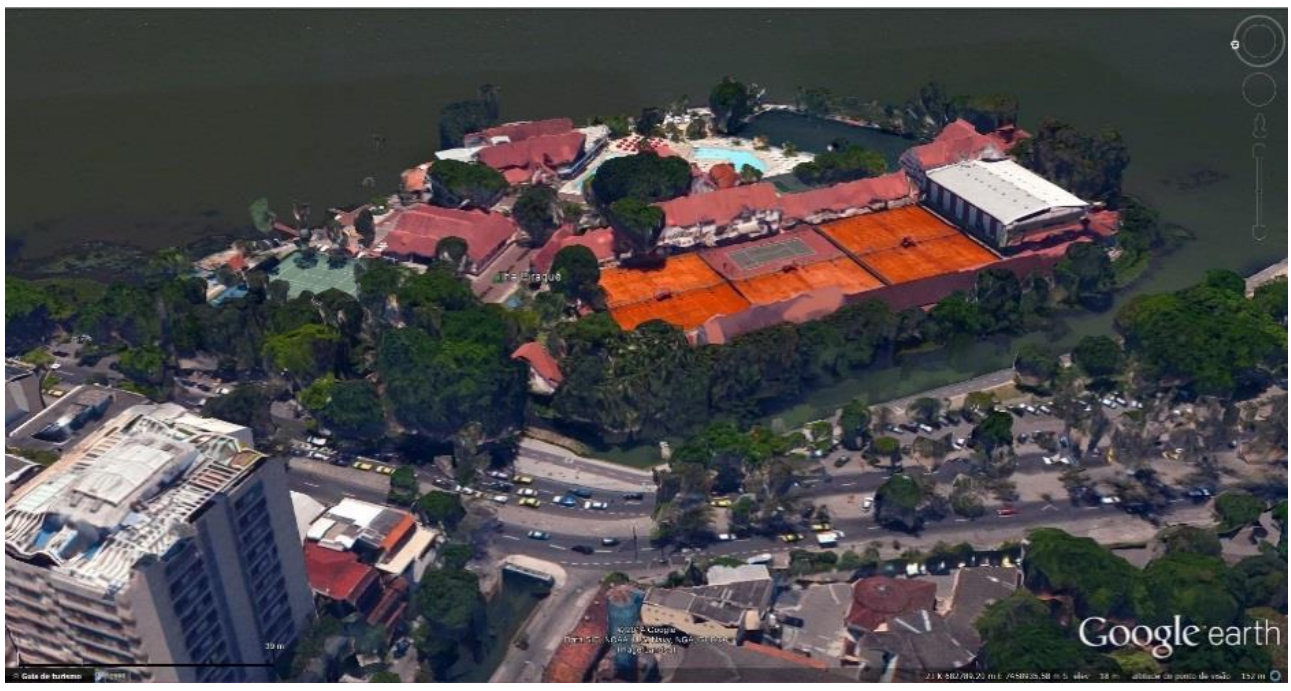

Figura 34 - Google Earth - Perspectiva em 3D da llha Piraquê 


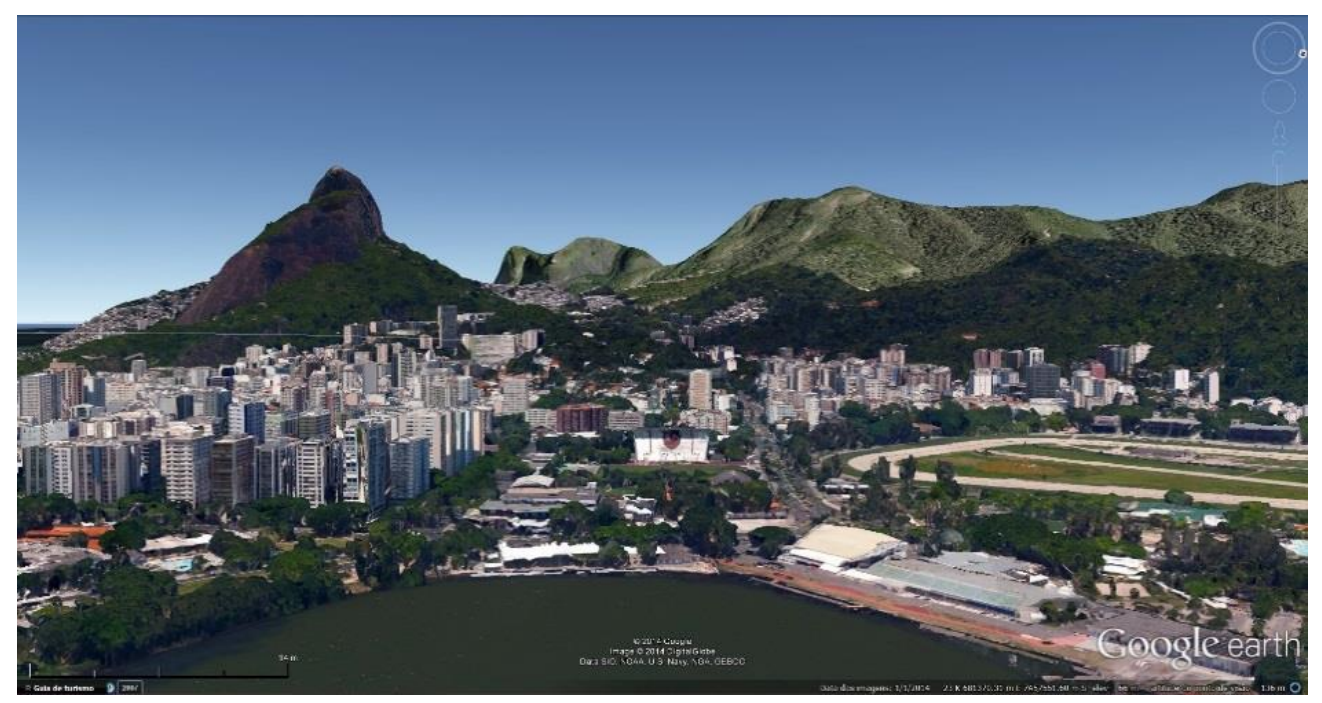

Figura 35 - Google Earth - Perspectiva em 3D Bairro da Gávea

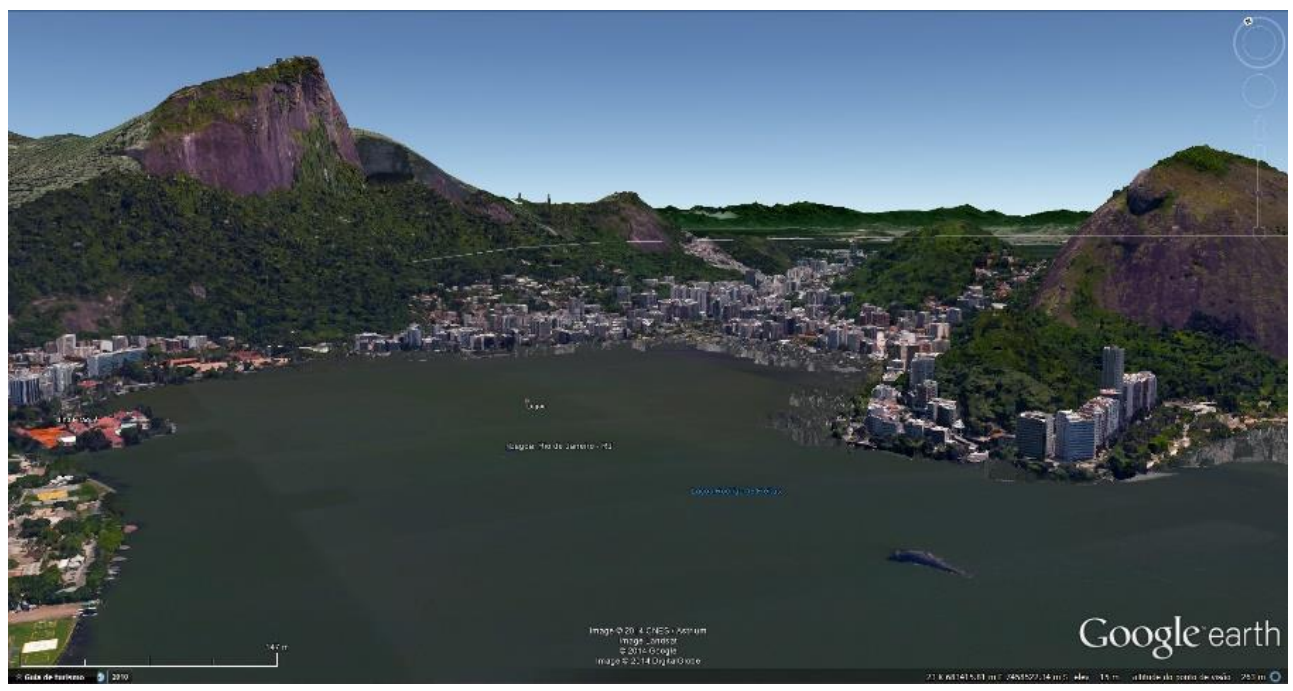

Figura 36 - Google Earth - Perspectiva em 3D Bairro do Humaitá

Possui também características paramétricas que permitem medições, indicações e cálculos; vínculos a bancos de dados; e até mesmo a extração de imagens por trecho previamente selecionado, gerando visualizações em planta e vistas em perspectivas, que possibilita o transporte ou inserção em um aplicativo específico e quando devidamente preparado e tratado gerar mapas e desenhos bem ilustrativos e úteis.

Devido às suas características técnicas, trata-se de um verdadeiro Sistema de Informações Geográficas (SIG) de grande utilidade, diversificando sua aplicação nos segmentos de nossa sociedade, e principalmente em serviços das áreas tecnológicas de mapeamento. 
Com esse aplicativo é possível realizar diversas análises e estudos preliminares e básicos, dimensionamento de distâncias e superfície, geração de diversos pontos, figuras e/ou polígonos vetoriais também georreferenciadas em formato próprio (*.kmz), bem como a criação de Banco de Dados e Atributos vinculados, onde podem ser armazenadas informações geográficas e cadastrais.

$\mathrm{O}$ alto grau de assertividade alcançado elimina na maioria das vezes a necessidade de visitas técnicas e serviços de campo e/ou o uso de outras fontes, que demandariam mais tempo e geração de maiores custos.

A qualidade das imagens hoje está associada à inserção de dados (BDG) e modelagens tridimensionais de diversos elementos de composição da imagem, que resultam em verdadeiras maquetes eletrônicas.

Diversos Órgãos Públicos e Privados já utilizam este aplicativo e plataforma para criação e disponibilização de dados, onde o IBGE é um exemplo, como pode ser visto na Figura 37, contendo um mapeamento com delimitação dos Municípios do RJ.

Dados Georreferenciados Urbano-Ambientais são disponibilizados nesta plataforma, que a cada dia vem sendo mais usada e popularizada.

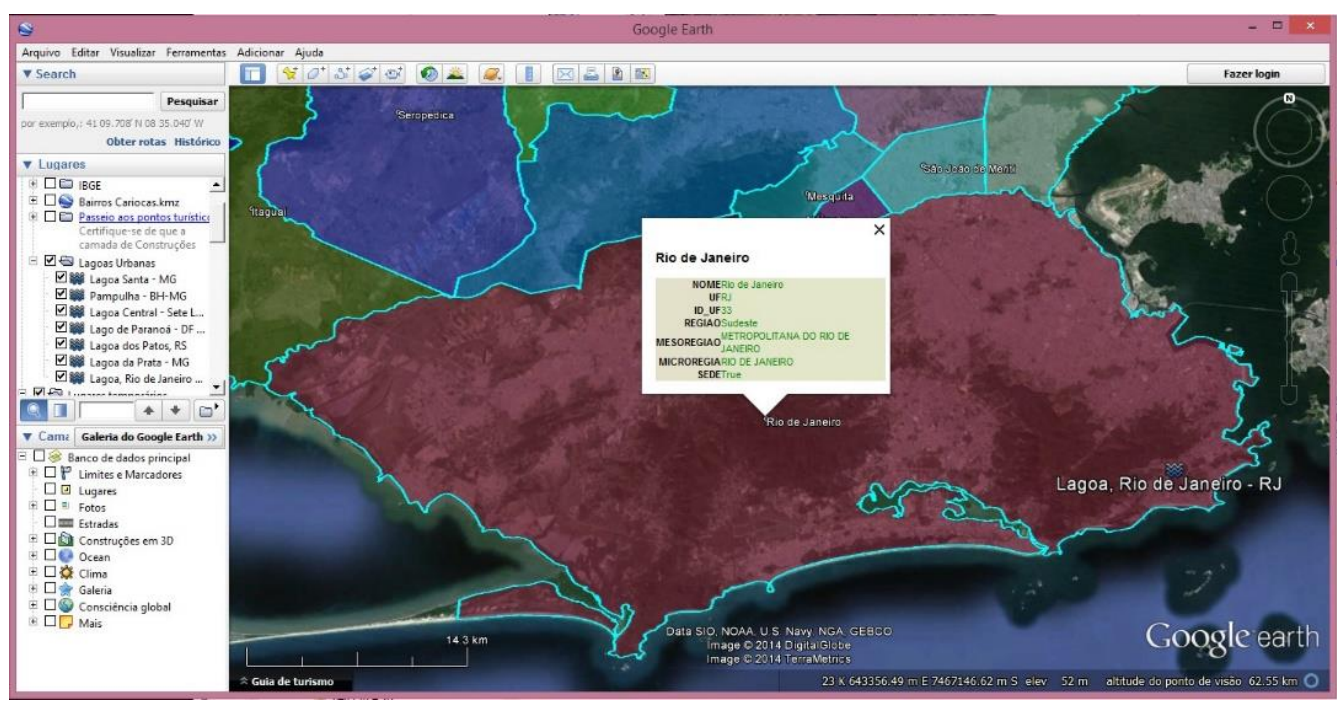

Figura 37 - Arquivo kmz - Delimitação dos Municípios do Estado do Rio de Janeiro

Arquivos de dados vetoriais georreferenciados podem ser gerados no formato nativo deste aplicativo, cuja extensão é .kmz, configurando e descrevendo diversos tipos de informações. 


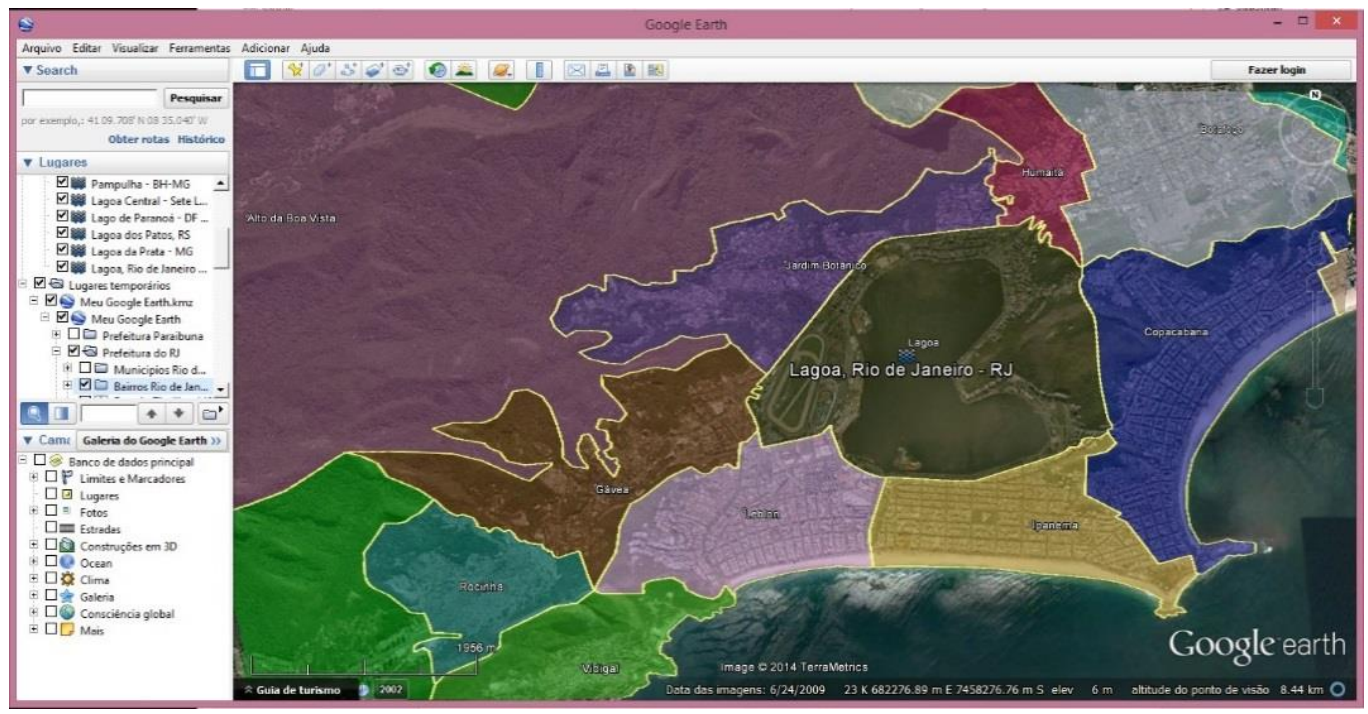

Figura 38 - Arquivo kmz - Delimitação dos Bairros do Município do Rio de Janeiro

Visualizando uma região e ajustando-se de modo adequado o Google Earth, podemos produzir verdadeiros mapas temáticos carregando-se arquivos *.kmz pré-elaborados.

Como exemplo o arquivo "Bairros do Município do Rio de Janeiro" quando carregado disponibiliza informações, permitindo a realização de diversos estudos de circunvizinhanças, com acessos a diversas informações por bairros. Exemplo Bairro da Lagoa e adjacências representado na Figura 38.

Outro bom exemplo é o arquivo disponibilizado pelo INEA com a delimitação de Regiões Hidrográficas, representado na Figura 39.

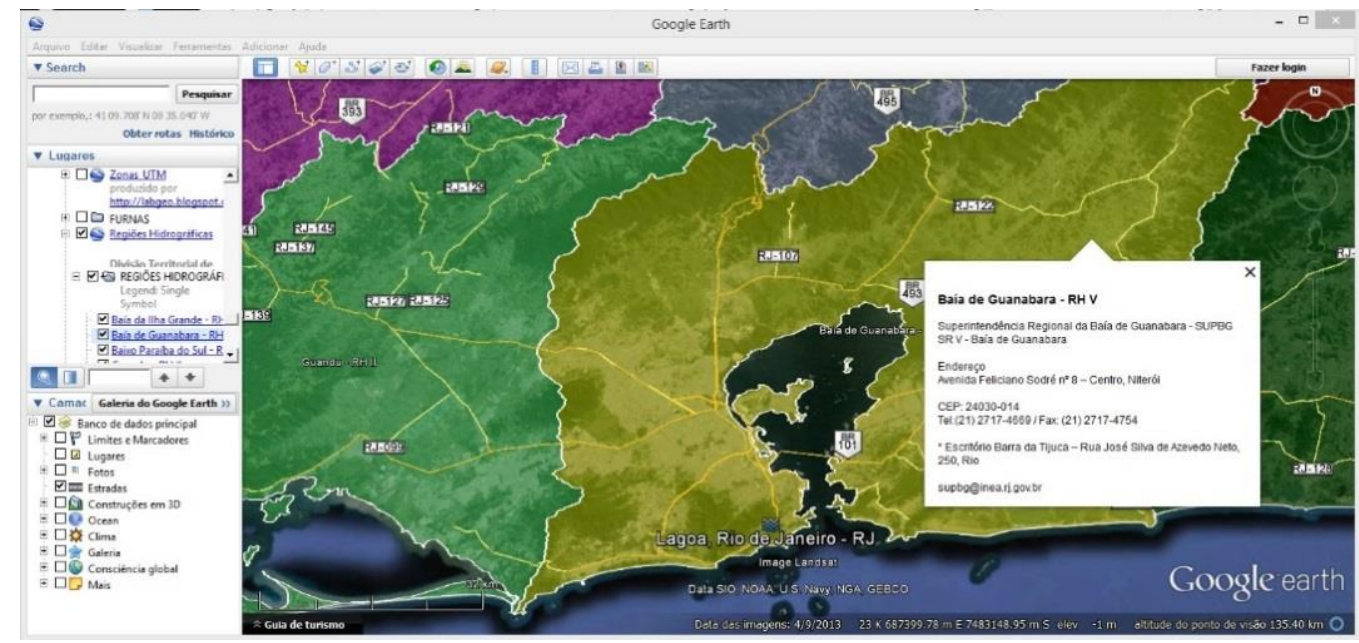

Figura 39 - Arquivo kmz - Delimitação de Regiões Hidrográficas - INEA 
Inicialmente no estudo da Lagoa Rodrigo de Freitas, foram obtidas diversas imagens conforme coleção representada na Figura 40, que possibilitam acesso a informações Urbano-Ambientais, elaborando-se análises que já inserem no contexto e realidade da região, e que podem ser tratadas e trabalhadas em outros aplicativos, gerando produtos particularmente interessantes e úteis.
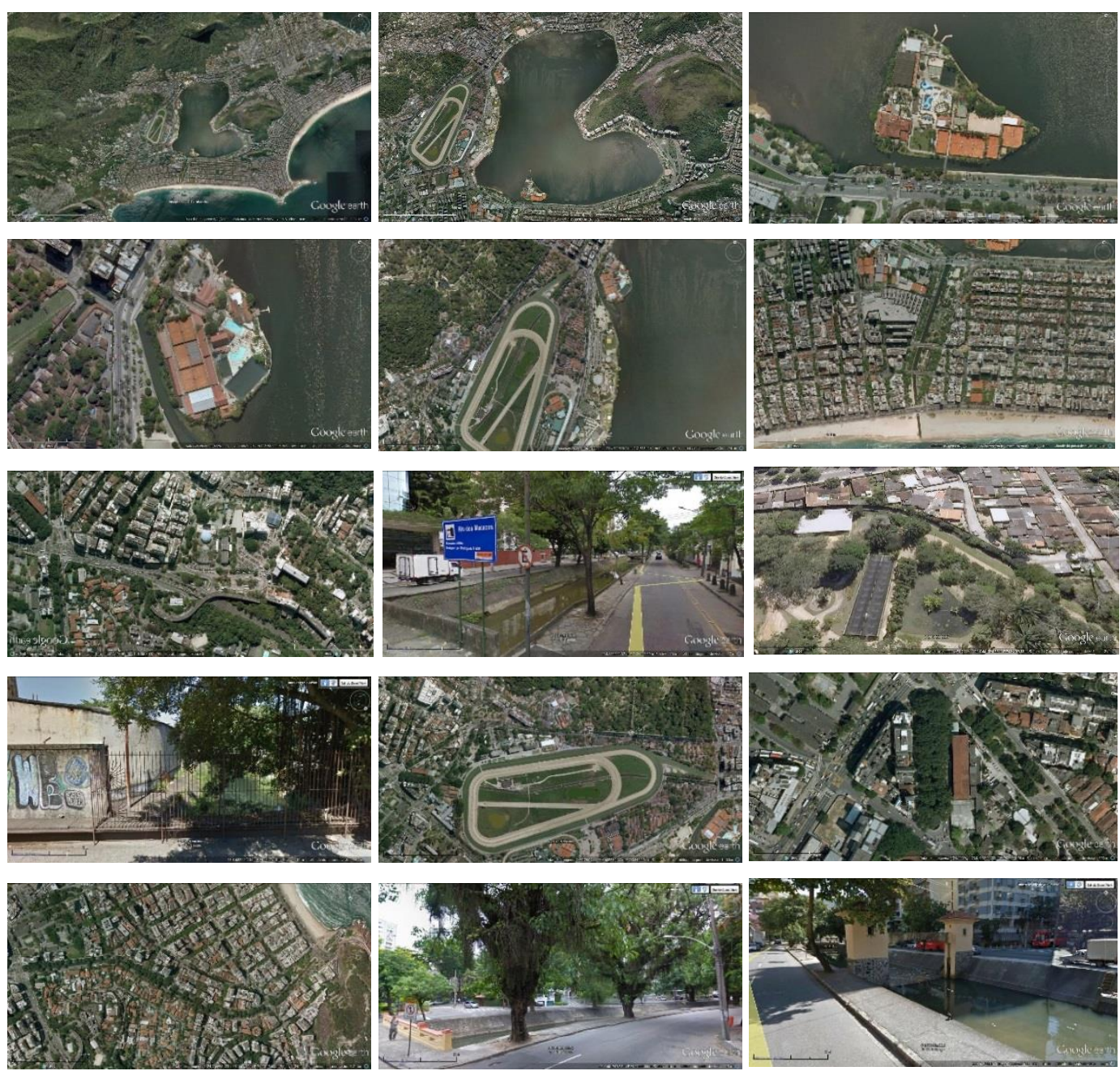

Figura 40 - Coleção de Imagens e Fotos do Google Earth 


\section{4}

\section{Embrapa}

O Portal da EMBRAPA é particularmente interessante para assuntos na área de agricultura, mas também disponibiliza conceitos, especificações, normas e dados gerais de grande aplicação e valor.

Por exemplo, na publicação "Coleção 500 Perguntas 500 Respostas: o produtor pergunta e a Embrapa responde", está disponível para download o Livro "Geotecnologias e Geoinformação". Este livro traz abordagens bem objetivas e esclarecedoras, sendo um balizador e orientador conceitual para obtenção, formação e montagem de dados. Capítulos do Livro indicados na Figura 41.

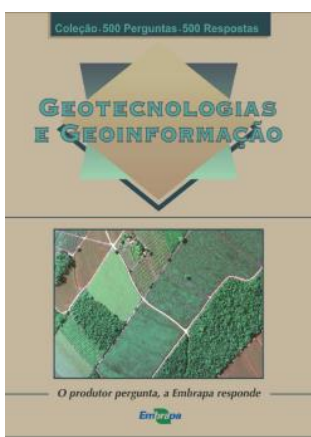

Processamento de
Imagens Digitais
e Gestão da Informação

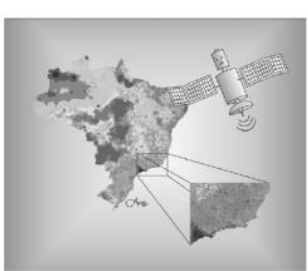

Celina Maki Takemura,
Debora Pignatari Drucker
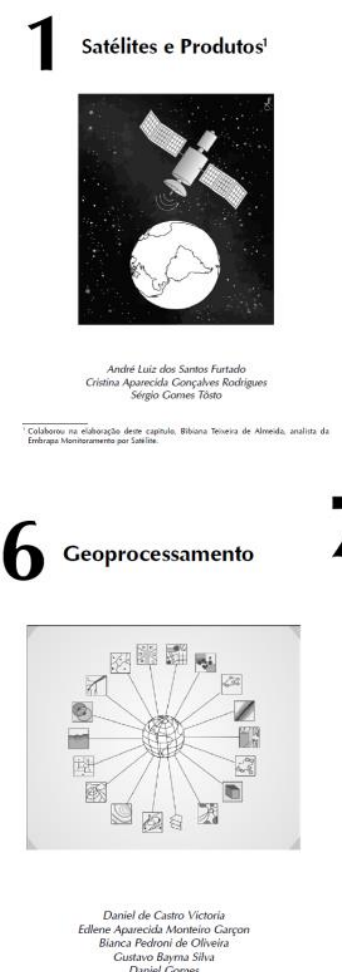

Figura 41 - Livro "Geotecnologias e Geoinformação”

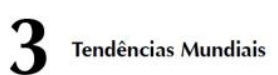

4 Sensoriamento Remoto
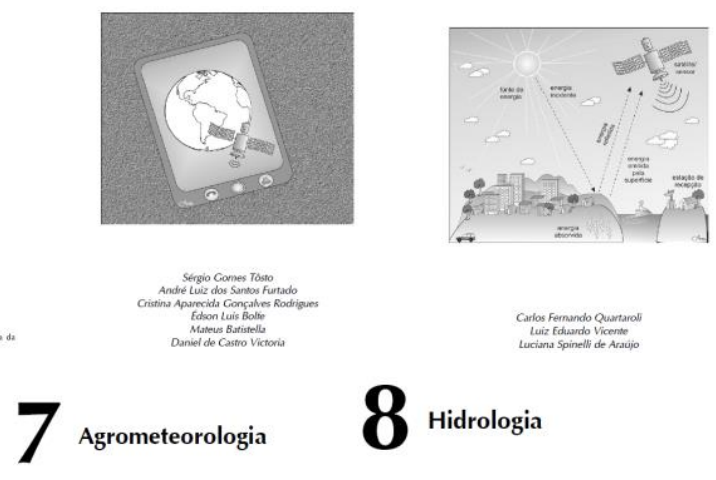

Hidrologia
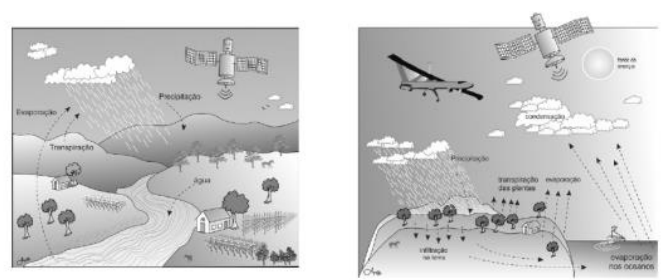

Sérgio Galdino
Daniel de Castro Victoria

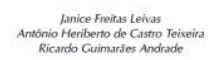

No Portal da EMBRAPA, no item "Base de Dados" destaca-se:

Banco de Dados Climáticos do Brasil- Neste item do portal são disponibilizados dados climatológicos de mais de 500 municípios do Brasil e o balanço hídrico climatológico para cada um desses locais, conforme Anexo 01, representado parcialmente na Figura 42. 
Município:Rio de Janeiro - RJ

Latitude: 22,92 S Longitude: 43,17 W Altitude: 5 m Período: 1973-1990

$\begin{array}{crrrrrrr}\text { Mês } & \begin{array}{c}\mathbf{T} \\ \left({ }^{\circ} \mathbf{C}\right)\end{array} & \begin{array}{c}\mathbf{P} \\ (\mathbf{m m})\end{array} & \text { ETP } & \begin{array}{c}\text { ARM } \\ (\mathbf{m m})\end{array} & \begin{array}{r}\text { ETR } \\ (\mathbf{m m})\end{array} & \begin{array}{r}\text { DEF } \\ (\mathbf{m m})\end{array} & \begin{array}{r}\text { EXC } \\ (\mathbf{m m})\end{array} \\ \text { Jan } & 26,2 & 114 & 147 & 72 & 142 & 5 & 0 \\ \mathrm{Fev} & 26,5 & 105 & 139 & 51 & 125 & 13 & 0 \\ \text { Mar } & 26,0 & 103 & 139 & 36 & 119 & 21 & 0 \\ \mathrm{Abr} & 24,5 & 137 & 107 & 66 & 107 & 0 & 0 \\ \text { Mai } & 23,0 & 86 & 87 & 65 & 87 & 0 & 0 \\ \text { Jun } & 21,5 & 80 & 66 & 79 & 66 & 0 & 0 \\ \text { Jul } & 21,3 & 56 & 66 & 72 & 64 & 2 & 0 \\ \text { Ago } & 21,8 & 50 & 73 & 57 & 65 & 8 & 0 \\ \text { Set } & 21,8 & 87 & 74 & 70 & 74 & 0 & 0 \\ \text { Out } & 22,8 & 88 & 93 & 66 & 91 & 2 & 0 \\ \text { Nov } & 24,2 & 96 & 112 & 56 & 106 & 6 & 0 \\ \text { Dez } & 25,2 & 169 & 135 & 90 & 135 & 0 & 0 \\ \text { TOTAIS } & \mathbf{2 8 4 , 8} & \mathbf{1 . 1 7 1} & \mathbf{1 . 2 3 9} & \mathbf{7 7 9} & \mathbf{1 . 1 8 1} & \mathbf{5 8} & \mathbf{0} \\ \text { MÉDIAS } & \mathbf{2 3 , 7} & \mathbf{9 8} & \mathbf{1 0 3} & \mathbf{6 5} & \mathbf{9 8} & \mathbf{5} & \mathbf{0} \\ \text { Fonte:INMET } & & & & & & & \end{array}$

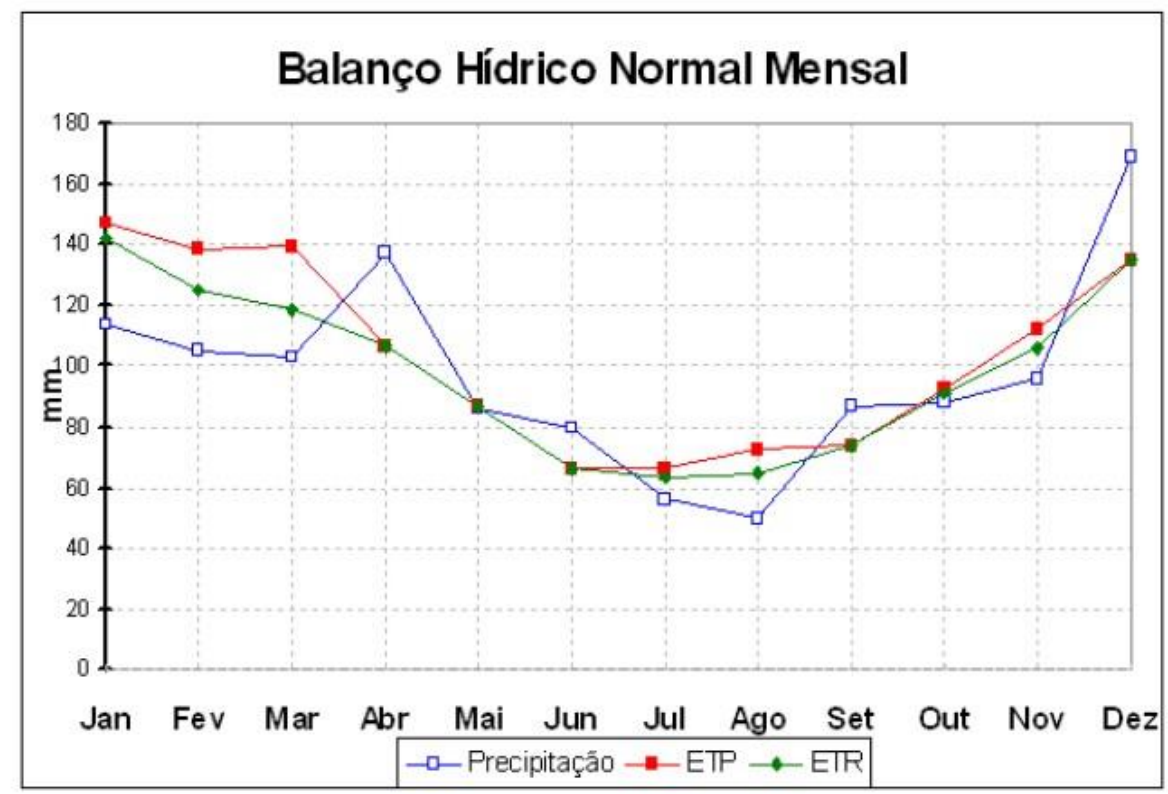

Figura 42 - Dados e Gráficos Climáticos - Embrapa - Anexo 01

São apresentados gráficos com a seguinte legenda:

T Temperatura;

P Precipitação Total Média;

ETP Evapotranspiração Potencial;

ARM Armazenamento;

ETR Evapotranspiração Real;

DEF Deficiência Hídrica;

EXC Excedente Hídrico.

No item Brasil em Relevo - São disponibilizadas Imagens do Brasil visto do espaço, com detalhes do relevo e da topografia (figura 43). 
Estes produtos foram gerados a partir de dados de radar, obtidos de sensores a bordo do ônibus espacial Endeavour, no projeto SRTM (NASA).

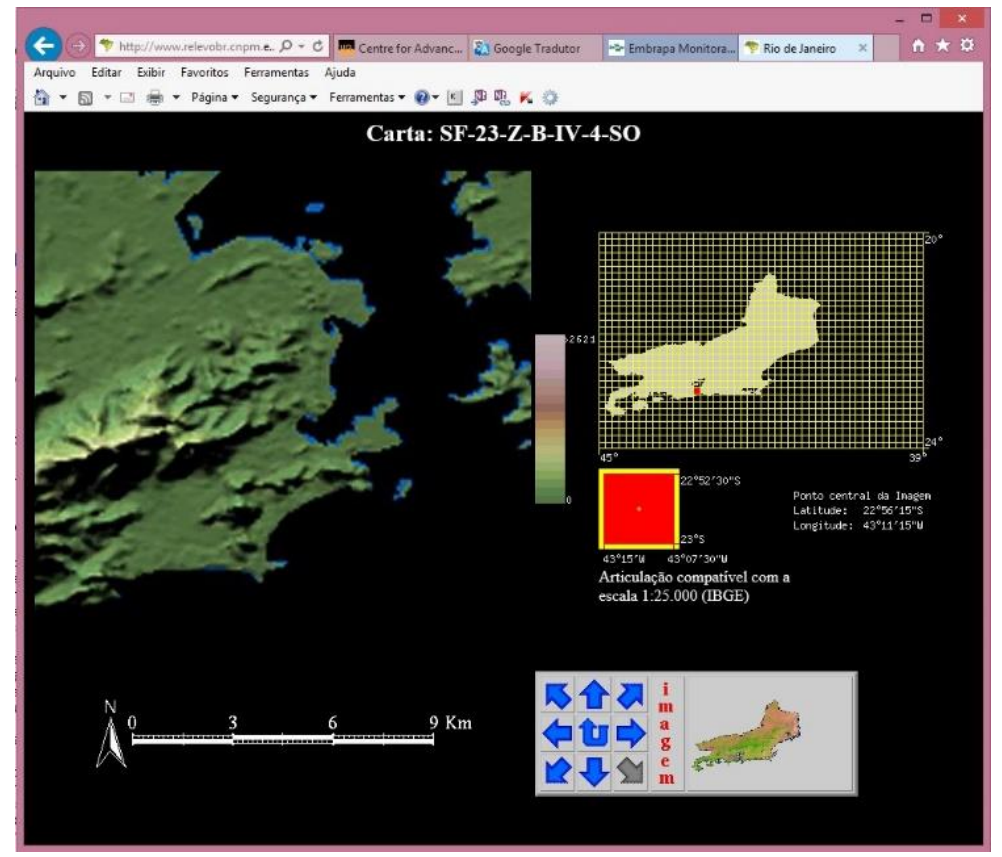

Figura 43 - Carta SF-23Z-B-IV-4-SO - MDT

Monitoramento por Satélite - A Embrapa também oferece produtos e serviços em seu portal, e em Monitoramento por Satélite sistematizou e disponibilizou mosaicos dessas imagens. O território brasileiro foi um dos primeiros a ser disponibilizado nesse sistema de monitoramento, conforme Figura 44.

Consultas ao mosaico de imagens do relevo, obtendo via download os dados originais dos Modelos Numéricos de Elevação, podem ser feitas por especialistas em geotecnologias. Utilizando aplicativos de manejo de bacias hidrográficas, podem ser utilizados Dados Altimétricos para diversos fins. 


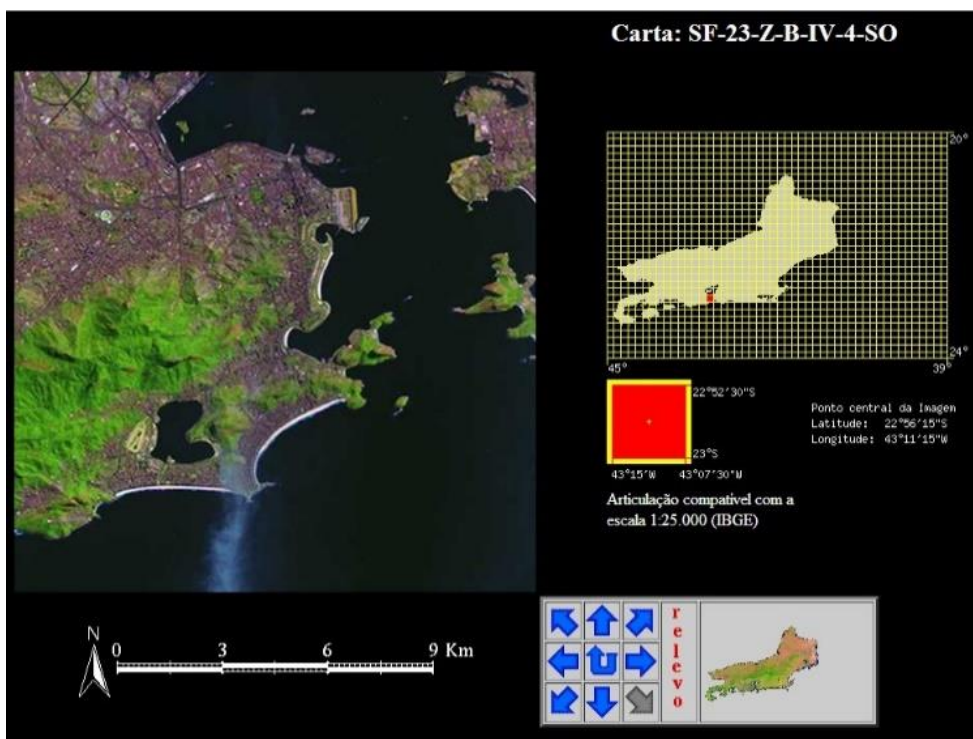

Figura 44 - Carta SF-23Z-B-IV-4-SO - FSR

\section{5}

\section{Portal do Exército Brasileiro:}

São disponibilizados vários mapas topográficos matriciais e vetoriais em diversas escalas para uso em sistemas informatizados no Geoportal representado na Figura 45.

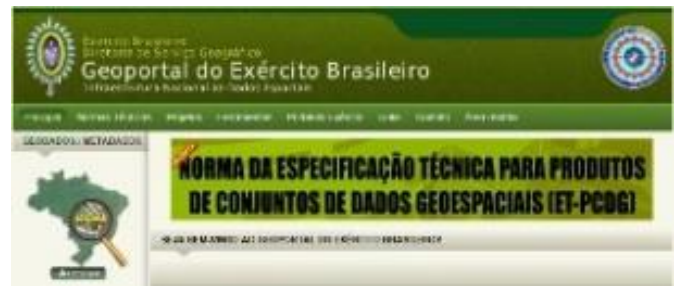

Figura 45 - Geoportal do Exército Brasileiro

Neste Portal, o Exército Brasileiro através da Diretoria de Serviços Geográficos - DSG, disponibiliza uma base de mapas e informações do território brasileiro (Banco de Dados Geográficos do Exército - BDGEx), chamada de Infraestrutura Nacional de Dados Espaciais.

Para acesso às informações deste Portal, denominado Geoportal do Exército Brasileiro, é necessário realizar um cadastramento para login. Lá utilizando o "Manual do Usuário BDGEx", é possível conhecer os produtos, escalas e formas de mapas e geodados para download, inserção e visualização em um aplicativo CAD ou SIG. 
O DSG - Diretoria de Serviços Geográficos, é um órgão militar de apoio Técnico do Departamento de Ciências e Tecnologia - DCT, destacando-se que é responsável pela Normatização e Participação da Execução do Mapeamento Sistemático Terrestre Nacional, nas escalas 1/250.000; 1/100.000; 1/50.000; e 1/25.000; Produção e Manutenção de Mapeamento; e suprir em imagens e produtos cartográficos de interesse ao Exército, exemplo apresentado nas Figuras 46 e 47.

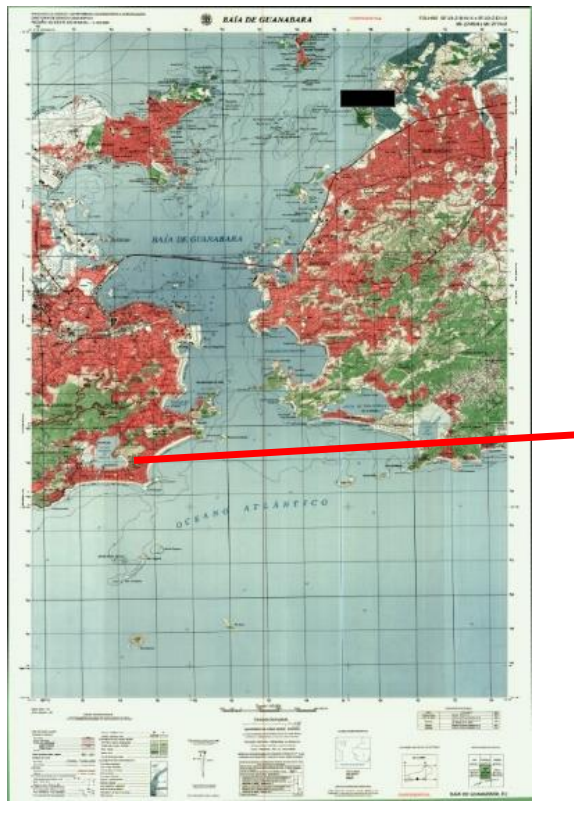

Figura 46 - Folha Baía da Guanabara

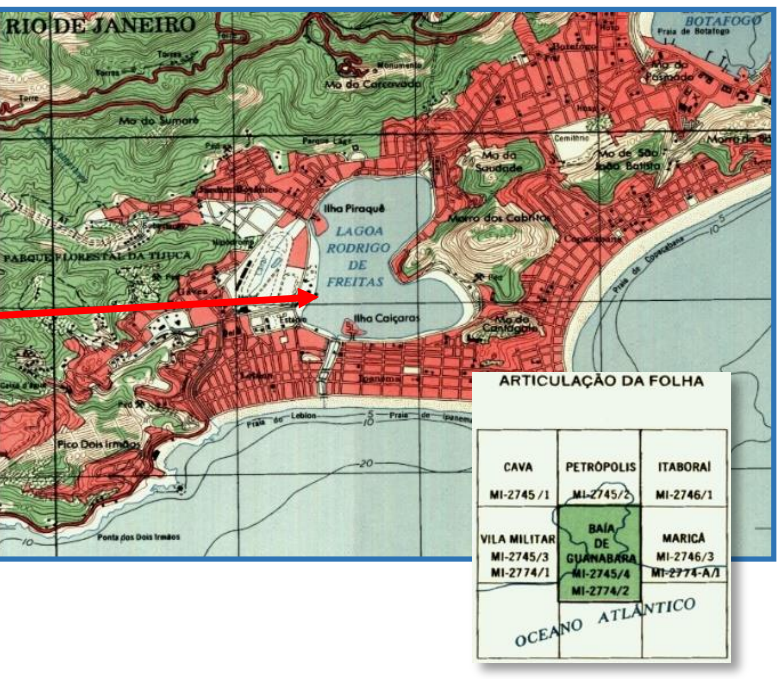

Figura 47 - Detalhe da LRF

Os mapas matriciais também são georreferenciados, o que permite que sejam utilizados em vários aplicativos que utilizam esse recurso (SIG e de navegação).

Utilizando-se os mapas topográficos disponibilizados na escala 1/50.000, foi possível elaborar no aplicativo ArcGIS, um mapa com as folhas da Vila Militar e Baía de Guanabara, com o lançamento a seguir, do Traçado da Malha Rodoviária (TMR) disponibilizada pelo DNIT no formato shape file (*.shp), todos georreferenciados conforme Mapa E01 - Folhas Vila Militar, Baía de Guanabara e TMR, representado na Figura 48. 


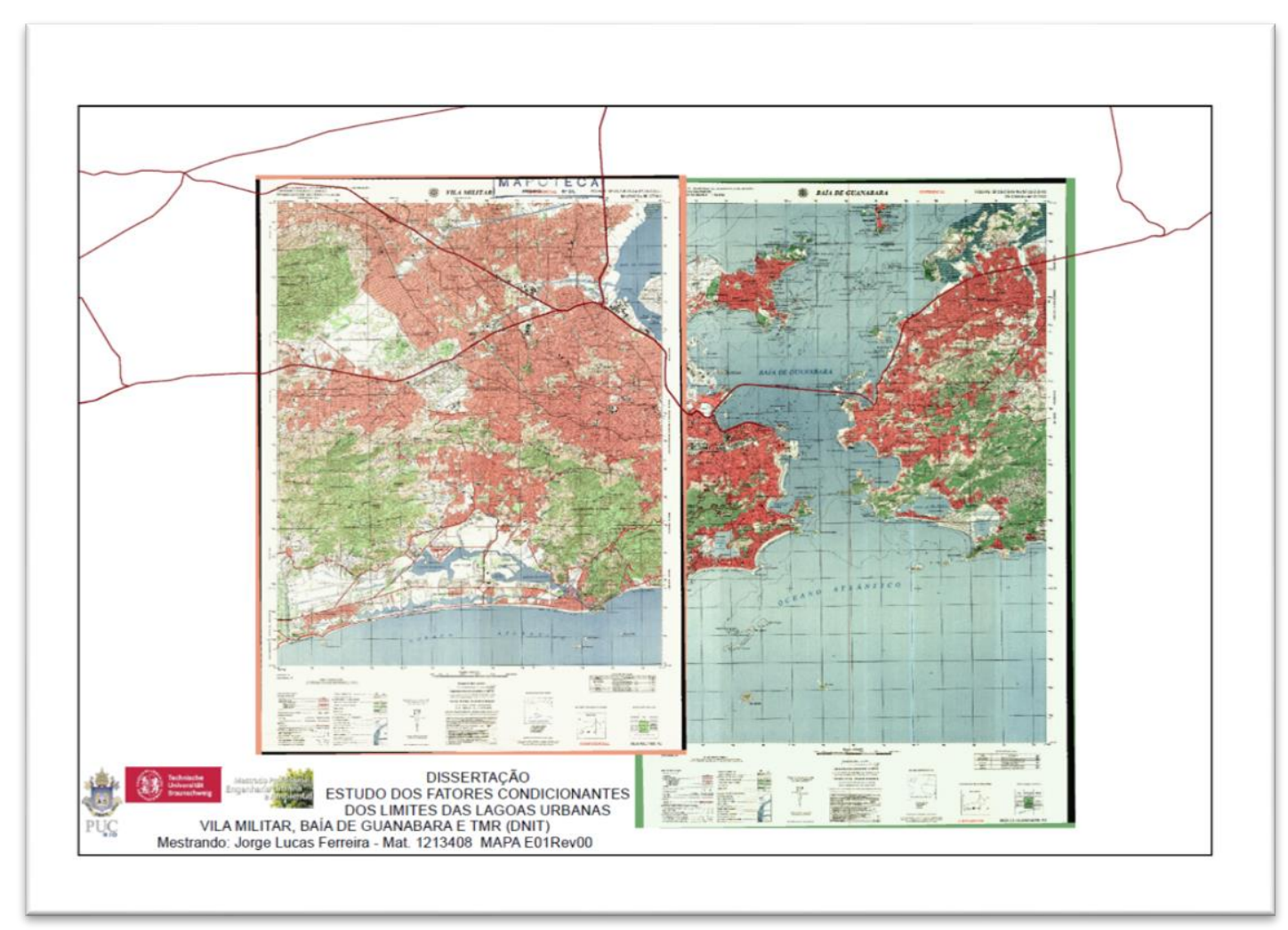

Figura 48 - Mapa E01 - Folhas Vila Militar, Baía de Guanabara e TMR

Particularmente neste mapa, foi possível atestar a confiabilidade do Sistema de Georreferenciamento contido e inerente em cada folha no formato matricial do exército, e no arquivo em formato Shape File do DNIT, visto que os arquivos tanto de imagem matricial, tanto de imagem vetorial se ajustaram e ocuparam no sistema de coordenadas adotado, sua posição Georreferenciada em grau de precisão compatível com a escala declarada dos mapas de 1/50.000. 


\section{6}

\section{Portal do DNIT}

Nesse portal indicado na Figura 49, são disponibilizados Mapas Multimodais; Atlas Multimodais, conforme Figura 50 e arquivos no formato Shapefiles das Estradas do Brasil e dos Estados da Federação, com detalhamento e traçado (malha rodoviária).

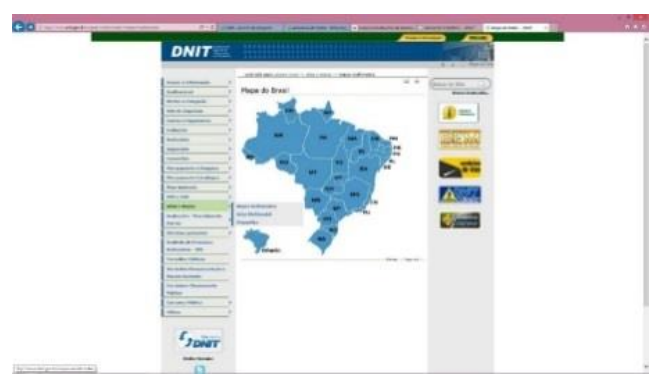

Figura 49 - Portal do DNIT

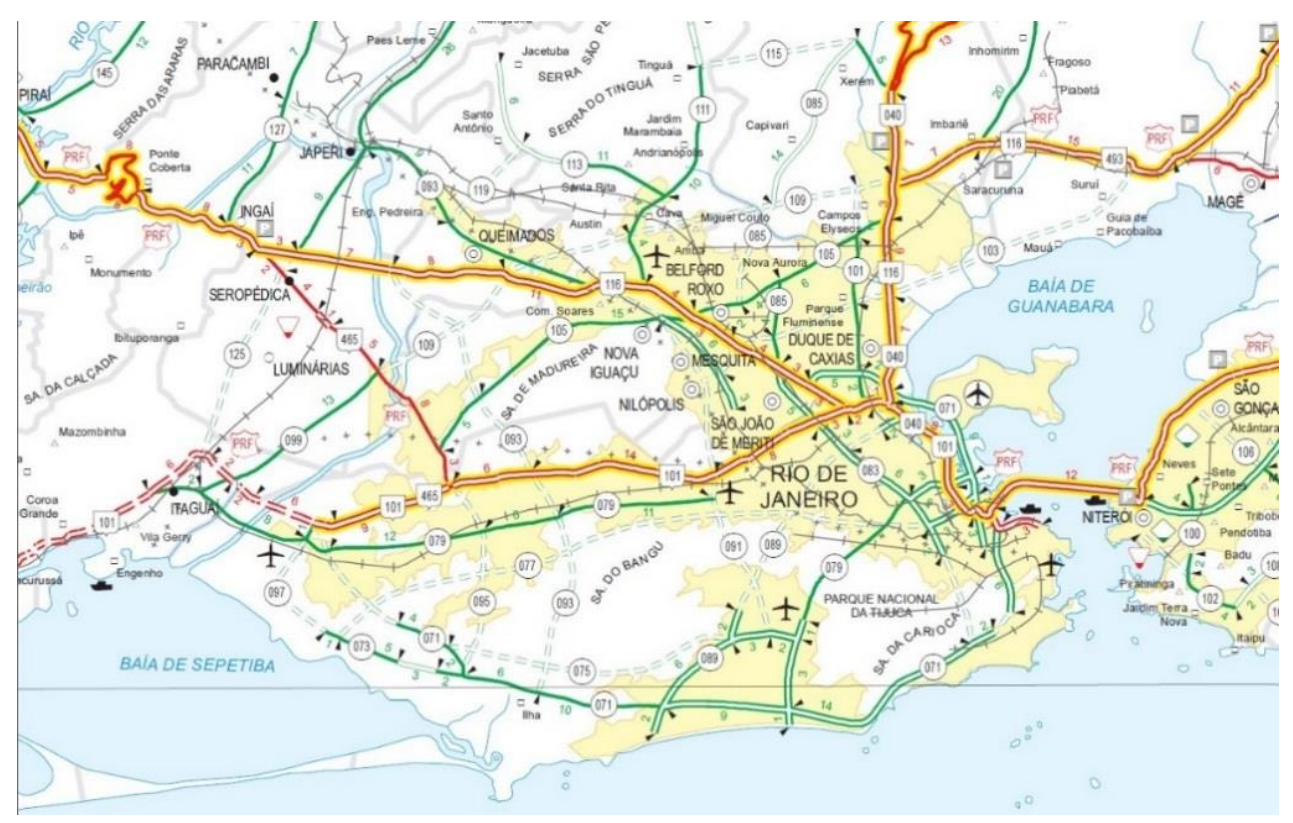

Figura 50 - Extrato do Mapa Multimodal RJ - RJ071

Observa-se neste mapa o traçado da RJ-071, Rodovia Estadual Duplicada (conforme Legenda), que no trecho em que esta confronta com a Lagoa Rodrigo de Freitas, é denominada pela Prefeitura como Avenida Borges de Medeiros, trecho da antiga denominação "Auto-Estrada Lagoa-Barra”.

Assim, podemos eleger o nosso primeiro indicador de fator condicionante para a determinação do Alinhamento da Lagoa, que vem a ser o projeto viário 
dessa Estrada (PAA - Projeto Aprovado de Alinhamento), que determina condições de alinhamento específicos mínimos, face ao fluxo de veículos de uma Auto-Estrada em trecho urbano e "faixa de domínio".

Neste caso, fica o Município da Cidade do Rio de Janeiro, responsável pelo alinhamento e faixa de domínio desta RJ-071. O que nos remete a estudar o assunto no Portal deste Município RJ.

Primeiro indicador de fator condicionante: PAA-071 - DER - Projeto de Alinhamento Aprovado da Rodovia RJ-071, no trecho junto à Lagoa Rodrigo de Fretas, Projeto Rodoviário ilustrado na Figura 51, referente ao Mapa E02 - Extrato Mapa Rodoviário - Trecho RJ-071 - LRF.

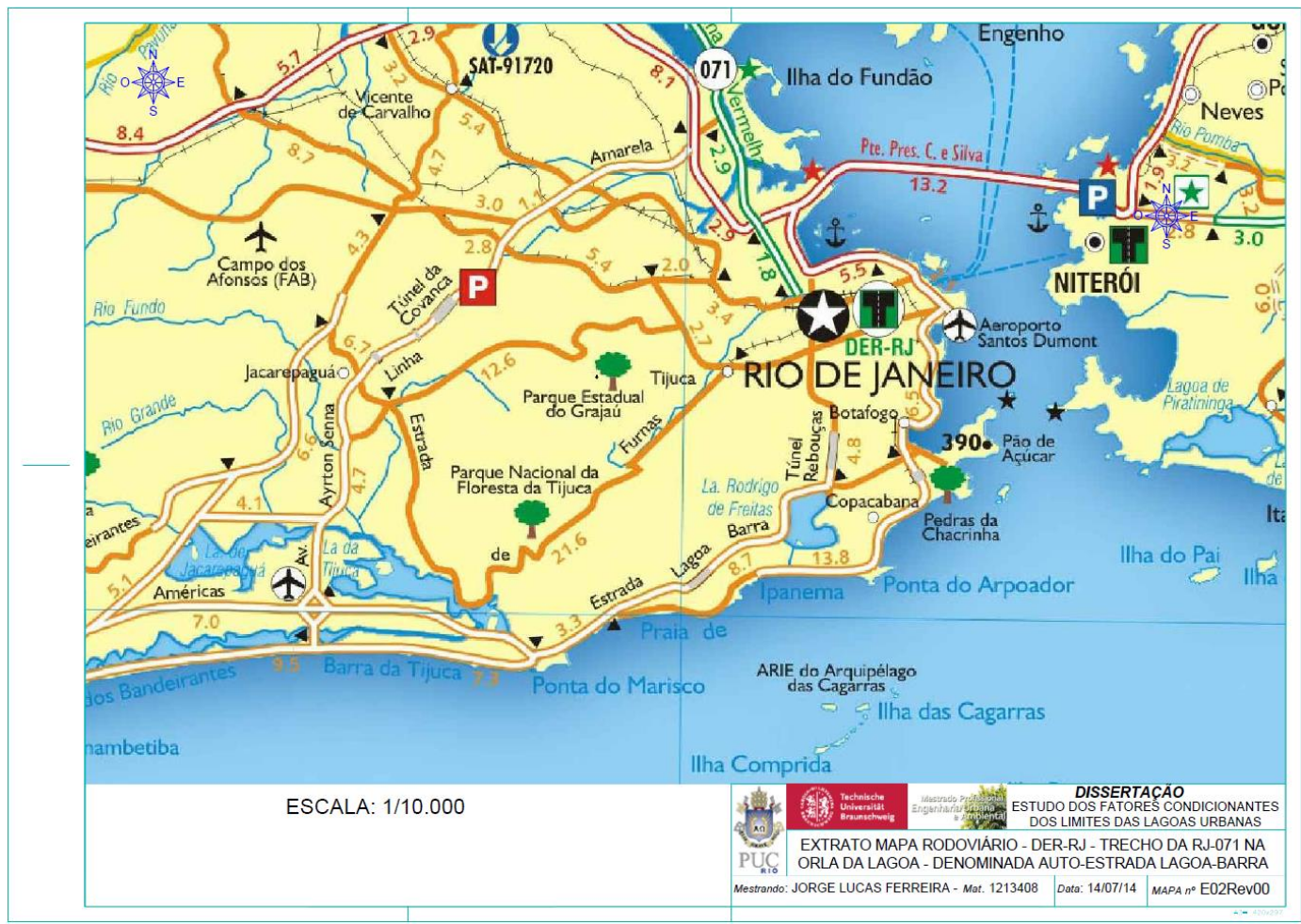

Figura 51 - Mapa E02 - Extrato Mapa Rodoviário - Trecho RJ-071 - Orla LRF

Definição de “FAIXA DE DOMÍNIO" - (Extraído do Portal do DNIT).

"Define-se como "Faixa de Domínio" a base física sobre a qual assenta uma rodovia, constituída pelas pistas de rolamento, canteiros, obras-de-arte, acostamentos, sinalização e faixa lateral de segurança, até o alinhamento das cercas que separam a estrada dos imóveis marginais ou da faixa do recuo (Glossário de Termos Técnicos Rodoviários). 
Conforme o Art. 50 do Código de Trânsito Brasileiro, o uso de faixas laterais de domínio e das áreas adjacentes às estradas e rodovias obedecerá às condições de segurança do trânsito estabelecidas pelo órgão ou entidade com circunscrição sobre a via.

Procedimentos e documentações necessários para formalização de solicitação para o uso das Faixas de Domínio."

\section{7}

\section{Portal do DER}

Neste Portal representado na Figura 52, são disponibilizados: Mapa Rodoviário Estadual; Mapa da Região Metropolitana do RJ, Figura 53, e Mapa dos Aeródromos e Helipontos do Estado do RJ.

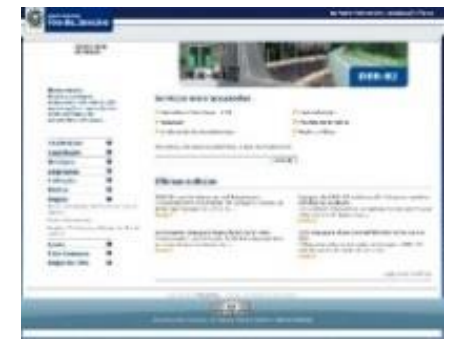

Figura 52 - Portal do DER

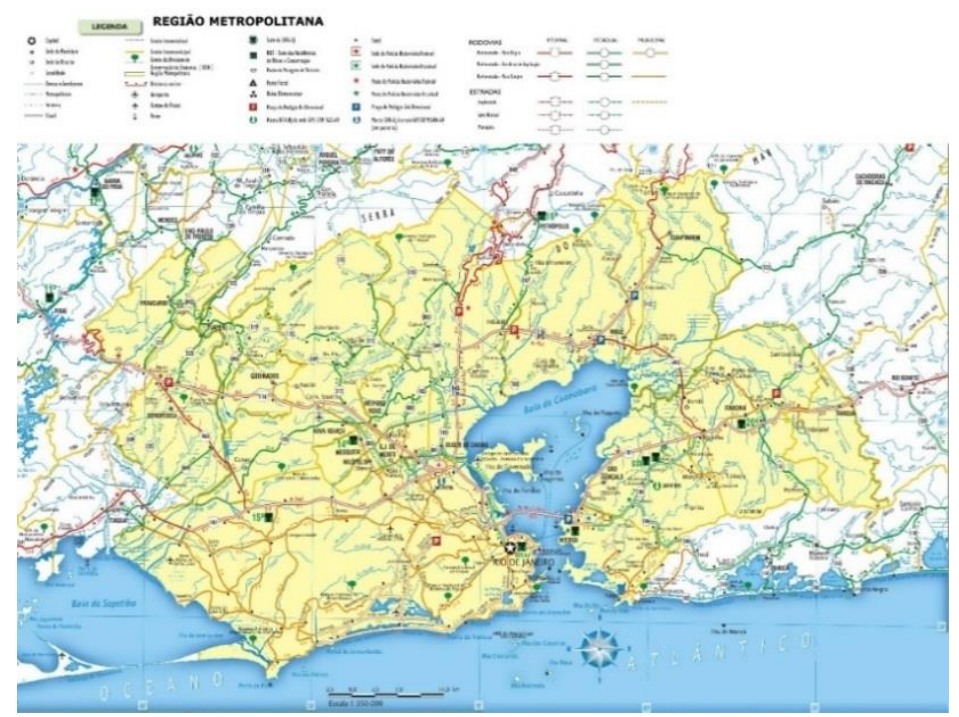

Figura 53 - Mapa da RMRJ - DER

Estes mapas matriciais não são georreferenciados, servindo apenas para visualização, impressão e uso em sistemas CAD/SIG como referência. 
Interessante ressaltar a existência de um Heliponto na Orla da Lagoa, conforme representado Figura 54.

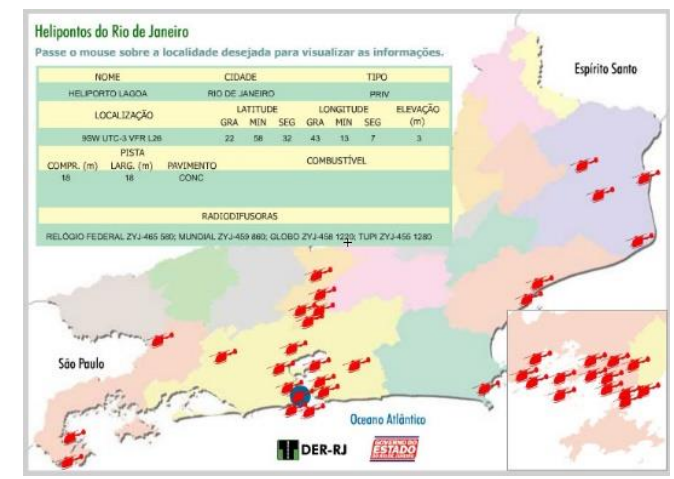

Figura 54 - Mapa de Helipontos no Estado do RJ

\section{8}

\section{Portal da Prefeitura Municipal da Cidade do Rio de janeiro}

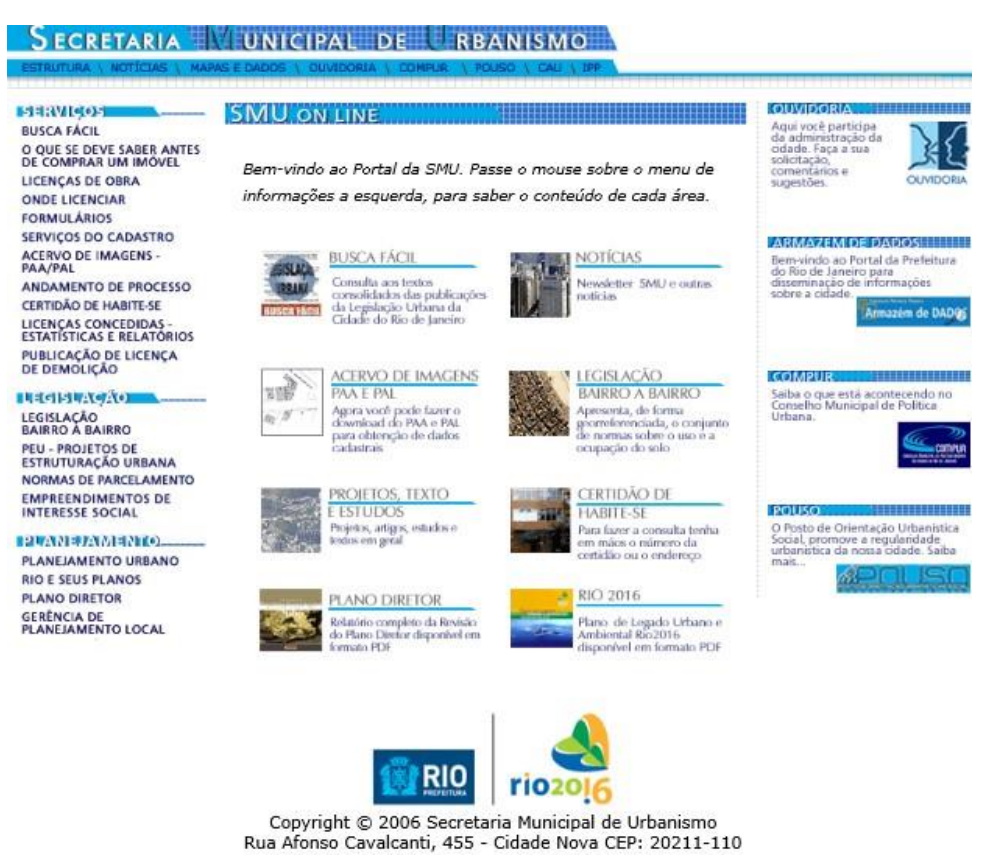

Figura 55 - Portal da SMU on line - Rio de Janeiro

Trata-se de um portal extremamente abrangente, completo e diversificado, de bastante relevância e interesse para os profissionais que atuam nas questões Urbano-Ambientais ligadas ao Município do Rio de Janeiro, detalhado na Figura 55.

O acesso à informação está disposto e organizado em três grupos:

- Serviços; 
- Legislação; e

- Planejamento.

Dentre as várias opções podemos citar:

a) Rio 2016

Do Plano de Legado Urbano e Ambiental Olimpíadas Rio 2016, pode-se destacar o item MA.4 Monitoramento Ambiental (figura 56).

\begin{tabular}{lll}
\hline MA.4.5 & $\begin{array}{l}\text { Programa de monitoramento } \\
\text { da balneabilidade da Lagoa } \\
\text { Rodrigo de Freitas, Lagoinha e } \\
\text { Prainha }\end{array}$ & $\begin{array}{l}\text { Restabelecimento do Programa de Monitoramento da Lagoa Rodrigo de Freitas, Lagoinha e Prainha } \\
\text { (em âmbito municipal); articulação com o Estado para a manutenção do monitoramento nas demais } \\
\text { praias da cidade; criação de um centro de dados de monitoramento da lagoa Rodrigo de Freitas; } \\
\text { articulação com o Estado para execução de monitoramento das águas dos rios que contribuem para } \\
\text { a Lagoa. }\end{array}$ \\
\hline
\end{tabular}

Figura 56 - Item MA.4 - Monitoramento Ambiental

Além de outras ações de Saneamento Ambiental e Sistema de Proteção e Limpeza da Lagoa Rodrigo de Freitas.

b) Legislação Bairro a Bairro

Trata-se de um aplicativo on-line que dispõe mapa georreferenciado, com acesso às informações sobre a Legislação nos diversos bairros do Município do RJ, conforme exemplificado na Figura 57.

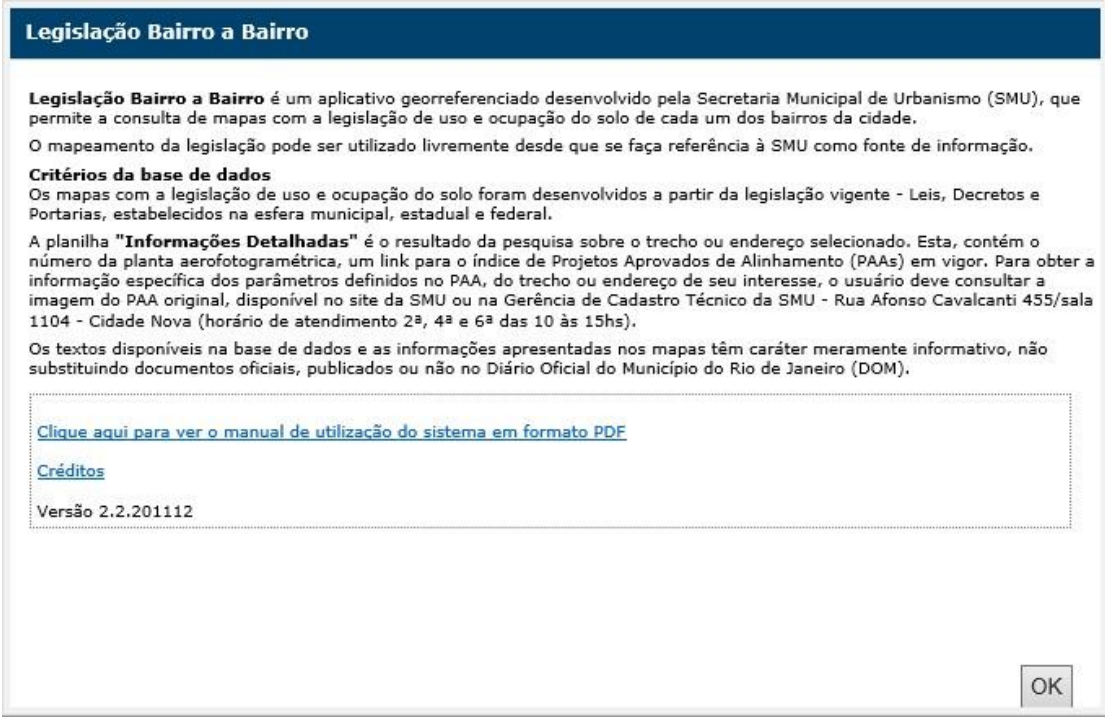

Figura 57 - Legislação Bairro a Bairro - RJ

Neste Portal é disponibilizado um Manual do Usuário - "Legislação Urbana On-Line" instruindo a utilização do sistema para pronta referência, conforme Anexo 02. 


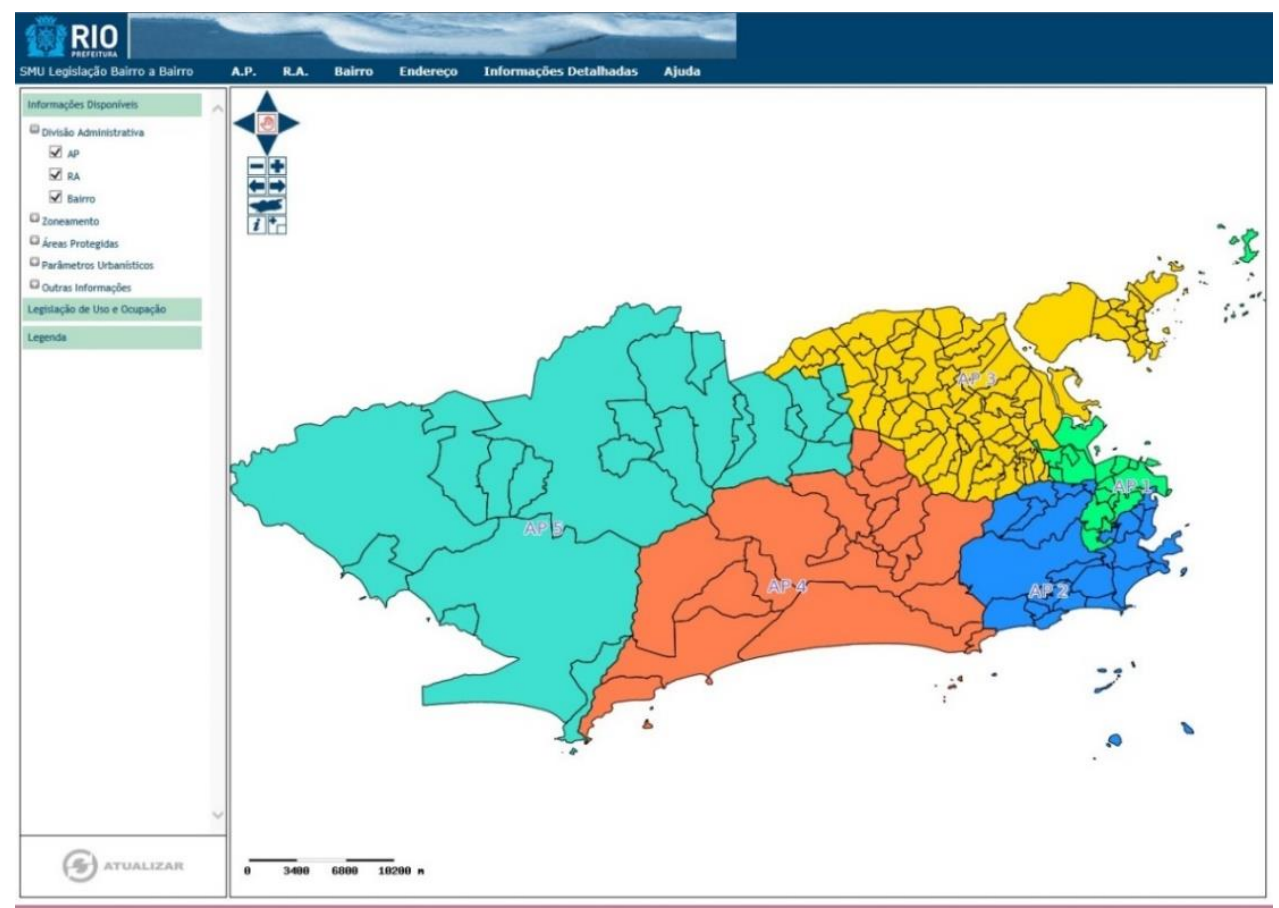

Figura 58 - Legislação Bairro a Bairro - RJ - SIG

É possível selecionar um trecho ou uma área para obtenção de dados da Legislação, clicando no local desejado ou digitando um endereço, como ilustrado nas Figuras 58 e 59.

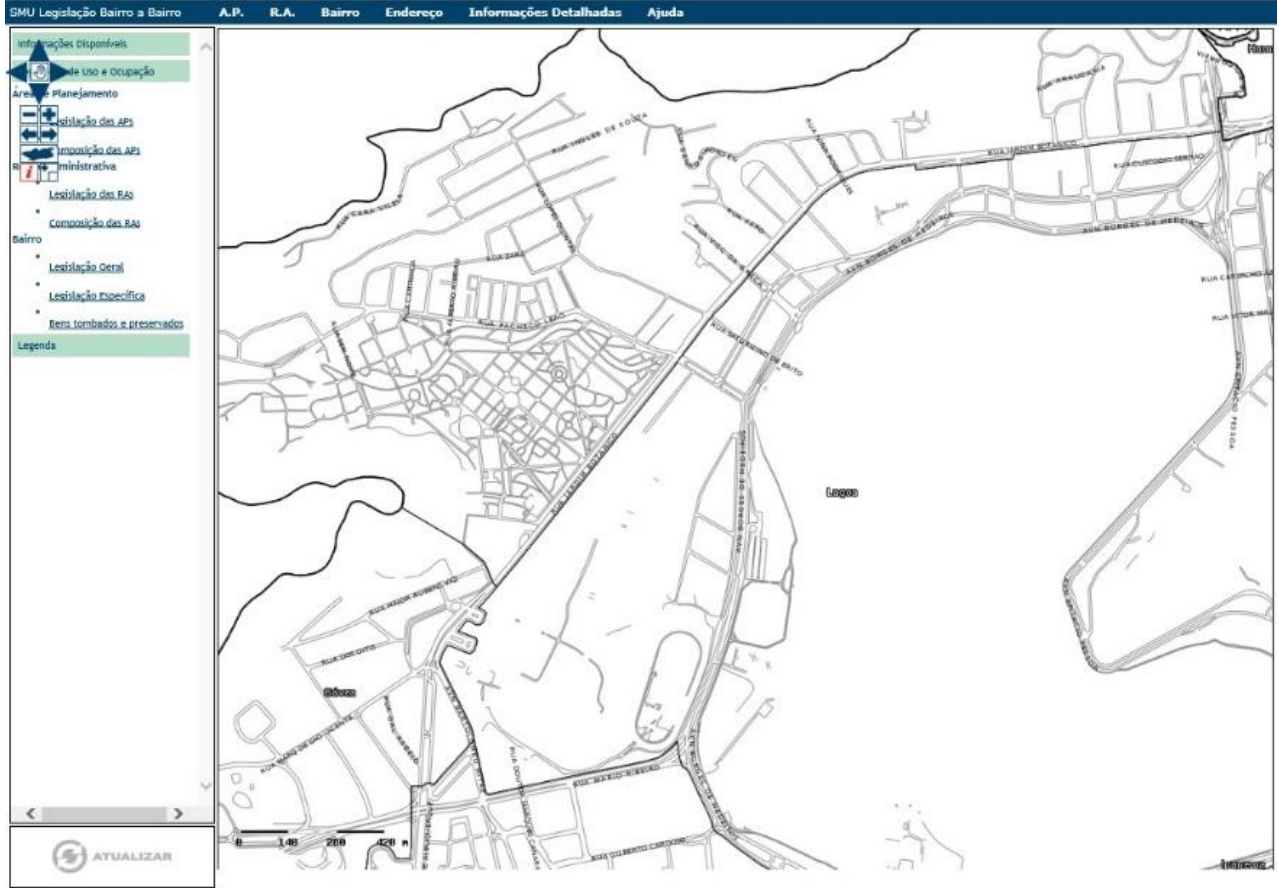

Figura 59 - Trecho selecionado na Av. Borges de Medeiros

Assim, é gerada um Certidão de Informações - CI detalhada, conforme o exemplo e modelo pesquisado para a Av. Borges de Medeiros, próximo à Rua General Garzon, conforme Anexo 03. 
Outros exemplos para o caso da Lagoa foram testados, onde obtivemos a Certidão de Informações - CI para Av Epitácio Pessoa - Av H Doosworth (Anexo 03a); e a Certidão de Informações - CI para Av Epitácio Pessoa - R Tabatinguera (Anexo 03b).

Através desse formulário On-Line, é possível acessar Mapas, Decretos e Legislação inerente ao trecho selecionado, o que sugere um segundo indicador de fator condicionante que vem a ser a Legislação Urbana.

Interpretando e analisando essa Certidão concluem-se algumas questões importantes sobre a Lagoa:

1- Em 10 de setembro de 1975, o IPHAN - Instituto do Patrimônio Histórico e Artístico Nacional, através do Prefeito Municipal da Cidade do Rio de Janeiro, aprova o Projeto de Alinhamento - PAA $n^{\circ}$ 9.548, referente à delimitação da superfície de domínio do espelho de água da Lagoa Rodrigo de Freitas, e dá outras providências (Anexo 04).

2- Em 3 de março de 1976, pelo Decreto $n^{\circ}$ 322, o Prefeito aprova o Regulamento de Zoneamento do Município do Rio de Janeiro.

3- Em 13 de junho de 1990, pelo Decreto n9396, o Prefeito da Cidade do Rio de Janeiro, determina o tombamento definitivo do bem cultural que menciona e dá outras providências - O espelho d'água da Lagoa Rodrigo de Freitas, cujos limites estão definidos no PAA-9.548 (Anexo 05);

4- Em 27 de abril de 2012, o Prefeito da Cidade do Rio de Janeiro, dispõe sobre a criação da Zona de Preservação Paisagística e Ambiental - ZPPA1, da Cidade do Rio de Janeiro, para valorização da paisagem urbana e de ordenamento da exibição de publicidade.

Assim, podemos observar e concluir que sob o aspecto legal da Legislação Urbana do Município do RJ, o Projeto de Alinhamento da Orla - PAO da Lagoa Rodrigo de Freitas, segue em definitivo, os limites constantes do PAA9548.

Observamos então a confirmação do primeiro indicador de fator condicionante pela necessidade agora do estudo deste projeto de alinhamento PAA-9548.

c) Acervo de Imagens PAA e PAL 
Neste Portal, ficam disponíveis para consulta e download, todos os Projetos de Alinhamento Aprovados - PAA e Projetos de Loteamento Aprovados PAL, conforme Figura 60.

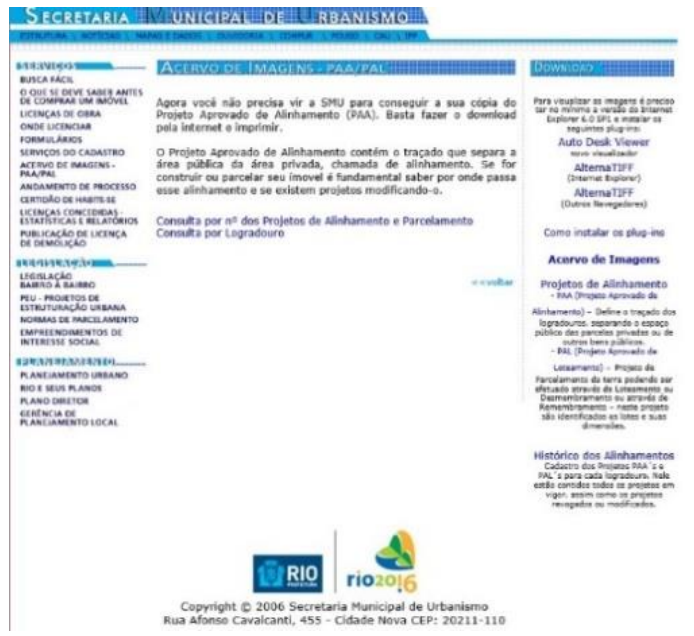

Figura 60 - Portal do Acervo de Imagens - PAA-PAL - RJ

Projeto obtido neste Portal: - PAA - 9548 - Limites do Espelho D’água da Lagoa.

Trata-se de Projeto elaborado na época em mídia física - papel vegetal (padrão na época desenhado manualmente em escala a nanquim), que passou por processo de digitalização, quando da informatização do Acervo de Projetos de Alinhamento e Loteamento do Município, ficando disponível neste portal para consulta e download em formato matricial.

Ocorre que para o uso e aplicação desse documento em Sistema CAD, o mesmo deverá ser inserido como imagem matricial utilizando-se técnicas e ferramentas apropriadas, adequando-se sua representação gráfica em escala, sendo possível até mesmo criar um vínculo de Georreferenciamento.

Devido às condições de envelhecimento e deterioração da mídia física papel vegetal, a imagem digitalizada neste formato matricial ficou de difícil visualização, criando dificuldades e deficiências na sua interpretação e utilização, mas mesmo assim, sendo inserida e estudada com a devida atenção, resultou em planta representativa no sistema CAD - AutoCAD pode ser visualizado na Figura 61. 


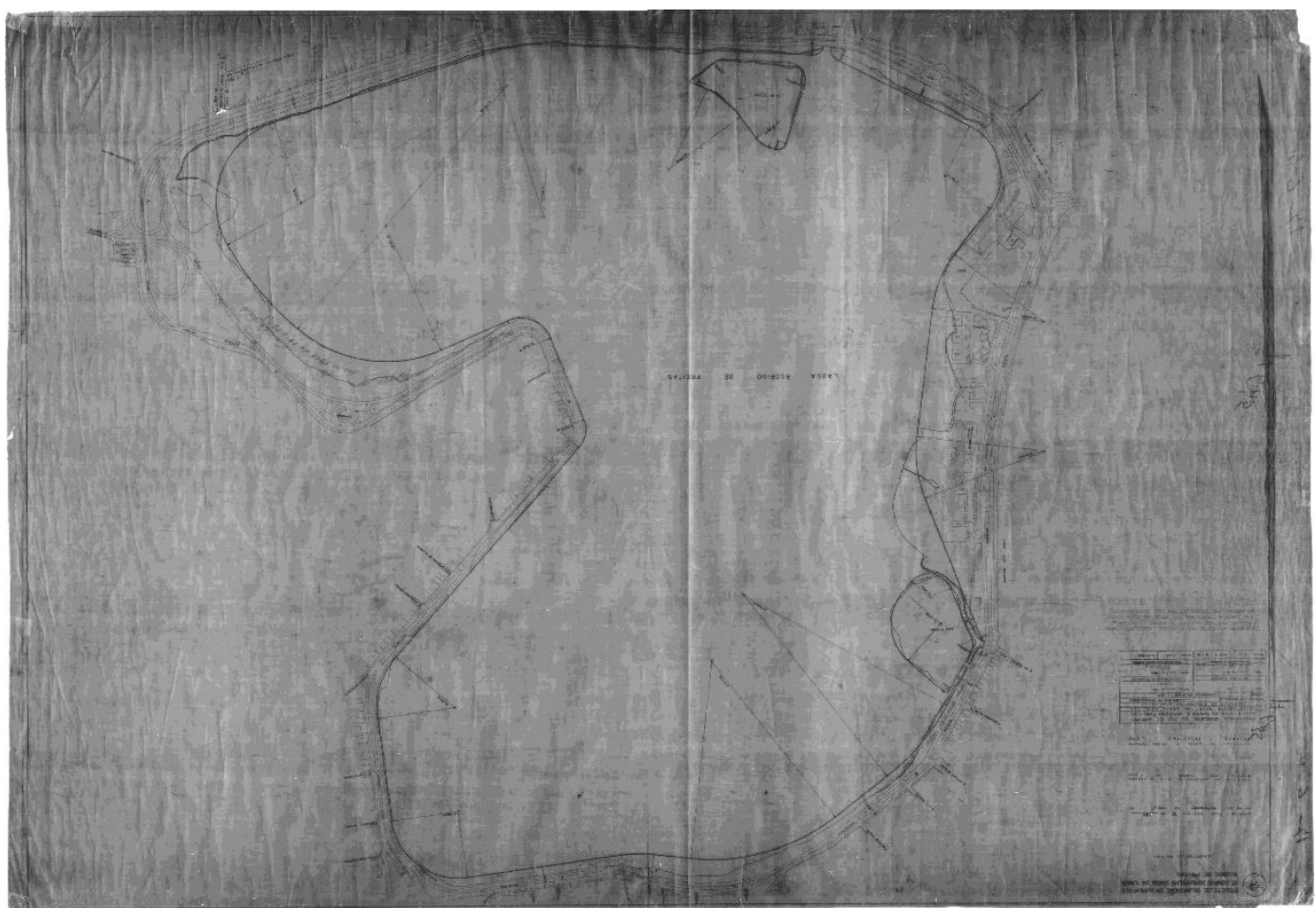

Figura 61 - Imagem do PAA-9548 - Orla da Lagoa

d) Portal do Armazém de Dados do IPP - Instituto Pereira Passos

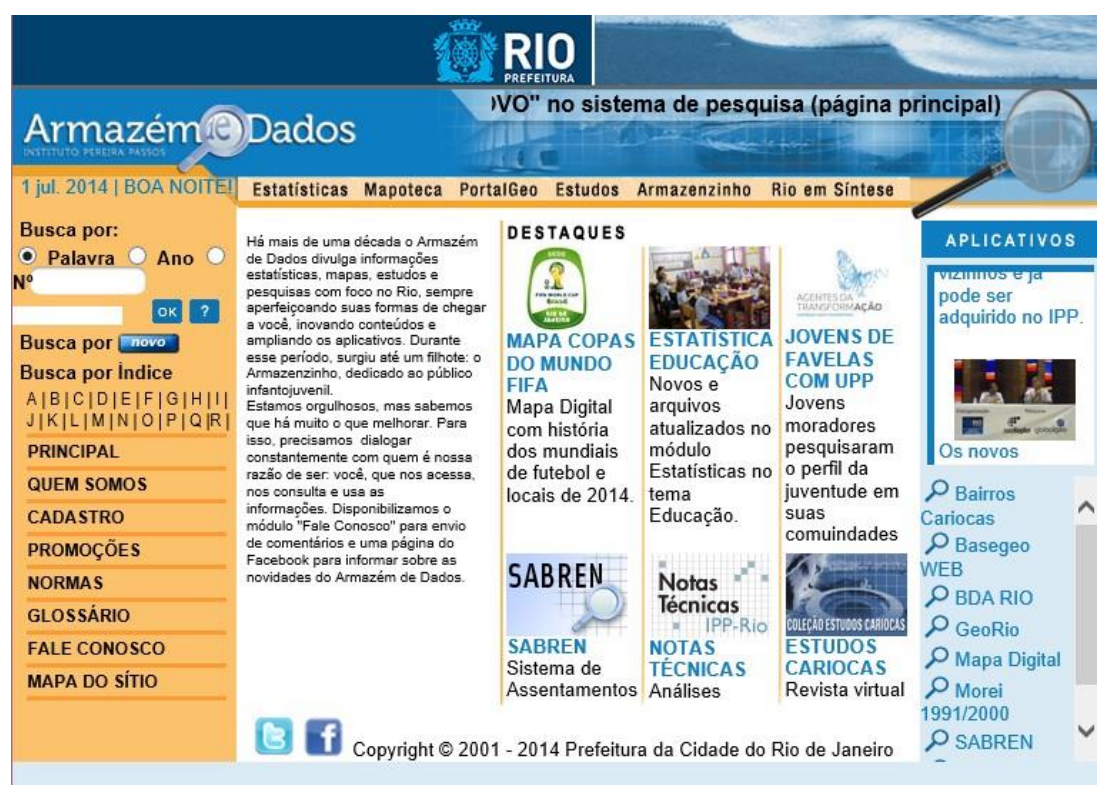

Figura 62 - Armazém de Dados - IPP - Instituto Pereira Passos

A Prefeitura Municipal da Cidade do Rio de Janeiro também disponibiliza seus dados de modo mais abrangente e diversificado num Portal denominado “Armazém de Dados", ilustrado na Figura 62, onde podem ser encontradas, além das opções anteriores, mais informações estatísticas e aplicativos de geração de 
mapas com diversas e relevantes informações e conteúdos sobre o Município, que listamos a seguir: MAPOTECA - Armazém de Dados - IPP - Rio de Janeiro Mapoteca

\author{
Bases Cartográficas \\ Mapas Temáticos \\ Território e Meio Ambiente
}

1) Áreas de Planejamento e Regiões Administrativas - 2014 (Mapa No 1313);

2) Bairros e áreas acima da cota 100 metros - 2014 (Mapa $N^{\circ} 1826$ );

3) Áreas de Planejamento, Regiões Administrativas e áreas acima da cota 100 metros (contorno) - 2014 (Mapa $\mathrm{N}^{\circ} 1827$ );

4) Bairros e áreas acima da cota 100 metros - 2014 (Mapa $N^{\circ} 1829$ );

5) Bairros e áreas acima da cota 100 metros - 2014 (transparente) (Mapa No 1831);

6) Áreas de Planejamento (AP) - 2014 (Mapa No 1311);

7) Regiões Administrativas - RAs 2014 (Mapa No 1312);

8) Regiões de Planejamento (RP) - Bairros - 2014 (Mapa No 3370);

9) Divisão do Município do Rio de Janeiro em Áreas de Planejamento - AP1 e AP2 - 2007 (Mapa No 2515);

10) Divisão do Município do Rio de Janeiro em Áreas de Planejamento - AP3 2007 (Mapa No 2516);

11) Divisão do Município do Rio de Janeiro em Áreas de Planejamento - AP4 2007 (Mapa No 2517);

12) Divisão do Município do Rio de Janeiro em Áreas de Planejamento - AP5 2007 (Mapa N²518);

13) Bairros e cota 100 - 2005 (contorno) (Mapa No 1830);

14) Áreas de Planejamento, Regiões Administrativas e cota 100 - 2005

(transparente) (Mapa No 1828);

15) Ciclovias Cariocas (Mapa $\mathrm{N}^{\mathrm{o}} 1616$ );

16) Bairros - 2004 (Mapa No 1314);

17) Esquema de Articulação de Folhas da Cartografia Municipal com Bairros 2004 (Mapa No 1315);

18) Bacias e Sub-bacias Hidrográficas (Mapa № 1316);

19) Altimetria e Traçado Viário - 2004 (Mapa No 1317);

20) Geologia - 2004 (Mapa No 1318); e

21) Chuva Média Anual (1997-1998) (Mapa No 1319).

\title{
População
}

1) Dinâmica da população, por Região Administrativa - Município do Rio de Janeiro - 2010 (Mapa No 2965); e

2) População total por bairro - Município do Rio de Janeiro - 2010 (Mapa N ${ }^{\circ}$ 2979). 


\section{Economia}

1) Mapa da variação do número de postos de trabalho formais entre 2000 e 2008, e participação total dos postos de trabalho no Município do Rio de Janeiro em 2008, segundo as Regiões Administrativas (Mapa No 2827).

Culturas, Esporte, Lazer e Turismo

1) Mapa Turístico da Floresta da Tijuca - 2004 (Mapa No 3178).

Infraestrutura e Uso do Solo

1) Coordenadorias Regionais de Urbanismo (CRU) e Regiões Administrativas 2004 (Mapa N 1365).

Transporte

1) Principais vias terrestres (Rodoviárias, ferroviárias e metroviárias) (Mapa $\mathrm{N}^{\circ}$ 1364).

\section{Desenvolvimento Social}

1) Índice de Desenvolvimento Humano Renda, por Regiões Administrativas 2000 (Mapa No 1377).

\section{Mapas de Uso do Solo}

1) Mapa de uso do solo da Cidade do Rio de Janeiro - 2012 (Mapa No 3321).

Bases Cartográficas

1) Mapa da Cidade do Rio de Janeiro - 2013 (Mapa N 3083).

As principais Vias terrestres podem ser visualizadas no Mapa 02 e a Altimetria da região e traçado viário no Mapa 03, publicados pelo IPP em 2004.

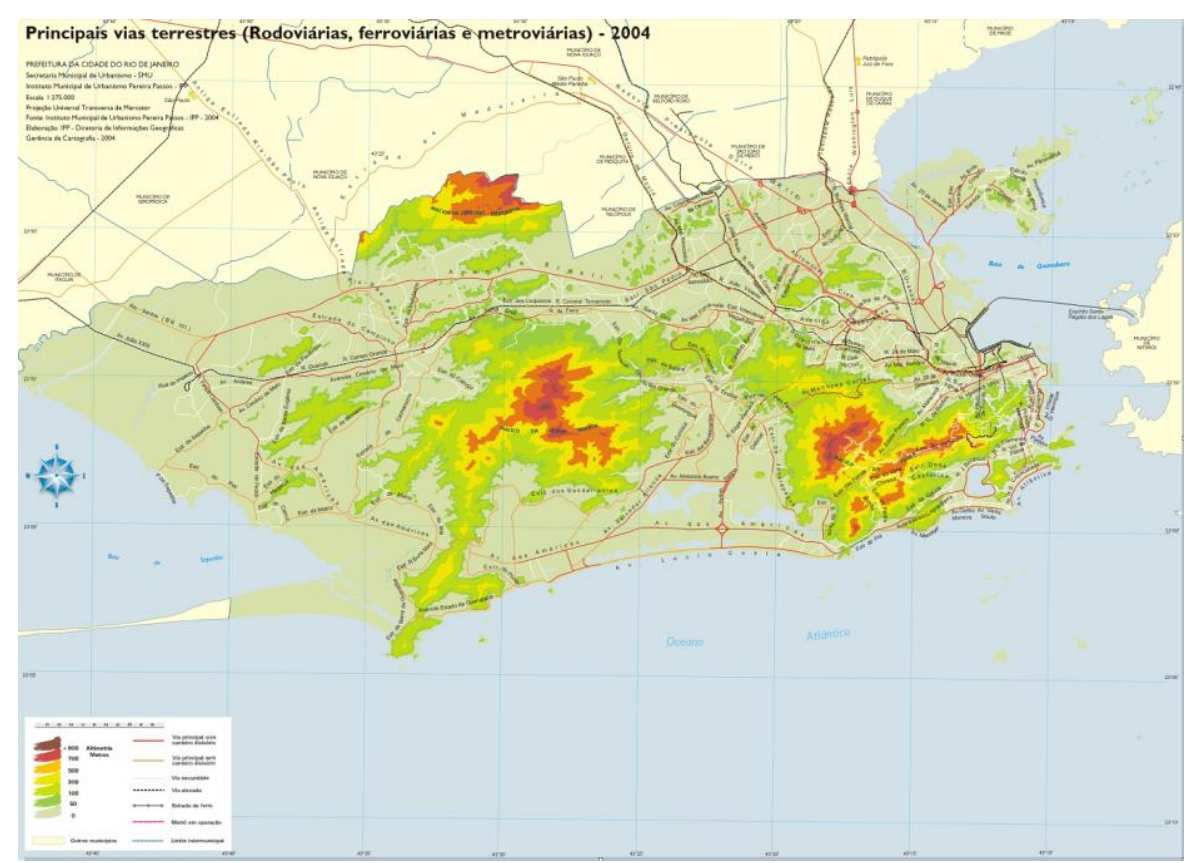

Mapa 02 - Principais Vias Terrestres (Rodoviárias, ferroviárias, metroviárias) 2004 Fonte IPP 


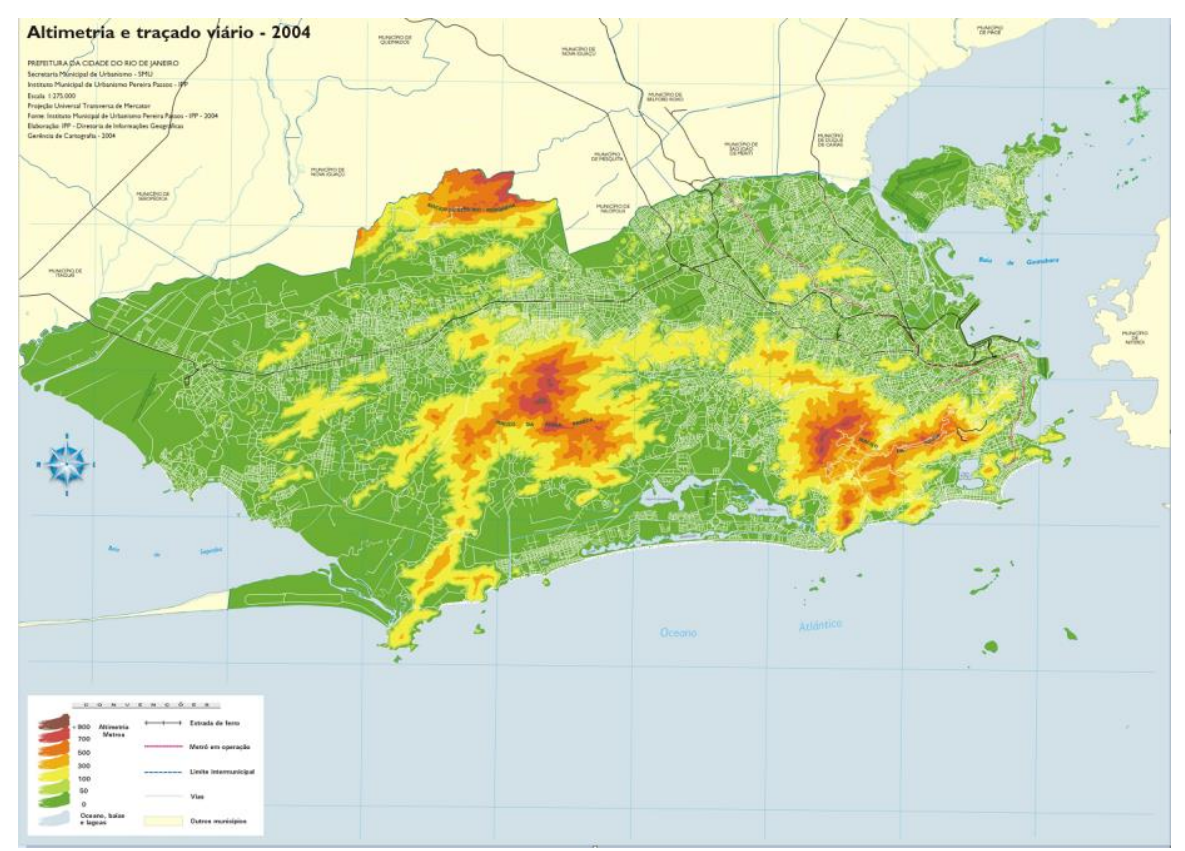

Mapa 03 - Altimetria e traçado viário - 2004 - Fonte IPP

d.1- No item Bairros Cariocas é possível obter informações temáticas bairro a bairro num outro formato, conforme Figura 63, Portal Sigweb.

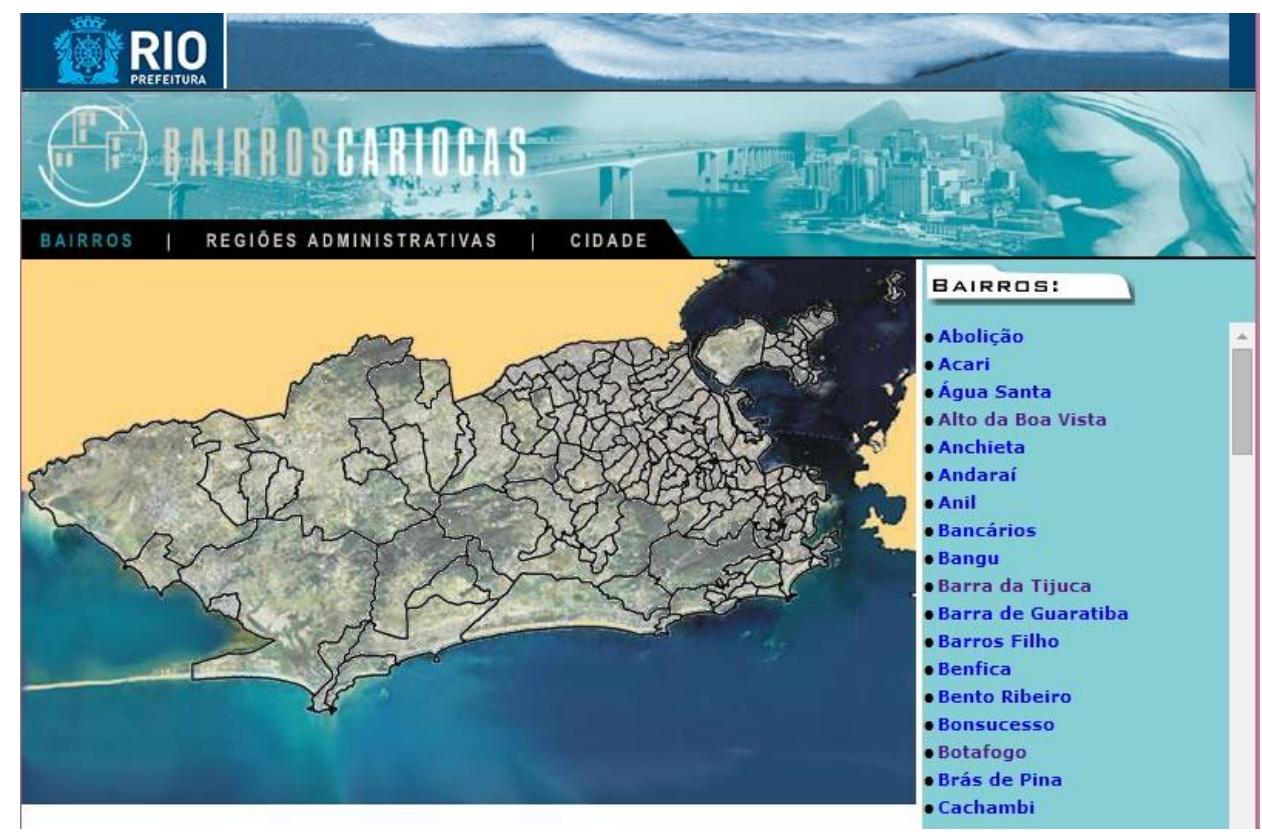

Figura 63 - Portal Sigweb - Bairros Cariocas

Neste item do Portal podemos acessar dados censitários, políticos, estatísticos e geográficos dos diversos bairros do Município, conforme representação do Portal na Figura 64 e nas Tabelas de 02 a 08. 


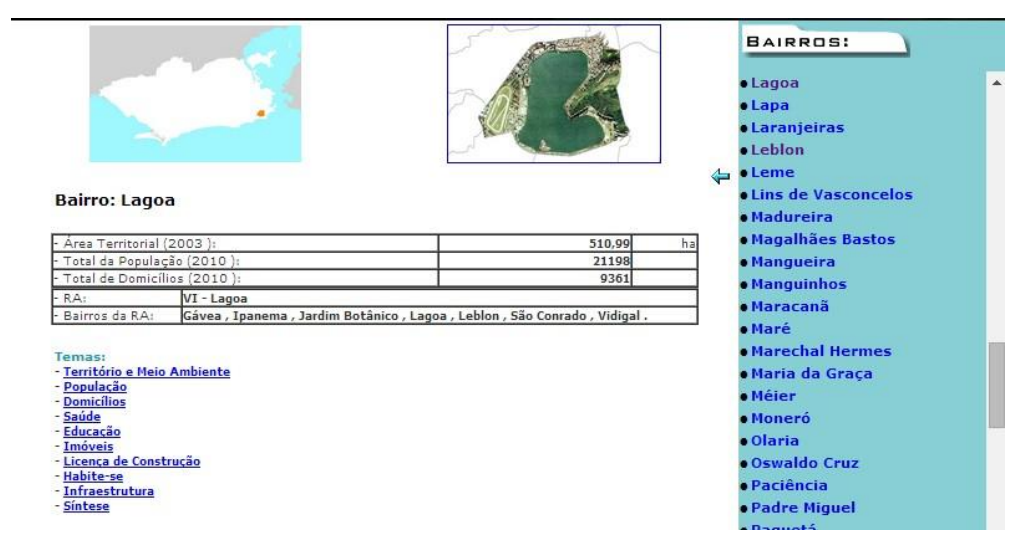

Figura 64 - Bairro selecionado - Lagoa

Tabela 02 - Dados do Bairro da Lagoa

\section{Bairro: Lagoa}

\begin{tabular}{|l|r|r|}
\hline - Área Territorial (2003): & 510,99 & ha \\
\hline - Total da População (2010): & 21198 & \\
\hline - Total de Domicilios (2010): & 9361 & \\
\hline \hline - R.A: & VI - Lagoa & \\
\hline - Bairros da R.A: & Gávea , Ipanema , Jardim Botânico, Lagoa, Leblon, São Conrado, Vidigal . \\
\hline
\end{tabular}

Tabela 03 - Dados do Bairro de Ipanema

Bairro: Ipanema

\begin{tabular}{|l|r|r|}
\hline - Área Territorial (2003): & 308,49 & ha \\
\hline - Total da População $(2010):$ & 23018 & \\
\hline - Total de Domicílios $(2010):$ & 23018 & \\
\hline \hline R.A: & VI - Lagoa & \\
\hline - Bairros da RA: & Gávea, Ipanema, Jardim Botânico, Lagoa, Leblon, São Conrado, Vidigal. \\
\hline
\end{tabular}

Tabela 04 - Dados do Bairro do Jardim Botânico

\section{Bairro: Jardim Botânico}

\begin{tabular}{|c|c|c|c|}
\hline \multicolumn{2}{|c|}{ - Area Territorial (2003): } & 268,92 & ha \\
\hline \multicolumn{2}{|c|}{ - Total da População (2010) } & 18009 & \\
\hline \multicolumn{2}{|c|}{ - Total de Domicílios (2010) } & 7725 & \\
\hline - RA: & VI - Lago: & & \\
\hline - Bairros da RA: & Gávea, I & , Vidiga & \\
\hline
\end{tabular}

Tabela 05 - Dados do Bairro da Gávea

\section{Bairro: Gávea}

\begin{tabular}{|l|r|r|}
\hline - Area Territorial $(2003):$ & 257,96 & ha \\
\hline - Total da População $(2010):$ & 16003 & \\
\hline - Total de Domicílios (2010): & 7069 & \\
\hline \hline - R.A: & VI - Lagoa & \\
\hline - Bairros da RA: & Gávea , Ipanema, Jardim Botânico, Lagoa, Leblon, São Conrado, Vidigal . \\
\hline
\end{tabular}


Tabela 06 - Dados do Bairro do Humaitá

\section{Bairro: Humaitá}

\begin{tabular}{|c|c|c|c|}
\hline \multicolumn{2}{|c|}{ - Área Territorial (2003): } & 105,45 & ha \\
\hline \multicolumn{2}{|c|}{ - Total da População (2010): } & 13285 & \\
\hline \multicolumn{2}{|c|}{ - Total de Domicilios (2010) } & 6546 & \\
\hline R.A: & IV - Bota & & \\
\hline - Bairros da RA: & Botafogo & -aranjei & \\
\hline
\end{tabular}

Tabela 07 - Dados do Bairro de Copacabana

\section{Bairro: Copacabana}

\begin{tabular}{|l|r|r|}
\hline - Área Territorial $(2003):$ & 410,09 & ha \\
\hline - Total da População $(2010):$ & 146392 & 81188 \\
\hline - Total de Domicilios $(2010)$ : & \\
\hline \hline - RA: $\quad$ V - Copacabana & \\
\hline - Bairros da RA: $\quad$ Copacabana, Leme. & \\
\hline
\end{tabular}

Tabela 08 - Dados do Bairro do Leblon

\section{Bairro: Leblon}

\begin{tabular}{|l|r|r|}
\hline - Área Territorial (2003): & 215,31 & ha \\
\hline - Total da População $(2010):$ & 46044 & 22259 \\
\hline - Total de Domicílios (2010): & & \\
\hline \hline - RA: VI - Lagoa & & \\
\hline - Bairros da RA: & Gávea, Ipanema, Jardim Botânico, Lagoa, Leblon, São Conrado, Vidigal. \\
\hline
\end{tabular}

Assim, podemos realizar uma análise político-sócio-econômica da região e adjacências, buscando elementos complementares para balizar parâmetros e justificar métricas para mensuração e determinação de resultados estatísticos, que podem vir a ser aplicados nas análises e conclusões, conforme ilustrado no Mapa 04 e no Mapa 05, População Total por Bairro e População Urbana por Bairro respectivamente - Publicados em 2010.

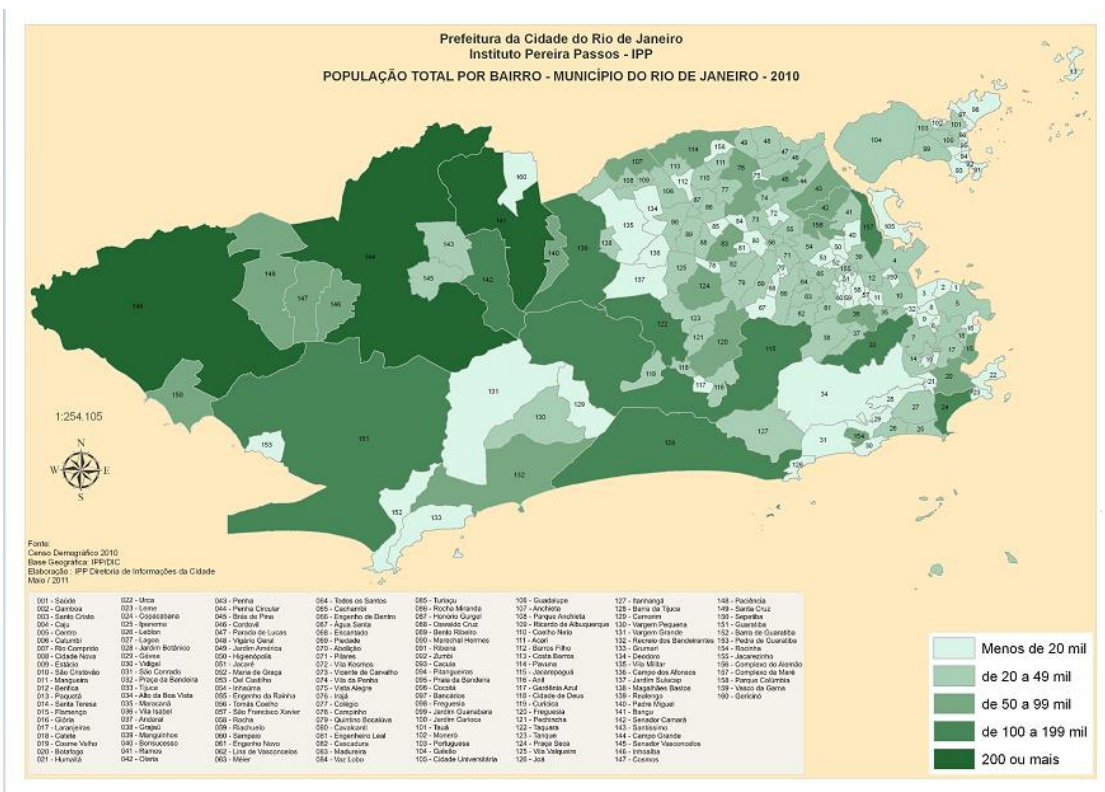

Mapa 04 - População Total Urbana por Bairro - 2010 - Fonte IPP 


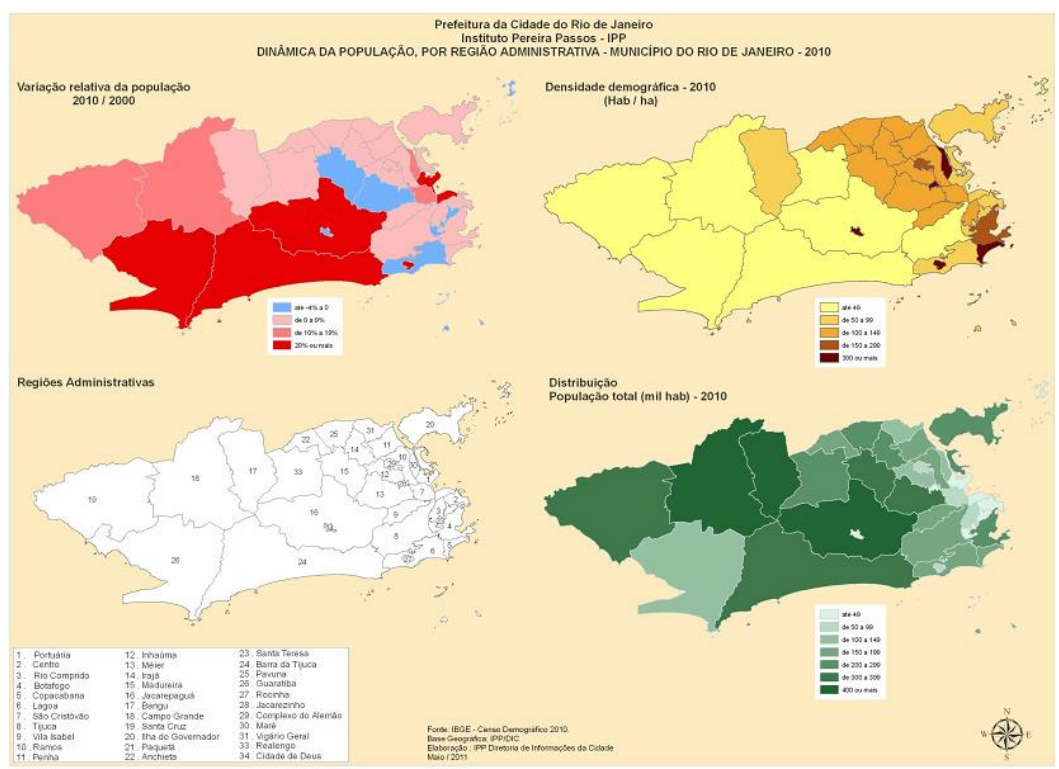

Mapa 05 - Dinâmica da População por Região Administrativa - 2010 - Fonte IPP

d.2- No item $\underline{\text { BaseGeo } \boldsymbol{W E B}}$ é possível extrair dados e fazer download de arquivos em diversos formatos, através da seleção de determinada área, conforme Figura 65.

Estes arquivos são obtidos segundo a delimitação feita na determinação da área escolhida, sendo bastante úteis na montagem de mapas temáticos do trecho em estudo.

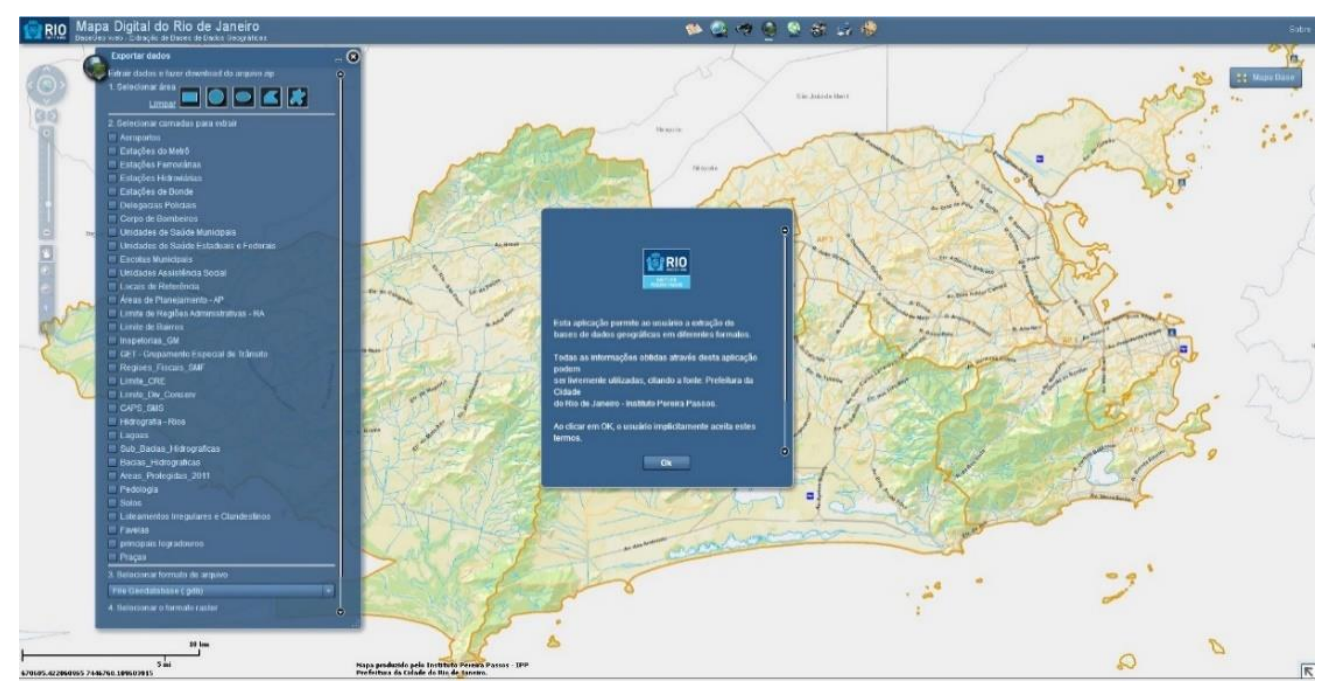

Figura 65 - Mapa Digital do Rio de Janeiro - BaseGeo WEB

Formatos Disponíveis:

File Geodatabase (*.gdb); Shapefile (*.shp); Autodesk AutoCAD (*.dwg); e Bentley Microstation Design (V8) (*.dgn). 
Com a utilização dos Sistemas CAD/SIG uma série de mapas podem ser elaborados e montados sendo direcionados a cada disciplina e estudo. Os dados demonstram a especificidade e qualidade das informações obtidas.

d.3- No item GeoRio é disponibilizado um aplicativo em mapa WebSIG online, baseado em um estudo feito pela GeoRio sobre as áreas mais suscetíveis a escorregamentos, conforme Figura 66.

O Mapa de Suscetibilidade a Escorregamentos do Rio de Janeiro indica as áreas do Município em três classes (baixa, média e alta) de suscetibilidade, e serve de referência não conclusiva e incontestável, mas sim básica de orientação ao uso do solo, onde podemos observar no contexto geral, essa característica com bastante clareza e objetividade.

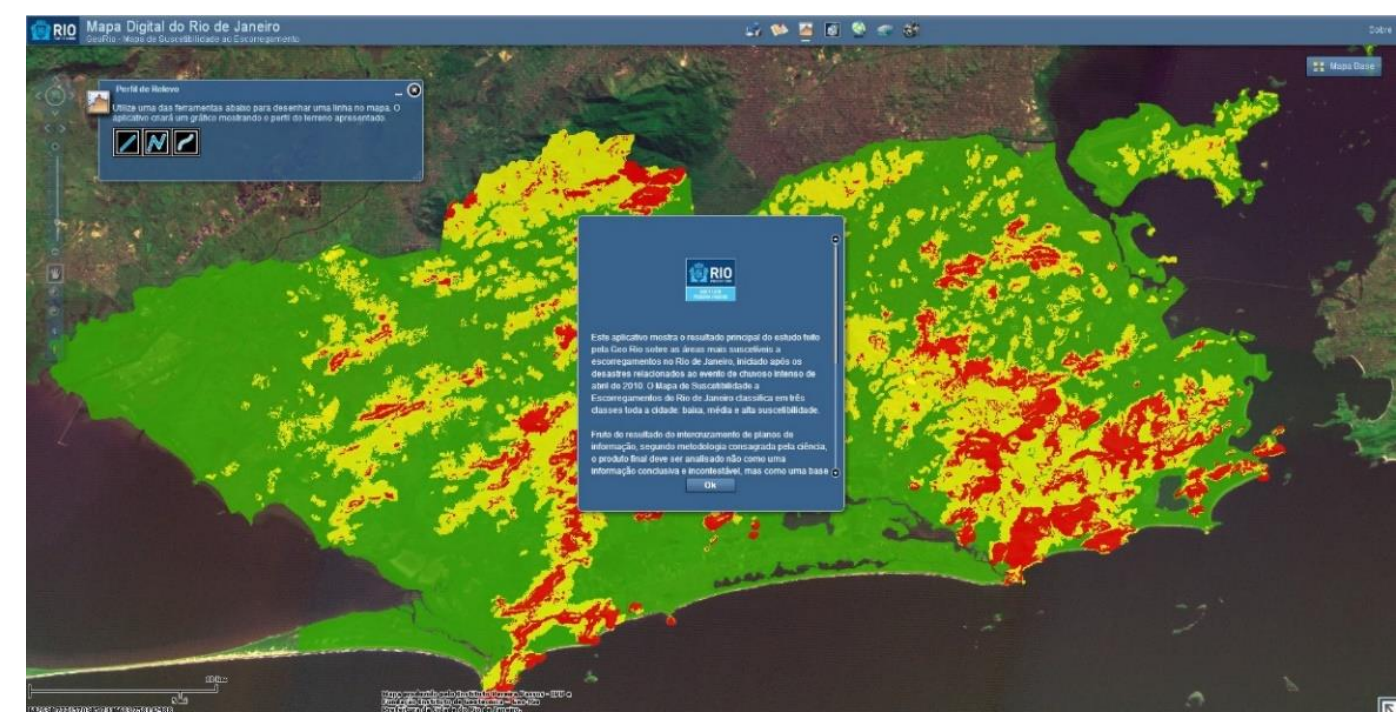

Figura 66 - Mapa Digital do Rio de Janeiro - Suscetibilidade a Escorregamento

É possível neste aplicativo, gerar um gráfico mostrando o perfil do terreno, conforme lançamento de linha de referência feita pelo usuário em área préselecionada.

O exemplo a seguir foi feito para a Lagoa, conforme visualizado na Figura 67. 


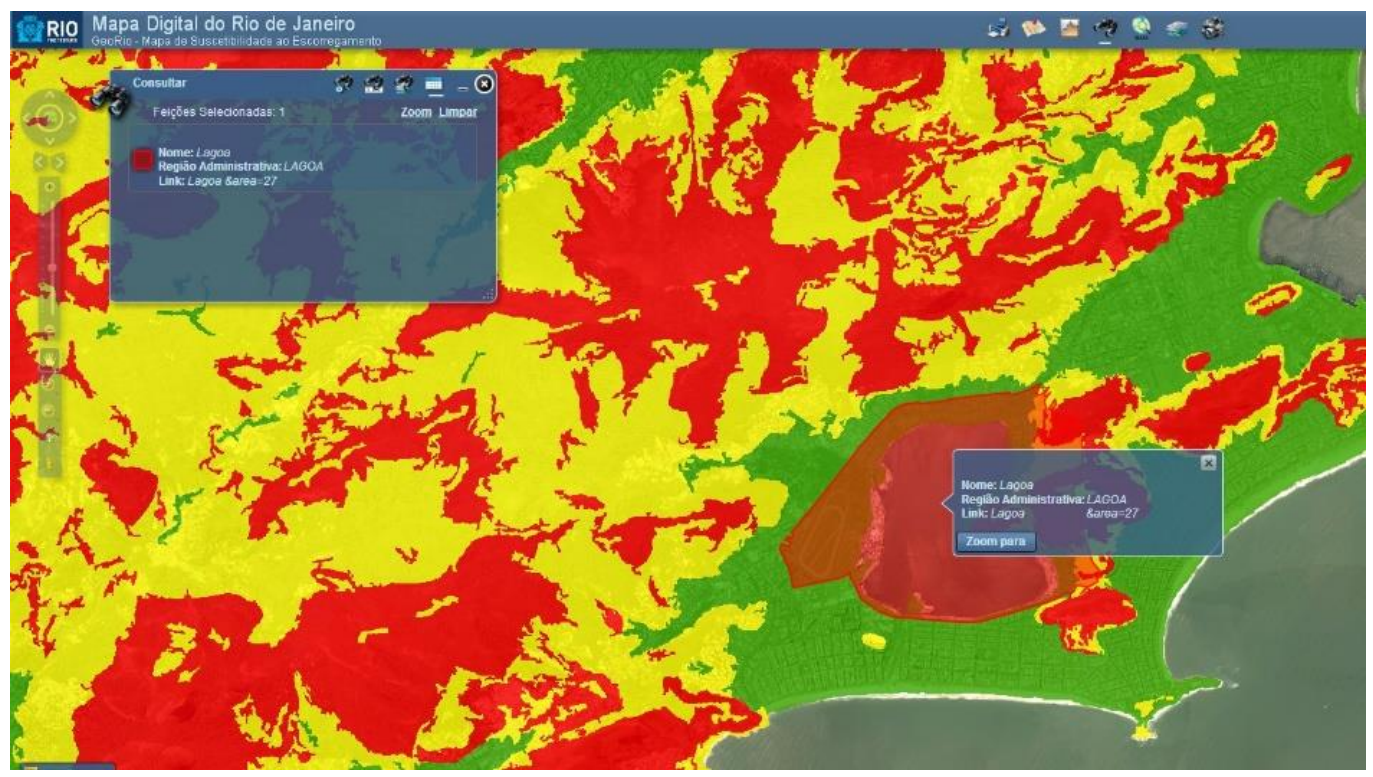

Figura 67 - Detalhamento da Lagoa e Adjacências

Para ilustrar e subsidiar os estudos desta Dissertação, elaboramos três traçados de perfil utilizando esse sistema, onde podemos observar com clareza o comportamento do relevo da região, demonstrado nas Figuras 68, 69 e 70.

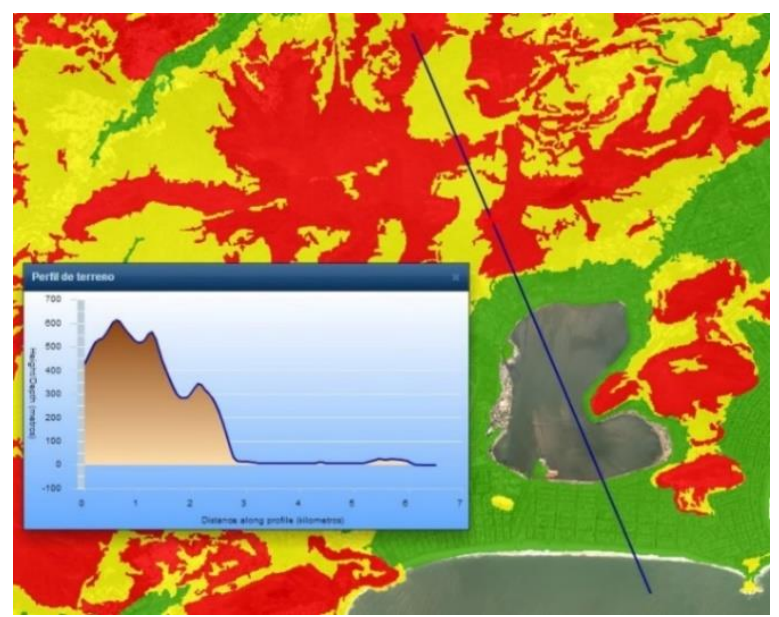

Figura 68 - Suscetibilidade Perfil 1

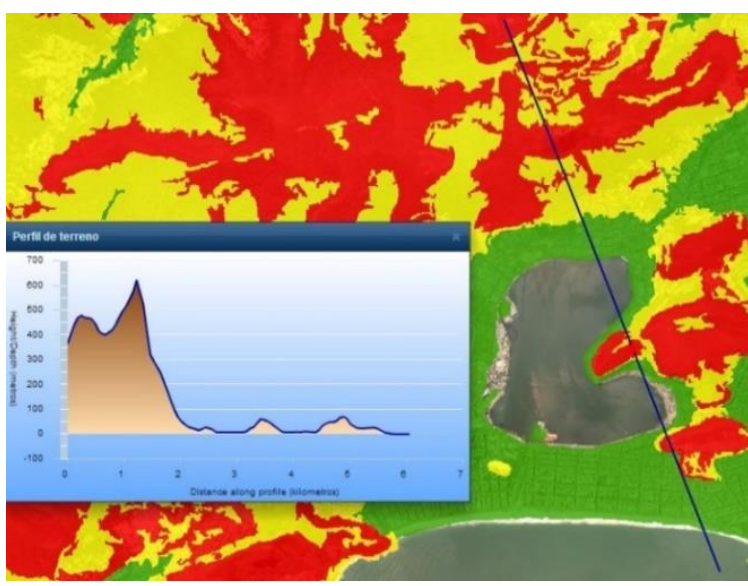

Figura 69 - Suscetibilidade Perfil 2 


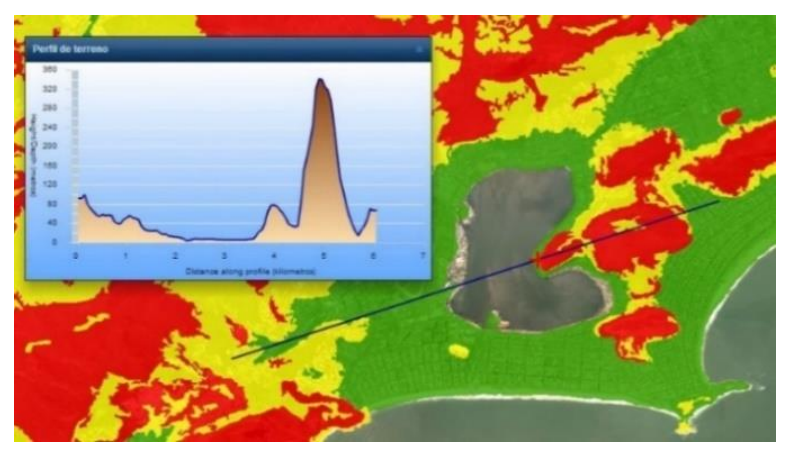

Figura 70 - Suscetibilidade Perfil 3

O Sistema SIG/WEB on-line mostrou-se de fácil utilização e compreensão, atingindo plenamente os objetivos propostos, dispensando maiores conhecimentos e tecnologia para obtenção dos resultados.

Notoriamente a região ocupada pela Lagoa (grande depressão no relevo), encontra-se confrontando com a orla oceânica e cercada por elevações, com destaque para a Serra da Carioca.

\section{d.4- No item Portal Geo-Mapas Digitais - Cartografia - Folhas}

Cartográficas e Foto Índice é possível acessar o aplicativo WebSIG on-line para pesquisa de produtos Cartográficos do IPP, conforme a Figura 71.

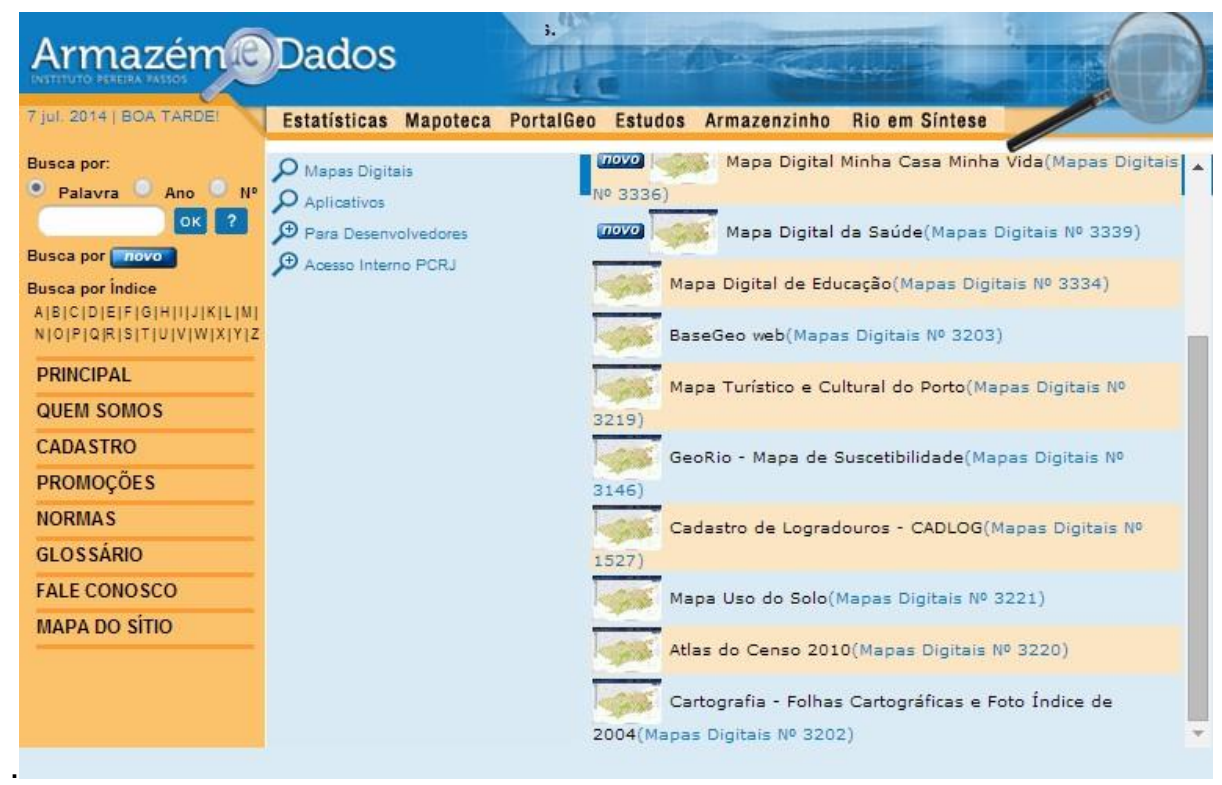

Figura 71 - Portal do Armazém de Dados - Opção Mapas Digitais

Permitindo a identificação de produtos cartográficos com busca por endereço, disponibiliza Plantas Cadastrais na escala 1/2.000 e 1/10.000 e Imagens de Fotografias Aéreas de 2004, conforme a tela apresentada na Figura 72. 


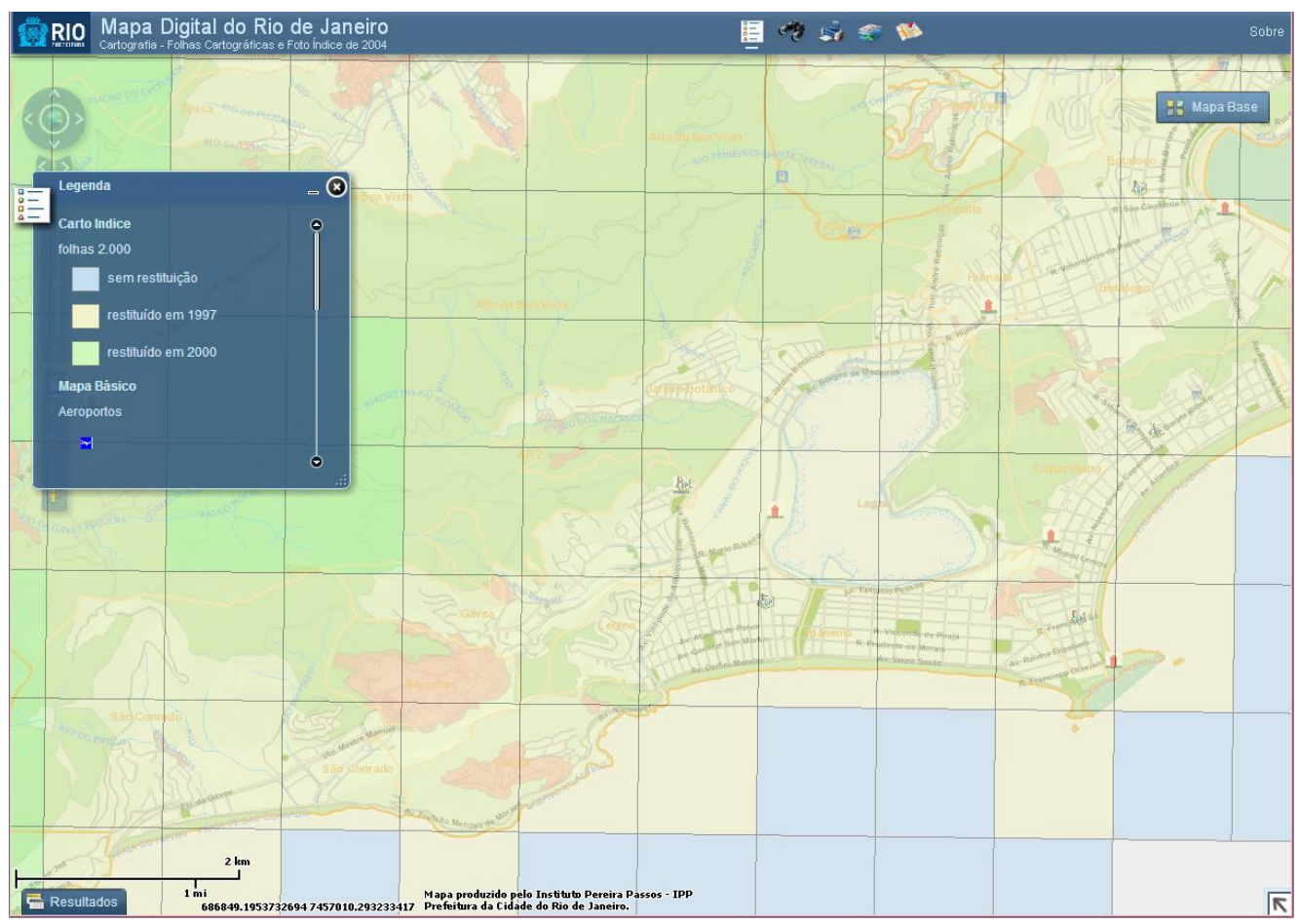

Figura 72 - Mosaico da região da Lagoa

d.5- Ainda no Armazém de Dados - IPP, podemos obter mapas numa melhor escala, elaborados e publicados pela GeoRio em maio de 1997. Trata-se da Carta Geológica-Geotécnica do Município do RJ, na escala 1/10.000.

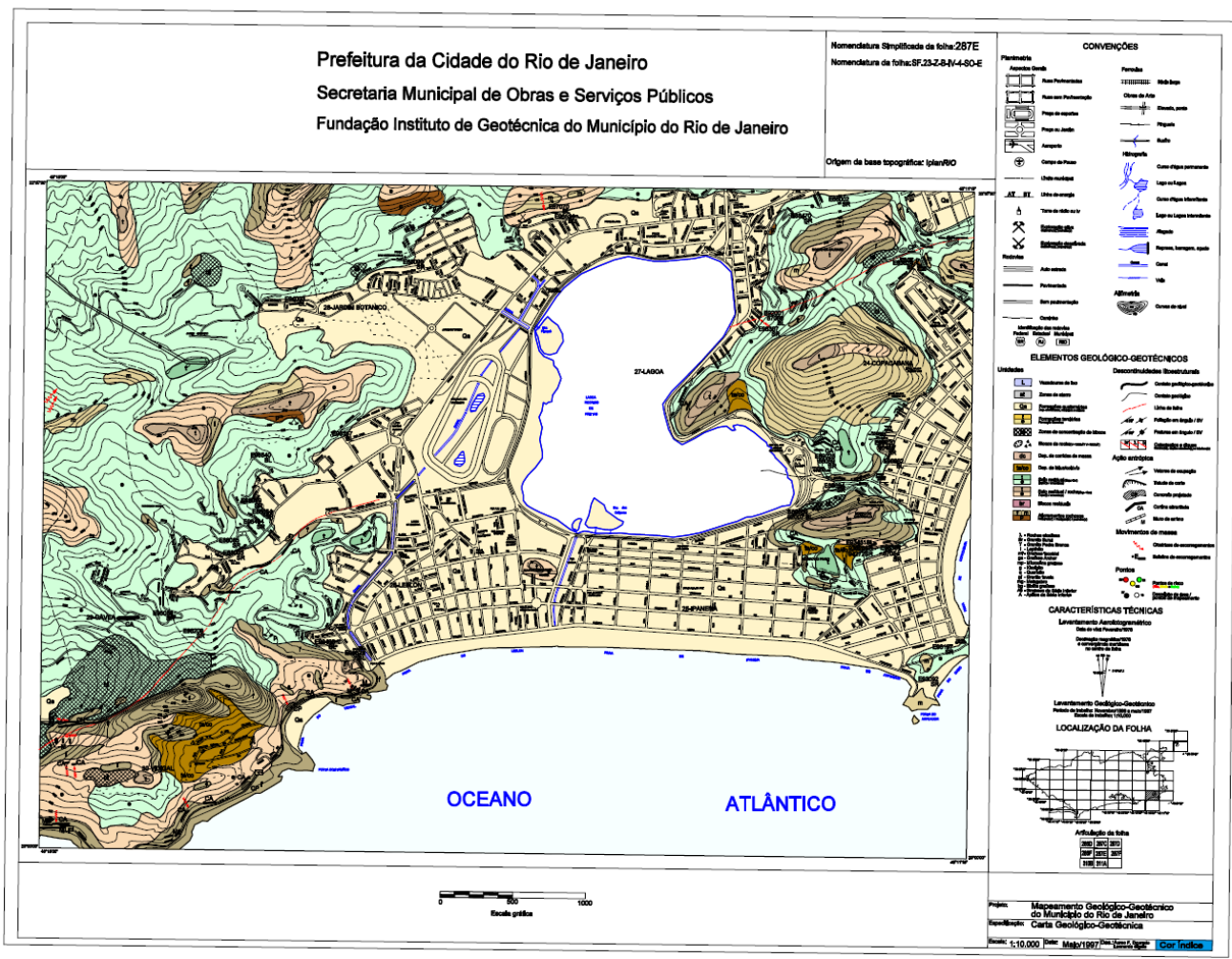

Mapa 06 - Carta Geológica-Geotécnica - da GeoRio - Folha 287e 
Observamos na leitura deste Mapa 06, representativo do espelho d'água da Lagoa e adjacências, que as áreas baixas no entorno da orla lagunar até a orla oceânica, são compostas geologicamente de formações quaternárias - depósitos aluvionares, marinhos e eólicos. Já as partes altas apresentam solo residual, afloramento de rochas e formação de encostas.

Para conhecer toda a Geotecnia da área em estudo, buscamos na coleção destes mapas conforme o mosaico disponibilizado, a folha $286 \mathrm{~d}$, visualizada no Mapa 07, a folha 286f, visualizada no Mapa 08, a folha 287c, visualizada no Mapa 09 e finalmente a folha 287e, visualizada no Mapa 06. Toda essa coleção está disponibilizada em formato digital pdf (impressão digital Adobe) e em formato CAD dgn (MicroStation V8 - Bentley).

Esse padrão de arquivo CAD também pode ser importado e editado para fins de impressão em outros aplicativos como o AutoCAD, democratizando assim o acesso a essa informação, necessitando apenas de algumas configurações de ajuste de formato (fontes, nomenclaturas, layers, etc.)

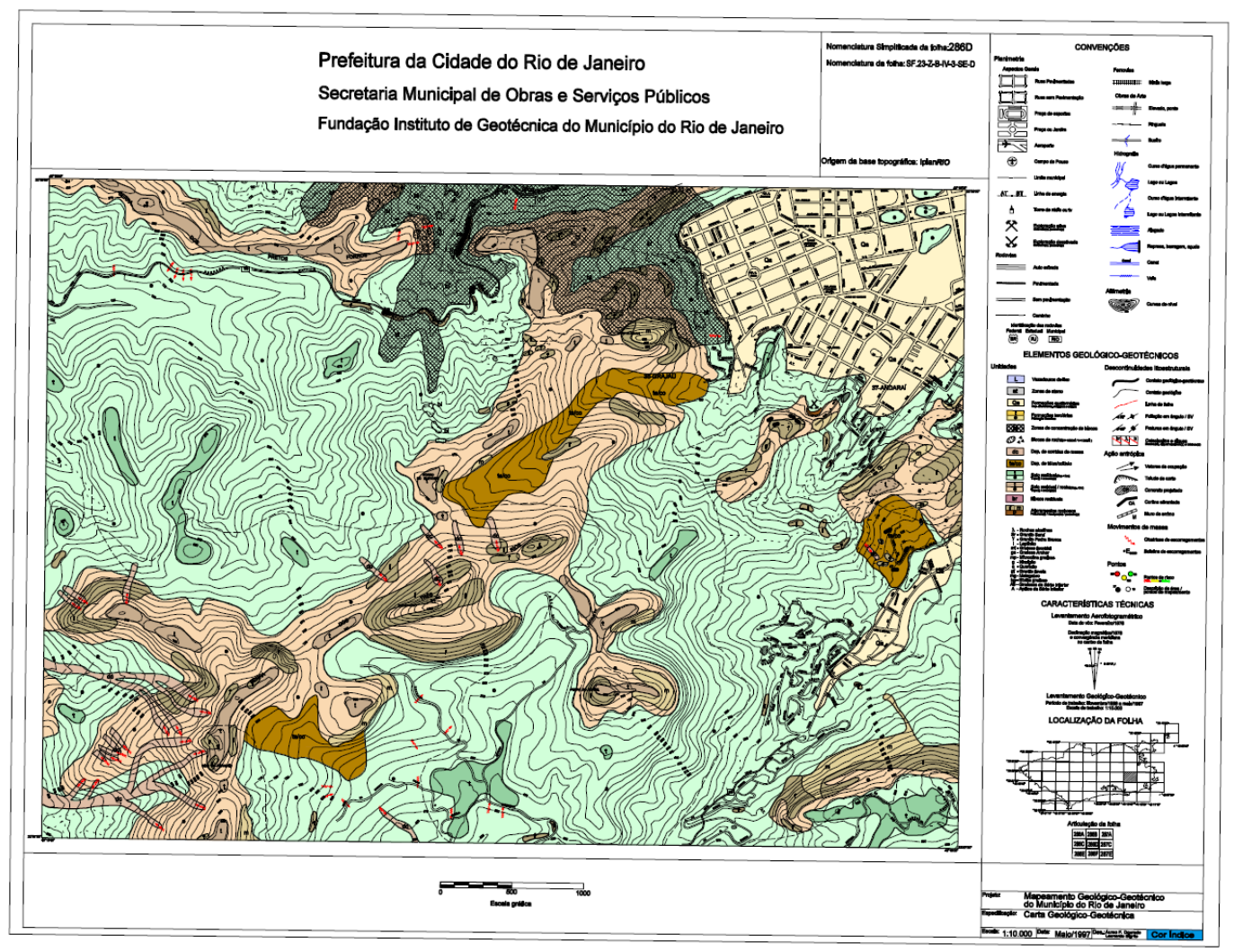

Mapa 07 - Carta Geológica-Geotécnica - da GeoRio - Folha 286d 


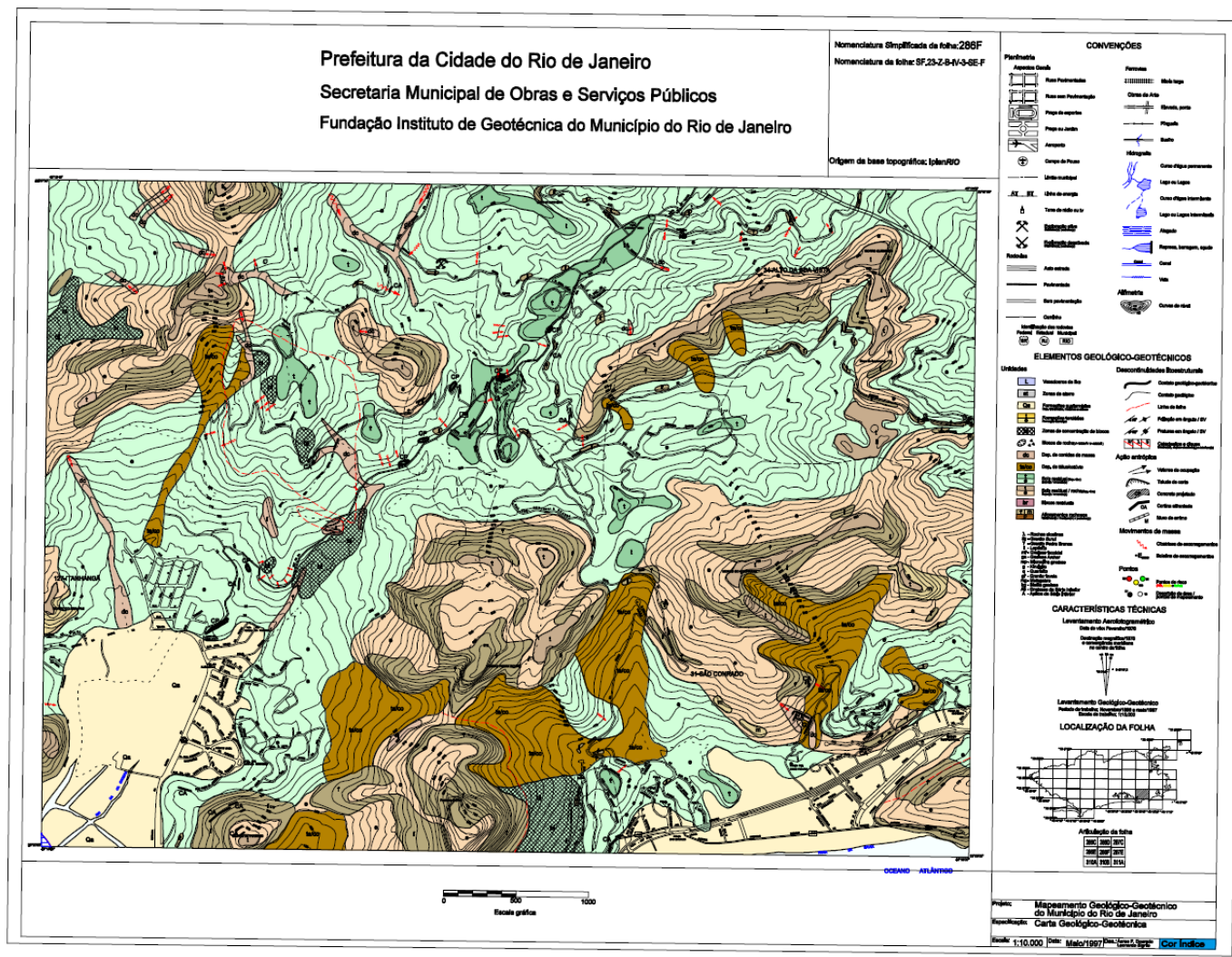

Mapa 08 - Carta Geológica-Geotécnica - da GeoRio - Folha 286f

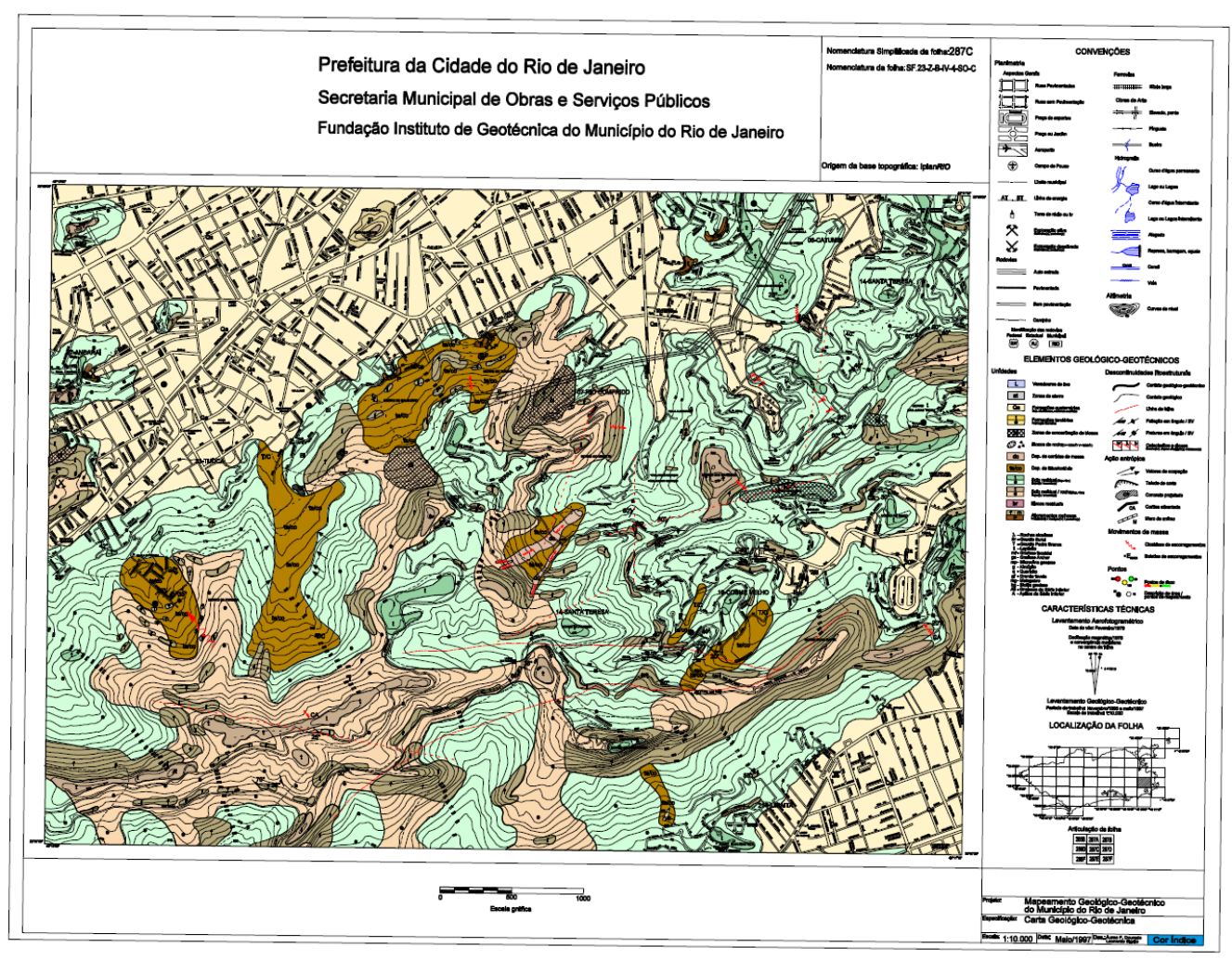

Mapa 09 - Carta Geológica-Geotécnica - da GeoRio - Folha 287c 
Este mapeamento temático é muito bem elaborado, permitindo através da interpretação da legenda, obter todas informações para análise e compreensão da formação geológica e geotécnica da região.

Outra fonte de informações geológicas do Município do RJ, está representada no Mapa 10 - Geologia 2004, publicado e disponibilizado no Armazém de Dados - IPP.

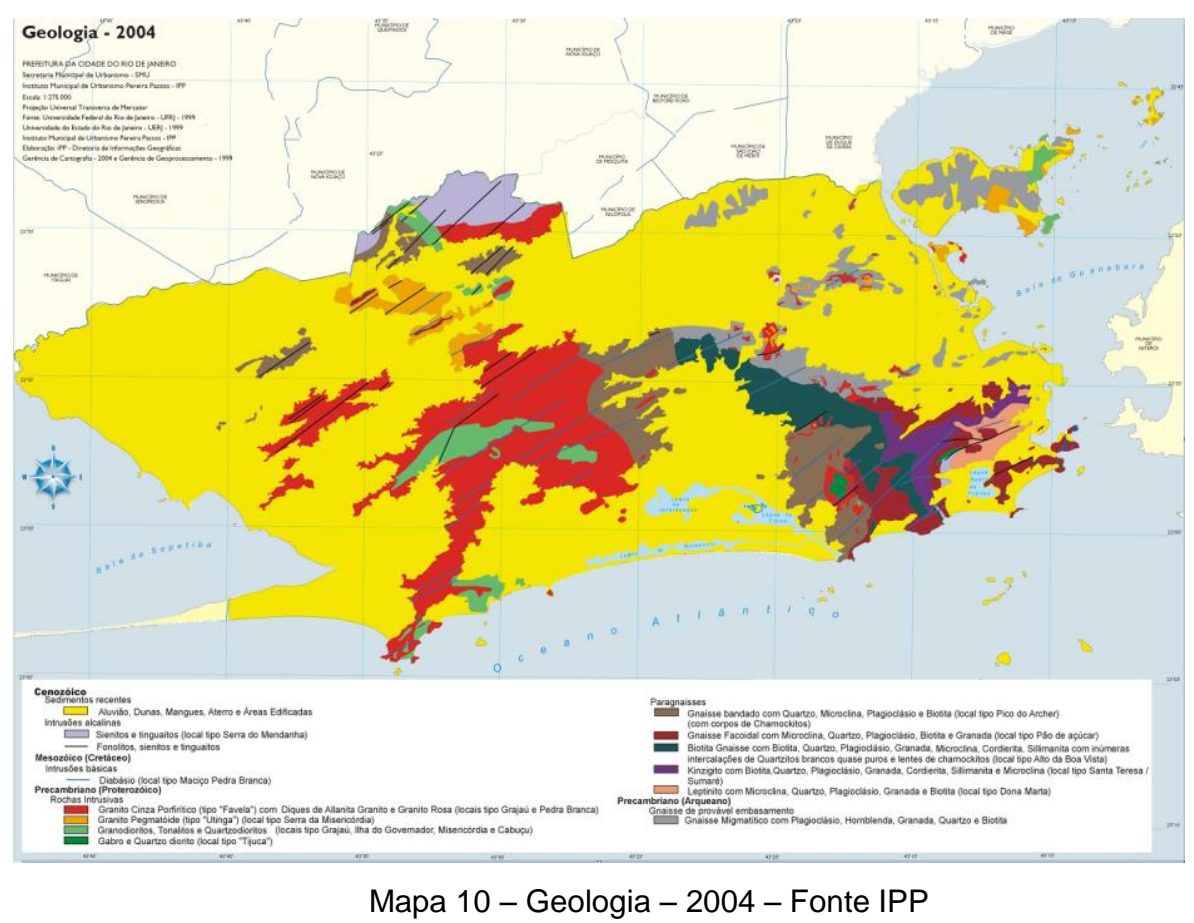

\section{9}

\section{CPRM - Dados Geológicos da Região}

No âmbito Federal, Ministério de Minas e Energia - Secretaria de Geologia, Mineração e Transformação Mineral, a Companhia de Pesquisa de Recursos Minerais - CPRM - Serviço Geológico do Brasil, através do Programa Geologia do Brasil, disponibiliza o Mapa Geológico do Brasil, na escala 1/100.000 - Para o caso da Lagoa, sua localização se dá na folha Baía de Guanabara (SF23-Z-B-IV) de 2009, conforme o Mapa 11, onde podemos observar os aspectos gerais Geológicos da região. Nesse mapa existe um detalhamento em perfil, cujo traçado se apresenta muito oportuno, pois atravessa parte da LRF, estando assinalado pela linha diretriz $\mathrm{AB}$ que pode ser mais bem observada nas Figuras 73, 74 e 75, que representam extratos do Mapa Geológico ampliados e em destaque. 


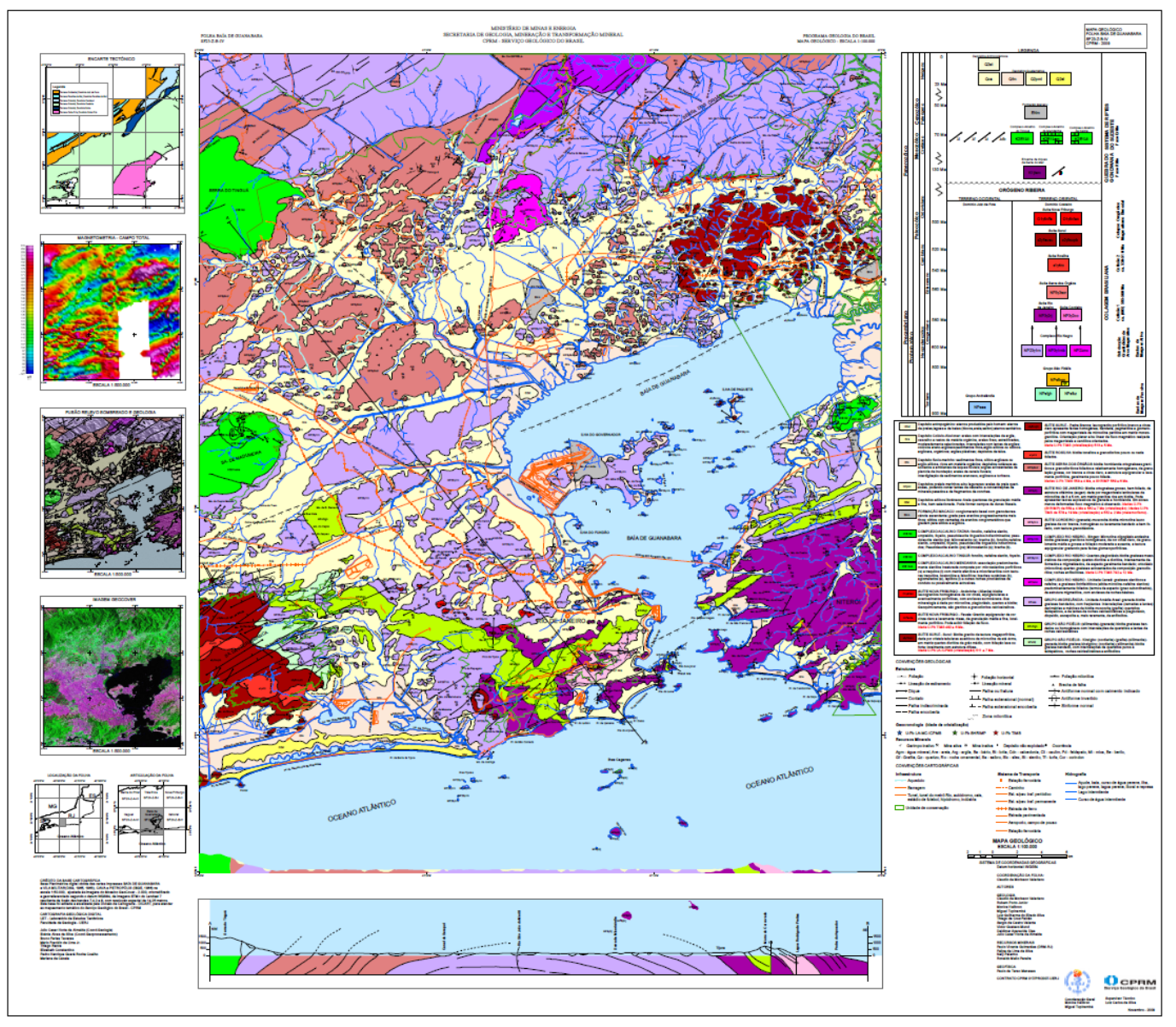

Mapa 11 - Mapa Geológico do Brasil - CPRM - Folha Baía de Guanabara

Assim, pode-se observar em mais detalhes, a composição geológica da região em estudo.

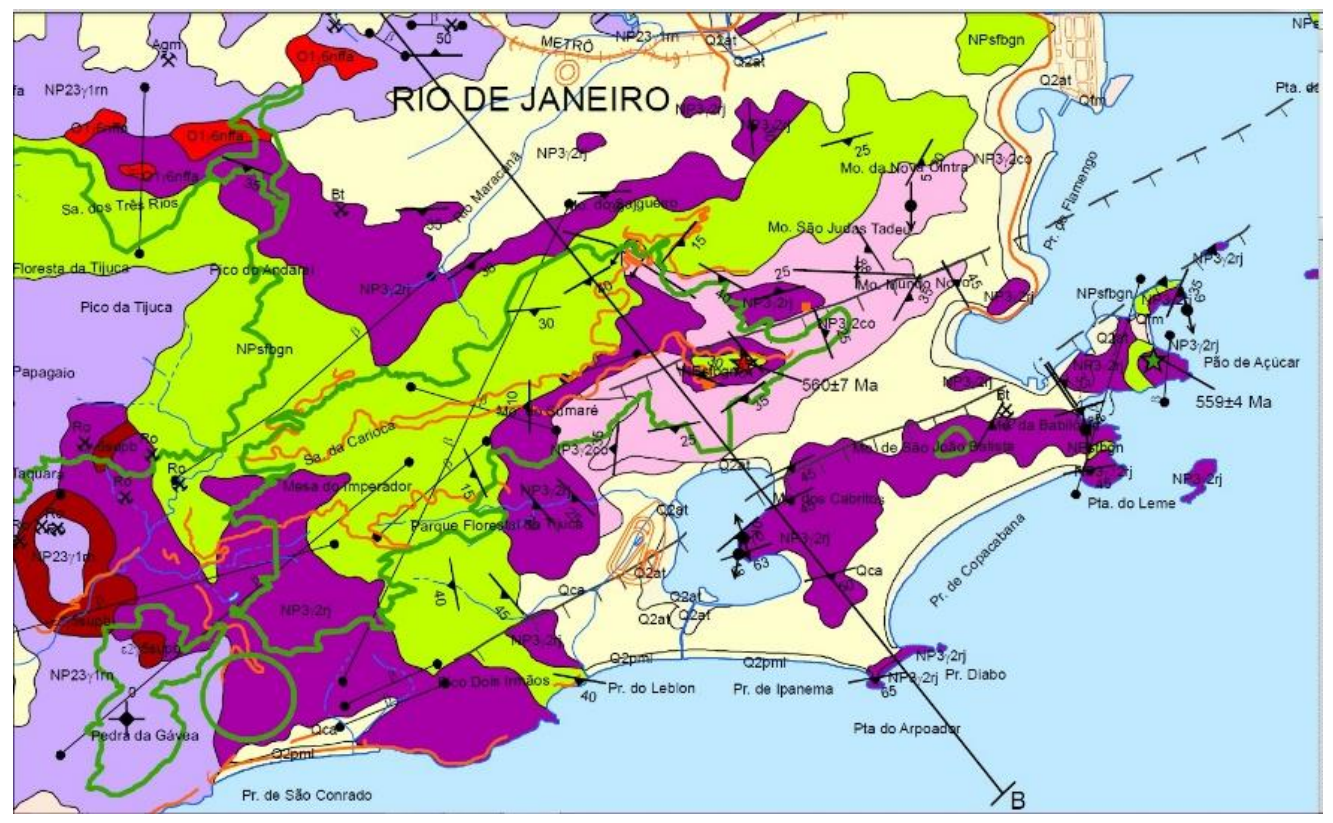

Figura 73 - Extrato do Mapa com Detalhe da Diretriz Geradora de Perfil 


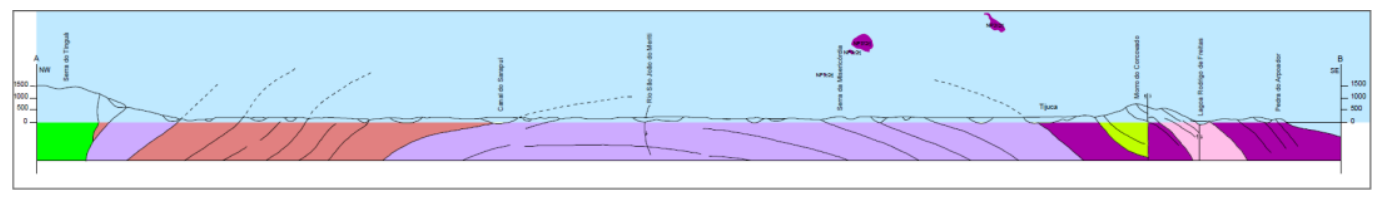

Figura 74 - Extrato do Mapa com o Perfil

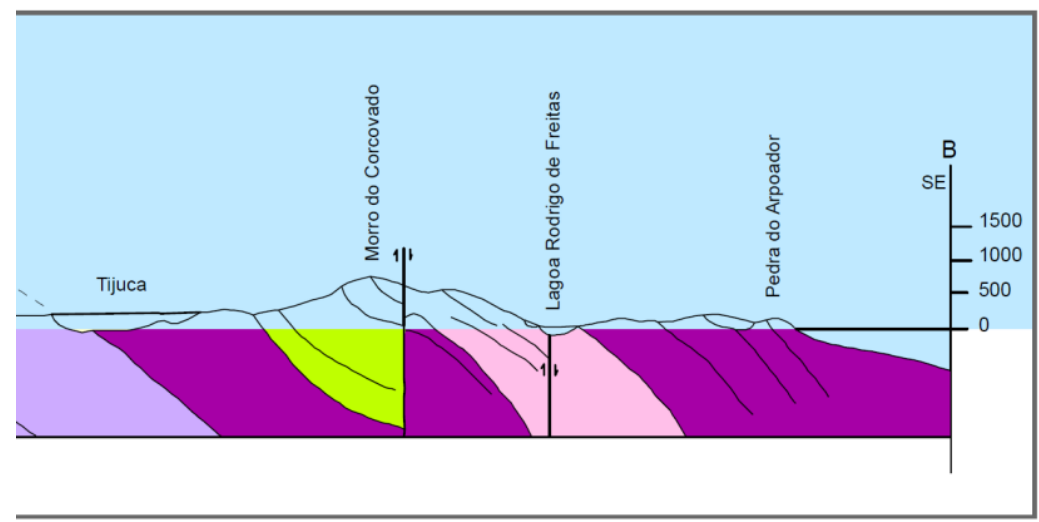

NP3 2 r j SUITE RIO DE JANEIRO: Biotita ortognaisse grosso, bem foliado, de estrutura oftálmica (augen) dada por megacristais lenticulares de microclina de 3 a $5 \mathrm{~cm}$, em matriz granítica rica em biotita. Pode apresentar teores expressivos de granada e hornblenda. Em zonas menos deformadas fluxo magmático é observado. Idades U-Pb (SHRIMP) de $559 \pm 4 \mathrm{Ma}$ e $560 \pm 7 \mathrm{Ma}$ (cristalização); Idades U-Pb TIMS de $578 \pm 19$ Ma (cristalização) e $552 \pm 2$ Ma (metamorfismo).

NP3 2 co

SUÍTE CORDEIRO: (granada)-muscovita-biotita-microclina leuco gnaisse de cor branca, homogêneo ou levemente bandado e bem foliado, com textura granoblástica.

Figura 75 - Extrato do Mapa Detalhe do Perfil Orla Oceânica, Lagoa e Morro do Corcovado

Ainda sobre os dados geológicos da região, segundo Carlos Gustavo Nunes Pereira (2009), a paisagem típica do litoral carioca é resultante do enrugamento da placa terrestre, provocada por movimentos tectônicos, formação que denominou "Os Morros Seriados", detalhado em perfil conforme a Figura 76, extraída do seu livro.

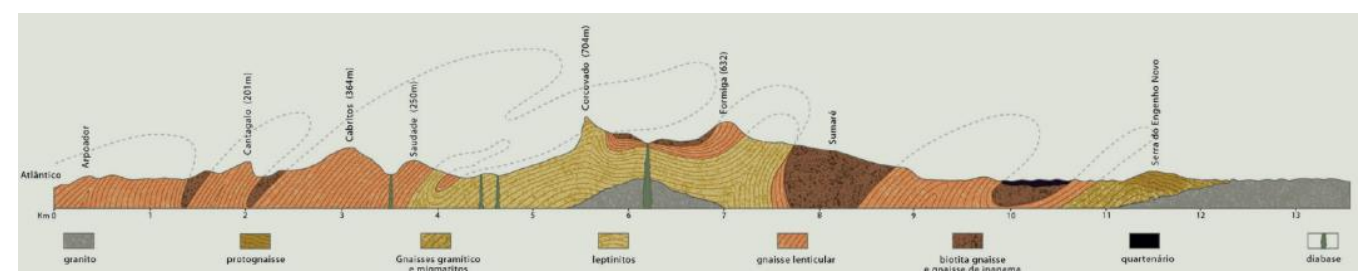

Figura 76 - Morros Seriados - Gustavo Nunes Pereira, 2009 


\subsection{0}

\section{Infraestrutura Urbana}

Para o entendimento da Infraestrutura Urbana existente na região da Lagoa, pesquisamos as características e funcionamento dos sistemas de controle da drenagem de águas pluviais e coleta e tratamento de esgoto, bem como demais questões inerentes ao meio urbano. Na pesquisa localizamos o Portal "Projeto Lagoa Limpa - EBX”, onde estão disponibilizadas e listadas várias ações e intervenções bastante relevantes, descritas e apresentadas em forma de Projeto.

Cada projeto está descrito em seus detalhes, acompanhado de mapeamento de referência.

\subsection{0 .1}

\section{Controle das Galerias de Águas Pluviais}

Segundo este projeto, existem 26 pontos de conexão de chegada de galerias de águas pluviais que coletam e transportam a água das chuvas pelos bueiros das ruas até a Lagoa ou o canal de Jardim de Alah, conforme pode ser visualizado no Mapa 12. Pelo projeto, todo o fluxo de águas pluviais da região entorno da Lagoa, é controlado pela operação de comportas e pontos de deságue das GAP's (Galerias de Águas Pluviais).

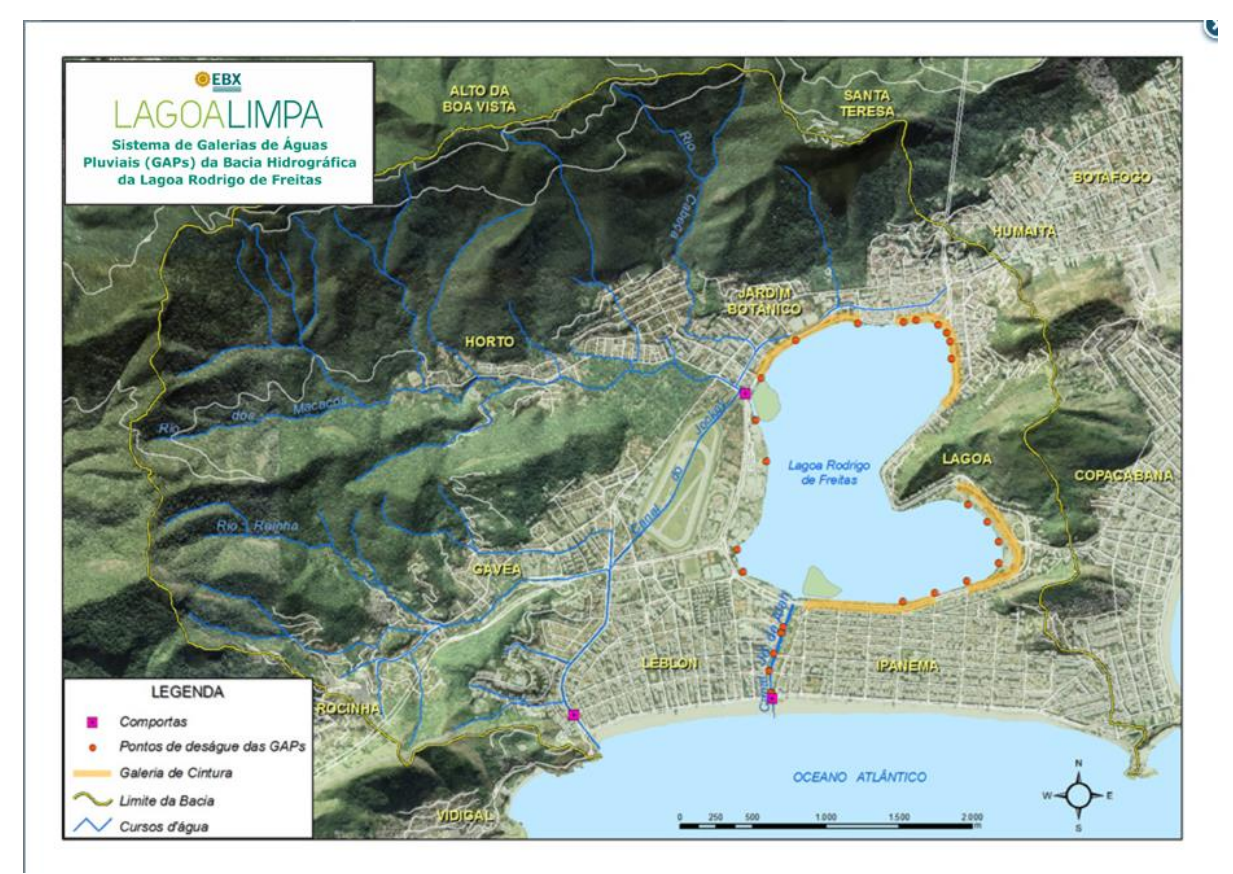

Mapa 12 - Sistemas de Galerias de Águas Pluviais - Fonte LAGOA LIMPA 


\subsection{0 .2}

\section{Centro de Controle Operacional de Esgoto - CCOE}

Projeto responsável pela automação do sistema de esgotamento sanitário do entorno da Lagoa, que vem contribuindo para prevenir eventuais descargas de efluentes, associado a problemas de funcionamento das elevatórias de esgoto.

No Mapa 13, podemos observar os locais previstos para obras de instalação de sensores objetivando o monitoramento e automação do sistema, no Centro de Controle Operacional de Esgoto.

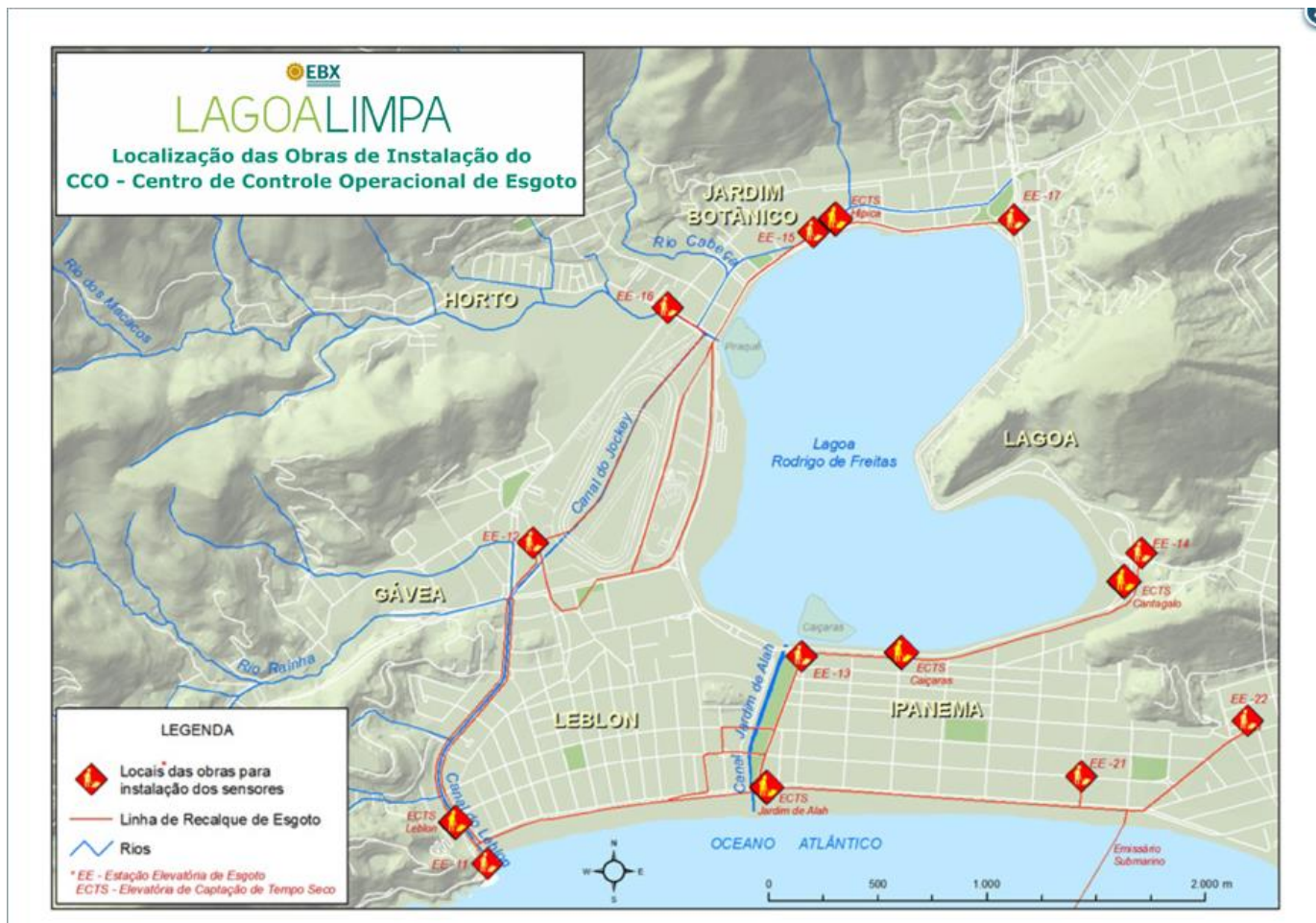

Mapa 13 - Sistema de Controle Operacional de Esgoto - Fonte LAGOA LIMPA

Nesse Portal encontramos também uma coleção de mapas temáticos sobre a região em estudo, oportunos para a verificação e comparação de dados e informações, tornando possível atestar a qualidade e a confiabilidade das fontes de informação utilizadas.

A seguir listamos esses mapas. 
1. Comparativo do limite do espelho da Lagoa pré-aterros e atual, como também a indicação do limite da Bacia Hidrográfica está representado no Mapa 14.

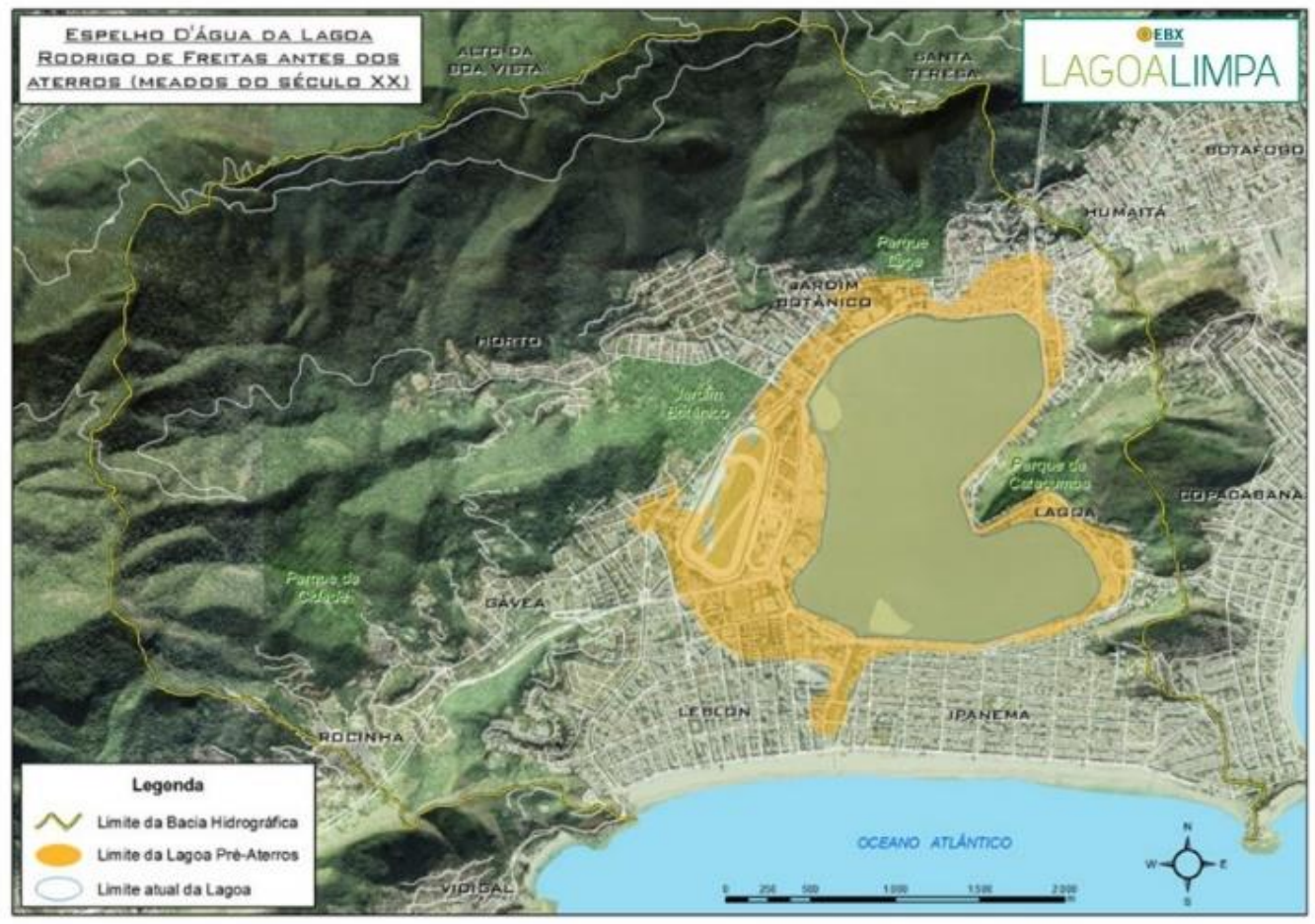

Mapa 14 - Espelho D’água da Lagoa - Fonte LAGOA LIMPA

2. Áreas de dragagem, cavas, rios e canais está representado no Mapa 15.

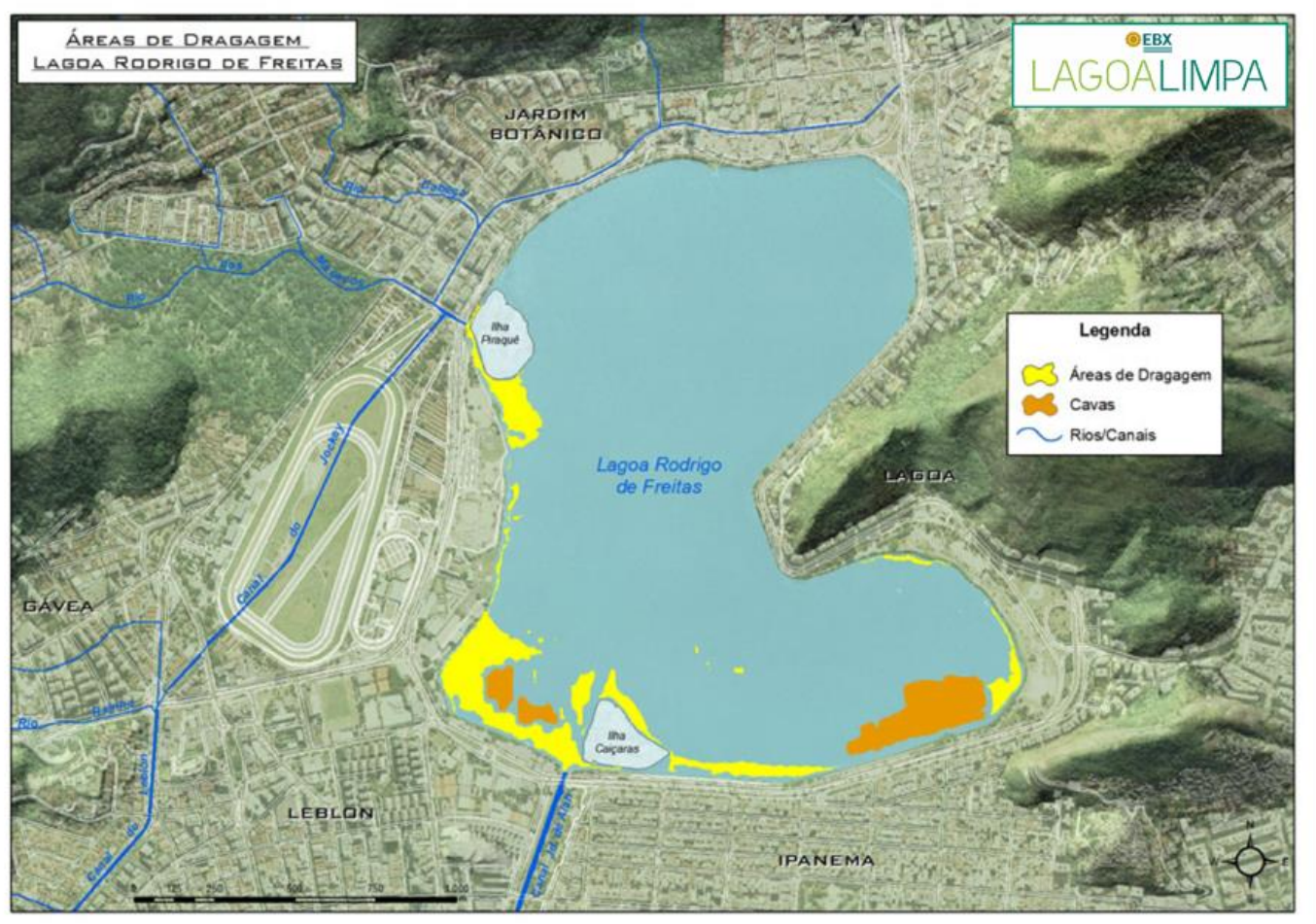

Mapa 15 - Áreas de Dragagem da Lagoa - Fonte LAGOA LIMPA 
3. Sistema Regionalizado de Esgotamento Sanitário da Bacia da Lagoa visualizado no Mapa 16.

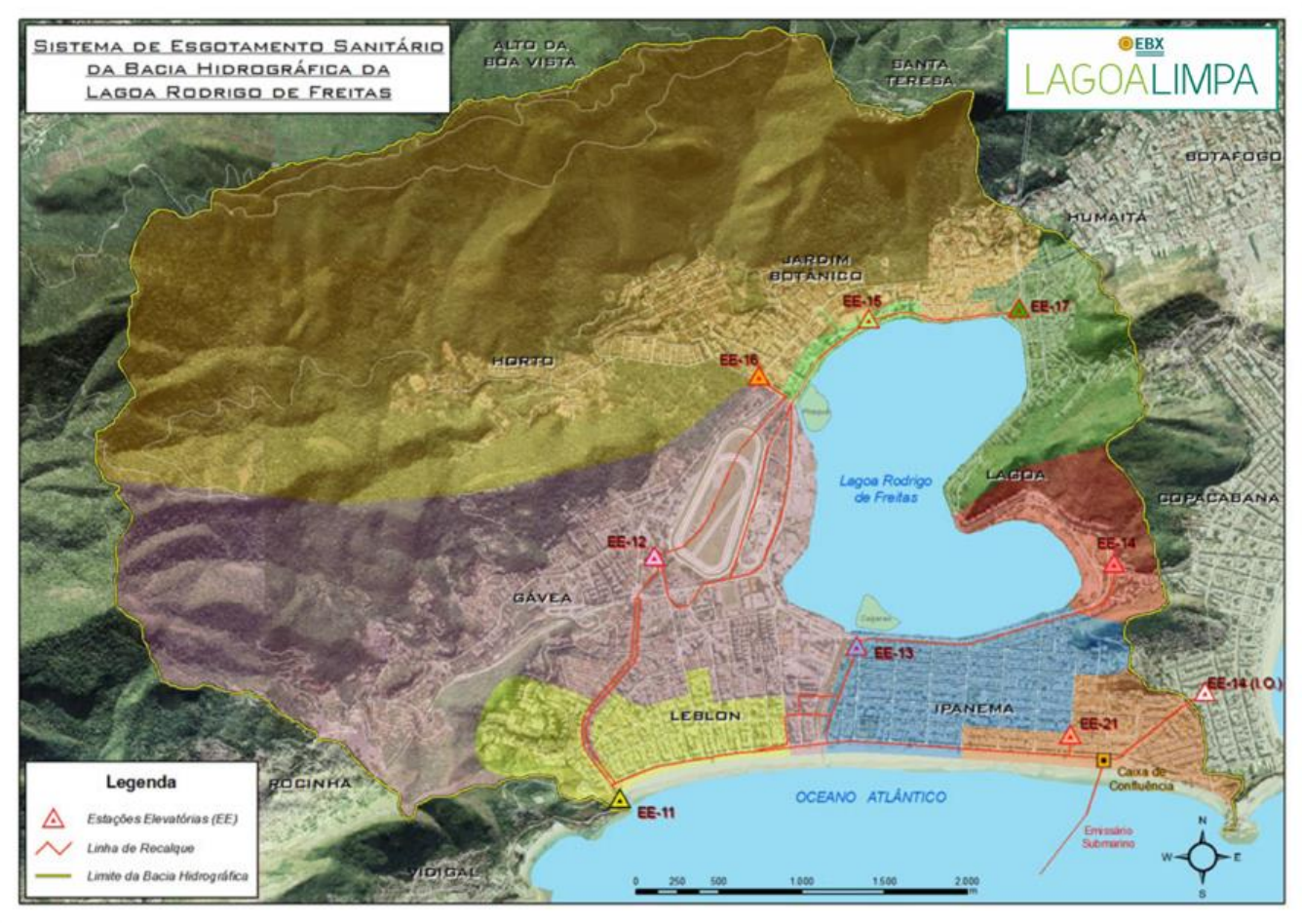

Mapa 16 - Sistema de Esgotamento Sanitário da Bacia da Lagoa - Fonte LAGOA LIMPA

4. Bacia e Sub-bacias Hidrográficas da Lagoa representadas e indicadas no Mapa 17.

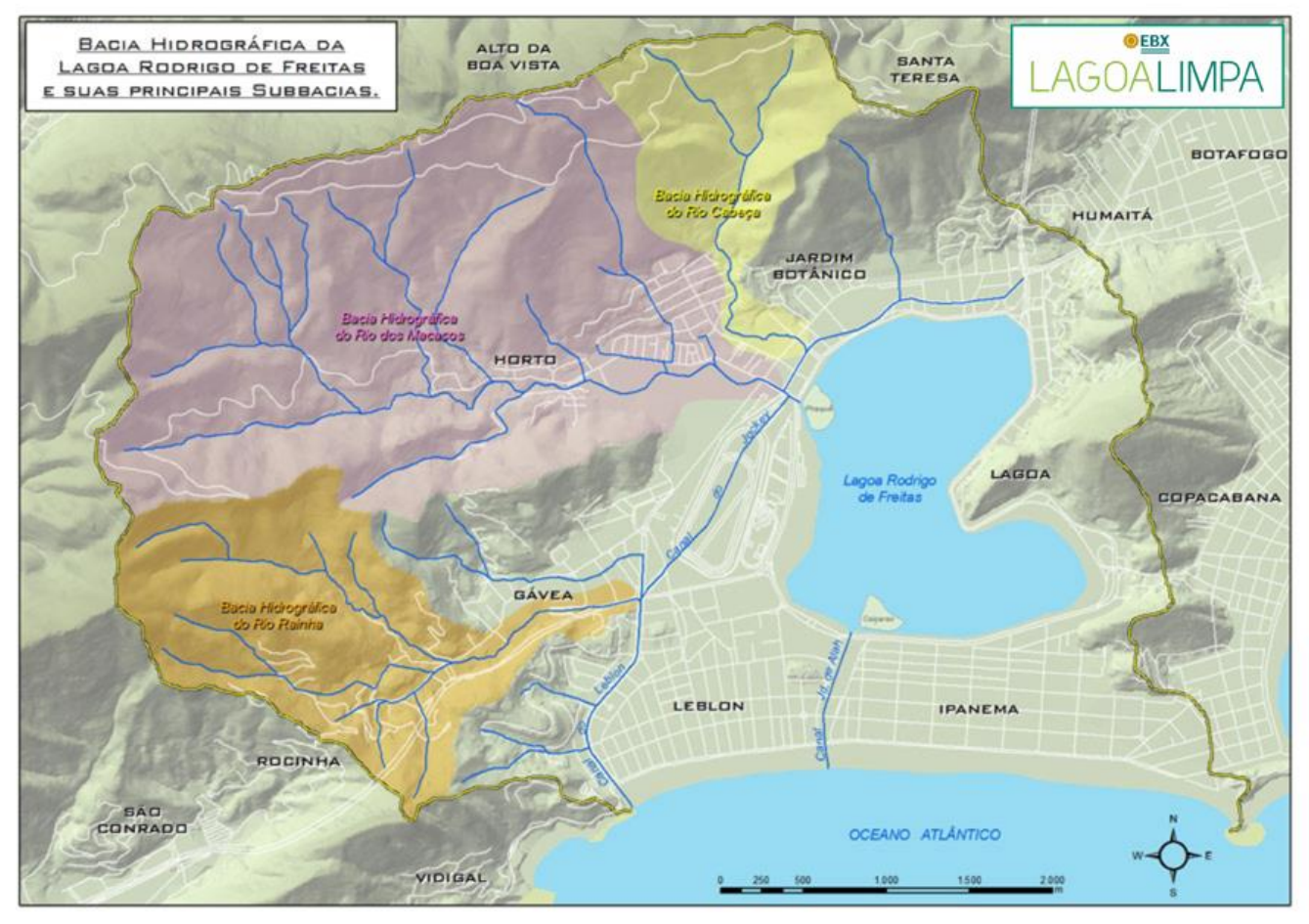

Mapa 17 - Bacia Hidrográfica da Lagoa - Fonte LAGOA LIMPA 
5. Batimetria com o Mapeamento do fundo da Lagoa agora visualizado no Mapa 18.

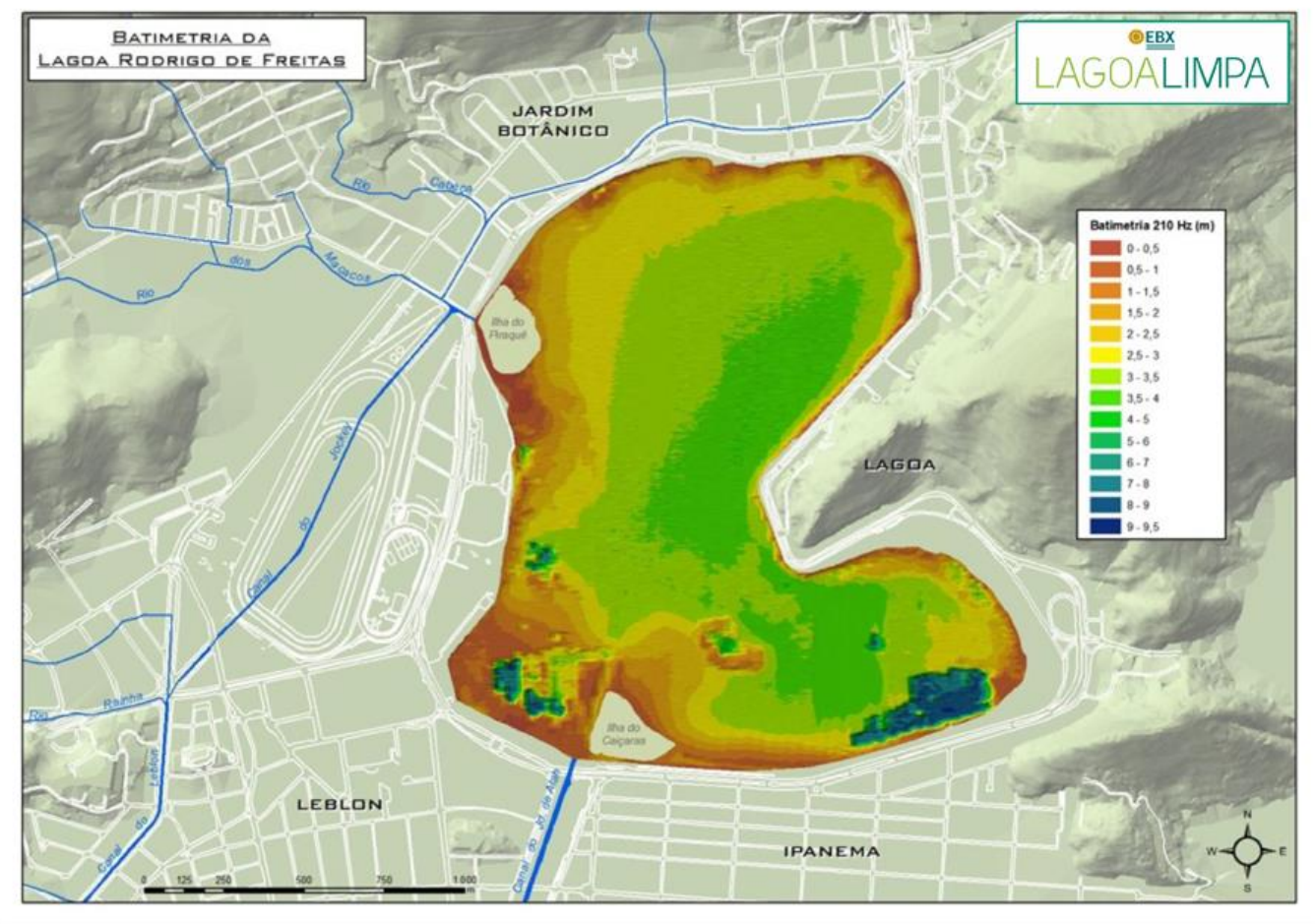

Mapa 18 - Batimetria da Lagoa - Fonte LAGOA LIMPA

6. Bairros da Bacia Hidrográfica da Lagoa visualizados no Mapa 19

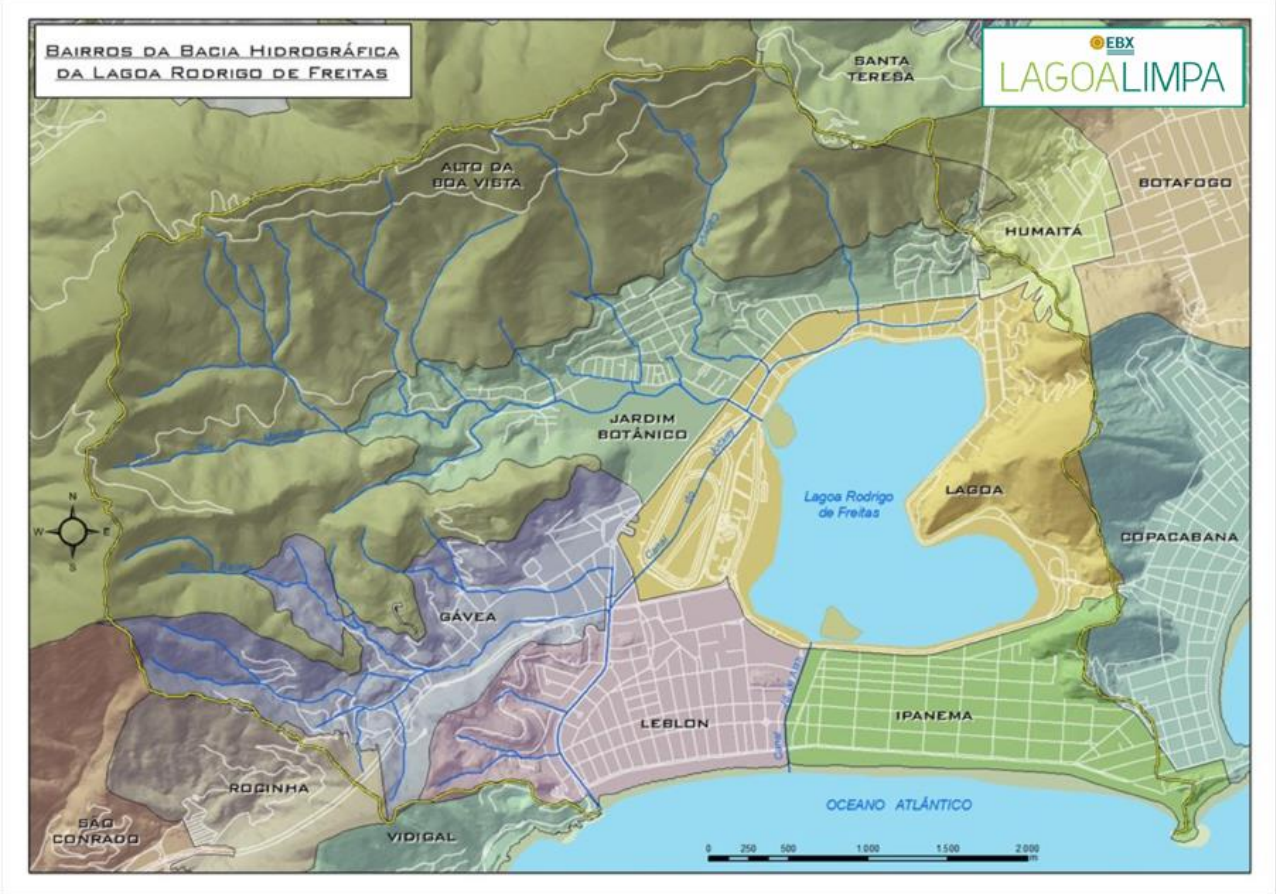

Mapa 19 - Bairros da Bacia da Lagoa - Fonte LAGOA LIMPA 


\subsection{1}

\section{Carta Náutica da Lagoa}

Nesta planta da Lagoa na escala 1/6.000 de abril de 2000, elaborada pelo CREA-RJ e outras entidades, denominada de "Carta Náutica da Lagoa Rodrigo de Freitas", conforme representado no Mapa 20, podemos observar o mapeamento topográfico do fundo da Lagoa, com a indicação de curvas de nível de profundidade e cotas - mapa de profundidade.

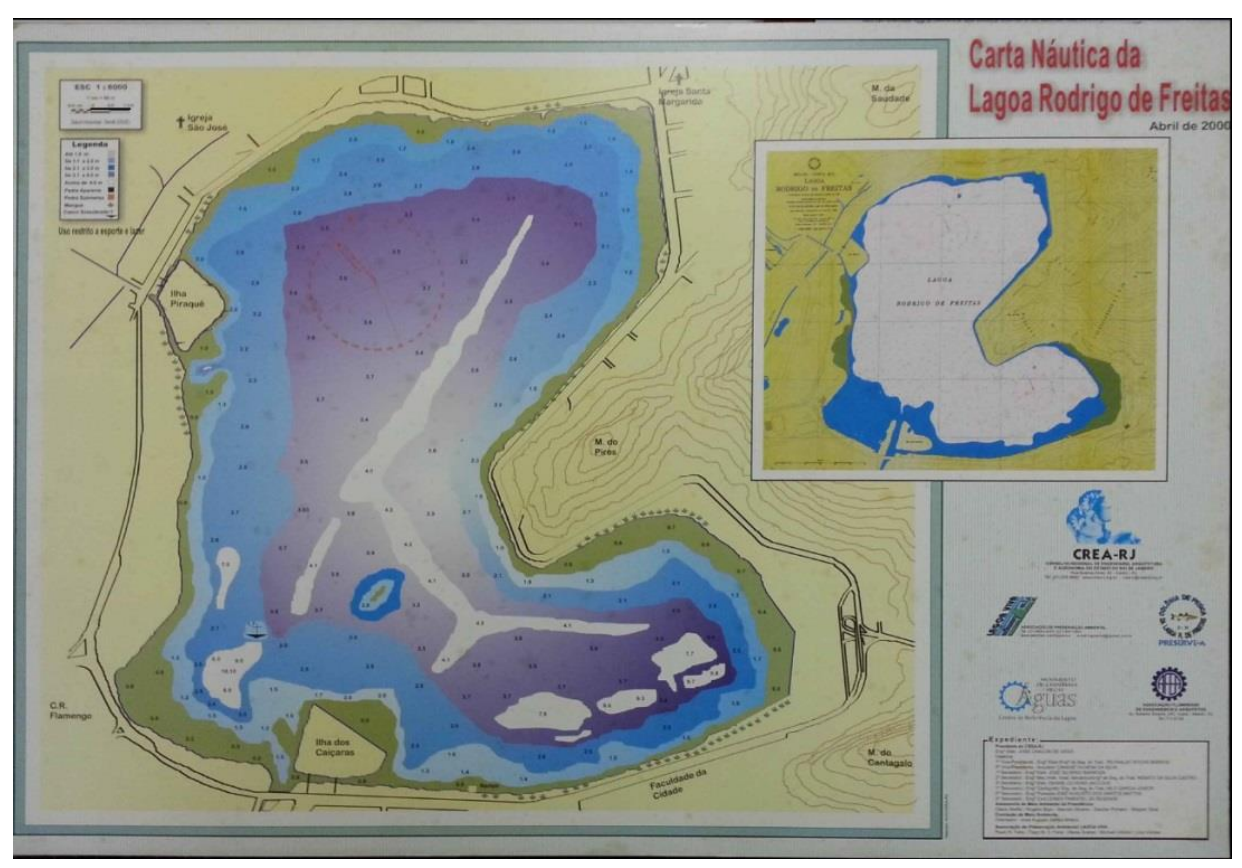

Mapa 20 - Carta Náutica da Lagoa da Lagoa Rodrigo de Freitas

A baixa energia hidrodinâmica da Lagoa, associada ao semi-confinamento de suas águas, acabou por resultar em uma estagnação dos seus estratos mais profundos com acúmulo de sedimentos (Fonseca e Neto - 2014).

Assim, a configuração da sua topografia de substrato é influenciada fortemente pelo depósito de poeira e acumulo de sedimentação por transporte de drenagem e dos corpos hídricos. O que torna a Lagoa fragilizada neste aspecto ficando passível de sucessivos assoreamentos, com consequente diminuição da espessura da sua lâmina d'água.

Isto explica em parte algumas diferenças que podem ser observadas entre os dois mapas pesquisados, que definem a Batimetria da Lagoa. Quando comparamos a Carta Náutica da Lagoa (2000), com a Batimetria indicada no mapa elaborado pelo projeto Lagoa Limpa (2014), podemos constatar diferenças de valores de profundidade em algumas regiões e de trechos de áreas fundas. 


\subsection{2}

\section{Urbanização, Adensamento e Expansão}

No Portal do IPP é possível obter também vários mapas sobre o assunto Legislação Urbana, de modo que pode-se a avaliar e detalhar o Planejamento e Projetos da região em estudo com grande exatidão. No Mapa 21 na escala 1/10.000 são delineados os limites das Regiões Administrativas, destaque VI-RA Lagoa.

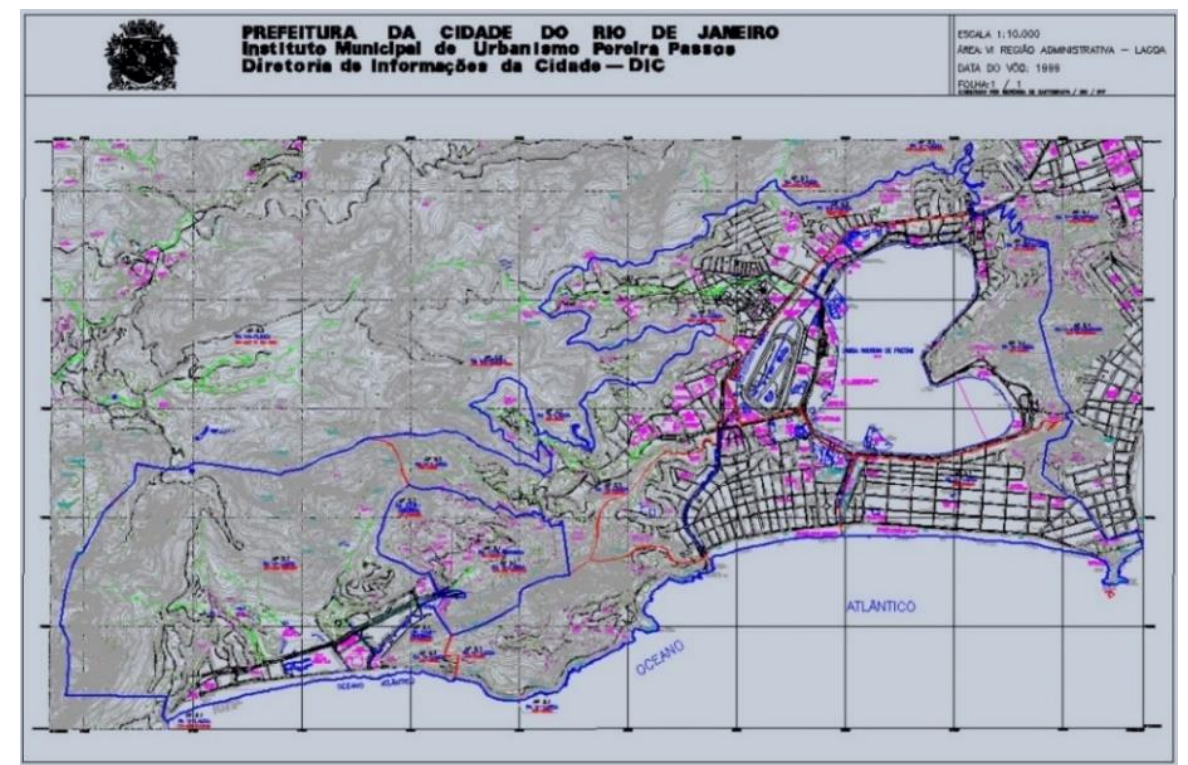

Mapa 21 - Planta Topográfica com a delimitação da VI-RA Lagoa

Já no Mapa 22 temos uma Planta Topográfica com a indicação das Área de Planejamento, e em específico a APA2, onde encontra-se a região da Lagoa.

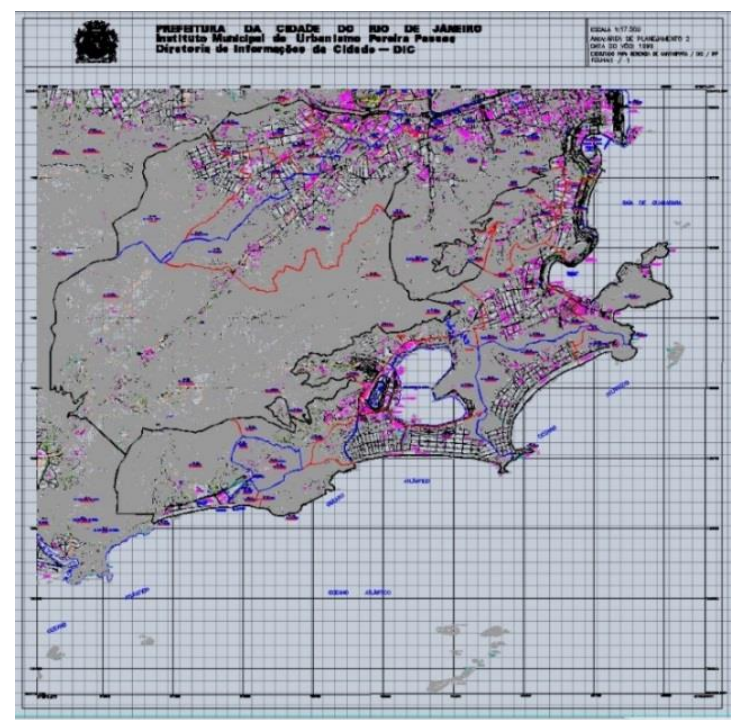

Mapa 22 - Planta Topográfica com a delimitação APA2 
Observando o Mapa 23 que se apresenta em outra convenção cartográfica (padrão de cores e símbolos), temos também os limites da APA1 e APA2.

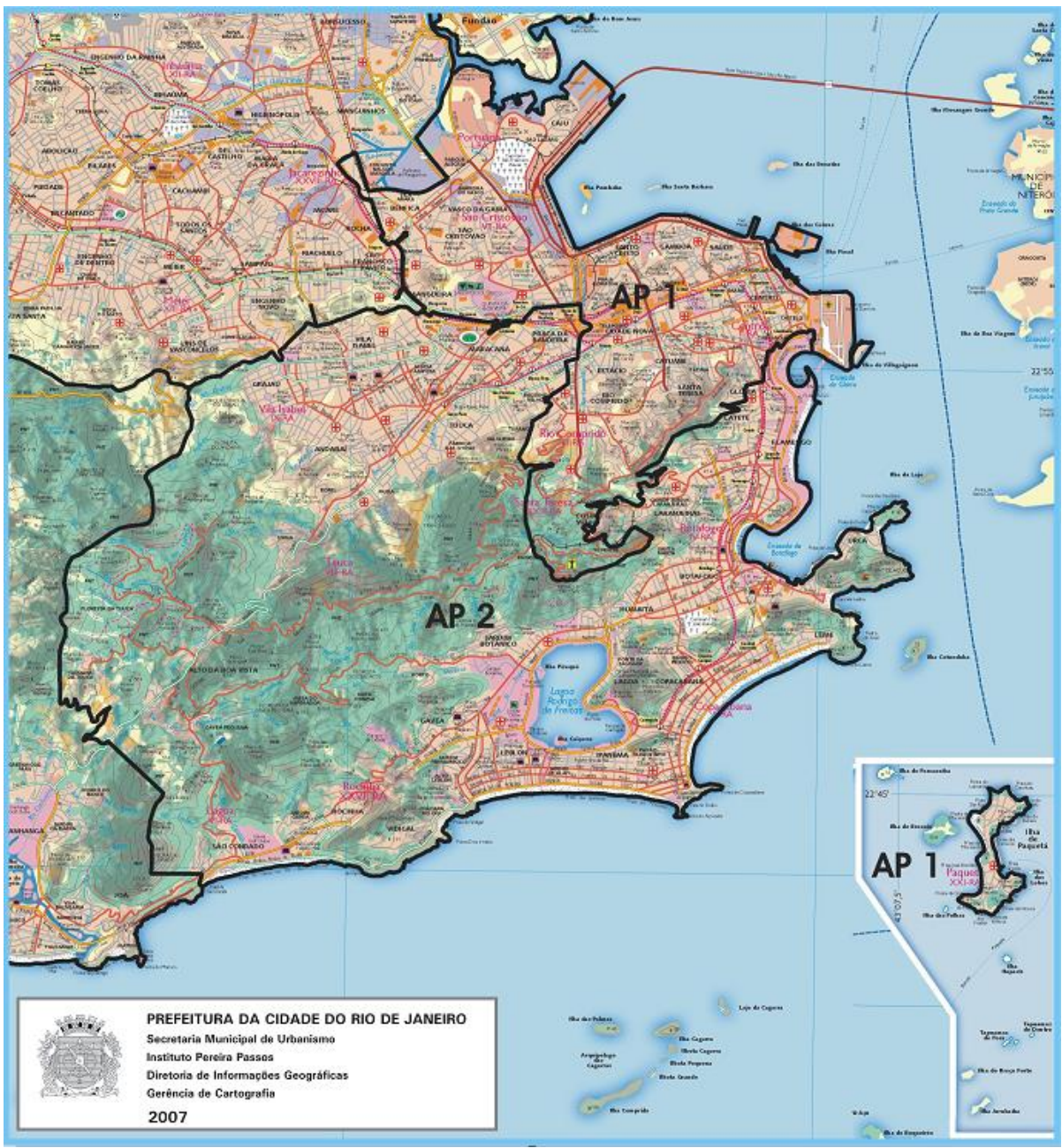

Mapa 23 - AP 1 e AP 2 - Fonte IPP

Em 2012 foi realizado um trabalho que consiste na vetorização das classificações de uso e cobertura do solo da Cidade do Rio de Janeiro, em conjunto com experiências acumuladas em trabalhos de campo e vistorias, denominado:

\section{"USO DO SOLO 2012 - CRITÉRIOS DE MAPEAMENTO"}

Nesse trabalho foram definidos critérios de Mapeamento a partir da interpretação das ortofotos na escala 1/10.000, do ano de 2012; Legenda com definição das ocupações predominantes; e definição de dois grupos de áreas: 
Urbanizadas e Não Urbanizadas, sendo cada grupo dividido em subgrupos, tudo conforme detalhamento constante no Anexo 06.

No Mapa 24 temos a delimitação das Regiões de Planejamento e Bairros publicado em 2014 pelo IPP.

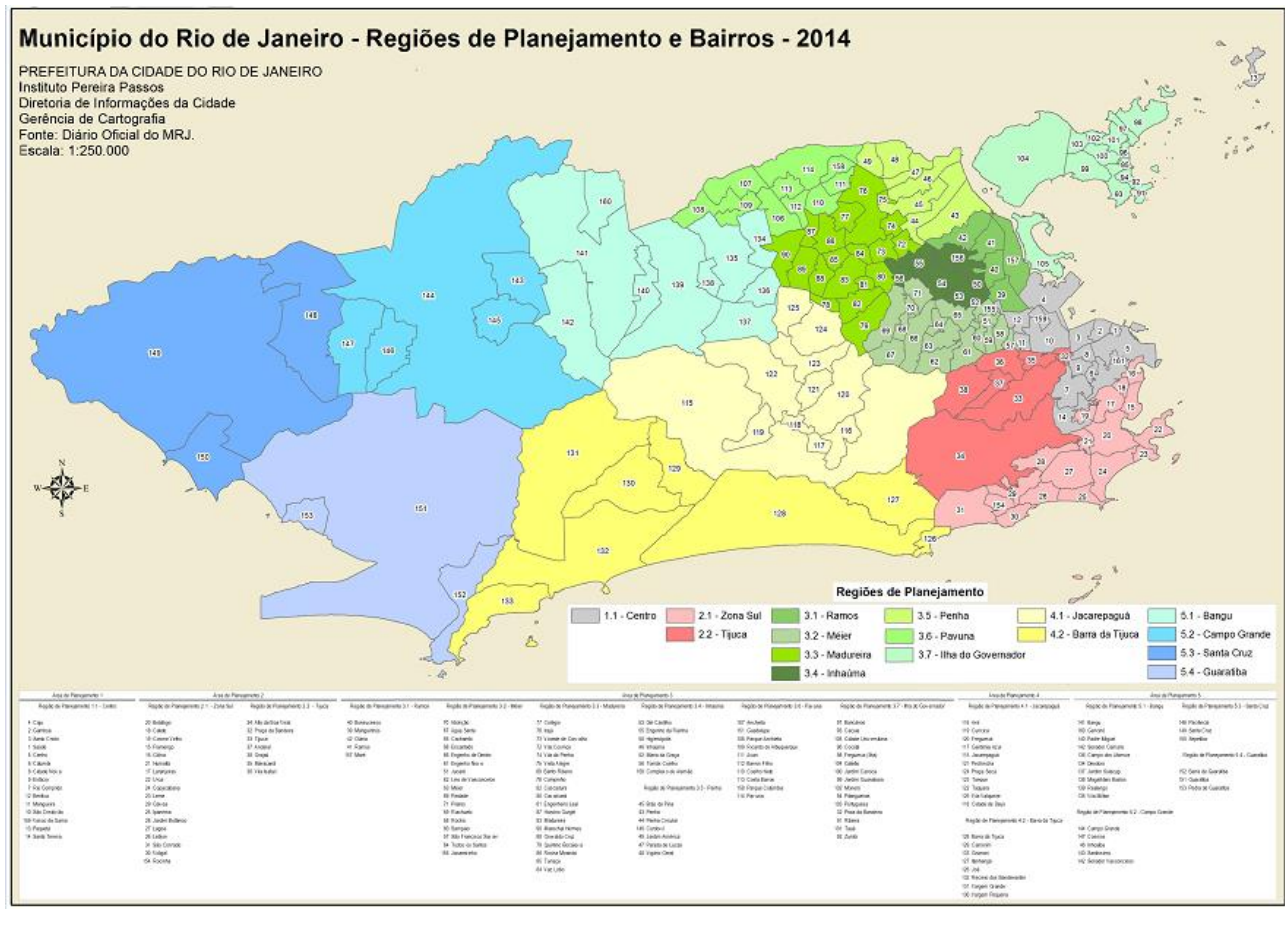

Mapa 24 - Região de Planejamento e Bairros - 2014 - Fonte IPP

E avançando com o detalhamento do Plano Diretor temos o Mapa 25, onde são indicados o Índice de Aproveitamento de Terreno (IAT) Máximo - Lei Complementar n. ${ }^{\circ} 111 / 2011$. 


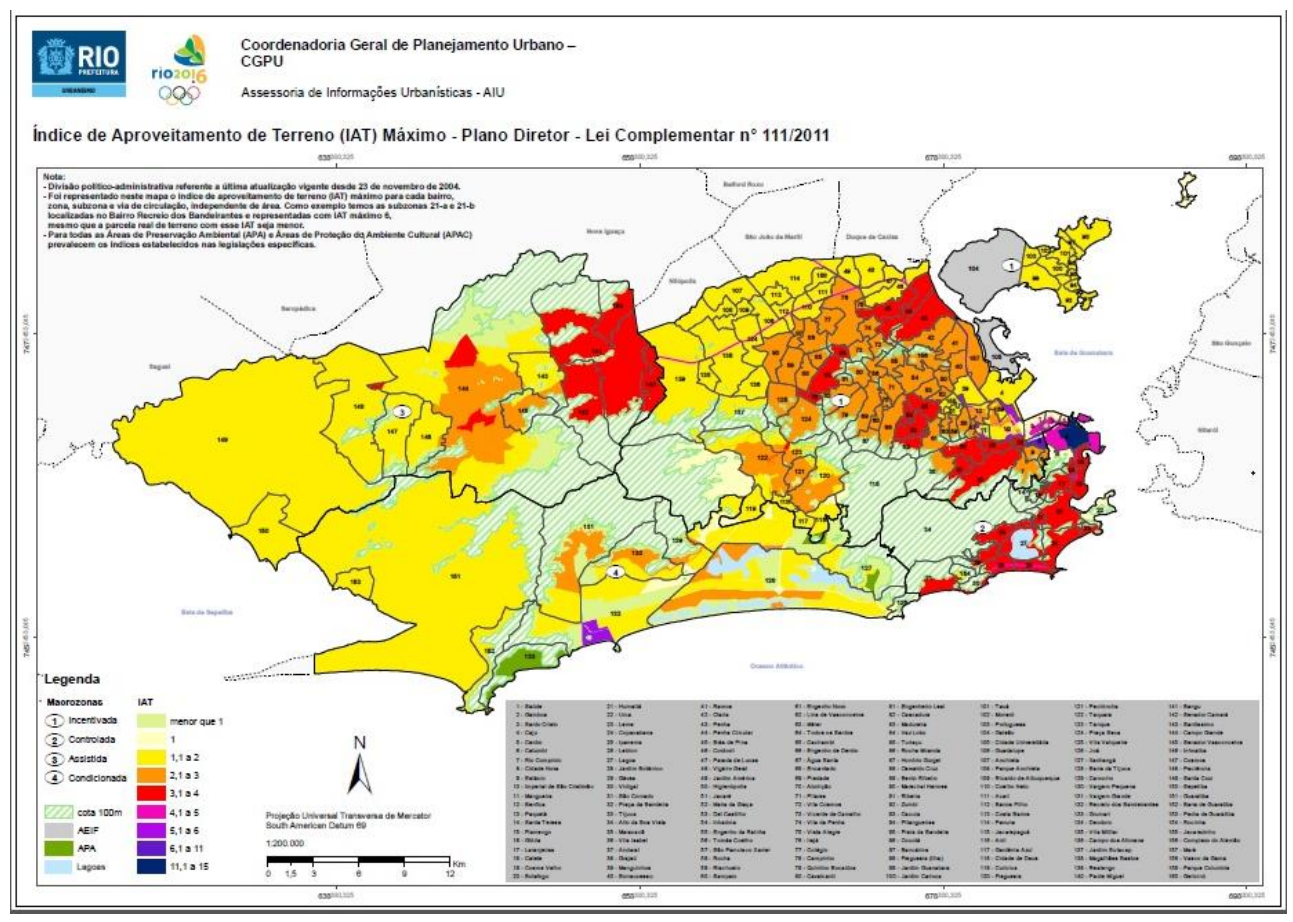

Mapa 25 - IAT Máximo - Plano Diretor - Fonte IPP

Através da consulta das Certidões de Informações (CI - Anexo 3), podemos identificar e obter Plantas Topográficas Cadastrais na escala 1/2.000, onde estão indicados todos os Projetos Aprovados de Alinhamento ou de Loteamento (PAA's e PAL's) do município, sendo possível assim, análise detalhada de todos os limites de logradouros, quadras e lotes para a região em estudo, o que acaba por esgotar o tema pelo alto grau de detalhamento alcançado.

No Mapa 26 podemos observar a região do Canal de Jardim de Alah em toda a sua extensão, com a indicação dos Projetos Aprovados na cor vermelha. 


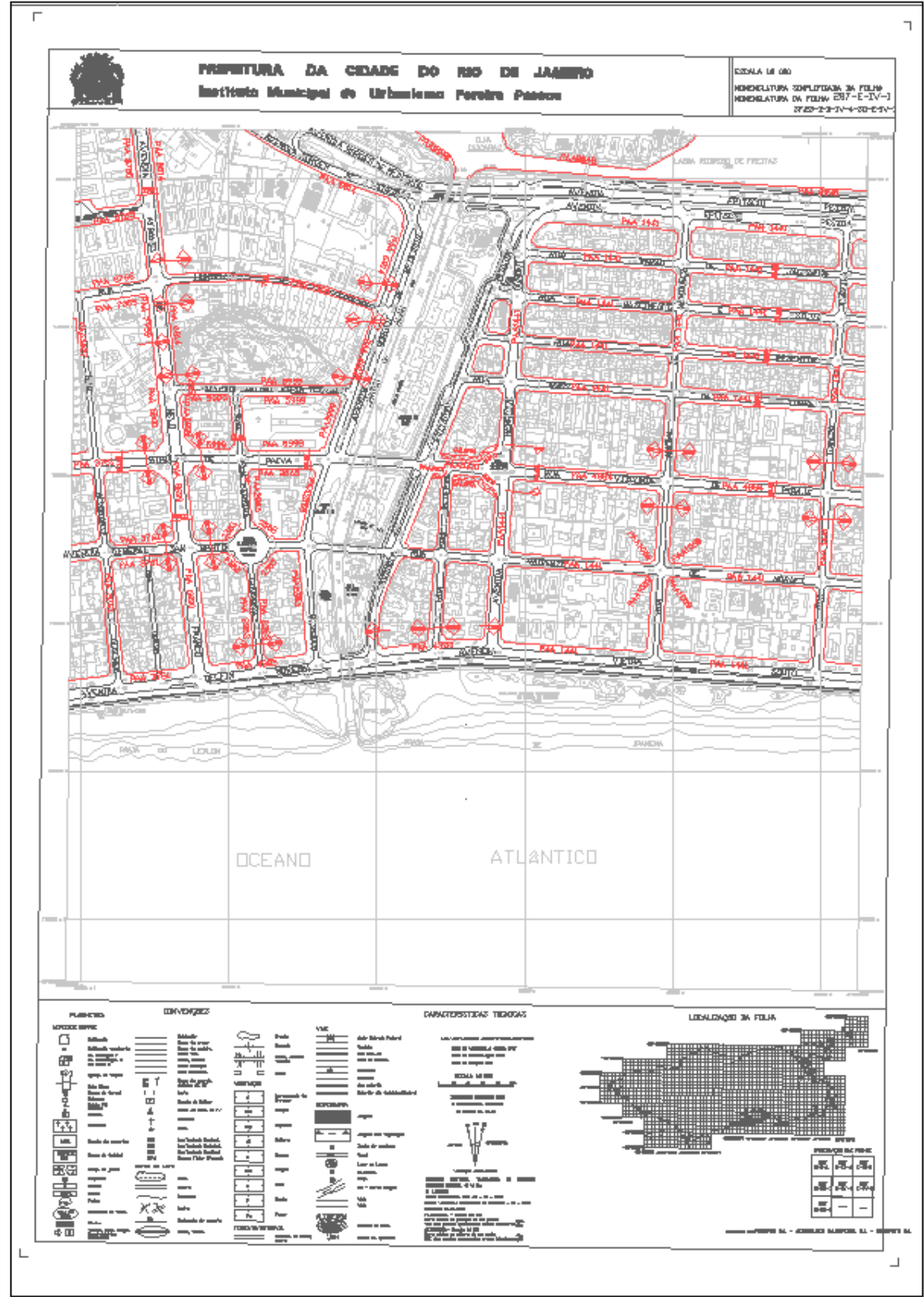

Mapa 26 - Planta Topográfica Cadastral - 287-E-IV-1 - Fonte IPP

Idem para o Mapa 27 e Mapa 28 e Figura 77, que retratam trechos ao longo da orla da Lagoa. 


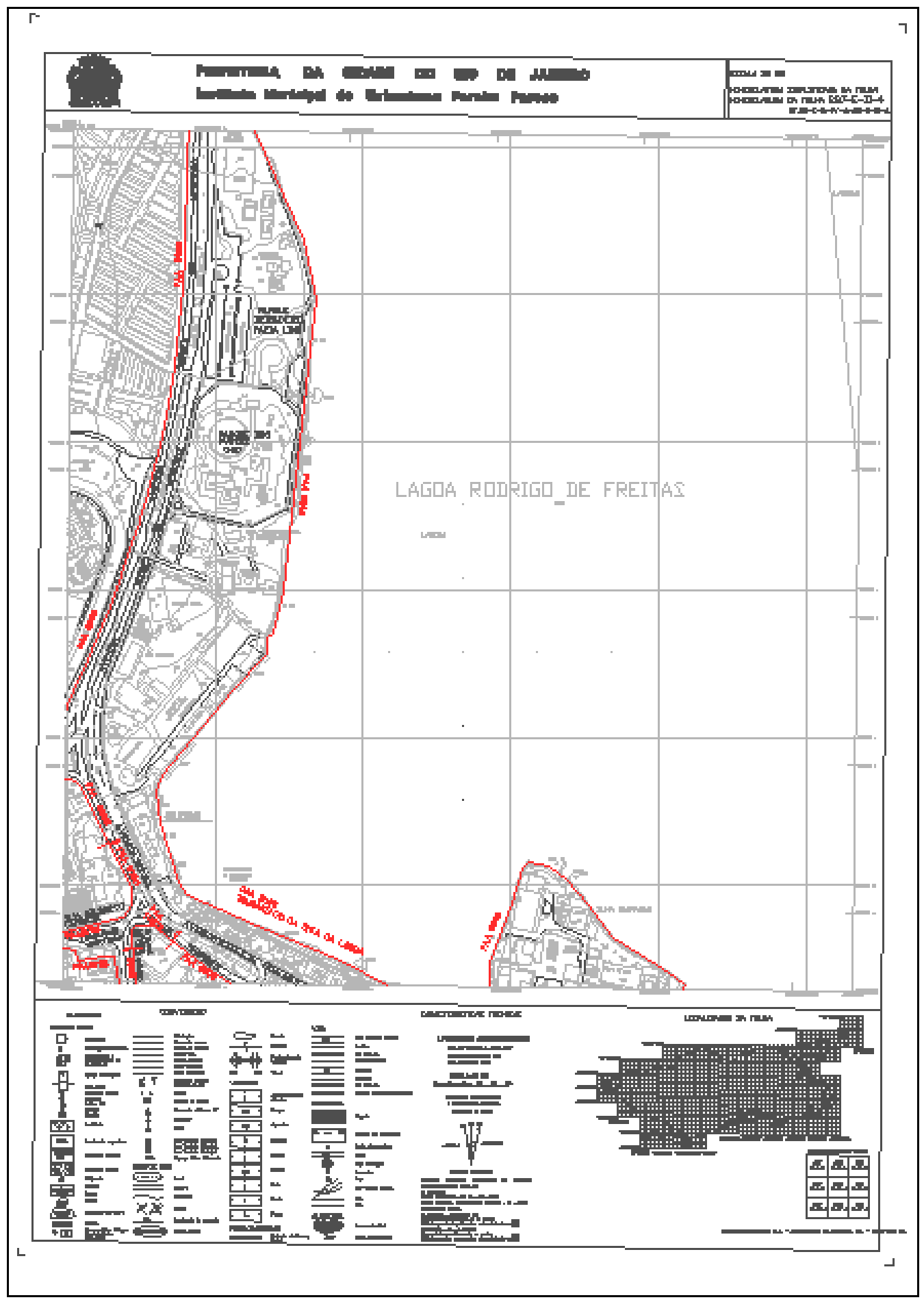

Mapa 27 - Planta Topográfica Cadastral - 287-E-II-4 - Fonte IPP 


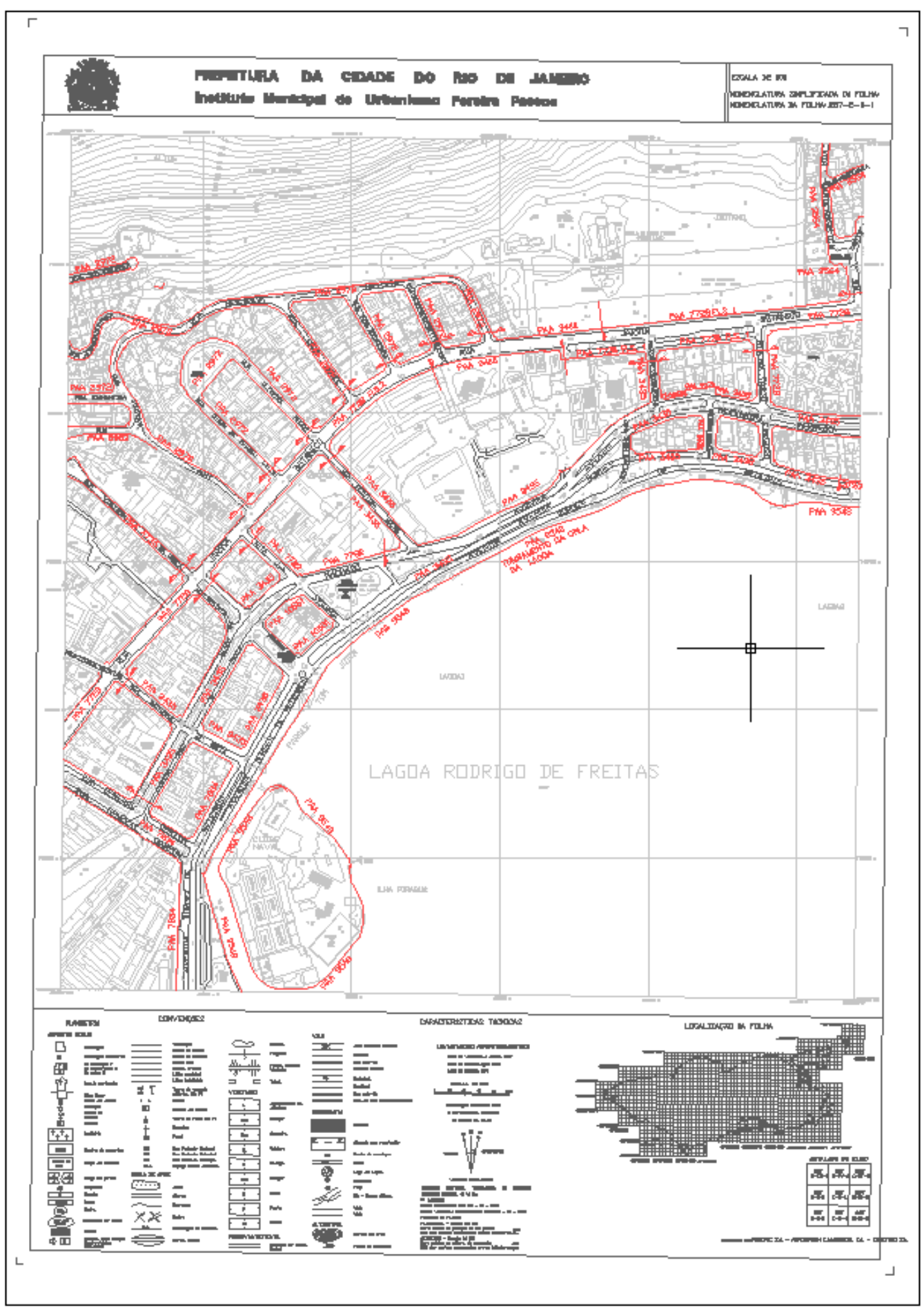

Mapa 28 - Planta Topográfica Cadastral - 287-E-II-1 - Fonte IPP 


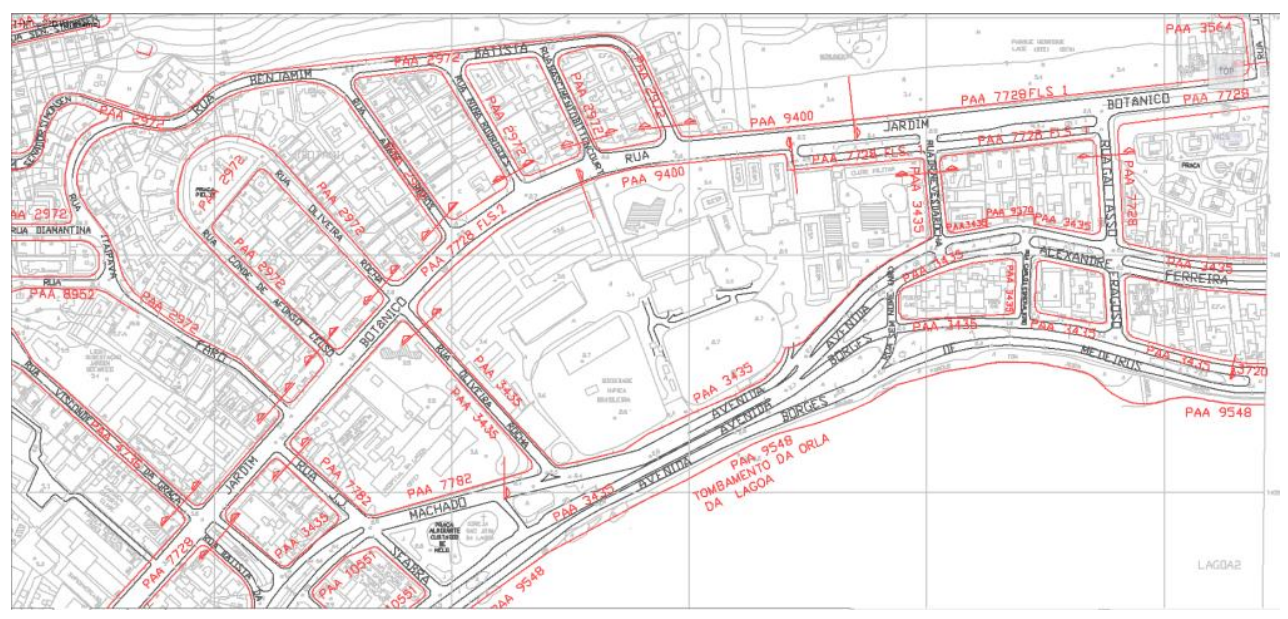

Figura 77 - Extrato da Planta Topográfica Cadastral - 287-E-II-1 - Fonte IPP

Nesta escala de observação - 1/2.000, o grau de detalhamento é elevado, mas em contra partida a quantidade de mapas envolvidos para cobrir toda a região da Lagoa também é muito grande, alcançando um total de 45 mapas.

\subsection{3}

\section{Estudos e Mapeamento com Ortofotografia}

A técnica básica de elaboração da grande maioria dos mapas do município do RJ é a Aerofotogrametria. Esta técnica se utiliza em lugar do levantamento topográfico clássico e se justifica para uma determinada faixa de escala da planta a ser elaborada e em função principalmente das extensões a serem representadas.

Embora implique em custos bem mais elevados, se justifica plenamente em grande escala de produção (áreas estaduais, municipais, grandes empreendimentos, etc.) e por suas características vantajosas de detalhamento do mapeamento, acaba por se caracterizar como ferramenta indispensável e fundamental nas questões ligadas ao uso do solo.

Segundo Brito, 2002, trata-se de ciência e tecnologia para obtenção de dados e informações confiáveis utilizando-se imagens adquiridas por sensores.

Assim, a elaboração de mapeamento sistemático territorial ganhou grande incremento face à abrangência e precisão dessa ferramenta.

No IPP - Armazém de Dados, item Mapa Digital do Rio de Janeiro, estão disponibilizadas Folhas Cartográficas e Foto Índice datado de 2004, relativas ao Levantamento Aerofotogramétrico do Município do Rio de Janeiro, possibilitando a escolha e seleção de determinada fotografia aérea e realizar o seu download. 
Nas Figuras 78 e 79 temos exemplos de aerofotografias obtidas diretamente do Aero-recobrimento, o que vem a possibilitar com uso de aplicativos específico, a elaboração de foto-montagens conforme a representada na Figura 80.

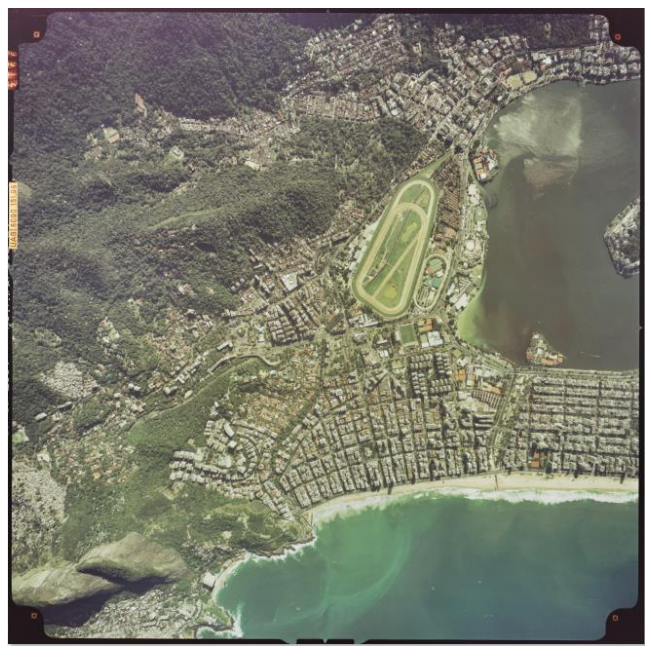

Figura 78 - Fotografia Aérea n.ำ 2166

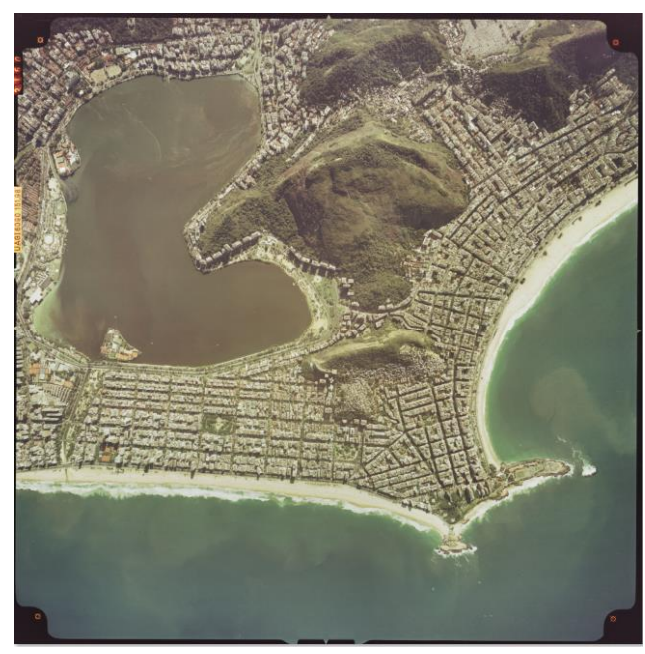

Figura 79 - Fotografia Aérea n. $\stackrel{0}{2160}$

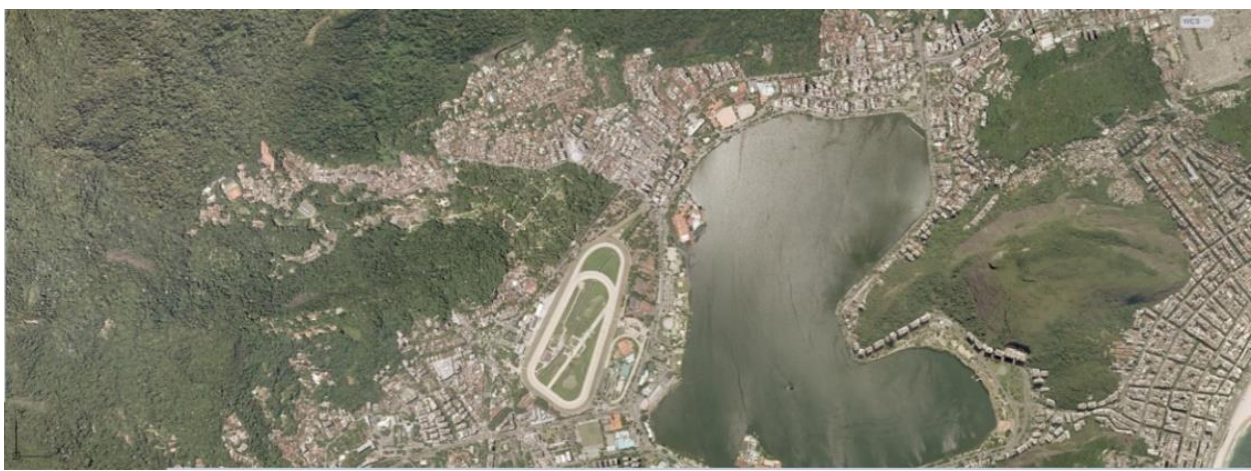

Figura 80 - Fotografia - Trecho do Mosaico da área em estudo da Lagoa

A qualidade das fotografias aéreas é hoje uma realidade, o que permite a elaboração de estudos e detalhamentos mais diversos nas questões de uso do solo, conforme visualizado nas Figuras 81 e 82.

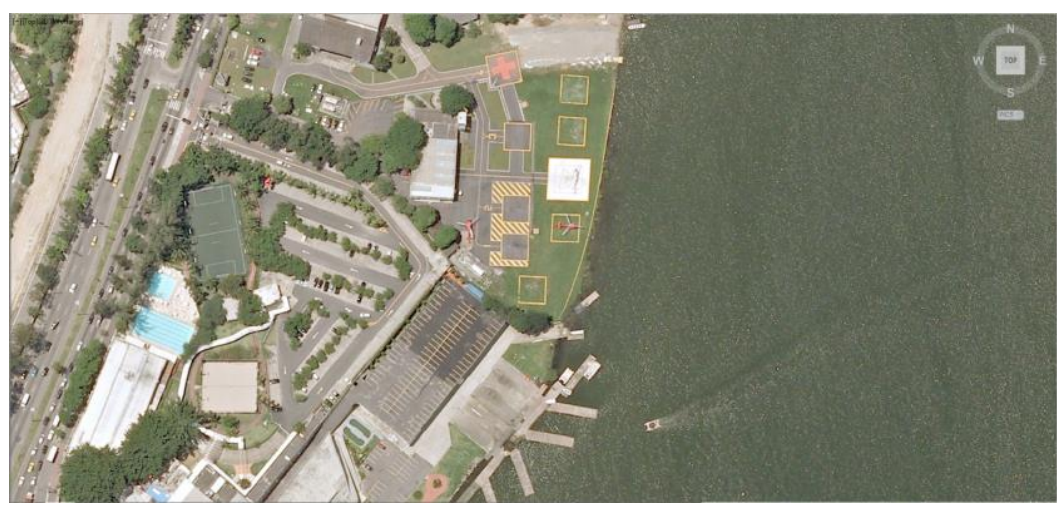

Figura 81 - Foto - Detalhe do Heliponto e Adjacências 


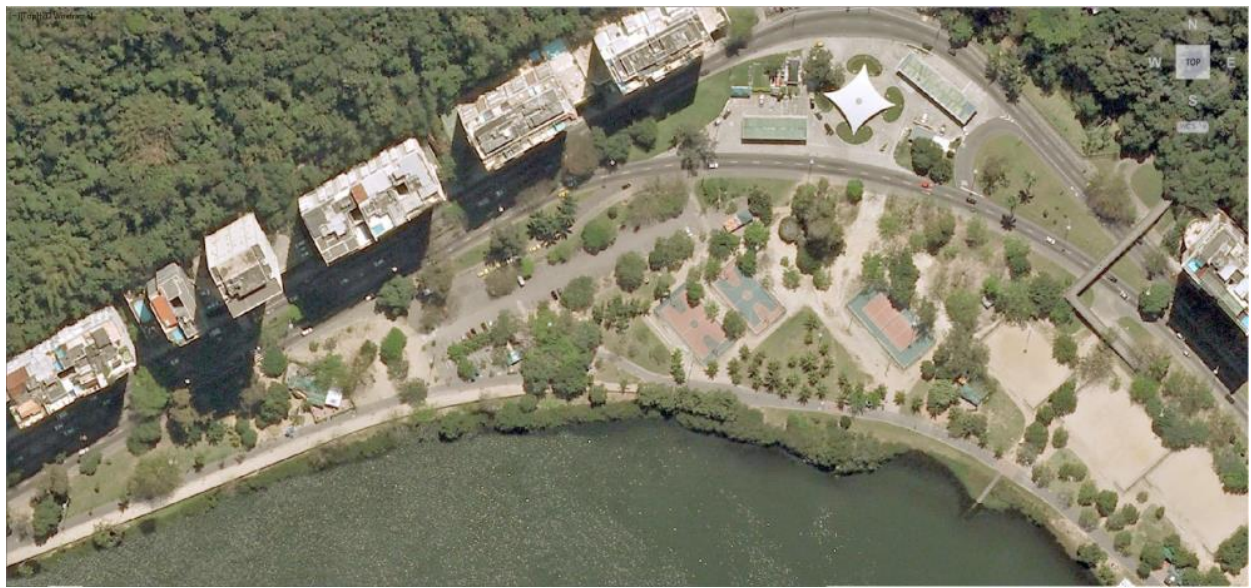

Figura 82 - Foto - Detalhe do Parque e Demais Ocupações no entorno

O Mapa 29 que é a Ortofotocarta Digital de um trecho da Floresta da Tijuca, vem exemplificar bem as técnicas utilizadas pela Aerofotogrametria, onde as fotos foram obtidas na escala 1/15.000 e o mapa elaborado na escala 1/10.000, obtendose assim, um alto grau de detalhamento e nitidez da imagem.

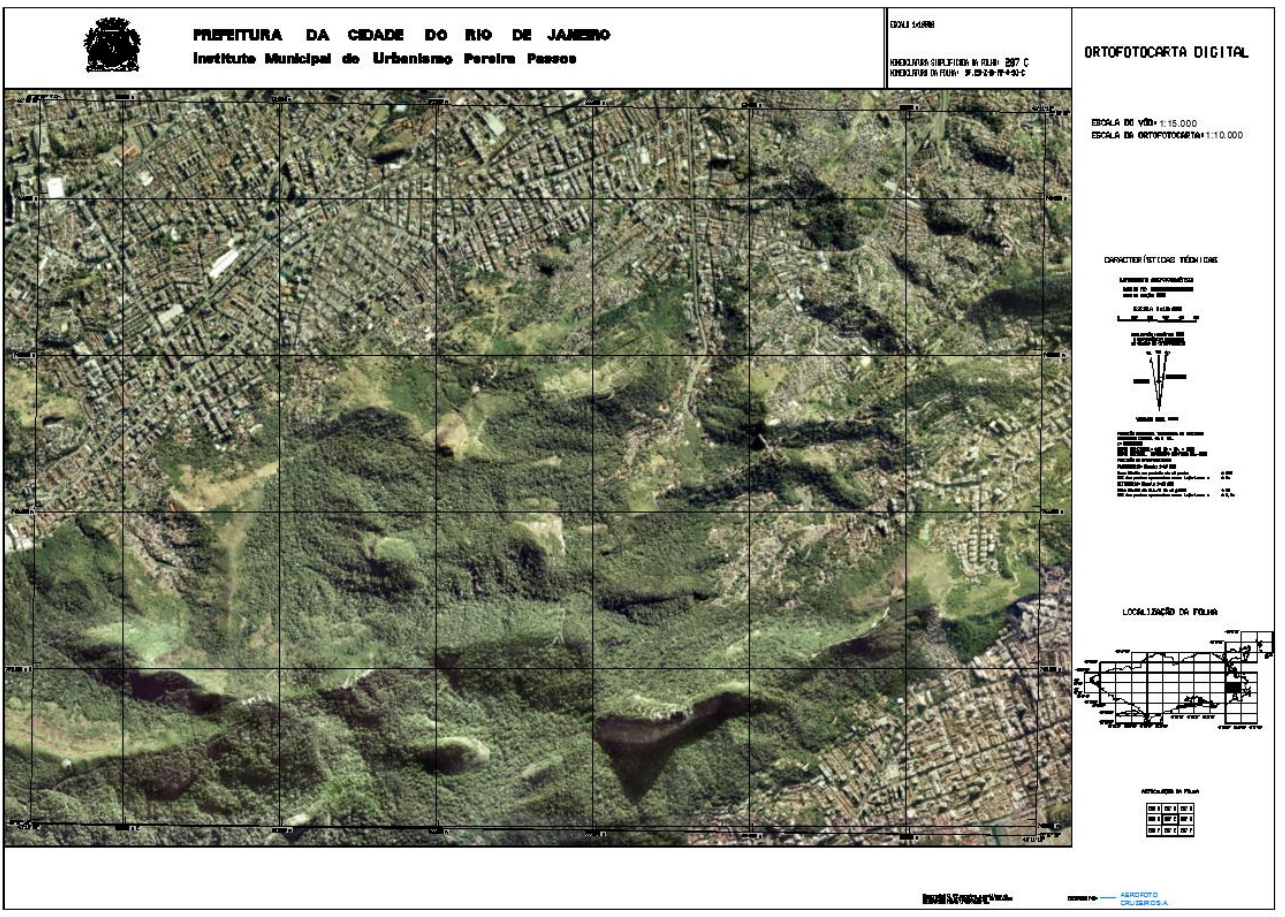

Mapa 29 - Ortofotocarta Digital - Fonte IPP

Esta qualidade pode ser observada e comprovada no extrato do mapa Ortocarta Digital demonstrando a qualidade da resolução das fotos na Figura 83. 


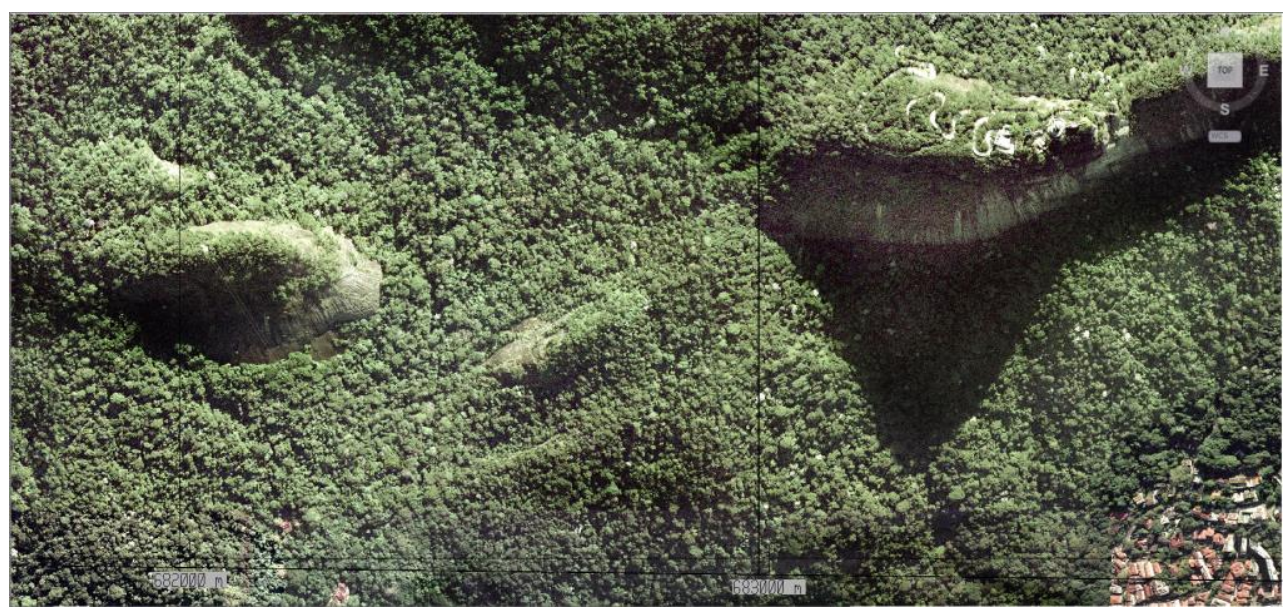

Figura 83 - Foto - Detalhe da Ortofotocarta Digital - Fonte IPP

No Portal do IBGE obtivemos o mapa Ortofotomosaico da Baía de Guanabara, na escala 1/25.000, com Mosaicagem em 2009, Cobertura Aérea e Apoio de Campo de 2004, visualizado no Mapa 30.

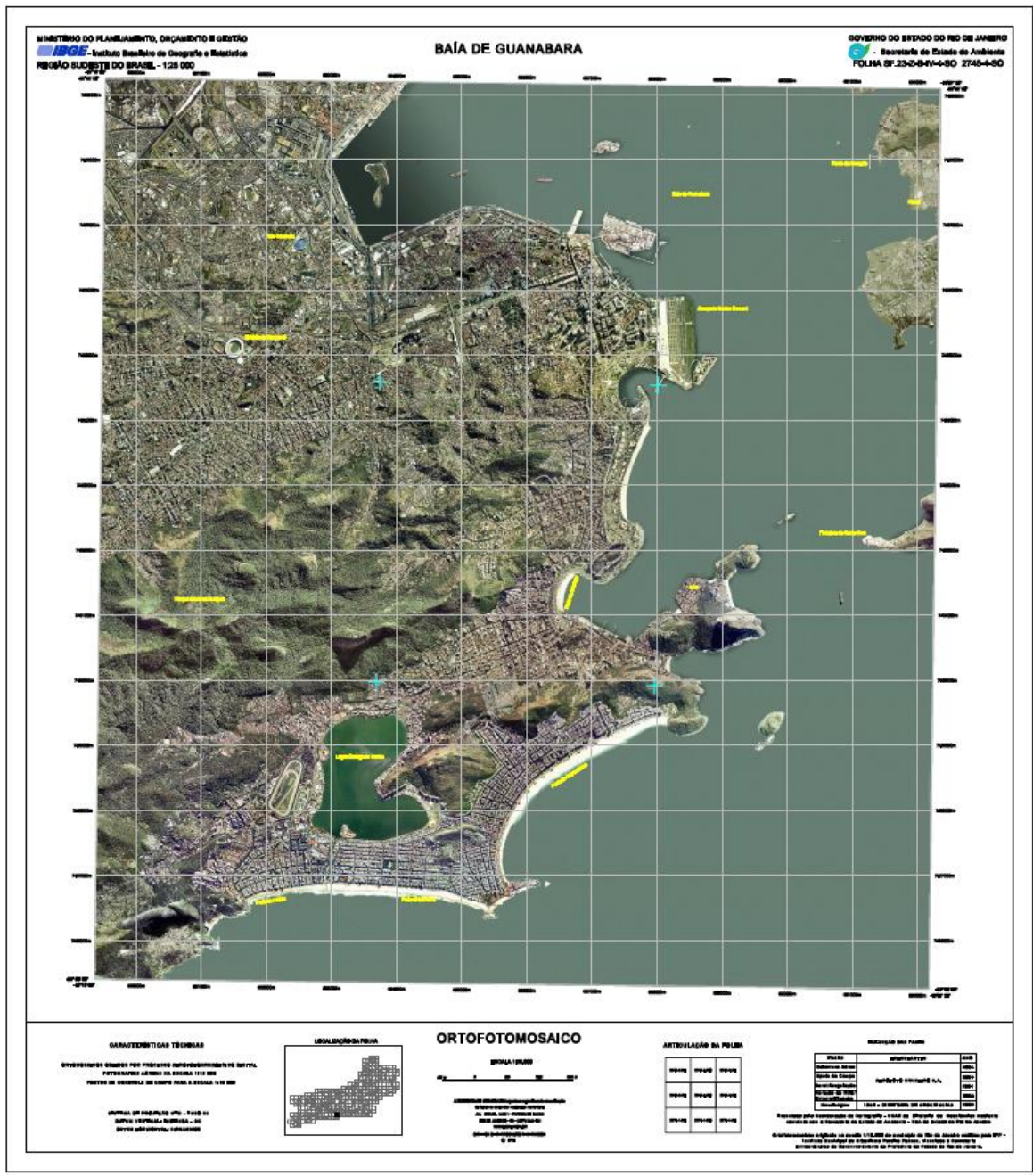

Mapa 30 - Mapa Ortofotomosaico da Baía de Guanabara - Fonte IBGE 
No detalhe ampliado observamos a região da Lagoa, Figura 84.

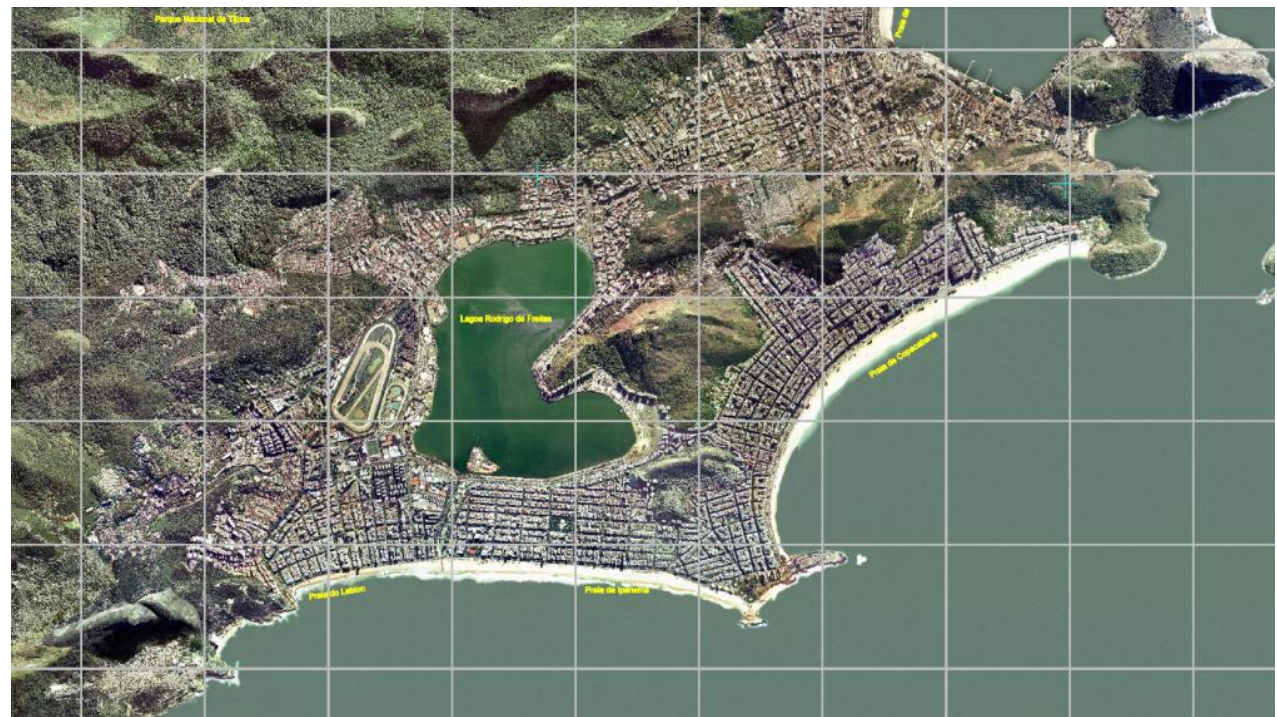

Figura 84 - Extrato do Mapa Ortofotomosaico detalhe da região da Lagoa - Fonte IBGE

Tradicionalmente o meio técnico utiliza-se com muita frequência, Plantas Topográficas elaboradas através de mapeamento por aerofotogrametria. As clássicas Plantas Cadastrais do Município sempre servem de referência e base para os estudos preliminares, planejamentos e até mesmo em alguns casos elaboração de Projetos Básicos. Para o caso da Lagoa a Folha 287E, na Escala 1/10.000, representada no Mapa 31, já permite a visualização de muitos parâmetros e condições da região.

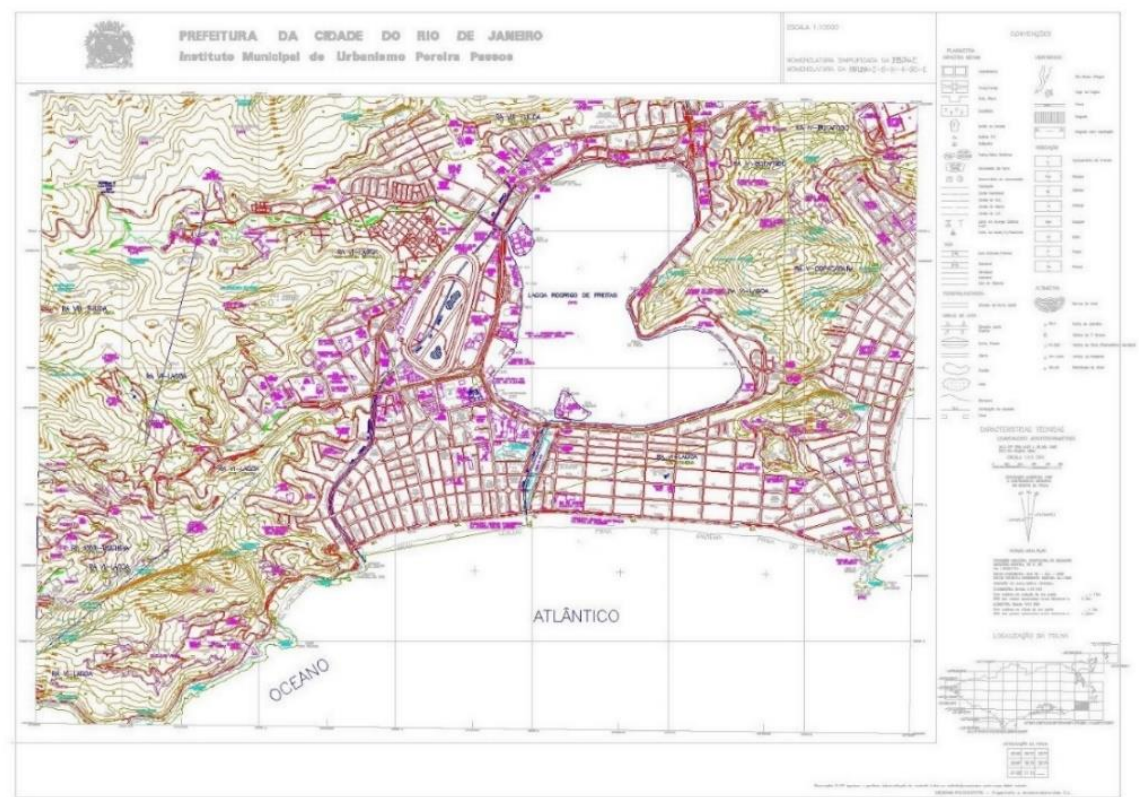

Mapa 31 - Planta Cadastral Aerofotogramétrica - Escala 1/10.000 
4

Desenvolvimento - Mapas Produzidos e Análises

Concluída a fase de pesquisa e conforme a Estruturação do Projeto de Estudo desta Dissertação (apresentado no item 3.2), passamos a tratar as informações e base de dados elaborando mapas, estudos e análises dentro das diversas disciplinas e condições envolvidas.

\section{1}

\section{Utilização e Aplicação dos Recursos de CAD/SIG}

A utilização do sistema CAD - AutoCAD em conjunto com o sistema SIG ArcGIS, forma uma dinâmica necessária e fundamentalmente importante, considerando as características técnicas (formato e linguagem) dos dados pesquisados e obtidos.

Deste modo, foram elaborados mapas temáticos e específicos, essência e conteúdo básico nos diversos estudos, análises e abordagens realizadas.

\section{2}

Relevo

Para uma primeira visualização da região da Lagoa, elaboramos o Mapa E03 - Planta da Lagoa Rodrigo de Freitas, ilustrado abaixo, utilizando fotografia aérea extraída do aplicativo Google Earth e inserido no aplicativo AutoCAD. Após a inserção utilizamos técnicas gráficas de ajuste de escala e georreferenciamento. 


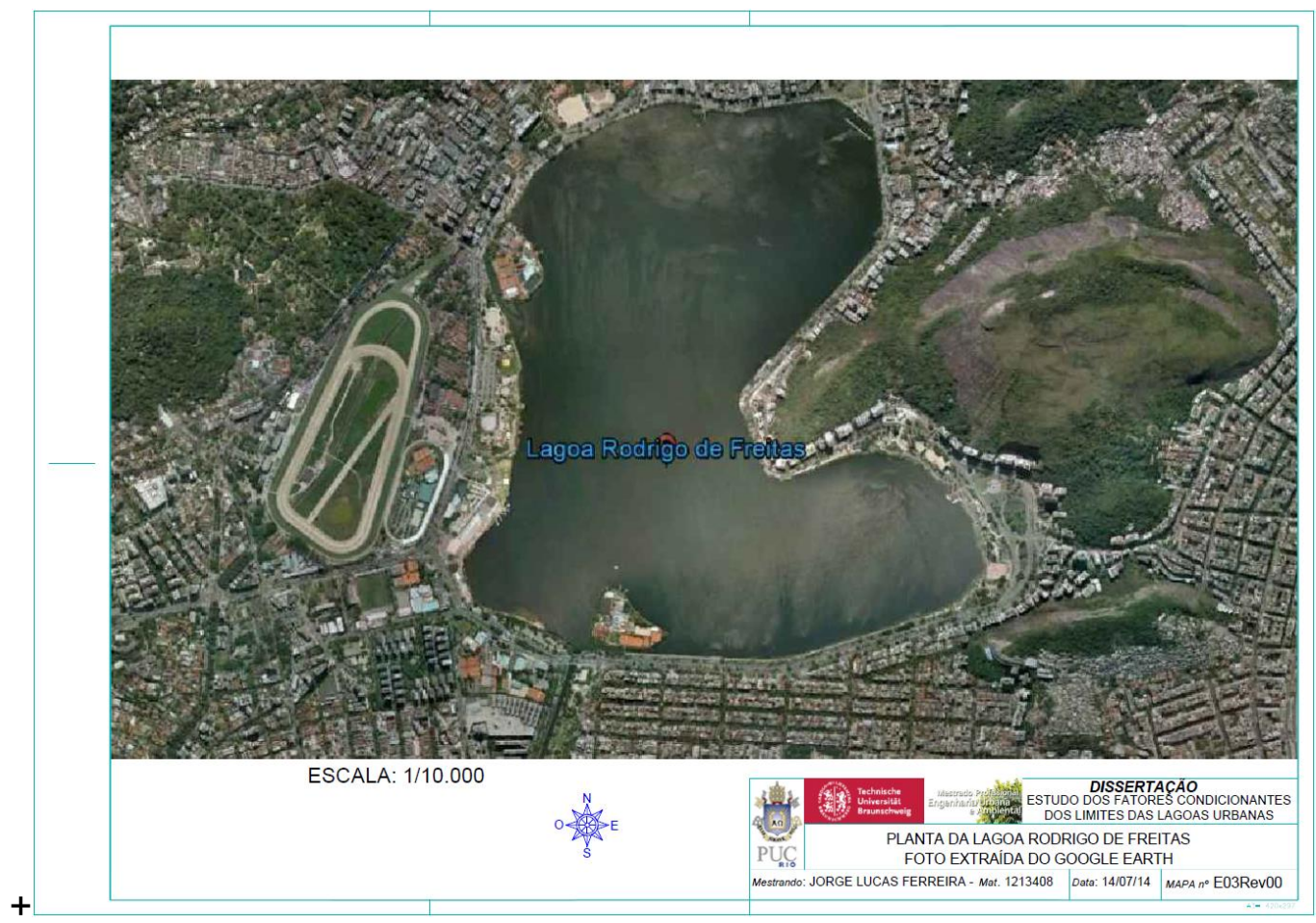

Mapa E03 - Planta da Lagoa Rodrigo de Freitas - Extraída do Google Earth - Escala 1/10.000

As formas básicas de ocorrência do relevo são as elevações e depressões, que conjugadas a outros fatores diversificam a sua formação e apresentação.

A ocorrência e formação de um Lago ou Lagoa em termos de relevo, parte basicamente da existência de uma grande depressão na superfície topográfica em uma determinada região, associada as características do solo (Geotecnia), afluência de águas periódicas ou permanentes (Hidrologia), condições climáticas, de vegetação (Fauna-Flora), etc.

Nas plantas topográficas a representação gráfica pelo processo das curvas de nível e demais convenções, permitem a representação e leitura do relevo, sendo de grande utilidade e basicamente essencial para o estudo e desenvolvimentos das demais disciplinas envolvidas.

Um mapeamento topográfico sistemático bem elaborado e detalhado, vem a ser o primeiro projeto a ser obtido e/ou elaborado, e que servirá de referencial aos demais estudos específicos e temáticos. 
Na figura 85 observamos em extrato de planta topográfica da região da Lagoa e adjacências, obtido da base de dados do ArcGIS (ESRI).

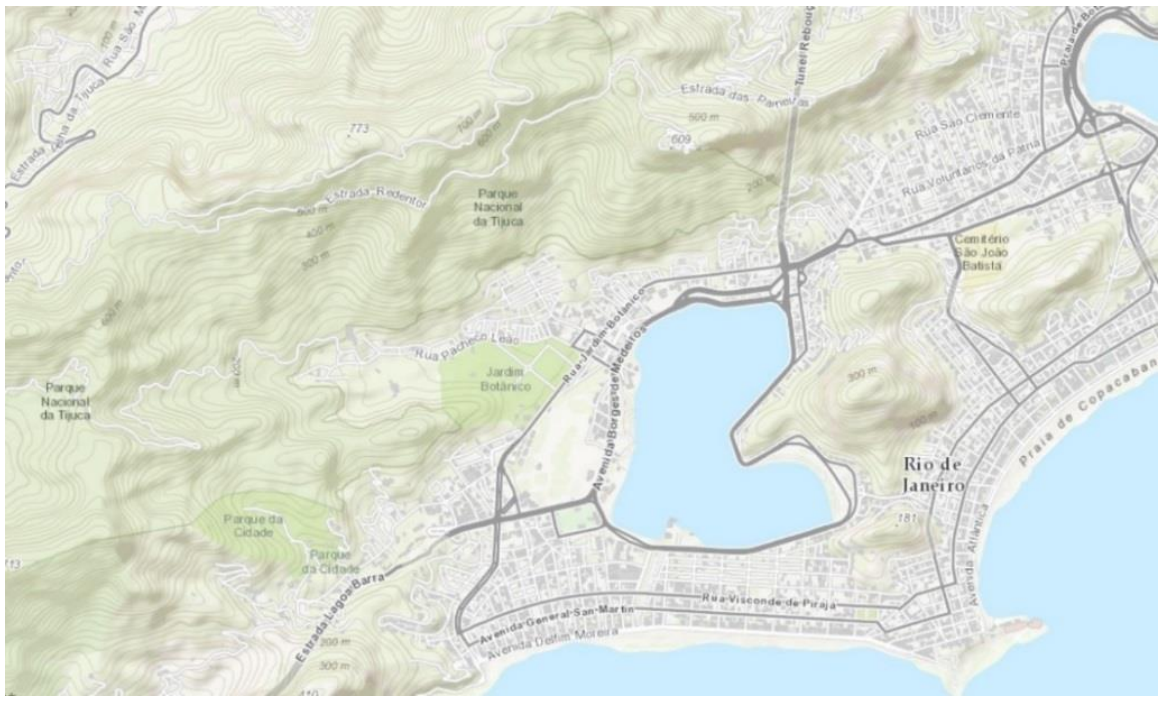

Figura 85 - Extrato de Planta Topográfica no ArcGIS

Uma base bem detalhada e sólida e que foi obtida junto à Prefeitura Municipal do Rio de Janeiro (Base de Dados do IPP), constituída das Plantas Topográficas Cadastrais na escala 1/2.000, elaboradas como vimos a partir de técnicas de aerofotogrametria, cuja escala permite um grau elevado de detalhamento.

Estas plantas são disponibilizadas por regiões inicialmente definidas pelos bairros, e sua localização e configuração são dispostas numa planta mosaico, onde observam-se as partes que no conjunto cobrem todo o município do RJ, conforme Figura 86.

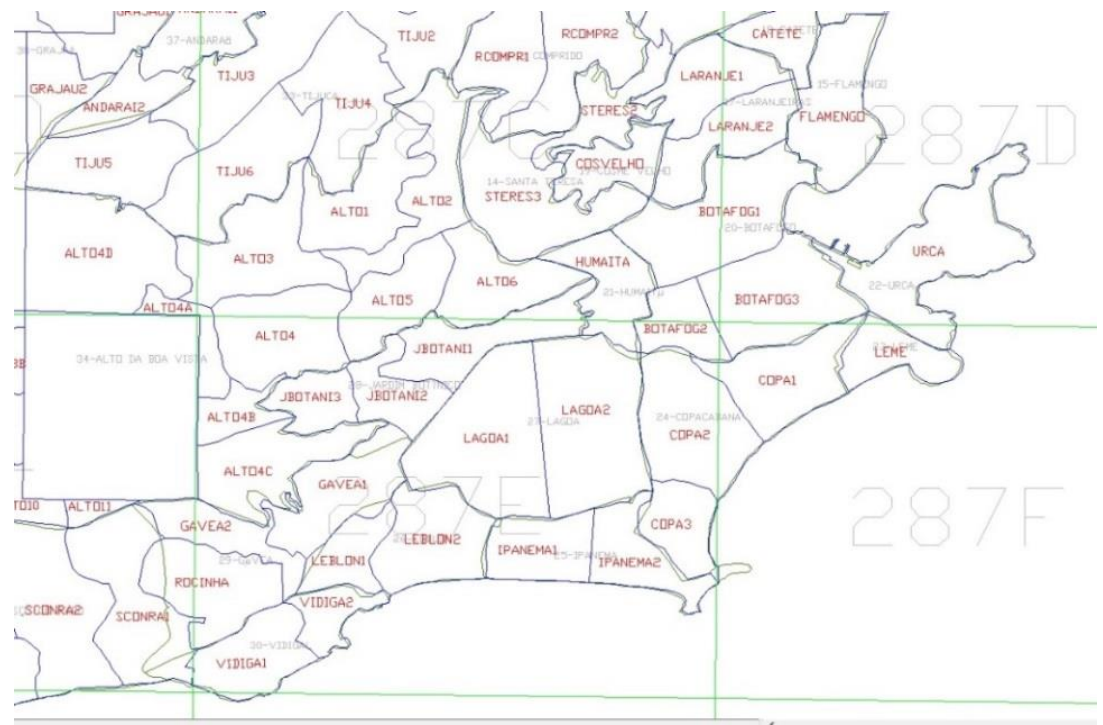

Figura 86 - Extrato do Mosaico da Planta Cadastral da Base de Dados do IPP 
Desse conjunto de plantas, objetivando alcançar a abrangência da região de interferência com a Lago Rodrigo de Freitas, listamos os arquivos necessário, os quais foram baixados do Portal para a base de dados, conforme abaixo:

Alto1, AltO2, ALTO3, ALTO3B, ALtO3C, ALTO4, ALTO4A, ALTO4B, ALTO4C, ALTO4D, ALTO5, ALTO6, ALTO7, ALTO7A, ALTO8, ALTO9, ALTO10, e ALTO11 (18 arquivos);

BOTAFOG2 (1 arquivo);

COPA2 e COPA3 (2 arquivos);

GAVEA1 E GAVEA2 (2 arquivos);

HUMAITA (1 arquivo);

IPANEMA1 e IPANEMA2 (2 arquivos);

JBOTAN1, JBOTANI2, e JBOTANI3 (3 arquivos);

LAGOA1 e LAGOA2 (2 arquivos);

LEBLON1 e LEBLON2 (2 arquivos);

ROCINHA (1 arquivo);

SCONRA1 (2 arquivos);

STERES3 (1 arquivo);

VIDIGA1 e VIDIGA2 (2 arquivos).

Total: 38 (trinta e oito) arquivos

A montagem desses arquivos disponibilizados pela Prefeitura no formato *.dxf, foi realizada utilizando-se o aplicativo AutoCAD.

Esse formato (*.dxf) é básico e comum a todo e qualquer sistema CAD, e caracteriza-se como um arquivo de padrão universal, utilizado para intercâmbio de modelos e arquivos de CAD. Do inglês DXF - Drawing Exchange Format.

O procedimento de inserção e grupamento desses arquivos num único ambiente, foi facilitada considerando-se que cada um deles está georreferenciado, o que permitiu os respectivos enquadramentos exatos nas suas coordenadas topográficas.

A abrangência desejada acabou por gerar um arquivo bastante extenso e pesado para processamento em equipamentos padrão, o que acaba por acarretar uma certa lentidão em sua manipulação. 
Isto se deve ao fato de que os arquivos usados em sua composição, foram elaborados com detalhamento compatível com a escala 1/2000, cuja precisão é bem adequada a serviços de detalhamento, mas acabam por resultar em arquivos muito grandes.

O resultado obtido pode ser observado na Figura 87, onde alcançamos a totalidade de inserções necessárias.

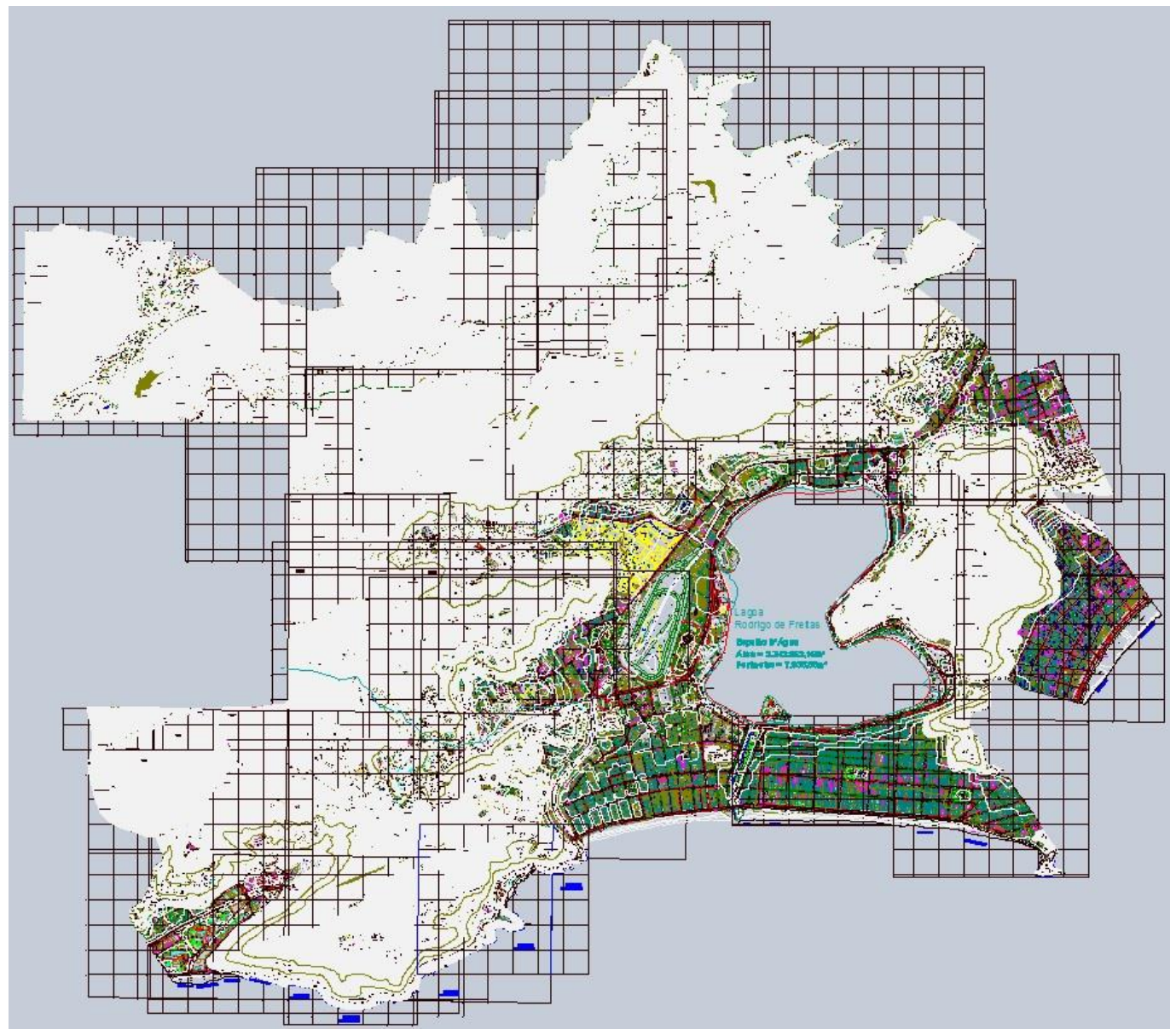

Figura 87 - Planta Topográfica Cadastral - Aerofotogramétrica - Escala 1/2000 - IPP-RJ

Neste mapa foram feitos então estudos, desenhos e cálculos gráficos sobre o Espelho D'água e PAO da Lagoa, e os resultados obtidos podem ser comparados com aqueles obtidos por outras fontes de informação e escala, a título de observarmos a precisão e confiabilidade de cada um deles.

A partir desse arquivo básico elaboramos o Mapa E04 representado abaixo, destinado ao estudo do Relevo na Planta Cadastral do Município. 


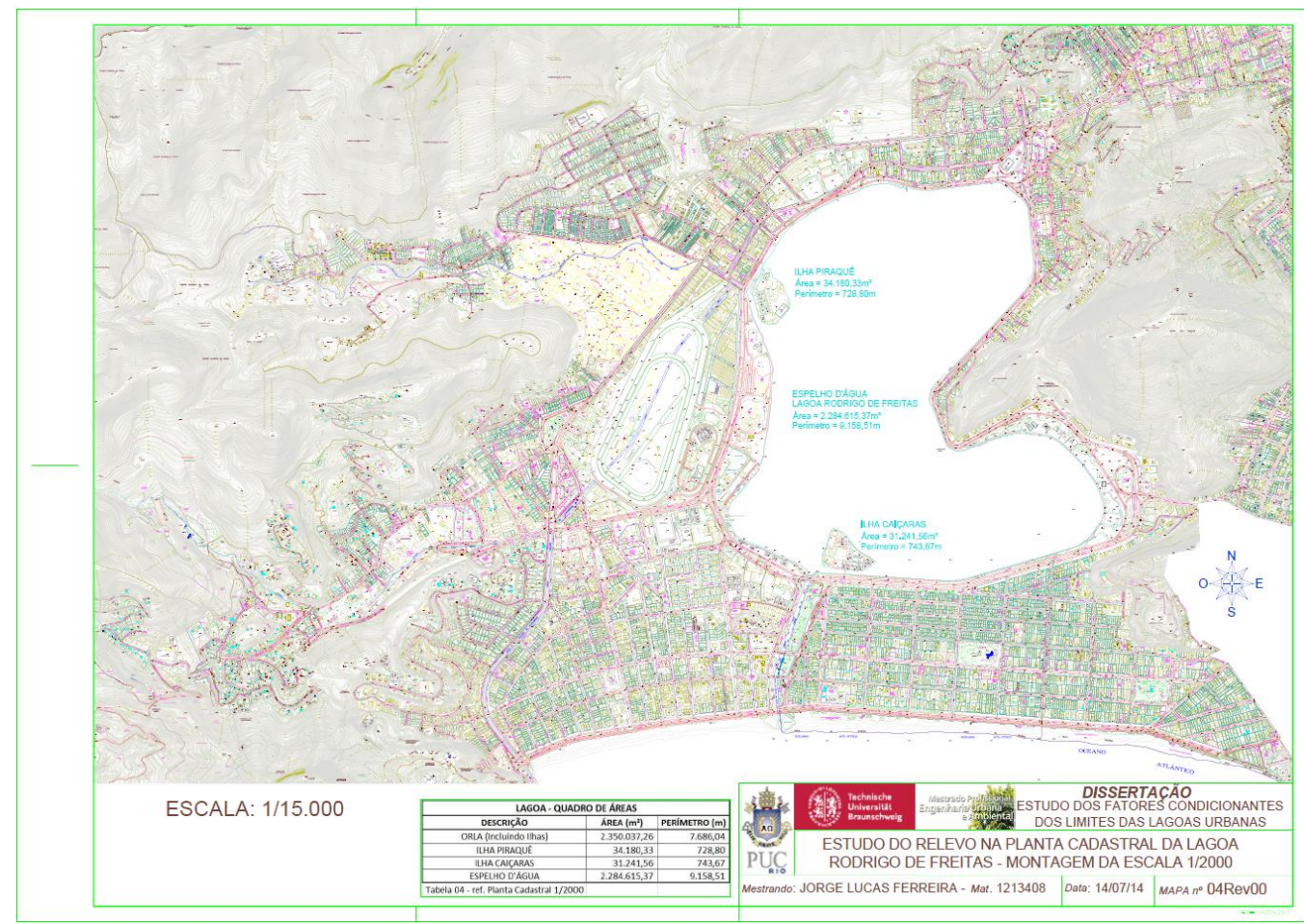

Mapa E04 - Planta Cadastral - Montagem da escala 1/2000 - Detalhe Lagoa

Segundo Loch (1995) a precisão gráfica de uma escala é a menor dimensão gráfica percebida pela visão humana. Conforme normas técnicas a olho nu é possível uma estimativa gráfica na ordem de 1/5 de milímetro, ou seja 0,0002m.

Assim, o erro admissível nas interpretações em desenho elaborados para uma determinada escala é calculado de modo diretamente proporcional ao denominador da escala conforme a equação abaixo:

Erro Gráfico Tolerável $-\mathrm{EGT}=0,0002 \mathrm{~m}$. M, onde M é o denominador da escala.

Para mapas elaborados na escala 1/50.000 temos:

$$
\mathrm{EGT}=0,0002 \mathrm{~m} .50 .000=10 \mathrm{~m} \text {, ou seja } 1.000 \mathrm{~cm}
$$

Já para mapas elaborados na escala 1/2.000 temos:

$$
\mathrm{EGT}=0,0002 \mathrm{~m} \cdot 2 \cdot 000=0,400 \mathrm{~m} \text {, ou seja } 40 \mathrm{~cm}
$$

O que demonstra o quanto é importante sabermos em que escala os dados gráficos foram produzidos e/ou elaborados em cada mapa utilizado, principalmente se estivermos usando os ambientes CAD / SIG / WEB. 


\section{3}

\section{Hidrologia}

O estudo da Lagoa Rodrigo de Freitas considerando o ponto de vista e o contexto do sistema lagunar, abrange uma região cuja delimitação envolve aspectos topográficos e hidrológicos bem característicos.

Sua formação decorre elementarmente dos contornos topográficos da ocorrência de uma depressão no relevo, resultante da localização entre a Orla Oceânica de Ipanema e a Serra da Carioca, sendo sua hidrologia assim desenvolvida nessa confinação, é composta por sub-bacias de pequeno porte (Rios Rainha, Macacos e Cabeça), cuja demanda de drenagem está cada vez mais influenciada por ocupações urbanas.

Como vimos também anteriormente, a interação dessa hidrologia com a Lagoa foi bastante descaracterizada em relação à sua origem natural, apresentando uma nova dinâmica de fluxos d'água.

Observamos na Figura 88 abaixo, a interface entre solo-vegetaçãoatmosfera, que tem uma forte influência no ciclo hidrológico. Associado aos processos naturais, já complexos, existe também a interferência humana que age sobre esse sistema natural (Tucci, 2006).

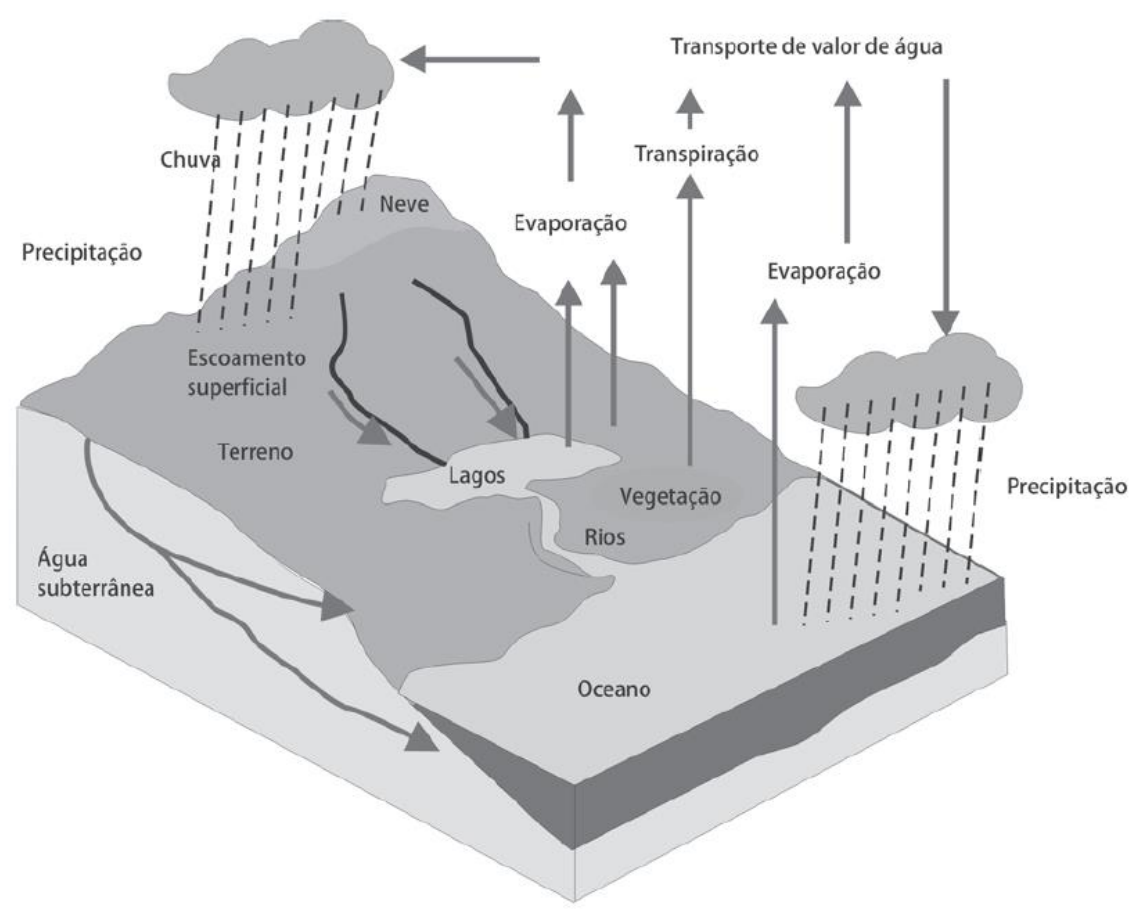

Figura 88 - Ciclo Hidrológico Global (fonte: Tucci, 2006) 
Logo, os Processos Hidrológicos Naturais e Antrópicos - PHNA acrescentam um maior grau de complexidade, necessitando o incremento de modelos experimentais, tema objeto de fartos estudos de especialistas e pesquisadores.

Da Mapoteca do Armazém de Dados - IPP, extraímos o Mapa 32, relativo às bacias e sub-bacias hidrográficas da região do Município do RJ.

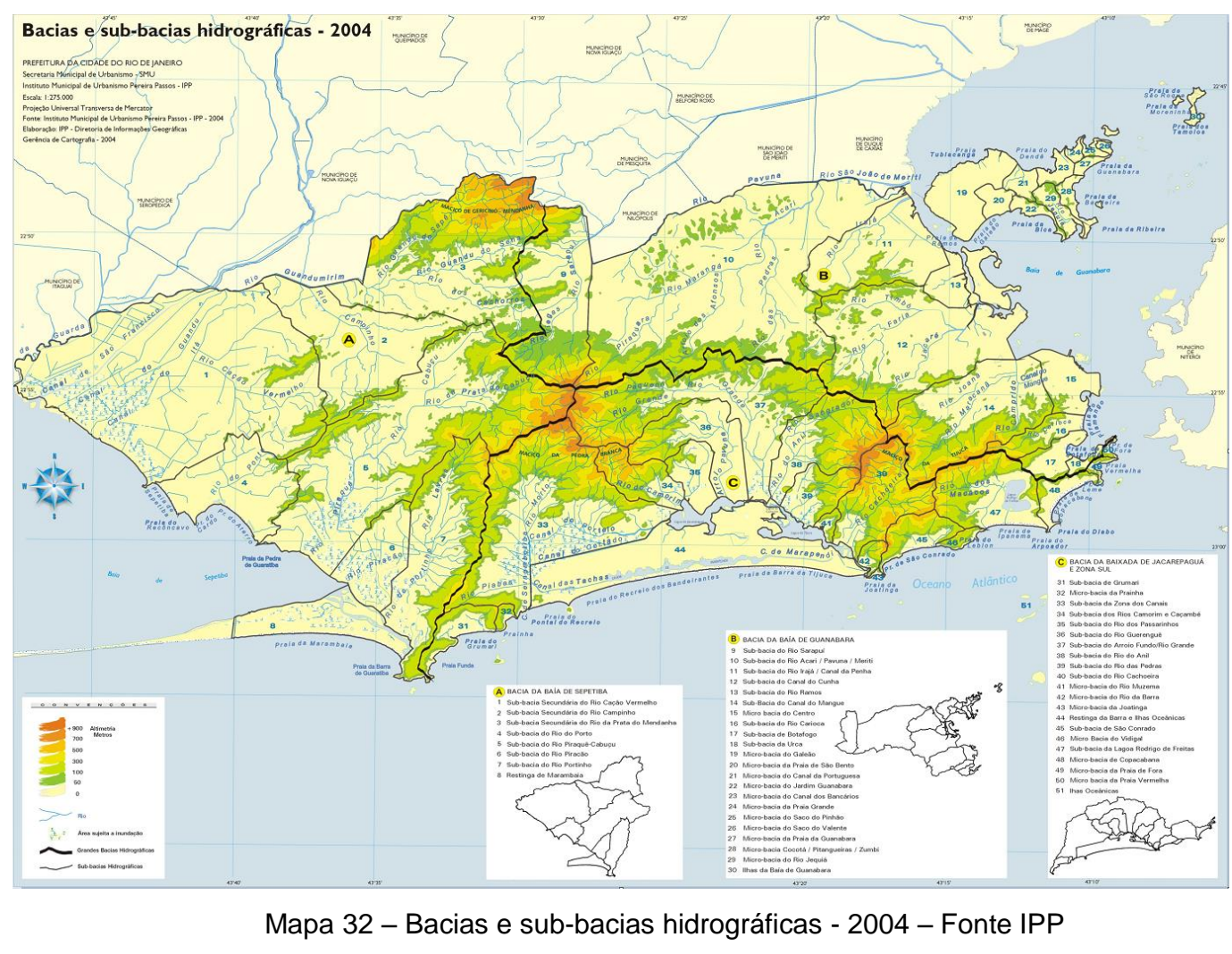

Neste mapa o Município do RJ é dividido em três principais bacias hidrográficas:
A - Bacia da Baía de Sepetiba;
B - Bacia da Baía de Guanabara; e
C - Bacia da Baixada de Jacarepaguá e Zona Sul.

Deste modo, a LRF encontra-se na Bacia C - Baixada de Jacarepaguá e Zona Sul, sub-bacia 47 - Lagoa Rodrigo de Freitas. 
Utilizando o Mapa do Município do Rio de Janeiro - Escala 1/50.000, Mapa 33, representado a seguir, elaboramos também utilizando o aplicativo AutoCAD, um mapeamento hidrológico básico, objetivando obtenção, dimensionamento e mensuração de dados para estudo dos Rios e Bacia Hidrográfica da Lagoa.

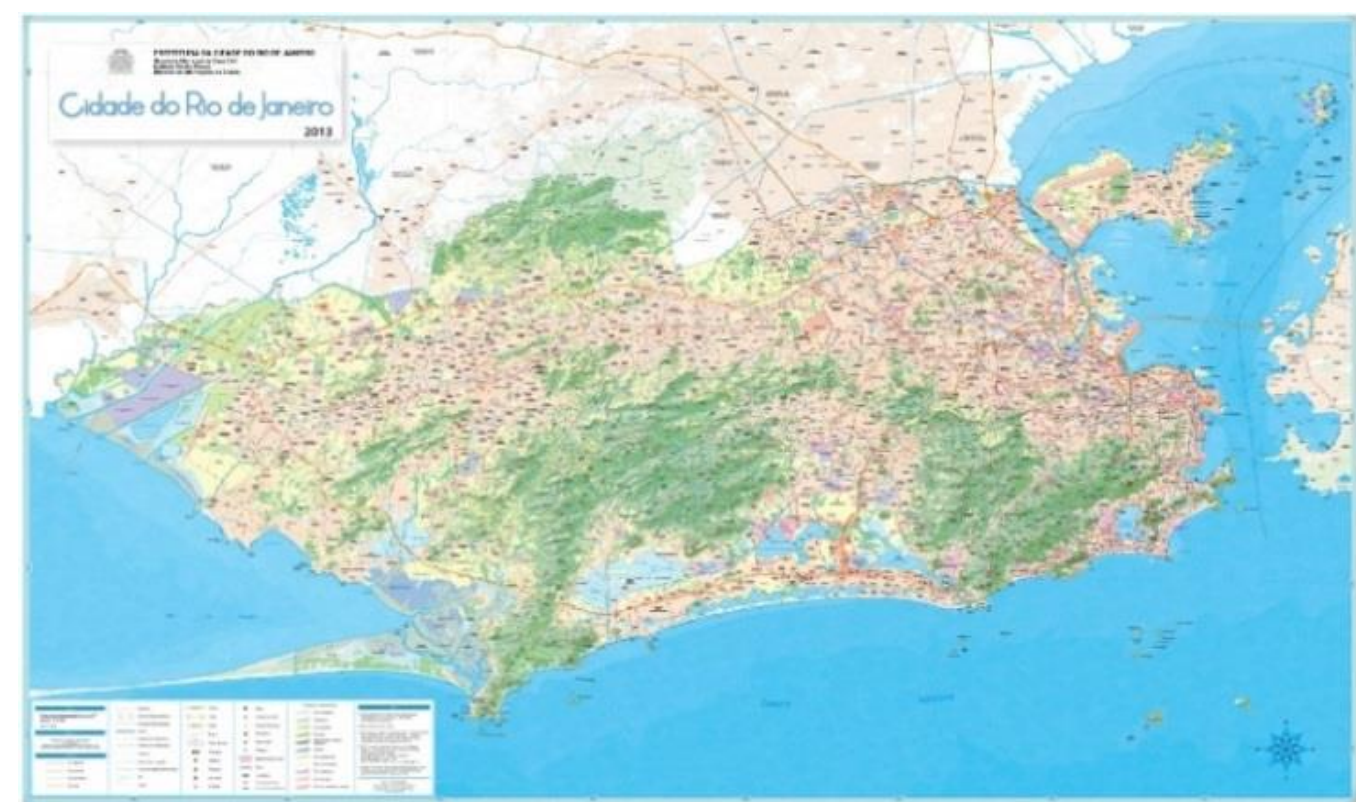

Mapa 33 - Mapa do Município do Rio de Janeiro - Escala 1/50.000

Este Mapa 33, disponibilizado pela Prefeitura em arquivo digital no formato matricial foi inserido no aplicativo AutoCAD, objetivando a obtenção de dados para esta pesquisa, etapa que pode ser visualizada na Figura 89.

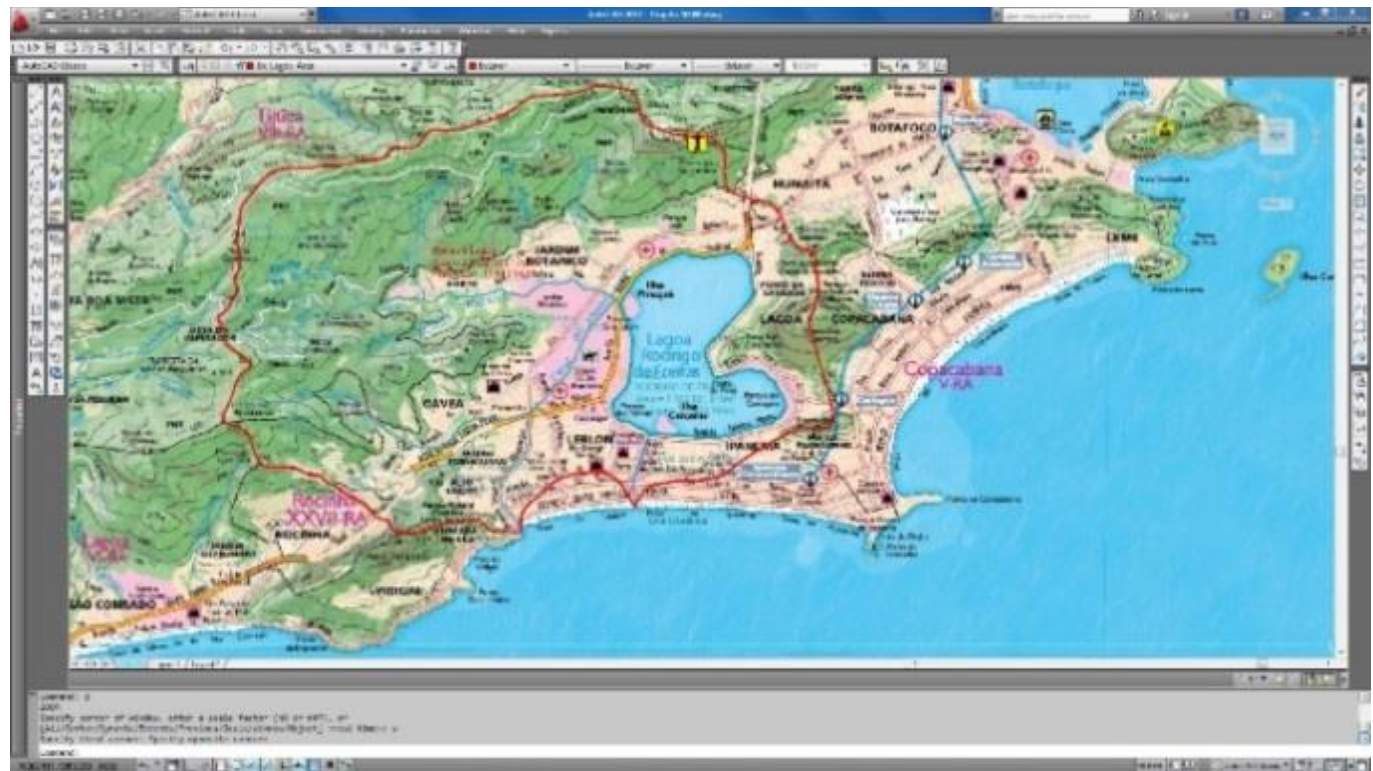

Figura 89 - Extrato do Mapa Estudo da Bacia/Malha Hidrográfica da Lagoa 
Ajustado inicialmente em escala e desenvolvido processo de digitalização de seus elementos gráficos, conforme demonstrado nas Figuras 89 e 90, elaboramos dois novos mapas dos quais foram obtidos dados e informações. Mapa E05 - Estudo da Bacia e Malha Hidrográfica da Lagoa e Mapa E06 - Espelho D’Água, Rios e Bacia Hidrográfica.

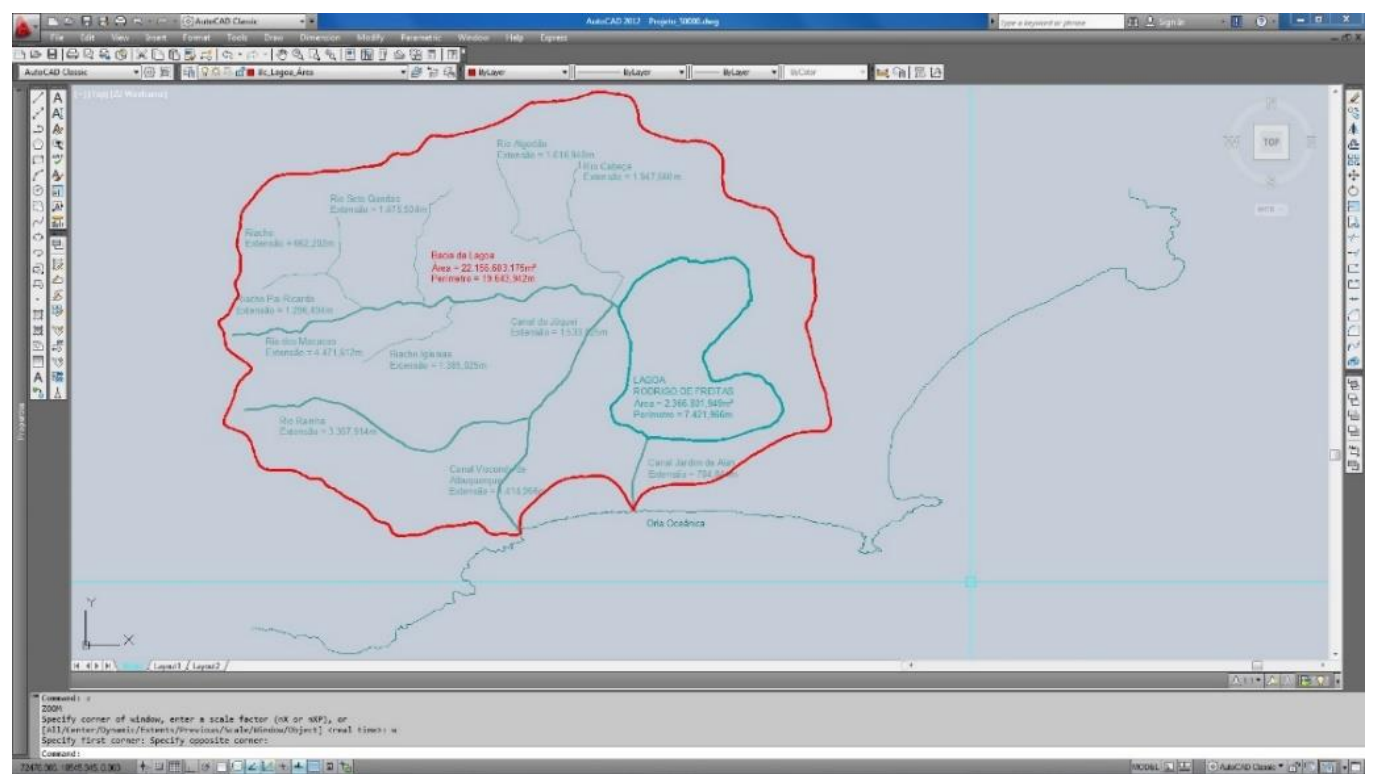

Figura 90 - Espelho D’Água, Rios e Bacia Hidrográfica

O processo de digitalização se desenvolveu observando e interpretando os elementos gráficos e cadastrais desse Mapa 33, culminando com medições e interpretações indicadas nos quadros de cadastro e valores conforme Tabelas 09 e 10.

Tabela 09 - Hidrologia - Quadro de Rios - Mapa 1/50.000

\begin{tabular}{|c|r|r|c|}
\hline \multicolumn{4}{|c|}{ HIDROLOGIA - QUADRO DE RIOS } \\
\hline \multirow{2}{*}{ DESCRIÇÃO } & \multirow{2}{*}{ EXTENSÃO $(\mathbf{m})$} & \multicolumn{2}{|c|}{ ALTITUDE (m) } \\
\cline { 3 - 4 } & & NASCENTE & FINAL \\
\hline RIO DOS MACACOS & 4.470 & 440 & 2 \\
\hline RIACHO PAI RICARDO & 1.300 & 430 & 130 \\
\hline RIACHO & 660 & 450 & 230 \\
\hline RIO SETE QUEDAS & 1.480 & 410 & 50 \\
\hline RIACHO IGLESIAS & 1.390 & 210 & 30 \\
\hline RIO CABEÇA & 1.950 & 230 & 3 \\
\hline RIO ALGODÃO & 1.620 & 510 & 60 \\
\hline RIO RAINHA & 3.360 & 630 & 5 \\
\hline CANAL DO JÓQUEI & 1.530 & 5 & 3 \\
\hline CANAL VISCONDE DE ALBUQUERQUE & 1.410 & 5 & 0 \\
\hline CANAL JARDIM DE ALAH & 780 & 2 & 0 \\
\hline EXTENÇ̃̃O TOTAL & 19.950 & $\mathbf{1 1}$ & RIOS \\
\hline
\end{tabular}

ref. MAPA $1 / 50000$ 
Tabela 10 - Hidrologia - Bacia Hidrográfica - Mapa 1/50.000

\begin{tabular}{|c|c|r|}
\hline \multicolumn{3}{|c|}{ BACIA HIDROGRÁFICA - QUADRO DE ÁREAS } \\
\hline DESCRIÇÃO & ÁREA $\left(\mathbf{m}^{2}\right)$ & PERÍMETRO (m) \\
\hline \hline BACIA DA LAGOA & 22.156 .600 & 7.420 \\
\hline ref. MAPA $1 / 50000$ & & \\
\hline
\end{tabular}

Com o levantamento e dimensionamento da bacia hidrográfica da Lagoa, e obtendo-se os dados hidrológicos da região, podemos calcular o volume de chuva conforme dados climáticos contidos no Anexo, que poderá vir a servir de indicador para a parametrização da condicionante Hidrológica.

Considerando o fluxo de água que ocorre no Canal do Jardim de Alah, um dado que também deve ser observado é a amplitude da Maré Média de Sizígia (ou de águas vivas - diferença entre as preamares muito altas e baixa-mares muito baixas). No Portal do IBGE obtém-se um mapa com a indicação de que no litoral do Município do RJ, essa amplitude está entre 101 e $200 \mathrm{~cm}$, conforme ilustrado na Figura 91.

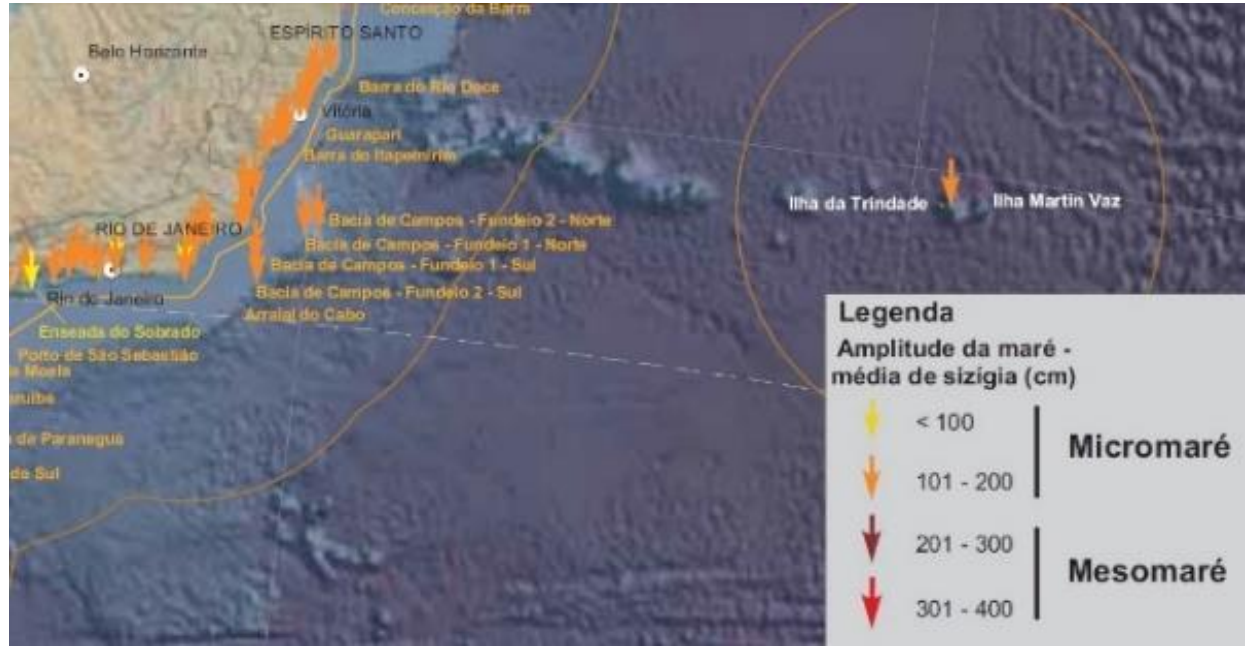

Figura 91 - Extrato do Mapa Amplitude da Maré - Média de Sizígia - IBGE

Torna-se importante referenciar o Mapa 34 - Chuva Média Anual (1997/1998), onde observamos os índices e estações pluviométricas em todo o município do RJ. 


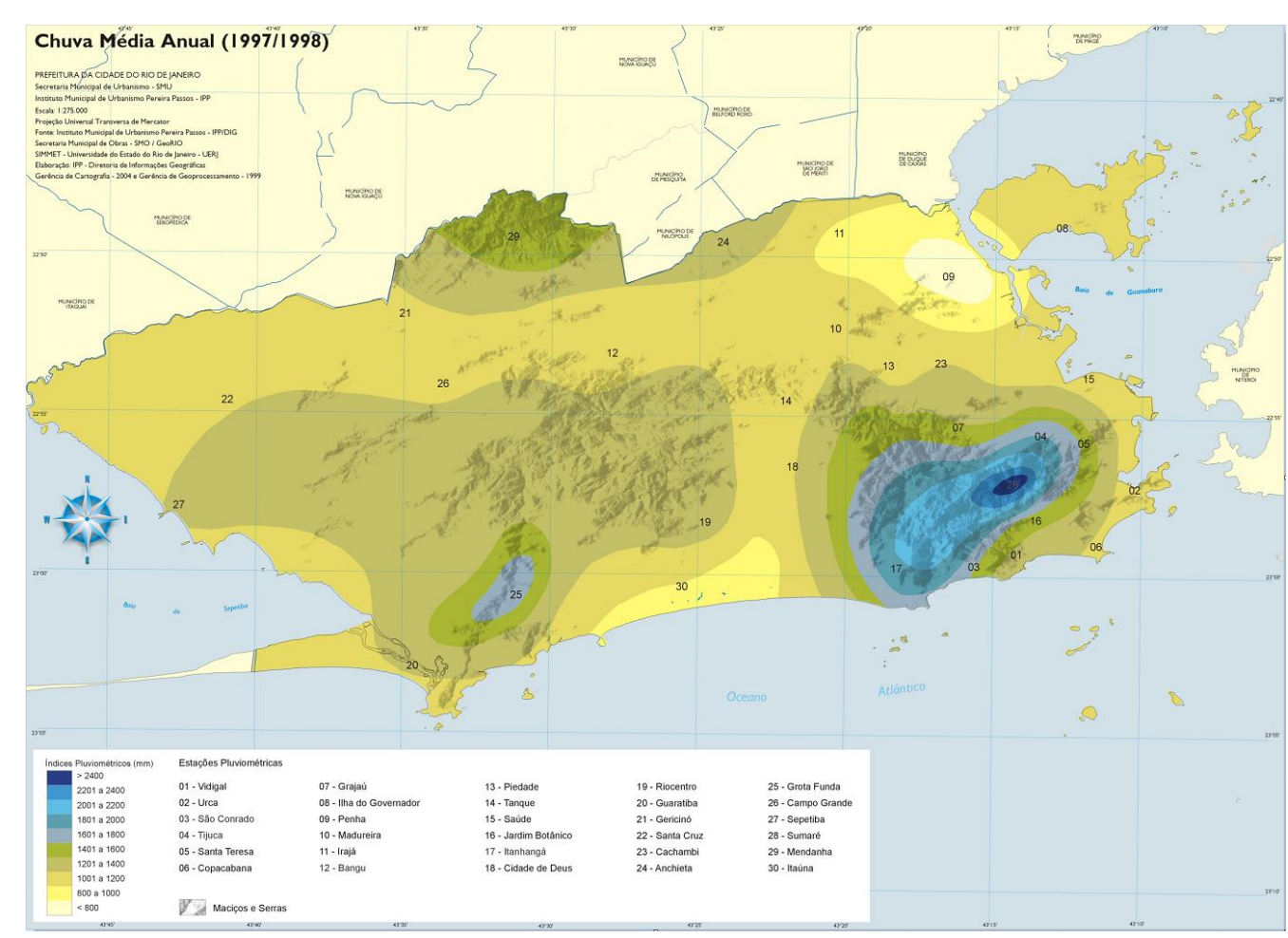

Mapa 34 - Chuva Média Anual (1997/1998) - Fonte IPP

Para dados mais atualizados, pesquisamos o Relatório Anual de Chuvas 2009, publicado pela GeoRio, onde encontram-se dados mais detalhados sobres as ocorrências de chuvas na região do município do RJ.

Na Figura 92 observa-se extrato da página 3 do citado relatório, onde na figura 01 desse extrato encontra-se um mapa referente ao Sistema Alerta Rio Localização dos Pluviômetros e uma Tabela 1, os Endereços das Estações Tele pluviométricas.

Destacamos para a nossa região em estudo (LRF), as Estações 01 (Vidigal), 04 (Tijuca), 05 (Santa Tereza), 06 (Copacabana), 16 (Jardim Botânico), 28 (Sumaré) e 31 (Laranjeiras). 


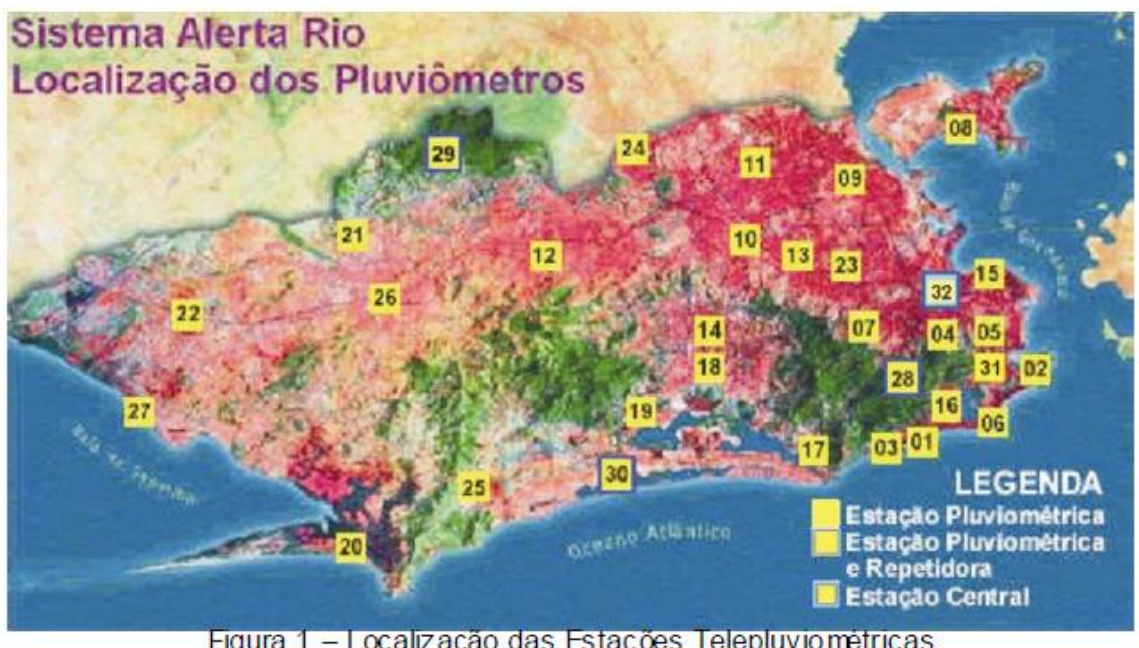

Figura 1 - Localizaçáo das Estaçœes Telepluvio metricas

\begin{tabular}{|c|c|c|c|}
\hline $\mathrm{N}^{0}$ & Nome da Estação & Localização & Tipo \\
\hline 1 & VIDIGAL & Hotel Sheraton - Av. Niemeyer. 121 & Remota \\
\hline 2 & URCA & In stituto Militar de Engenharia - Av. Pasteur. 35 & Remota \\
\hline 3 & ROCINHA & Região Admin istrativa - Estrada da Gávea. 242 & Remota \\
\hline 4 & TIJUCA & Centro de Estudos do Sumaré - Estrada do Sumaré, 670 & Remota \\
\hline 5 & SANTA TEREZA & Escola Suico-Brasileira -Rua Almirante Alexandrino, 2495 & Remota \\
\hline 6 & COPACABANA & Hotel Rio Palace - Av. Atlântica, 4240 & Remota \\
\hline 7 & GRAJAÚ & Grajaú Country Club - Rua Professor Valadares $n^{\circ} 262$ & Remota \\
\hline 8 & 1. GOVERNADOR & late Clube Jardim Guan abara - Rua Orestes Barbosa, 229 & Remota \\
\hline 9 & PENHA & Irmandade de N. S. da Penha de Franca - Largo da Penha, 19 & Remota \\
\hline 10 & MADUREIRA & Ed ficio Pólo l - Estrada do Portela, 99 & Remota \\
\hline 11 & IRAJÁ & Ceasa - Av. Brasi, 19001 & Remota \\
\hline 12 & BANGU & Cassino Banqu - Rua Fonseca, 534 & Remota \\
\hline 13 & PIEDADE & Sociedad e Universitária Gama Fiho - Rua Ma nuel Vitorino, 553 & Remota \\
\hline 14 & TANQUE & Inst. Est. de Dermatologia Sanitária - Rua Godofredo Viana, 64 & Remota \\
\hline 15 & SAÚDE & Rád io Tupi - Rua Livramento, 189 & Remota \\
\hline 16 & JARDIM BOTANICO & Jóquei Clube -Rua Jardim Botânico, 1003 & Remota \\
\hline 17 & ITANHANGÁ & Encosta a montante do Cond. Portinho do Ma ssarú - Estrad a da Barra & Remota \\
\hline 18 & CIDADE DE DEUS & Teleri - Estrada Mal. Salazar de Moraes. 1409 & Remota \\
\hline 19 & RIOCENTRO & Centro de Convencões - Av. Salvador Alende, 6555 & Remota \\
\hline 20 & GUARATIBA & Campo de Provas Marambaia - Estrada Barra de Guaratiba, 9140 & Remota \\
\hline 21 & GERICINÓ & Fábrica da Cogumelo - Av. Brasil, 44879 & Remota \\
\hline 22 & SANTA CRUZ & IBEComb - Praca Ruão $\mathrm{s} / \mathrm{n}^{\circ}$ & Remota \\
\hline 23 & CACHAMBI & Paróquia Sto. Antônio de Pádua - Rua Tenente França, 141 & Remota \\
\hline 24 & ANCHIETA & Esc. Municipal Cyro Monteiro - Rua Antúria, 31 & Remota \\
\hline 25 & GROTA FUNDA & Posto Pionero do Pontal - Estrada do Pontal, 459 & Remota \\
\hline 26 & CAMPO GRANDE & Fac. Integradas Moacy Sreder Bastos - Rua Eng. Trind ade. 229 & Remota \\
\hline 27 & SEPETIBA & Base Aére a de Santa Cruz - Rua do Império s/n & Remota \\
\hline 28 & SUMARÉ & Torre de Transmissão da TV Globo - Estrada do Sumaré s/n & Concentrador \\
\hline 29 & MENDANHA & Serra do Mendanha - Estrada de Fumas $s / n^{\circ}$ & Concentradore \\
\hline 30 & ITAUUNA & Condomínio Verdes Mares - Av. Luiz Aranha. 890 & Concentrador: \\
\hline 31 & LARANJEIRAS & 1a. CIPM - Rua Card oso Junior. 479 & Remota \\
\hline 32 & SÄOCRISTÓVÃO & Campo de São Cristo vão. 268 & Remota \\
\hline
\end{tabular}

Tabela 1 - Endereços das Estações Telepluvio métricas

Figura 92 - Extrato da página 3 do Relatório Anual de Chuvas 2009 - GeoRio

No "Quadro da Precipitação Anual (2009)" podem ser observados os índices mensais e totais, onde colocamos em destaque as estações de interesse conforme Figura 93. 


\section{Quadro da Precipitação Anual (2009)}

\begin{tabular}{|c|c|c|c|c|c|c|c|c|c|c|c|c|c|}
\hline ESTAÇÖES & JAN & FEV & MAR & ABR & MAN & JUN & JUL & AGO & SET & OUT & NOV & DEZ & TOTAL \\
\hline 1 Vidgal & 107,8 & 49,0 & 76,6 & 131,0 & 57,4 & 102,2 & 81,8 & 35.4 & 80.4 & 133,0 & 63,6 & 359,2 & 1277,4 \\
\hline 2 Urca & 140,2 & 50,8 & 93,4 & 100,8 & 34,6 & 76,0 & 109,8 & 35.0 & 942 & 161,6 & 69,0 & 307.8 & 1282,2 \\
\hline 3 Rocinha & 196,0 & 89,8 & 115,0 & 123,6 & 87,2 & 102,6 & 203,2 & 64.6 & 229,0 & 282,0 & 105,6 & 388,4 & 1989 \\
\hline 4 Tíuca & 272,4 & 122.2 & 94,4 & 238.2 & 55,2 & 73,2 & 109,8 & 58.2 & 132,2 & 225,6 & 129.2 & 4622 & 1971,8 \\
\hline 5 Santa Teresa] & 206,0 & 101,6 & 83,8 & 149,0 & 61,0 & 55,6 & 112,2 & 36.4 & 129,0 & 193.2 & 114,0 & 370,8 & 1612,6 \\
\hline 6 Copacabana & 121.8 & 52,0 & 80,0 & 153.2 & 50,6 & 84,2 & 104.6 & 29.8 & 110,0 & 159,6 & 68,8 & 374,8 & 1389,4 \\
\hline 7 Grajaú & 224,6 & 134,2 & 129,8 & 291.2 & 44,8 & 64,6 & 84,4 & 44.2 & 892 & 170,4 & 120,6 & 403,6 & 1801,6 \\
\hline 81. Govemador & 253,0 & 115,8 & 154,6 & 12,8 & 19,8 & 47,2 & 55,8 & 18.6 & 652 & 201,6 & 172.2 & 439,6 & 1656,2 \\
\hline 9 Penha & 201,4 & 136,2 & 111,4 & 141,0 & 29,0 & 36,0 & 44,0 & 17.6 & 522 & 127,6 & 105,0 & 374,4 & 1375,8 \\
\hline 10 Madureira & 143,6 & 150,2 & 137.8 & 132,8 & 50.0 & 42,2 & 56,0 & 27.8 & 77,4 & 131,6 & 149,6 & 269.6 & 1368,6 \\
\hline 11 İajá & 216,6 & 201.8 & 176.4 & $\$ 8,6$ & 60,0 & 45,4 & 41,6 & 23.8 & 792 & 130,8 & 150,0 & 328,4 & 1542,6 \\
\hline 12 Bangu & 153,6 & 178,2 & 91,8 & $\mathbb{T}, 6$ & 51,0 & 42,8 & 76,6 & 26.6 & 894 & 114,6 & 66,8 & 367,0 & 1350 \\
\hline 13 Pledade & 188,0 & 119,0 & 108,4 & 208,8 & 22.2 & 46,8 & 62,6 & 24.8 & 668 & 132,4 & 133,0 & 339,0 & 1451,8 \\
\hline 14 Tanque & 168.2 & 113.6 & 132.0 & 97.0 & 79.6 & 59,8 & 73.2 & 31.4 & 994 & 102.4 & 182,8 & 434.2 & 1567,6 \\
\hline 15 Saúde & 221,8 & 79,6 & 115.0 & 81,2 & 48,6 & 56,8 & 62,0 & 25.8 & 758 & 162,8 & 115,6 & 308,8 & 13528 \\
\hline 16 dd. Botânico & 153,4 & 94,0 & 89,6 & 202,2 & 78,8 & 91,6 & 145,8 & 48.6 & 174,6 & 206.4 & 110,6 & 397,0 & 1792,6 \\
\hline 17 ltanhangá & 210,8 & 127,4 & 90,6 & 181,8 & 67,8 & 96,0 & 144,8 & 59.2 & 118,6 & 163,6 & 116,4 & 335,4 & 1714,4 \\
\hline 18 Gdade de Deus & 139,8 & 112.8 & 104,8 & 90,2 & 58,4 & 80,8 & 72,4 & 46.4 & 950 & 119.6 & 128,6 & 385,6 & 1414,4 \\
\hline 19 Rocentro & 186,0 & 86,8 & 96,4 & 87,4 & 92,4 & 81,6 & 100,2 & 52.2 & 918 & 188.0 & 79,6 & 418,4 & 1560,8 \\
\hline 20 Quaratiba & 148,0 & 69,2 & 111,6 & 108,0 & 34,6 & 69,8 & 93,8 & 46.4 & 646 & 108,4 & 149,0 & 319,2 & 1382,6 \\
\hline 21 Geriainó & 267,0 & 111,8 & 75,2 & 90,4 & 41.6 & 62,8 & 83,2 & 44.4 & 892 & 137,0 & 121,8 & 374,4 & 1507,8 \\
\hline 22 Santa Cruz & 229,4 & 119,4 & 105,0 & 113,8 & 48,6 & 56,2 & 75.6 & 43.4 & 862 & 132,0 & 114,0 & 317,4 & 1441 \\
\hline 23 Cachamb & 281,8 & 131,8 & 137,2 & 259,2 & 36,4 & 54,0 & 65,2 & 332 & 788 & 150,0 & 118.2 & 364,8 & 1710,6 \\
\hline 24 Anchieta & 202,8 & 188.6 & 176.2 & 10.0 & 81,0 & 41,6 & 48,4 & 21.8 & 802 & 116.4 & 159.2 & 350,0 & 1576,2 \\
\hline 25 Grota Funda & 213,2 & 67,2 & 129,4 & 152,2 & 85,0 & 78,0 & 103,2 & 53.8 & 115,2 & 196,6 & 138,0 & 380,2 & 1711 \\
\hline 26 Campo Grande & 156,0 & 76,6 & 42,6 & 8,2 & 28,6 & 47,2 & 80,0 & 39.8 & 792 & 150,8 & 100,6 & 356,2 & 1240,8 \\
\hline 27 Sepetiba & 299.4 & 107.8 & 112,4 & 202,6 & 43,6 & 71,4 & 86,6 & 36.2 & 814 & 140.2 & 85,4 & 392,6 & 1659,6 \\
\hline 28 Sumaré & 358.4 & 129.6 & 116.8 & 354,8 & 159.2 & 149.8 & 264,2 & B6.6 & 361,6 & 434,6 & 168,8 & 553,4 & 3187,8 \\
\hline 29 Mendanha & 330,4 & 212,0 & 110,8 & 161,4 & 71,2 & 63,0 & 135,6 & 75.6 & 181,4 & 228,0 & 124,8 & 550,0 & 2244,2 \\
\hline 30 ltauna & 175,0 & 74,8 & 101.4 & 71,2 & 53,0 & 58,8 & 75,2 & 40.0 & 816 & 175,4 & 59.2 & 292,8 & 1259,4 \\
\hline 31 Laranjeiras ] & 218,8 & 109.0 & 90,0 & 180,0 & 71,6 & 84,0 & 137.8 & 49.0 & 119,6 & 178,0 & 110,8 & 367,8 & 1716,4 \\
\hline 32 Sto Cristóvão & 213,2 & 75,2 & 102,6 & 134,6 & 90,4 & 57,4 & 64,8 & 23.0 & 546 & 112,0 & 89,0 & 220,6 & 1237,4 \\
\hline
\end{tabular}

Figura 93 - Extrato da página 4 do Relatório Anual de Chuvas 2009 - GeoRio

Como tivemos a oportunidade neste item de análise, em mensurar o espelho d'água da Lagoa em dois mapas distintos que se representam em duas escalas diferentes de informação (Mapa 33 - 1/50.000 e Mapa 1/2.000), a título de comparação listamos os resultados nos quadros abaixo: Ver Tabela 11 - Dados obtidos pela digitalização do Mapa 33 e Tabela 12 - Dados obtidos pela digitalização do Mapa E02.

Embora o mapa na escala 1/50.000 obviamente resulte em dados menos precisos, ainda assim, neste exercício comparativo, os valores encontrados são bastante significativos e próximos daqueles de maior precisão. Para determinadas análises e abordagens, se apresentam mais práticos, face à vantagem de ser mais fácil e rápida a sua manipulação e utilização. 
Tabela 11 - Quadro de Áreas - Mapa 1/50.000

\begin{tabular}{|c|r|r|}
\hline \multicolumn{3}{|c|}{ LAGOA - QUADRO DE ÁREAS } \\
\hline DESCRIÇÃO & \multicolumn{1}{|c|}{ ÁREA $\left(\mathbf{m}^{2}\right)$} & PERÍMETRO (m) \\
\hline \hline ORLA (Incluindo Ilhas) & 2.366 .803 & 7.420 \\
\hline ILHA PIRAQUÊ & 35.554 & 730 \\
\hline ILHA CAIÇARAS & 33.193 & 770 \\
\hline ESPELHO D'ÁGUA & 2.298 .056 & 8.920 \\
\hline
\end{tabular}

ref. MAPA $1 / 50000$

Tabela 12 - Quadro de Áreas - Mapa 1/2.000

\begin{tabular}{|c|r|r|}
\hline \multicolumn{3}{|c|}{ LAGOA - QUADRO DE ÁREAS } \\
\hline DESCRIÇÃo & \multicolumn{1}{|c|}{ ÁREA $\left(\mathbf{m}^{\mathbf{2}}\right)$} & PERÍMETRO (m) \\
\hline ORLA (Incluindo Ilhas) & $2.350 .037,26$ & $7.686,04$ \\
\hline ILHA PIRAQUÊ & $34.180,33$ & 728,80 \\
\hline ILHA CAIÇARAS & $31.241,56$ & 743,67 \\
\hline ESPELHO D'ÁGUA & $2.284 .615,37$ & $9.158,51$ \\
\hline
\end{tabular}

ref. Planta Cadastral $1 / 2000$

\section{4 \\ Projeto de Alinhamento Aprovado - PAA-9548}

Para o Projeto de Alinhamento Aprovado - PAA-9548 - Espelho D'água da LRF, objetivando sua reprodução e análises, iniciamos com a obtenção da respectiva imagem matricial (raster) que é disponibilizada no Portal do IPP, procedendo a sua inserção no ambiente gráfico digital do aplicativo AutoCAD, com os devidos ajustes principalmente de escala (1/2.000), o que resultou no Mapa E07 representado abaixo.

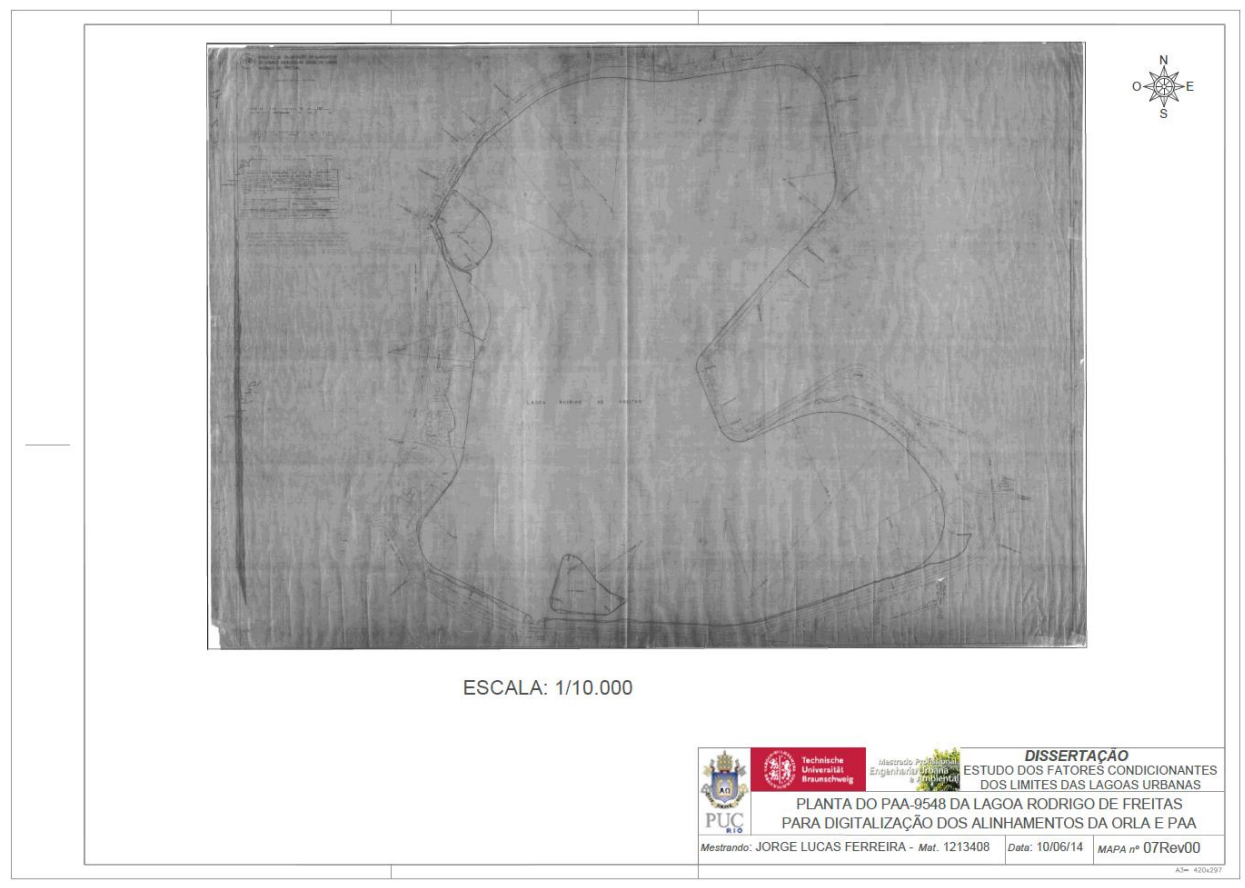

Mapa E07 - Projeto de Alinhamento Aprovado - PAA-9548 - Espelho D’água Lagoa 
No desenvolvimento do processo de digitalização, duas linhas de referência foram escolhidas dada sua importância:

- O Alinhamento Natural da Orla do Espelho D'água - ANOED, composto por suas sinuosidades e trajetórias naturais retratadas no desenho do projeto; e

- O Alinhamento Projetado da Orla do Espelho D’água - APOED, composto por retas tangentes e solução de curvas circulares de concordância, cuja geometria projetada propõe uma retificação/regularização do alinhamento da orla da lagoa.

Neste último, partimos da análise dos elementos geométricos indicados no desenho do PAA, e aplicando processo de reengenharia procedemos aos devidos cálculos e estruturação matemática, com articulações no desenho do projeto. Para tanto, utilizamos os conceitos matemáticos referentes às Curvas Circulares conforme ilustrado na Figura 94 e formulário inerente também abaixo ilustrado.

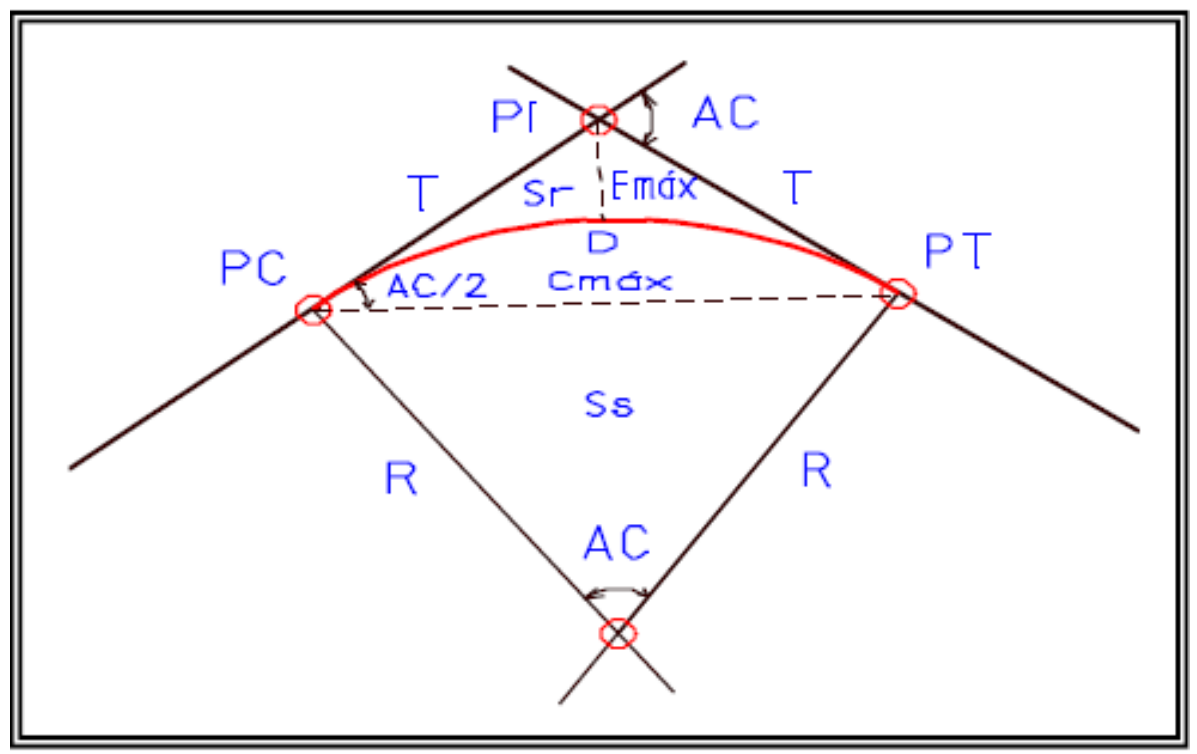

Figura 94 - Elementos Geométrico da Curva Circular

$\mathrm{R}=$ Raio da Curva.

D = Desenvolvimento da Curva (comprimento da Curva Circular).

AC $=$ Ângulo Central da Curva.

PC = Ponto de Concordância da Curva com a Tangente. 
PI = Ponto de Interseção das Tangentes à Curva.

PT = Ponto de Tangência da Curva.

$\mathrm{T}=$ Distância do PI ao PC ou PT.

Fmáx. = Distância do PI à Curva (chama-se flexa máxima).

Cmáx. = Distância do PC ao PT (chama-se corda máxima).

$\mathrm{Gm}=$ Ângulo Central que subentende uma corda de 1,00 m.

$\mathrm{dm}=$ É a deflexão que subentende uma corda de 1,00 m

G20 = É o Ângulo Central que subentende uma corda de $20,00 \mathrm{~m}$

Ss = Área do Setor.

$\mathrm{Sr}=$ Área de Recuo.

Formulário Utilizado:

$\mathrm{T}=\mathrm{R} \times$ Tangente $(\mathrm{AC} / 2)$

$\mathrm{D}=\pi \times \mathrm{R} \times \mathrm{AC} / 180$

Cmáx $=2 \times \mathrm{T} \times$ COSENO $(\mathrm{AC} / 2)$

Cmáx $=2 \times \mathrm{R} \times \mathrm{SENO}(\mathrm{AC} / 2)$

Fmáx $=\mathrm{R} x[(1 / \operatorname{COSENO}(\mathrm{AC} / 2))-1]$

Ss $=\pi \times \mathrm{R}^{2} \times \mathrm{AC} / 360^{\circ}$

Nas etapas do processo de Digitalização, criamos uma convenção de cores para melhor visualização e entendimento. 
No caso da comparação do alinhamento natural da orla com o alinhamento projetado linhas azuis e linhas vermelhas, conforme Figura 95:

- Linha em Azul

$\rightarrow$ ANOED - Alinhamento Natural da Orla do

Espelho D’água; e

- Linha em Vermelho $\rightarrow$ APOED - Alinhamento Projetado da Orla do Espelho D’água.

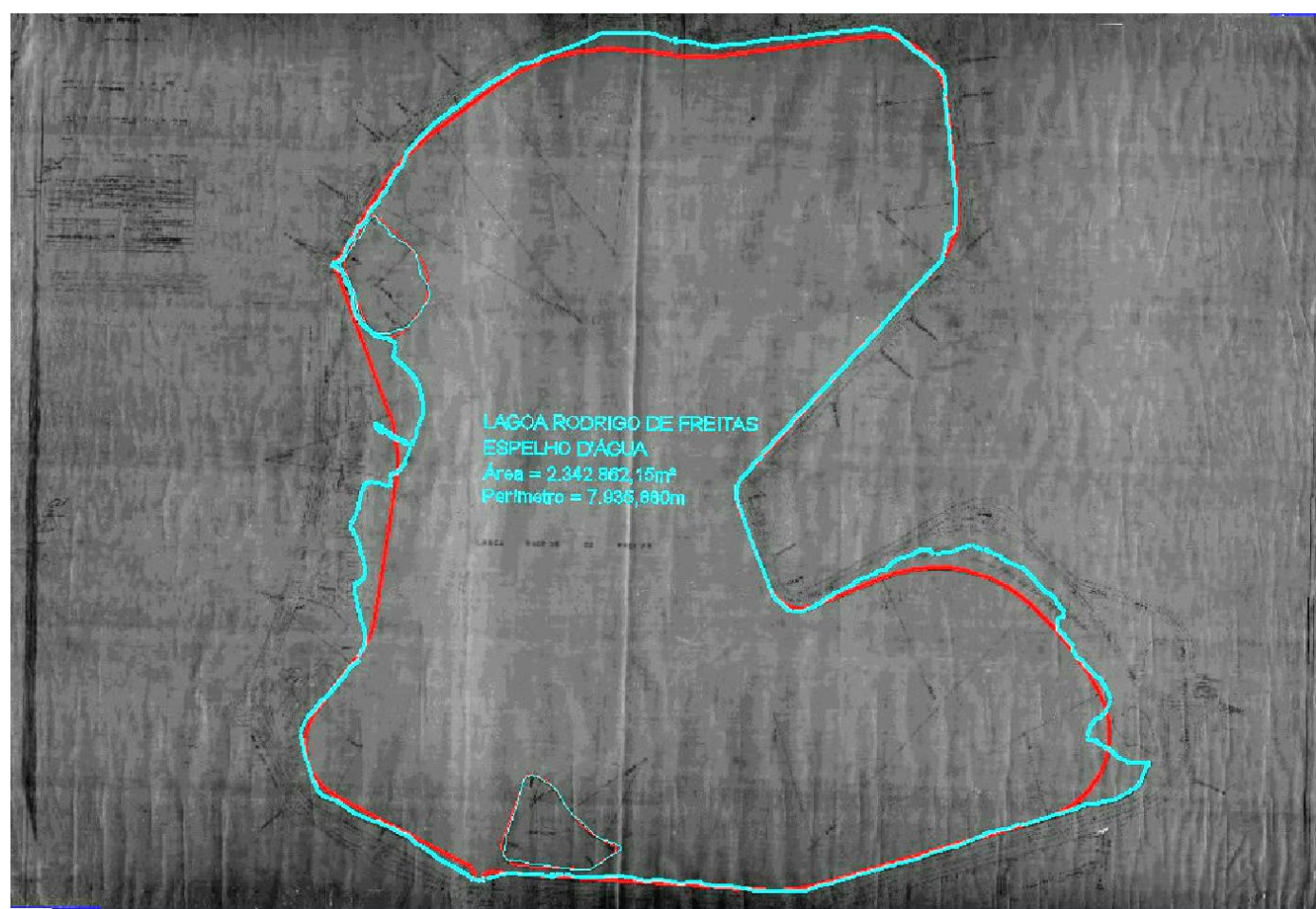

Figura 95 - PAA-9548 - Espelho D'água da Lagoa - Alinhamento Natural e Projetado

Já no caso da comparação do alinhamento natural da orla com o alinhamento projetado, agora atrelado ao conjunto de Curvas Circulares e Elementos Geométricos calculados, conforme Figura 96:

- Linha em Azul $\rightarrow$ ANOED - Alinhamento Natural da Orla do Espelho D’água; e

- Linha em Amarelo $\rightarrow$ Elementos Geométricos das Curvas Circular Projetadas. 


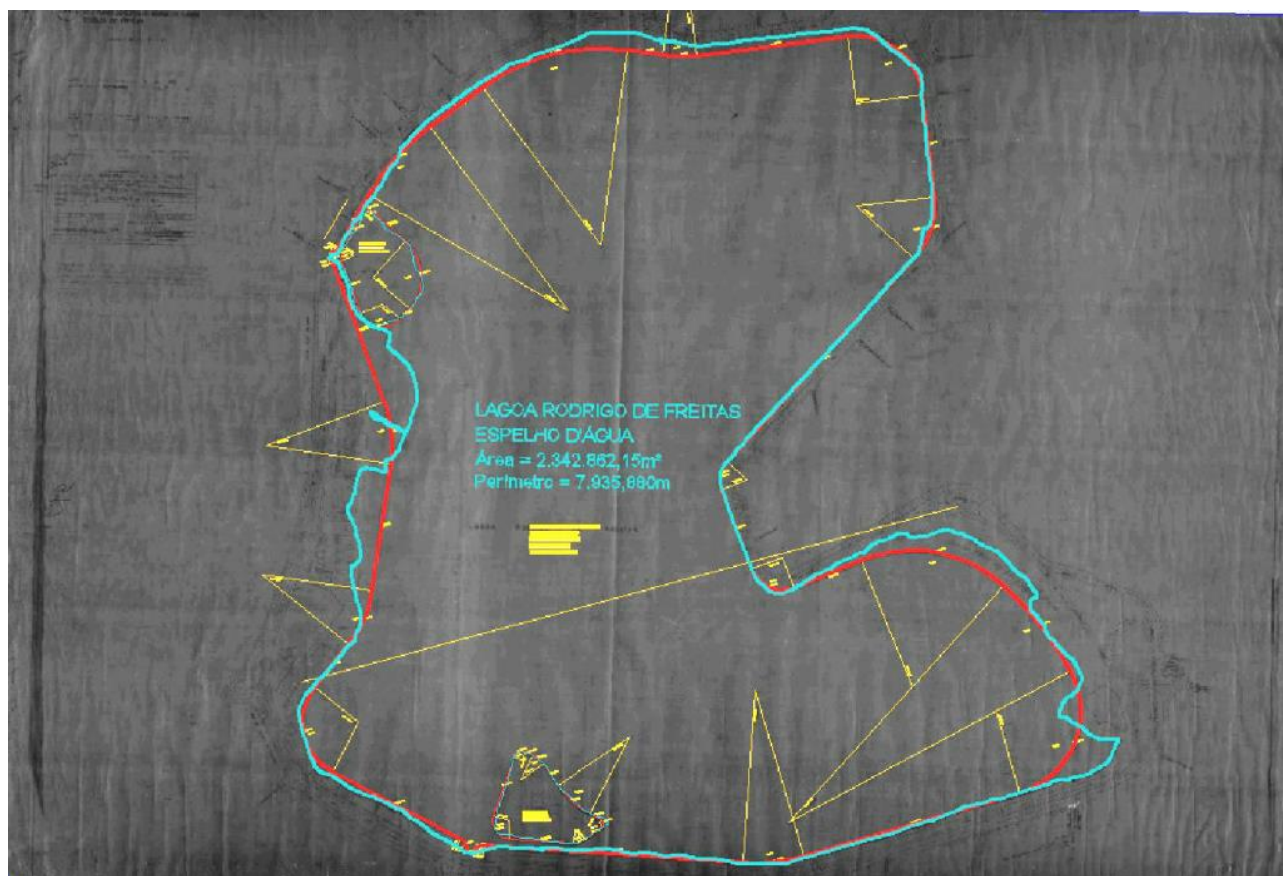

Figura 96 - PAA-9548 - Espelho D'água - Alinhamento Natural, Projetado e Elementos das CC

Foram calculadas ao todo 28 (vinte e oito) curvas circulares: 18 (dezoito) na Orla da Lagoa, 4 (quatro) na Orla da Ilha Piraquê, e 6 (seis) na Orla da Ilha Caiçaras, constituindo-se assim, a Reengenharia do Projeto PAA-9548, conforme a Tabela 13 a seguir.

Tabela 13 - Cálculo de elementos das Curvas Circulares

\begin{tabular}{|c|c|c|c|}
\hline \multicolumn{4}{|c|}{$\begin{array}{l}\text { LAGOA RODRIGO DE FREITAS } \\
\text { Cálculo de Elementos de Curva Circular } \\
\text { e Demais Segmentos de Perímetro }\end{array}$} \\
\hline \multicolumn{4}{|c|}{\begin{tabular}{|r|} 
CURVA CIRCULAR 01 \\
\end{tabular}} \\
\hline \multicolumn{4}{|c|}{ Dados Raio e Ângulo Central; } \\
\hline Raio & $\mathrm{R}=$ & 25,000 & \\
\hline Ângulo Central & $\mathrm{AC}=$ & $80^{\circ} 30^{\prime}$ & $40 "$ \\
\hline \multicolumn{4}{|c|}{ Calcular Tangente ( $T$ ) e Desenvolvimento (D) } \\
\hline Tangente & $T=$ & 21,16822 & \\
\hline Desenvolviment & $\mathrm{D}=$ & 35,12960 & $\mathrm{~m}$ \\
\hline
\end{tabular}

Alinhamento Retilineo $=\quad 600,265 \mathrm{~m}$

\section{CURVA CIRCULAR 02}

\begin{tabular}{|c|c|c|c|}
\hline \multicolumn{4}{|c|}{ Dados Raio e Ângulo Central; } \\
\hline Raio & $\mathrm{R}=$ & 400,000 & \\
\hline Ângulo Central & $\mathrm{AC}=$ & $20^{\circ} \quad 17^{\prime}$ & $33 "$ \\
\hline \multicolumn{4}{|c|}{ Calcular Tangente ( $T$ ) e Desenvolvimento ( $D$ ) } \\
\hline Tangente & $T=$ & 71,58403 & $\mathrm{~m}$ \\
\hline Desenvolvimento & $\mathrm{D}=$ & 141,66838 & $\mathrm{~m}$ \\
\hline
\end{tabular}

Alinhamento Retilíneo =

\begin{tabular}{|c|c|c|}
\hline \multicolumn{3}{|c|}{$\begin{array}{r}\text { CURVA CIRCULAR } 03 \\
\end{array}$} \\
\hline \multicolumn{3}{|c|}{ Dados Raio e Ângulo Central; } \\
\hline Raio & $\mathrm{R}=$ & $196,000 \mathrm{~m}$ \\
\hline Ângulo Central & $\mathrm{AC}=$ & $101^{\circ} 52^{\prime} 11^{\prime \prime}$ \\
\hline \multicolumn{3}{|c|}{ Calcular Tangente (T) e Desenvolvimento (D) } \\
\hline Tangente & $\mathrm{T}=$ & $241,47799 \mathrm{~m}$ \\
\hline Desenvolvimento & $\mathrm{D}=$ & $348,48056 \quad \mathrm{~m}$ \\
\hline
\end{tabular}

\begin{tabular}{|c|}
\hline Extensão \\
Parcial \\
Acumulada \\
\hline
\end{tabular}

$35,130 \mathrm{~m}$ $35,130 \mathrm{~m}$

$600,265 \mathrm{~m}$ $635,395 \mathrm{~m}$

$141,668 \mathrm{~m}$ $777,063 \mathrm{~m}$

$519,955 \mathrm{~m}$ $1.297,018 \mathrm{~m}$ 
Tabela 13 - Cálculo de elementos das Curvas Circulares - Continuação

\begin{tabular}{|c|c|c|}
\hline \multicolumn{2}{|c|}{ Sem Alinhamento Retilíneo = } & $\mathrm{m}$ \\
\hline \multicolumn{3}{|c|}{ CURYA CIRCULAR 04} \\
\hline \multicolumn{3}{|c|}{ Dados Raio e Angulo Central; } \\
\hline Raio & $\mathrm{R}=$ & $738,000 \mathrm{~m}$ \\
\hline Ángulo Central & $\mathrm{AC}=$ & $19 \cdot 33 \cdot 55$ \\
\hline \multicolumn{3}{|c|}{ Calcular Tangente [ $\mathrm{T}$ ] e Desenvolvimento ( $\mathrm{D}$ ] } \\
\hline Tangente & $\mathrm{T}=$ & $127,24445 \mathrm{~m}$ \\
\hline Desenvolvimento & $\mathrm{D}=$ & $252,01115 \mathrm{~m}$ \\
\hline
\end{tabular}
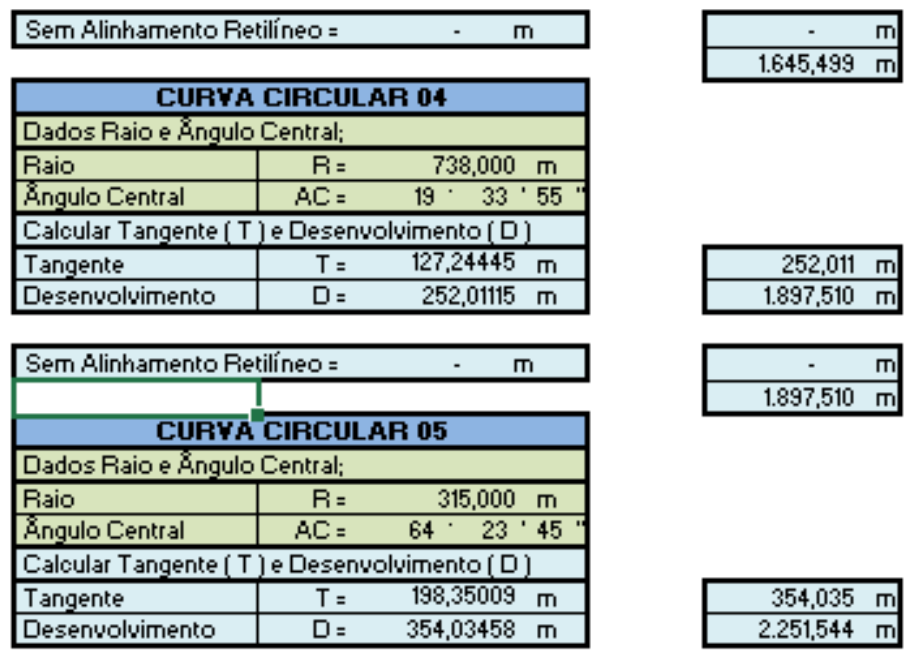

$252,011 \mathrm{~m}$

$1.897,510 \mathrm{~m}$

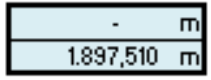

Alinhamento Retilíneo $=\quad 166,563 \mathrm{~m}$

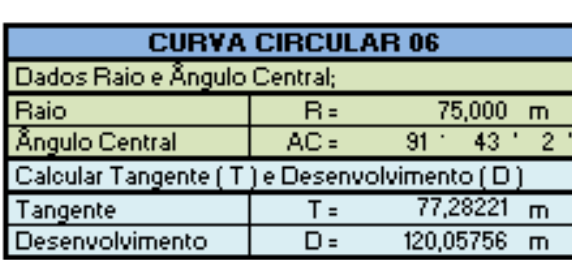

$166,563 \mathrm{~m}$

$2.418,107 \mathrm{~m}$

Alinhamento Retilíneo $=\quad 197,870 \mathrm{~m}$

\begin{tabular}{|c|c|c|}
\hline \multicolumn{3}{|c|}{ CURYA CIRCULAR 07} \\
\hline \multicolumn{3}{|c|}{ Dados Raio e Rngulo Central; } \\
\hline Riaio & $\mathrm{R}=$ & $63,000 \mathrm{~m}$ \\
\hline B.ngulo Central & $\mathrm{AC}=$ & $63 \cdot 9 \cdot 6$ \\
\hline \multicolumn{3}{|c|}{ Calcular Tangente [T] e Desenvolvimento $(\mathrm{D}$ ] } \\
\hline Tangente & $\mathrm{T}=$ & $38,72124 \mathrm{~m}$ \\
\hline Desenvolvimento & $\mathrm{D}=$ & $69,43888 \mathrm{~m}$ \\
\hline \multicolumn{2}{|c|}{ Alinhamento Retilíneo = } & $637,052 \mathrm{~m}$ \\
\hline \multicolumn{3}{|c|}{ CURYA CIRCULAR 08} \\
\hline \multicolumn{3}{|c|}{ Dados Raio e Rngulo Central; } \\
\hline Riaio & $\mathrm{R}=$ & $180,000 \mathrm{~m}$ \\
\hline 8.ngulo Central & $\mathrm{AC}=$ & $49 \cdot 5 \cdot 29$ \\
\hline \multicolumn{3}{|c|}{ Calcular Tangente $[T$ ] e Desenvolvimento $[\mathrm{D}]$} \\
\hline Tangente & $\mathrm{T}=$ & $82,20416 \mathrm{~m}$ \\
\hline Desenvolvimento & $\mathrm{D}=$ & $154,22515 \mathrm{~m}$ \\
\hline
\end{tabular}

$197,870 \mathrm{~m}$

$2.736,035 \mathrm{~m}$

Alinhamento Retilíneo $=\quad 236,516 \mathrm{~m}$

\begin{tabular}{|c|c|c|}
\hline \multicolumn{2}{|c|}{ 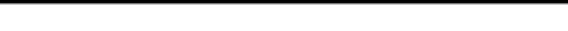 } & \multirow[t]{2}{*}{$3.833,267 \mathrm{~m}$} \\
\hline \multicolumn{2}{|c|}{ CURYA CIRCULAR 09} & \\
\hline \multicolumn{2}{|c|}{ Dados Raio e Ángulo Central; } & \\
\hline Raio & $155,000 \mathrm{~m}$ & \\
\hline Ëngulo Central & $90 \cdot 46 \cdot 20$ & \\
\hline \multicolumn{3}{|c|}{ Calcular Tangente [T] e Desenvolvimento ( $D$ ] } \\
\hline Tangente & $T=157,10327 \mathrm{~m}$ & $245,562 \mathrm{~m}$ \\
\hline Desenvolvimento & $\mathrm{D}=245,56249 \mathrm{~m}$ & $4.078,829 \mathrm{~m}$ \\
\hline \multirow{2}{*}{\multicolumn{2}{|c|}{ Alinhamento Retilíneo = }} & $352,230 \mathrm{~m}$ \\
\hline & & $4.431,059 \mathrm{~m}$ \\
\hline \multicolumn{2}{|c|}{ CURYA CIRCULAR 10} & \\
\hline \multicolumn{2}{|c|}{ Dados Raio e Ángulo Central; } & \\
\hline Raio & $300,000 \mathrm{~m}$ & \\
\hline Engulo Central & $A C=15 \cdot 2 \cdot 40$ & \\
\hline \multicolumn{2}{|c|}{ Calcular Tangente [ $T$ ] e Desenvolvimento [ $\mathrm{D}$ ] } & \\
\hline Tangente & $\mathrm{T}=39,61413 \mathrm{~m}$ & $78,773 \mathrm{~m}$ \\
\hline Desenvolvimento & $78,77253 \mathrm{~m}$ & $4.509,832 \mathrm{~m}$ \\
\hline
\end{tabular}

$236,516 \mathrm{~m}$ $3.833,267 \mathrm{~m}$ 
Tabela 13 - Cálculo de elementos das Curvas Circulares - Continuação

\begin{tabular}{|c|c|c|}
\hline Alinhamento $\mathrm{Re}$ & & $352,230 \mathrm{~m}$ \\
\hline \multicolumn{3}{|c|}{$\begin{array}{l}\text { CURYA CIRCULAR } 10 \\
\end{array}$} \\
\hline \multicolumn{3}{|c|}{ Dados Raio e Angulo Central; } \\
\hline Raio & $\mathrm{R}=$ & $300,000 \mathrm{~m}$ \\
\hline Ángulo Central & $\mathrm{AC}=$ & $15 \cdot 2 \cdot 40$ \\
\hline \multicolumn{3}{|c|}{ Calcular Tangente [ $T$ ] e Desenvolvimento (D) } \\
\hline Tangente & $T=$ & $39,61413 \mathrm{~m}$ \\
\hline Desenvolvimento & $\mathrm{D}=$ & $78,77253 \mathrm{~m}$ \\
\hline \multicolumn{2}{|c|}{ Alinhamento Retilíneo = } & $82,765 \mathrm{~m}$ \\
\hline \multicolumn{3}{|c|}{ CURYA CIRCULAR 11} \\
\hline \multicolumn{3}{|c|}{ Dados Raio e Angulo Central; } \\
\hline Raio & $\mathrm{R}=$ & $455,000 \mathrm{~m}$ \\
\hline Ángulo Central & $\mathrm{AC}=$ & $44^{\prime} 34^{\prime} 59$ \\
\hline \multicolumn{3}{|c|}{ Calcular Tangente ( T) ]e Desenvolvimento ( $\mathrm{D}$ ) } \\
\hline Tangente & $\mathrm{T}=$ & $186,53051 \mathrm{~m}$ \\
\hline Desenvolvimento & $\mathrm{D}=$ & $354,04511 \mathrm{~m}$ \\
\hline
\end{tabular}

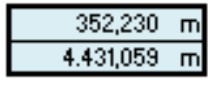

Alinhamento Retilíneo $=\quad 151,193 \mathrm{~m}$

\begin{tabular}{|c|c|c|}
\hline \multicolumn{3}{|c|}{ CURYA CIRCULAR 12} \\
\hline \multicolumn{3}{|c|}{ Dados Raio e Angulo Central; } \\
\hline Raio & $\mathrm{R}=$ & $530,000 \mathrm{~m}$ \\
\hline Ángulo Central & $\mathrm{AC}=$ & $22^{\circ} 59^{\prime} 41^{\prime}$ \\
\hline \multicolumn{3}{|c|}{ Calcular Tangente [ $T$ ] e Desenvolvimento ( $\mathrm{D}$ ] } \\
\hline Tangente & $\mathrm{T}=$ & $107,80430 \mathrm{~m}$ \\
\hline Desenvolvimento & $\mathrm{D}=$ & $212,70682 \mathrm{~m}$ \\
\hline
\end{tabular}

Alinhamento Retilíneo $=\quad 145,735 \mathrm{~m}$

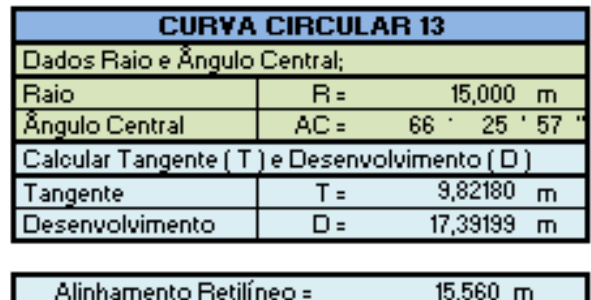

Alinhamento Retilíneo $=\quad 15,560 \mathrm{~m}$

\section{CURYA CIRCULAR 14}

\begin{tabular}{|c|c|c|}
\hline \multicolumn{3}{|c|}{ CURYA CIRCULAR 14} \\
\hline \multicolumn{3}{|c|}{ Dados Raio e Angulo Central; } \\
\hline Raio & $\mathrm{R}=$ & $10,000 \mathrm{~m}$ \\
\hline Éngulo Central & $\mathrm{AC}=$ & $73 \cdot 26 \cdot 23$ \\
\hline \multicolumn{3}{|c|}{ Calcular Tangente ( T) e Desenvolvimento ( $\mathrm{D}$ ) } \\
\hline Tangente & $T=$ & $7,45916 \mathrm{~m}$ \\
\hline Desenvolvimento & $\mathrm{D}=$ & $12,81765 \mathrm{~m}$ \\
\hline
\end{tabular}

Alinhamento Retilíneo $=\quad 346,339 \mathrm{~m}$

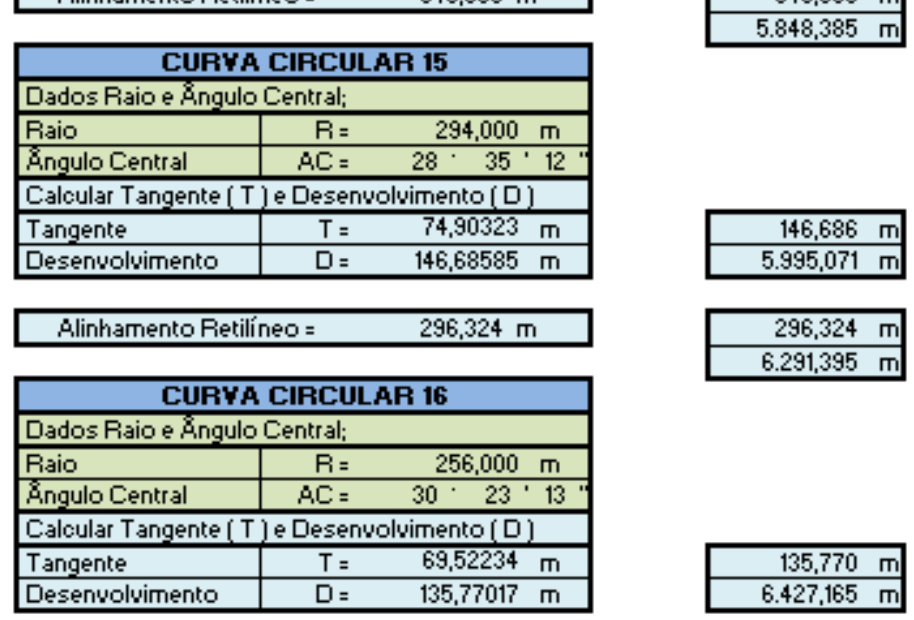

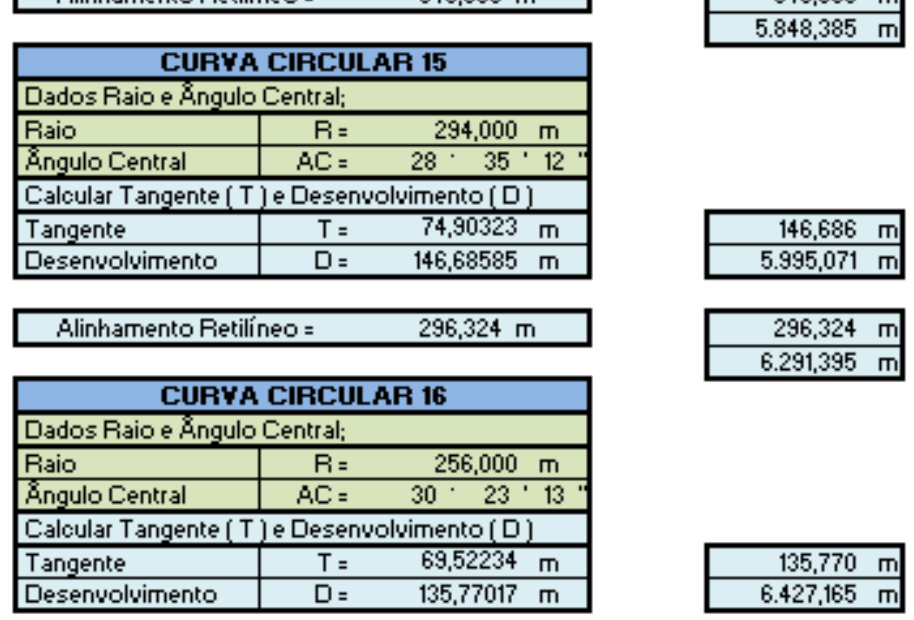

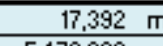

$346,339 \mathrm{~m}$ 
Tabela 13 - Cálculo de elementos das Curvas Circulares - Continuação

\begin{tabular}{|c|c|c|}
\hline \multicolumn{2}{|c|}{ Alinhamento Retilíneo $=$} & $125,772 \mathrm{~m}$ \\
\hline \multicolumn{3}{|c|}{ CURVA CIRCULAR 17} \\
\hline \multicolumn{3}{|c|}{ Dados Raio e Ángulo Central; } \\
\hline Raio & $R=$ & $130,000 \mathrm{~m}$ \\
\hline Ängulo Central & $\mathrm{AC}=$ & $100^{\prime} 58^{\prime} 26^{\prime \prime}$ \\
\hline \multicolumn{3}{|c|}{ Calcular Tangente (T) e Desenvolvimento (D) } \\
\hline Tangente & $\mathrm{T}=$ & $157,62942 \mathrm{~m}$ \\
\hline Desenvolvimento & $\mathrm{D}=$ & $229,10249 \mathrm{~m}$ \\
\hline \multicolumn{2}{|c|}{ Alinhamento Retilíneo $=$} & $334,711 \mathrm{~m}$ \\
\hline \multicolumn{3}{|c|}{ CURVA CIRCULAR 18} \\
\hline \multicolumn{3}{|c|}{ Dados Raio e Ángulo Central; } \\
\hline Raio & $R=$ & $30,000 \mathrm{~m}$ \\
\hline Ãngulo Central & $\mathrm{AC}=$ & $70^{\circ} 26 \cdot 39=$ \\
\hline \multicolumn{3}{|c|}{ Calcular Tangente (T) e Desenvolvimento (D) } \\
\hline Tangente & $T=$ & $21,17999 \mathrm{~m}$ \\
\hline Desenvolvimento & $\mathrm{D}=$ & $36,88448 \mathrm{~m}$ \\
\hline
\end{tabular}

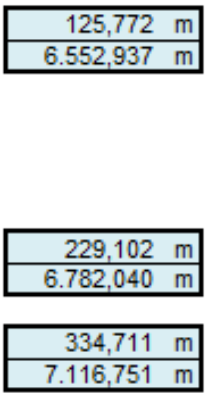

\begin{tabular}{|c|c|}
\hline PERIMETRO = & $7.168,666$ \\
\hline AREA = & $2.287,423,08$ \\
\hline
\end{tabular}

ESPELHO D'AGUA $=2.221 .890,51 \mathrm{~m}^{2}$

\section{ILHA DE CAIÇARA}

Cálculo de Elementos de Curva Circular e Demais Segmentos de Perímetro

\begin{tabular}{|c|c|c|}
\hline \multicolumn{3}{|c|}{ CURVA CIRCULAR 01} \\
\hline \multicolumn{3}{|c|}{ Dados Raio e Ángulo Central; } \\
\hline Raio & $\mathrm{R}=$ & $40,000 \mathrm{~m}$ \\
\hline Ângulo Ce & $A C=$ & $105^{\circ} 14^{\prime} 5^{\prime \prime}$ \\
\hline \multicolumn{3}{|c|}{ Calcular Tangente $(T)$ e Desenvolvimento (D) } \\
\hline Tangente & $T=$ & $52,35070 \mathrm{~m}$ \\
\hline Desenvol & $\mathrm{D}=$ & $73,46770 \mathrm{~m}$ \\
\hline \multicolumn{3}{|c|}{ linhamento Retilineo : } \\
\hline \multicolumn{3}{|c|}{ CURVA CIRCULAR 02} \\
\hline \multicolumn{3}{|c|}{ Dados Raio e Ángulo Central; } \\
\hline Raio & $\mathrm{R}=$ & 30,000 \\
\hline Ängulo CG & $A C=$ & $40^{\circ} 10^{\prime} 33^{\prime \prime}$ \\
\hline \multicolumn{3}{|c|}{ Calcular Tangente ( $T$ ) e Desenvolvimento (D) } \\
\hline Tangente & $T=$ & $10,97127 \mathrm{~m}$ \\
\hline Desenvol & $\mathrm{D}=$ & $21,03602 \mathrm{~m}$ \\
\hline
\end{tabular}

CURVA CIRCULAR 03

\begin{tabular}{|c|c|c|}
\hline \multicolumn{3}{|c|}{ Dados Raio e Ángulo Central; } \\
\hline \begin{tabular}{l|l} 
Raio & \\
\end{tabular} & $R=$ & $10,000 \mathrm{~m}$ \\
\hline Ängulo CE & $A C=$ & $116^{*} 33^{\prime} 16^{\prime \prime}$ \\
\hline \multicolumn{3}{|c|}{ Calcular Tangente ( $T$ ) e Desenvolvimento (D) } \\
\hline \begin{tabular}{l|l} 
Tangente \\
\end{tabular} & $T=$ & $16,17699 \mathrm{~m}$ \\
\hline Desenvol & $\mathrm{D}=$ & $20,34259 \mathrm{~m}$ \\
\hline
\end{tabular}

linhamento Retilineo : $\quad 28,440 \mathrm{~m}$

CURVA CIRCULAR 04

\begin{tabular}{|c|c|c|}
\hline Raio & $R=$ & $200,000 \mathrm{~m}$ \\
\hline Ängulo Ce & $A C=$ & $28^{\circ} 6^{\prime} 58^{\prime \prime}$ \\
\hline \multicolumn{3}{|c|}{ Calcular Tangente ( $T$ ) e Desenvolvimento (D) } \\
\hline Tangente & $T=$ & $50,08090 \mathrm{~m}$ \\
\hline Desenvol & $\mathrm{D}=$ & 98,14374 \\
\hline
\end{tabular}

$73.468 \mathrm{~m}$

$73,468 \mathrm{~m}$

$152,295 \mathrm{~m}$

$225,763 \mathrm{~m}$

Extensão

Acumulada 
Tabela 13 - Cálculo de elementos das Curvas Circulares - Continuação

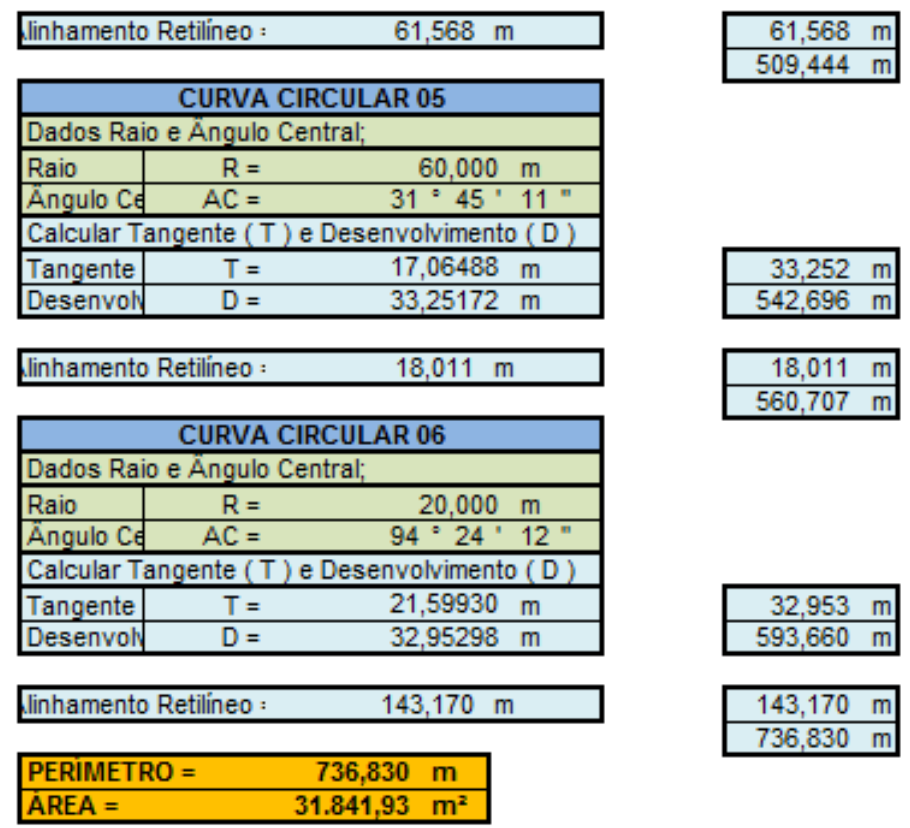

$61,568 \mathrm{~m}$

$509,444 \mathrm{~m}$

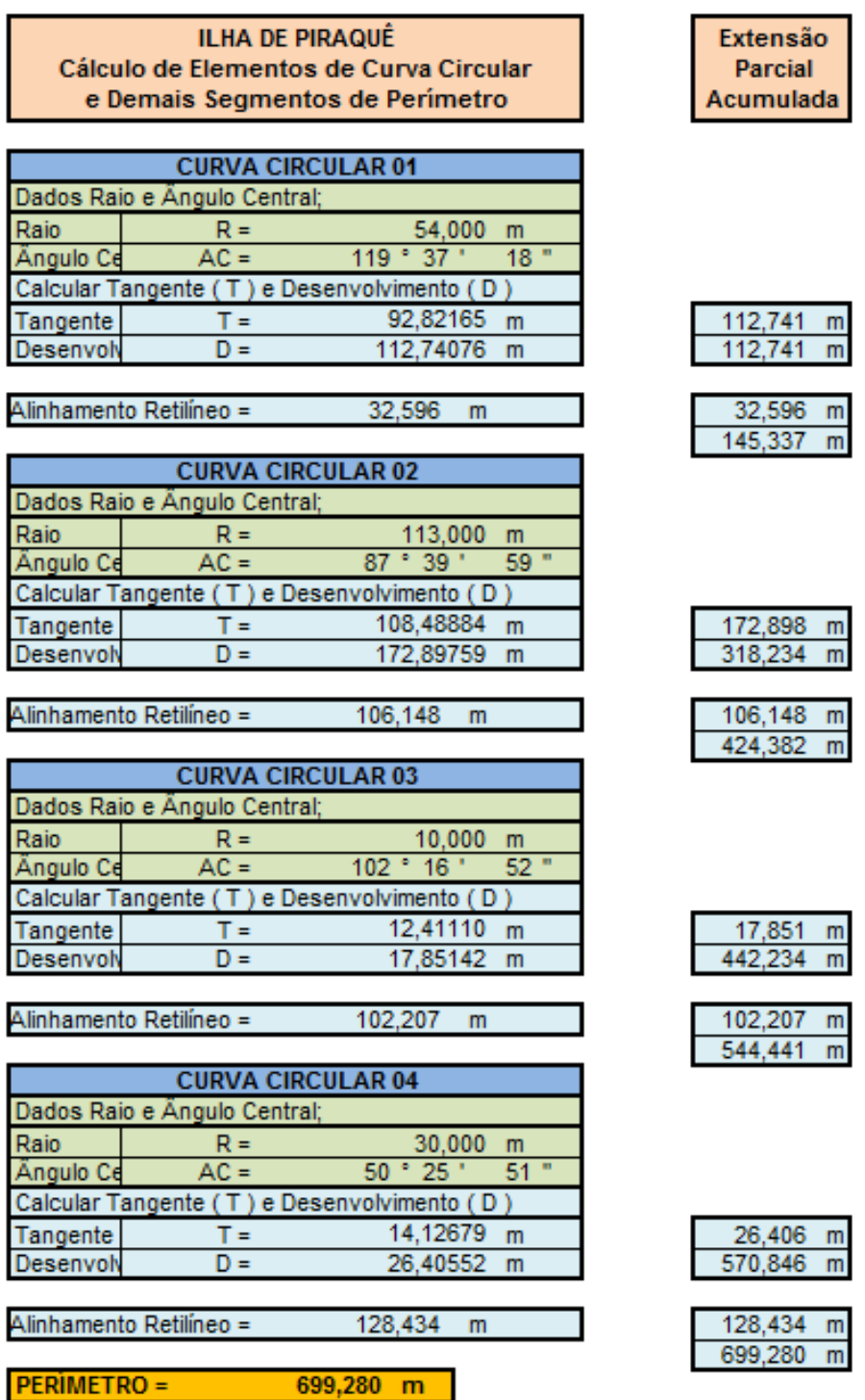


Concluídos todos os cálculos elaboramos o mapa resumo do processo de digitalização do Projeto de Alinhamento, representado no Mapa E08 - Mapa da Digitalização e Cálculo do PAA-9548.

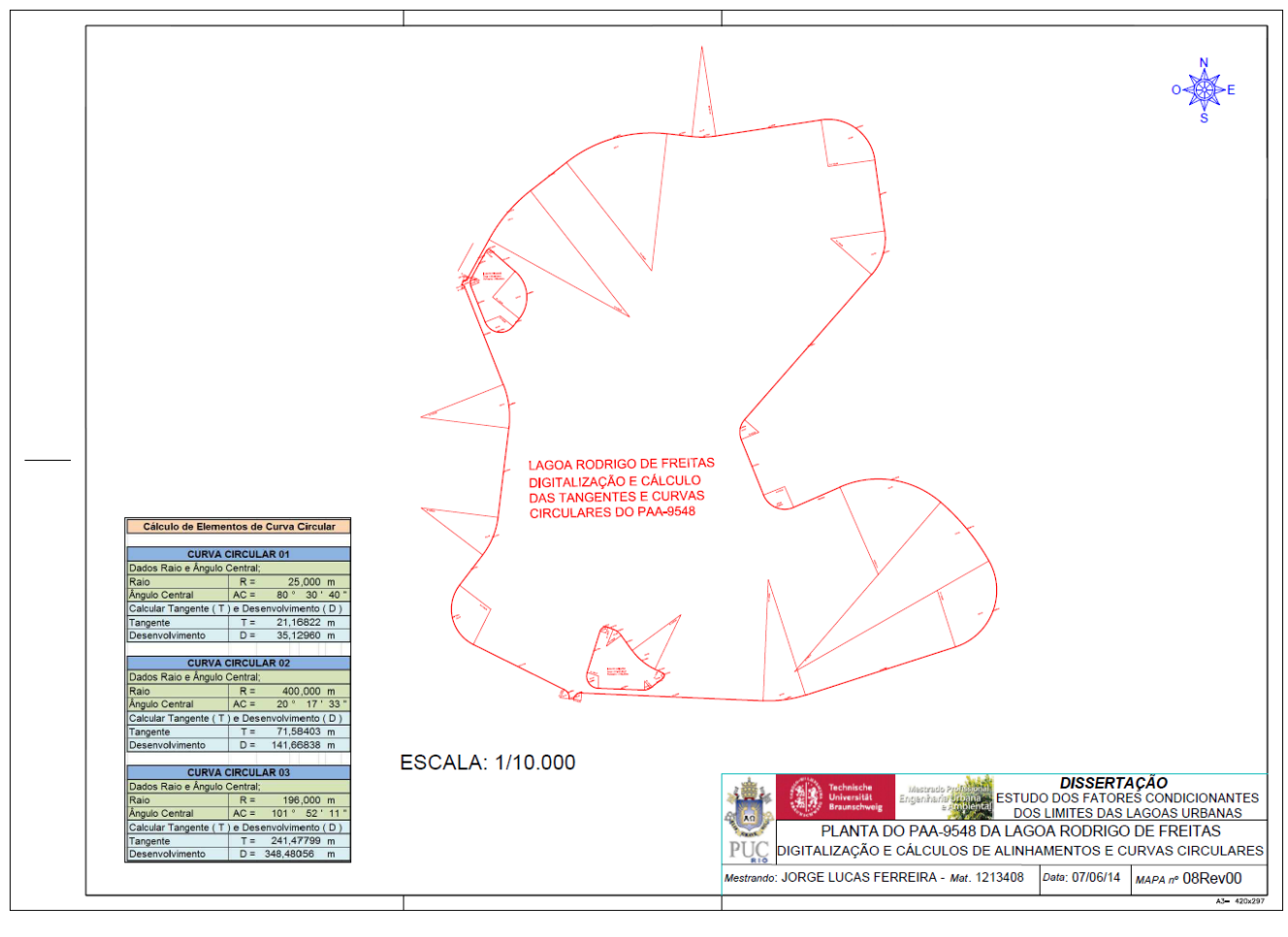

Mapa E08 - Mapa da Digitalização e Cálculo do PAA-9548

A seguir, procedemos às medições dos elementos geométricos do conjunto como um todo, obtendo área e perímetro da Lagoa e das Ilhas, segundo o Projeto da Prefeitura na Borda Natural (ver Tabela 14) e na Borda Projetada (ver Tabela $15)$.

Tabela 14 - Quadro de Áreas e Perímetro da Lagoa e llhas - Borda Natural

\begin{tabular}{|c|r|r|}
\hline \multicolumn{3}{|c|}{ LAGOA - ALINHAMENTO DA ORLA - QUADRO DE ÁREAS } \\
\hline DESCRIÇÃO & \multicolumn{1}{|c|}{ ÁREA $\left(\mathbf{m}^{2}\right)$} & PERÍMETRO (m) \\
\hline ORLA (Incluindo llhas) & $2.342 .862,16$ & $7.935,88$ \\
\hline ILHA PIRAQUÊ & $32.390,84$ & 706,19 \\
\hline ILHA CAIÇARAS & $30.959,64$ & 747,87 \\
\hline ESPELHO D'ÁGUA & $2.279 .511,68$ & $9.389,94$ \\
\hline
\end{tabular}

ref. PAA-9548 - ESCALA 1/2000 
Tabela 15 - Quadro de Áreas e Perímetro da Lagoa e llhas - Borda Projetada

\begin{tabular}{|c|r|r|}
\hline \multicolumn{3}{|c|}{ LAGOA - ALINHAMENTO DO PAA-9548 - QUADRO DE ÁREAS } \\
\hline DESCRIÇÃO & \multicolumn{1}{|c|}{ ÁREA $\left(\mathbf{m}^{2}\right)$} & \multicolumn{1}{|c|}{ PERÍMETRO (m) } \\
\hline \hline ORLA (Incluindo Ilhas) & $2.287 .423,08$ & $7.686,04$ \\
\hline ILHA PIRAQUÊ & $33.690,64$ & 699,28 \\
\hline ILHA CAIÇARAS & $31.841,93$ & 736,83 \\
\hline ESPELHO D'ÁGUA & $2.221 .890,51$ & $9.122,15$ \\
\hline
\end{tabular}

ref. PAA-9548 - ESCALA 1/2000

Analisando estes valores podemos concluir que segundo o PAA-9548, o espelho d'água natural da Lagoa com $2.279 .511,68 \mathrm{~m}^{2}$, passa a ter com o novo alinhamento agora projetado e retificado $2.221 .890,51 \mathrm{~m}^{2}$, ou seja, uma redução de $57.621,17 \mathrm{~m}^{2}$, que equivale a $2,53 \%$ da superfície natural, conforme demonstrado abaixo: Mapa E09 - Mapa da Medição das Bordas da LRF - Natural e Projetada.

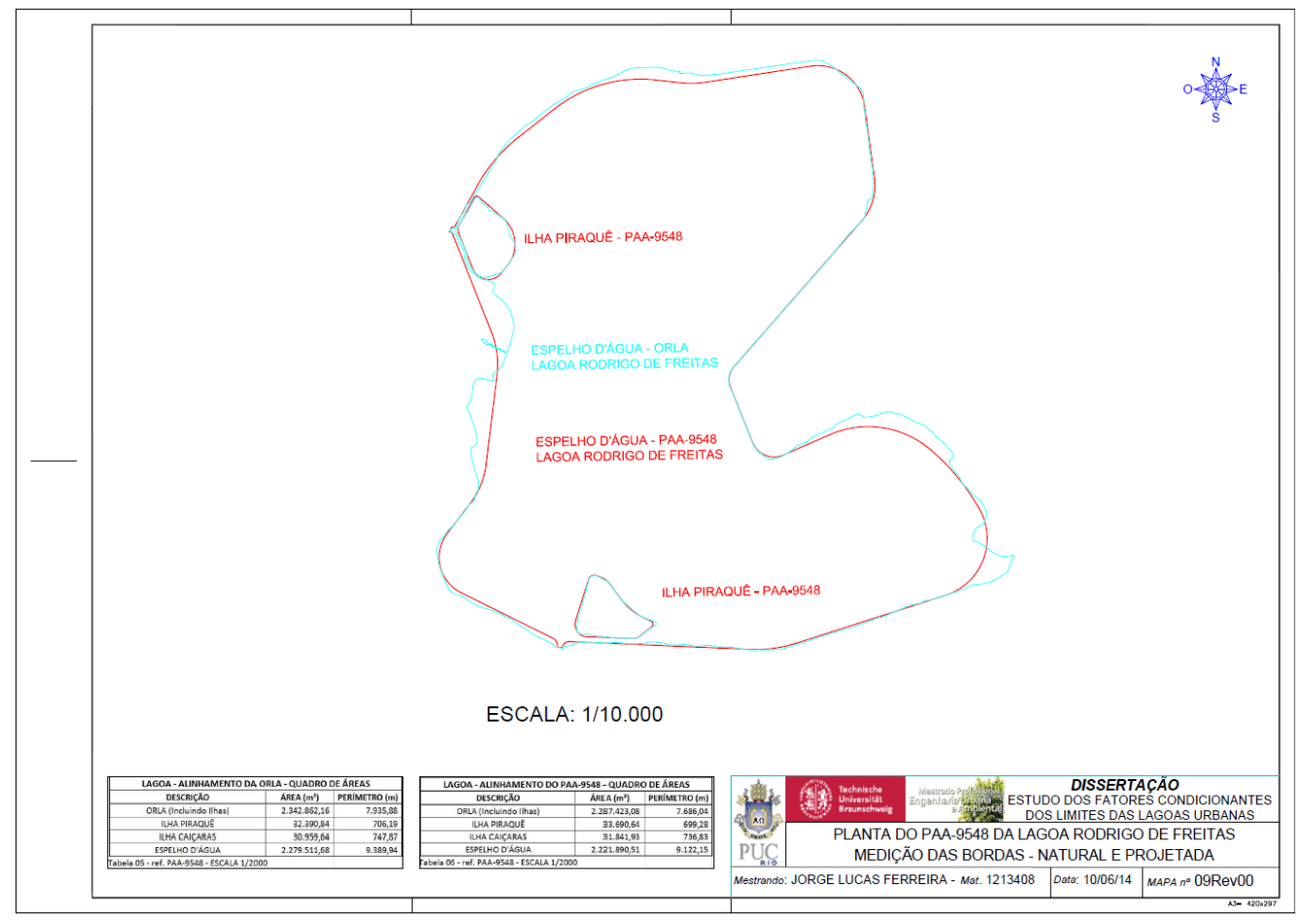

Mapa E09 - Mapa da Medição das Bordas da LRF - Natural e Projetada

Cabe ressaltar que o documento "Projeto do PAA-9548" foi obtido por um processo e origem diferenciados; originalmente na época de sua produção utilizavam-se mídias em papel vegetal, desenhadas manualmente com instrumentos e tinta nanquim, que posteriormente com a digitalização desses antigos documentos, foram transformados em imagens matriciais, por escaneamento, e finalmente disponibilizados no servidor da Prefeitura para consulta e download. 


\section{5 Ecossistema e Cobertura Vegetal}

A ocupação de um território como a RMRJ causa impactos ambientais que podem ser vistos a partir de três principais preocupações:

- O uso irracional de recursos naturais, com ameaças ao bem estar e até mesmo sobrevivência;

- A emissão de efluentes e/ou despejos acima da capacidade do equilíbrio da natureza, com impactos danosos à saúde e ao ecossistema; e

- A perda da biodiversidade, ameaçando a resiliência e a preservação de paisagens (Serra, 2012).

Estas questões Ambientais e Urbanas podem ser ilustradas num simples mapa de fácil obtenção, que utilize a fotografia aérea e o cadastro de logradouros como referência, como é o caso do Mapa 35 abaixo.

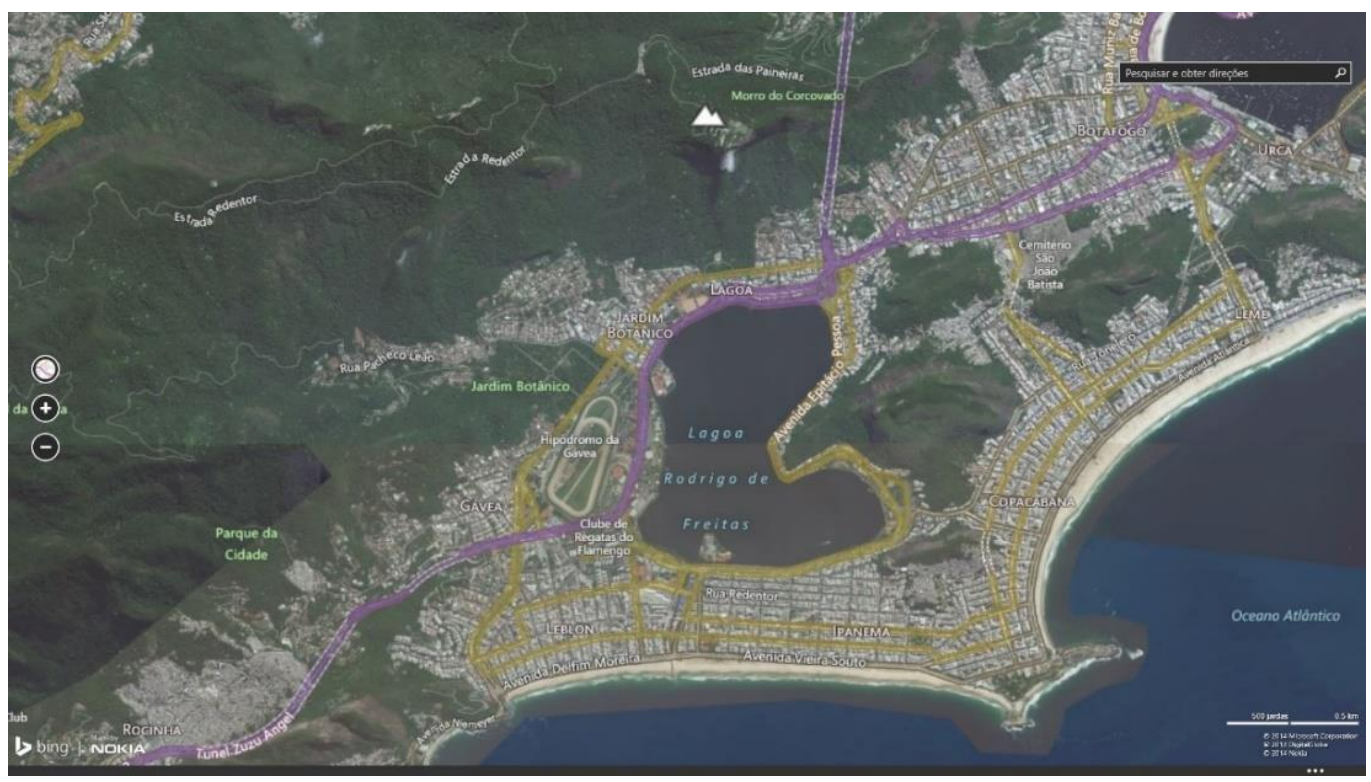

Mapa 35 - Visão Detalhada Urbano x Ambiental - Mapa 2014 - Guia de Ruas NOKIA/MS

Assim, ao pensarmos em dar sequência nas ocupações e modificação de uso do solo, especificamente nas margens das lagoas urbanas, desenvolvendo-se interferências forçadas, que passam até mesmo pela ação de aterros, alteração e extinção da vegetação ciliar e infraestrutura de capitação e condução de águas, devemos nos preocupar com o impacto ambiental e suas consequências, algumas vezes irreversíveis. 
A preservação ambiental com ações de manutenção paisagística e da faunaflora, encontra na implantação de Reservas, Parques, Bosques, etc. ações e medidas bastante eficientes e de grande valor para as Cidades num todo.

Segundo Pinheiro (2009), a Lagoa é o bairro da cidade com a maior dimensão de áreas protegidas proporcionalmente às áreas edificadas e à superfície total do bairro.

$\mathrm{Na}$ região podemos observar a existência de diversos parques e áreas de preservação, além do espelho D’água da LRF e sua Hidrologia:

O Parque Tom Jobim por exemplo, projetado pelo escritório técnico do arquiteto, paisagista e artista Burle-Marx, com área de $210.000,00 \mathrm{~m}^{2}$ e $7.500 \mathrm{~m}$ de perímetro localizado no entorno da Lagoa; e o Parque da Catacumba (ou Carlos Lacerda), acima do Tom Jobim, no Cantagalo inaugurado em 1979; dentre outros.

Assim, utilizando-se o aplicativo ArcGIS e a Base de Dados da região do Município do RJ, disponibilizada no servidor do Laboratório do NIMA - Núcleo Interdisciplinar de Meio Ambiente da PUC-RIO, elaboramos o mapa apresentado a seguir - Mapa E10 Ilustrativo das Áreas de Proteção Ambiental, Parques e Orlas da LRF.

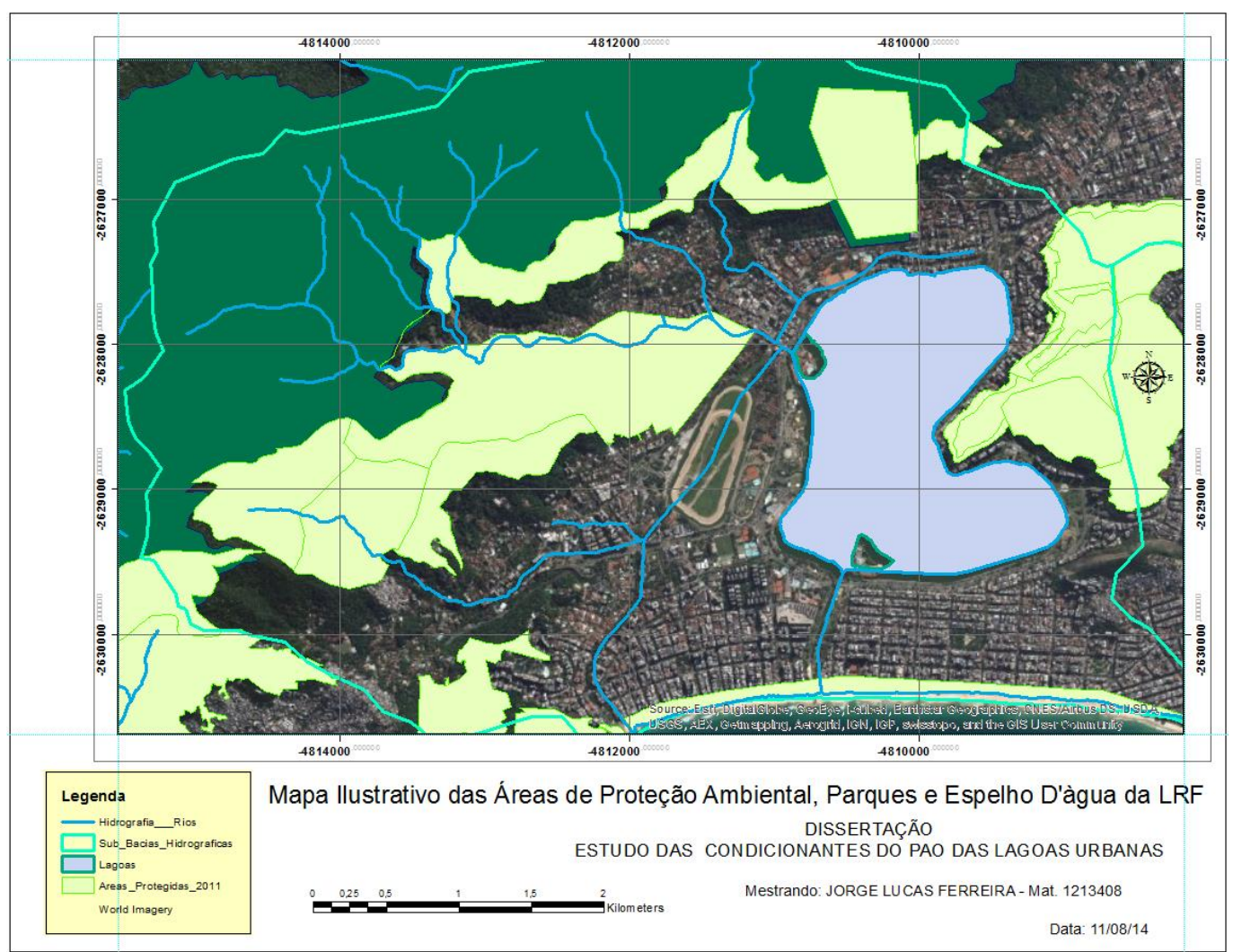

Mapa E10 - Áreas de Proteção Ambiental, Parques e Orla da LRF 
Neste mapa em formato SIG foram pesquisados e obtidos dados cadastrais referentes e vinculados aos Parques e Áreas de Preservação, conforme apresentado na Tabela 16, com itens de campos descritivos, referencias legais e índices quantitativos.

Tabela 16 - Quadro Comparativo de Áreas de Preservação

\begin{tabular}{|r|l|l|r|r|}
\hline \multicolumn{5}{|c|}{ Quadro Comparativo de Parques e Áreas de Preservação } \\
\hline Item & \multicolumn{1}{|c|}{ Legislação } & \multicolumn{1}{c|}{ Área $\left(\mathbf{m}^{\mathbf{2}}\right)$} & Perímetro (m) \\
\hline \hline 1 & Espelho D'água da LRF & Natural & $2.249 .216,25$ & $8.770,041$ \\
\hline 2 & Parque Tom Jobim & DM 14.272 de 09/10/95 & $273.201,97$ & $12.189,778$ \\
\hline 3 & Parque Carlos Lacerda & DM 1967 de 19/01/79 & $298.551,48$ & $2.231,875$ \\
\hline 4 & Parque Garoto de Ipanema & DM 1538 de 02/05/78 & $25.381,50$ & 740,146 \\
\hline 5 & Parque Nacional da Tijuca & DF 50923 de 06/07/61 & $39.726 .100,00$ & $85.477,600$ \\
\hline 6 & Parque Nacional da Tijuca & DF 50923 de 06/07/61 & $1.336 .996,58$ & $11.174,085$ \\
\hline 7 & Parque Henrique Laje & ICMBio & $510.949,98$ & $2.857,356$ \\
\hline 8 & Parque Natural Municipal da Cidade & SMAC & $467.802,74$ & $2.829,613$ \\
\hline 9 & Jardim Botânico & Federal - IP JB-RJ & $1.347 .691,86$ & $7.664,829$ \\
\hline 10 & Parque Natural Municipal do Penhas & DM 11850 de 21/12/92 & $395.475,21$ & $5.697,777$ \\
\hline 11 & APARU do Alto da Boa Vista & DM 11301 de 21/08/92 & $32.108 .800,00$ & $41.114,56$ \\
\hline 12 & APA do Morro dos Cabritos & SMAC & $1.280 .637,17$ & $6.728,69$ \\
\hline 13 & APA do Morro da Saudade & SMAC & $550.100,73$ & $4.433,97$ \\
\hline 14 & APA da Orla Marítma & SMAC & $2.154 .900,00$ & $51.931,21$ \\
\hline 15 & Sub Bacia da LRF & Natural & $23.565 .621,79$ & $21.130,572$ \\
\hline
\end{tabular}

\section{6}

\section{Tecnologia SIG}

O uso do Sistema de Informações Geográficas - SIG (ArcGIS), além da representação gráfica natural e referenciada a um sistema de coordenadas conhecidas (Projeções Georreferenciadas), disponibiliza e agrega também a cada uma das entidades desenhadas atributos e vínculos a um Banco de Dados estruturado, cuja integração com informações complementares permite características incomparáveis de análise, de gestão e de decisão.

Nesta questão, podemos observar que bons resultados também são atingidos naqueles sistemas em que o mapeamento está disponibilizado em sistemas SIG/WEB integrados a um banco de dados on-line, que permite um acesso a informação de modo simples, objetivo e prático, dispensando o uso de hardware, software e humanware especialmente mais apurados e específicos.

Considerando os recursos desse aplicativo SIG - ArcGIS e a disponibilidade da base de dados do Município do RJ no NIMA-PUC-RIO, elaboramos outros mapas temáticos conforme apresentado a seguir. 


\subsection{1}

\section{Padrão Geomorfológico da Bacia}

Foi possível comparar diversos temas de modo mais evidente e iterativo, conforme o Mapa E11 - Padrão Geomorfológico da Bacia da LRF, abaixo ilustrado. Temas como Cursos D’Água; Relevo; Limite de Bairros; Limite da Bacia da Lagoa, etc.

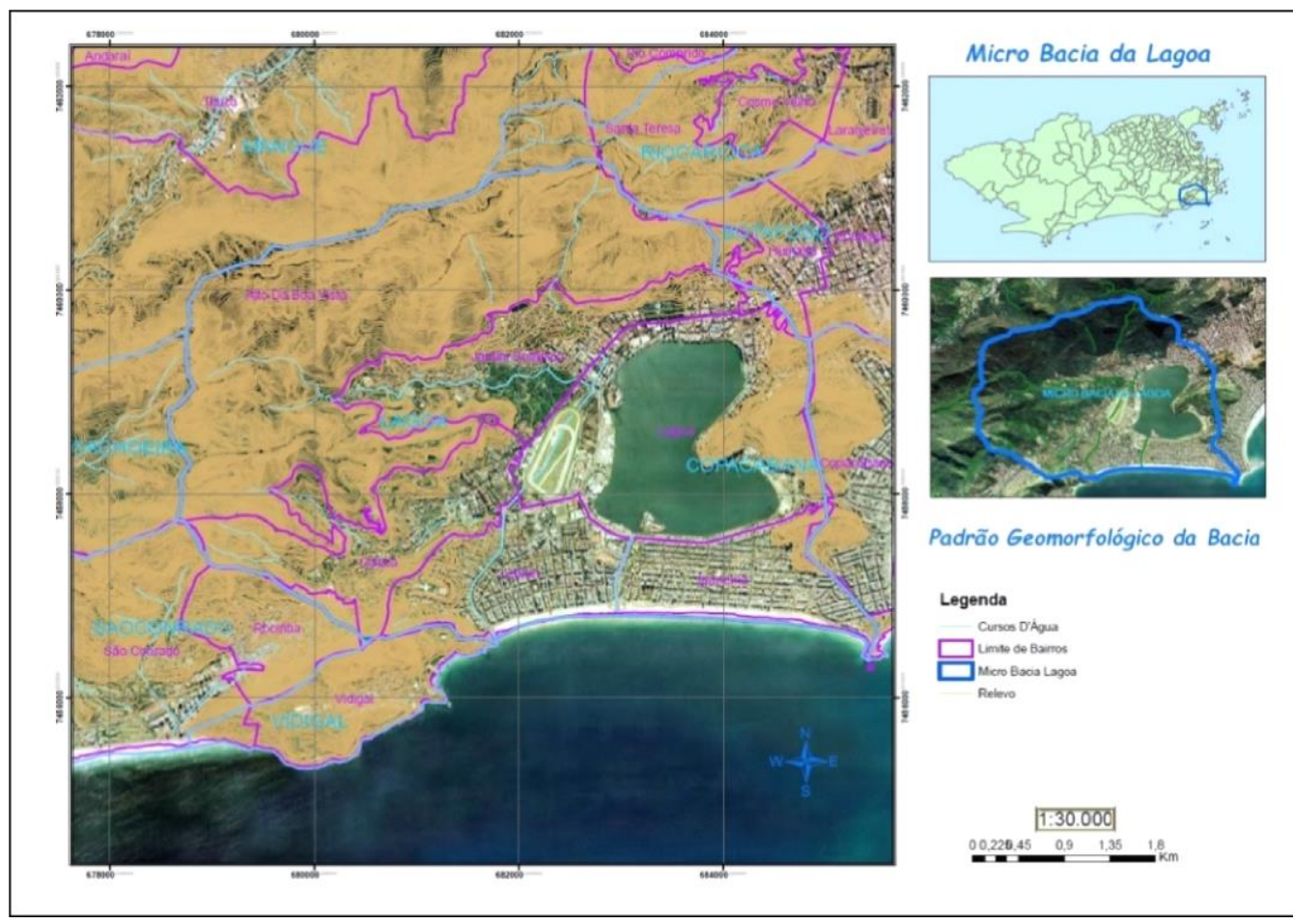

Mapa E11 - Padrão Geomorfológico da Bacia da LRF

\subsection{2}

\section{Padrão de Ocupação da Região}

Para esta análise elaboramos o detalhamento das ocupações na região, representados no Mapa E12 - Padrão de Ocupação, visualizado abaixo, onde destacamos o Eixo dos Logradouros; Áreas de Favelas; Quadras Urbanas; etc. 


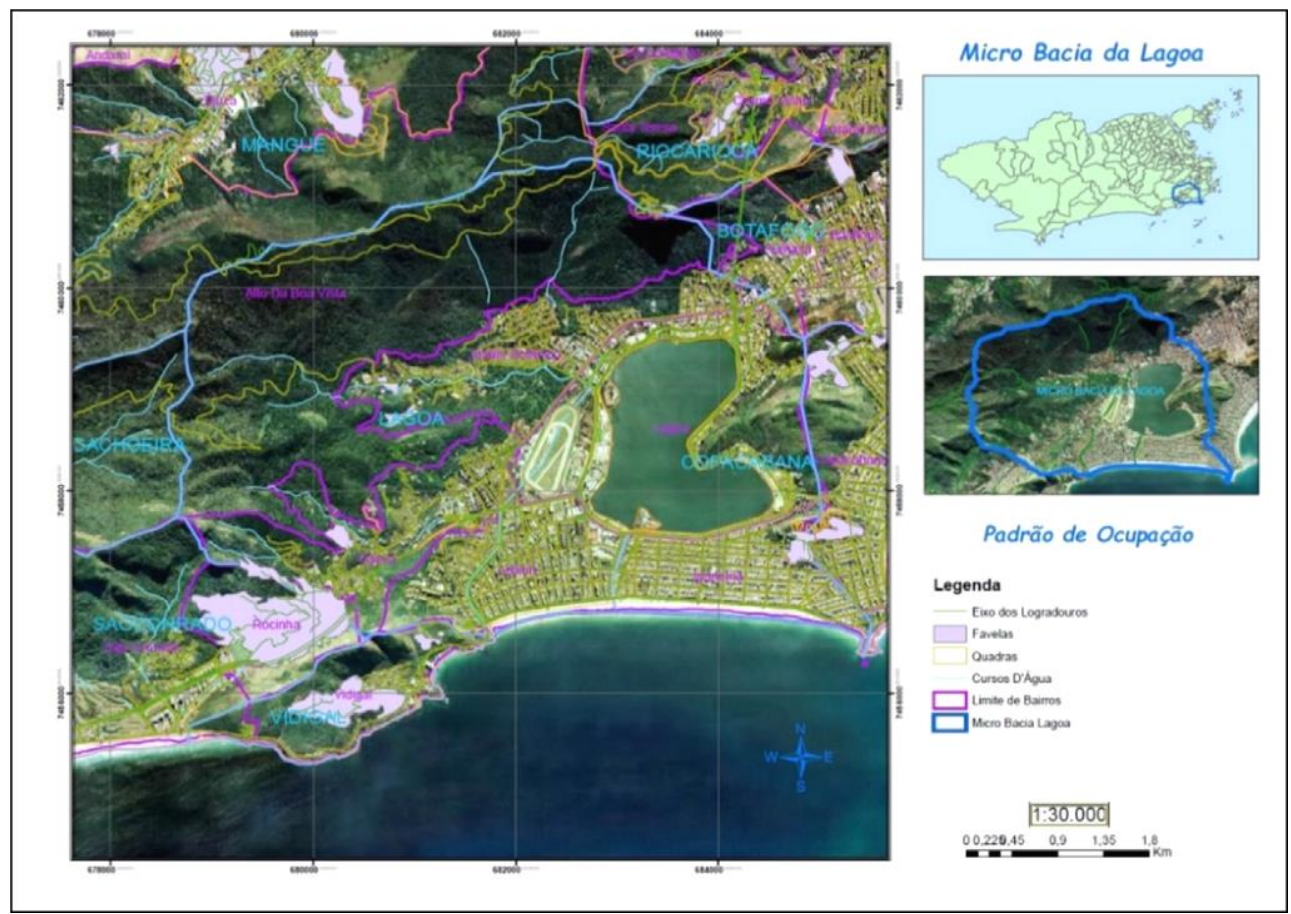

Mapa E12 - Padrão de Ocupação

\subsection{3 \\ Condições da Cobertura Vegetal}

Podemos destacar no Mapa E13 - Condições da Cobertura Vegetal da Região da LRF; abaixo apresentado, a visualização das áreas destinadas a Parques e Ocupações de Quadras e Limite de Bairros.

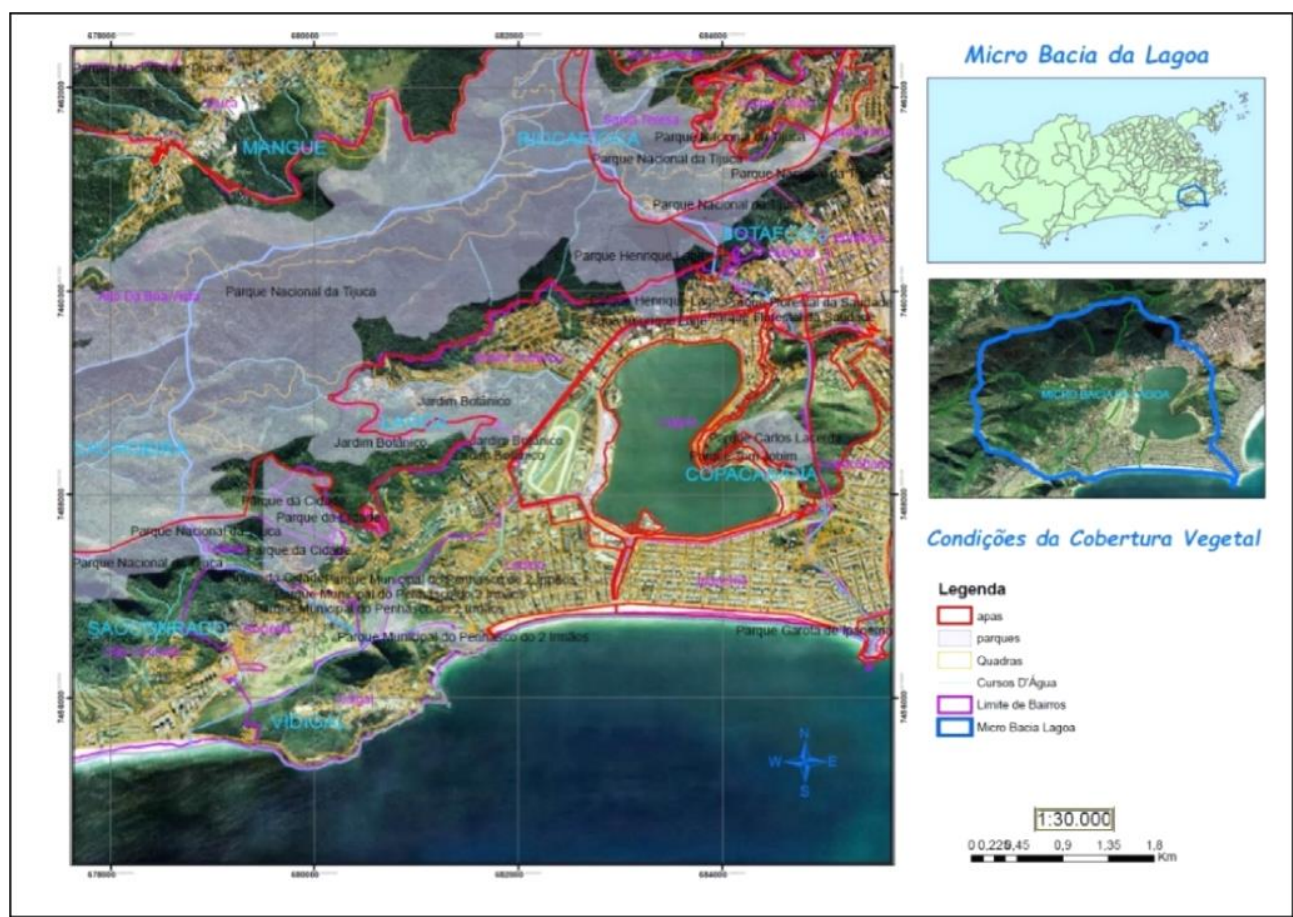

Mapa E13 - Condições da Cobertura Vegetal da Região da LRF 


\subsection{4}

\section{Caracterização da Bacia e Relação com Distribuição de Serviços}

Em função do Georreferenciamento do Banco de Dados utilizado, foi possível destacar e caracterizar os serviços distribuídos em comparação com a Bacia da LRF, conforme o Mapa E14 - Caracterização da Bacia e Relação com Distribuição de Serviços.

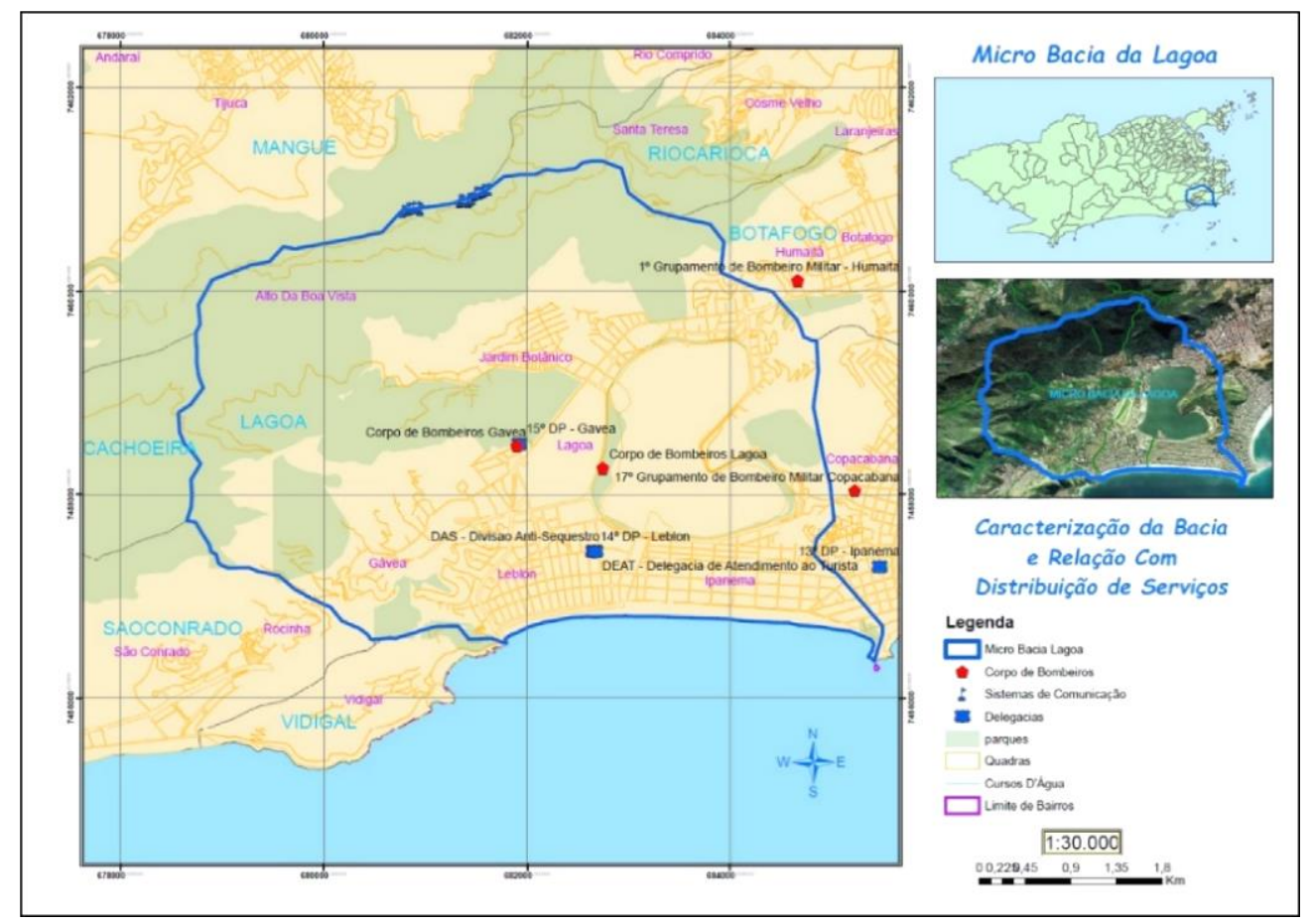

Mapa E14 - Caracterização da Bacia e Relação Com Distribuição de Serviços

\subsection{5}

Comparativo dos Mapas do ExB e DNIT

Outra vantagem do Sistema Georreferenciado foi observada na montagem das folhas Topográficas Cadastrais disponibilizadas pelo Exército Brasileiro, com o lançamento do Traçado da Malha Rodoviária - TMR, o que resultou em pronta referência para uma série de interpretações e visualizações de regiões em vários aspectos já existentes. Mapa já comentado no item 3.5, páginas 55 e 56 - Mapa E01 - Folhas Vila Militar, Baía de Guanabara e TMR. 


\section{5}

\section{CONCLUSÕES E SUGESTÕES}

A pesquisa e análise dos fatores condicionantes que definem o Alinhamento das Lagoas Urbanas, de modo a preservar as melhores condições ambientais, utilizando Tecnologia Digital (CAD/SIG/BDG/WEB), mostraram e comprovaram o grau de complexidade envolvido, conforme o que segue:

1) Quantidade e Diversificação de disciplinas envolvidas (assunto multidisciplinar);

2) Utilização de Tecnologias Digitais (CAD/SIG/BDG/WEB);

3) Utilização de Mapeamento Sistemático Municipal Multidisciplinar;

4) Acesso a Banco de Dados Informatizados complexos e abrangentes;

5) Características distintas e próprias da região em estudo; e

6) Ações Antrópicas intensas e inevitáveis pelas ocupações já existentes.

Assim considerando, concluímos inicialmente ser necessária a busca por uma estruturação organizada e gradualmente incrementada para a metodologia de estudo, dando uma condição evolutiva das ações envolvidas, conforme Tabela 17 abaixo.

Tabela 17 - Evolução das Ações da Metodologia

\begin{tabular}{|c|c|}
\hline \multicolumn{2}{|c|}{ EVOLUÇÃO DAS AÇÕES DA METODOLOGIA } \\
\hline AÇÃO & CARACTERIZAÇÃO \\
\hline ALINHAMENTO DAS LAGOAS URBANAS & OBJETO DE ESTUDO \\
\hline MONTAGEM DE BANCO DE DADOS E ACESSO A INFORMAÇÃO & QUANTIDADE \\
\hline PESQUISAS E ANÁLISES & QUALIDADE \\
\hline CONCEITOS E CORRELAÇÕES / CONCLUSÕES & INTELIGÊNCIA \\
\hline TOMADA DE DECISÕES / PROJETOS E OBRAS & GERÊNCIA E AÇÕES \\
\hline
\end{tabular}


A seguir, ilustramos também essa questão com a montagem do Gráfico 04.

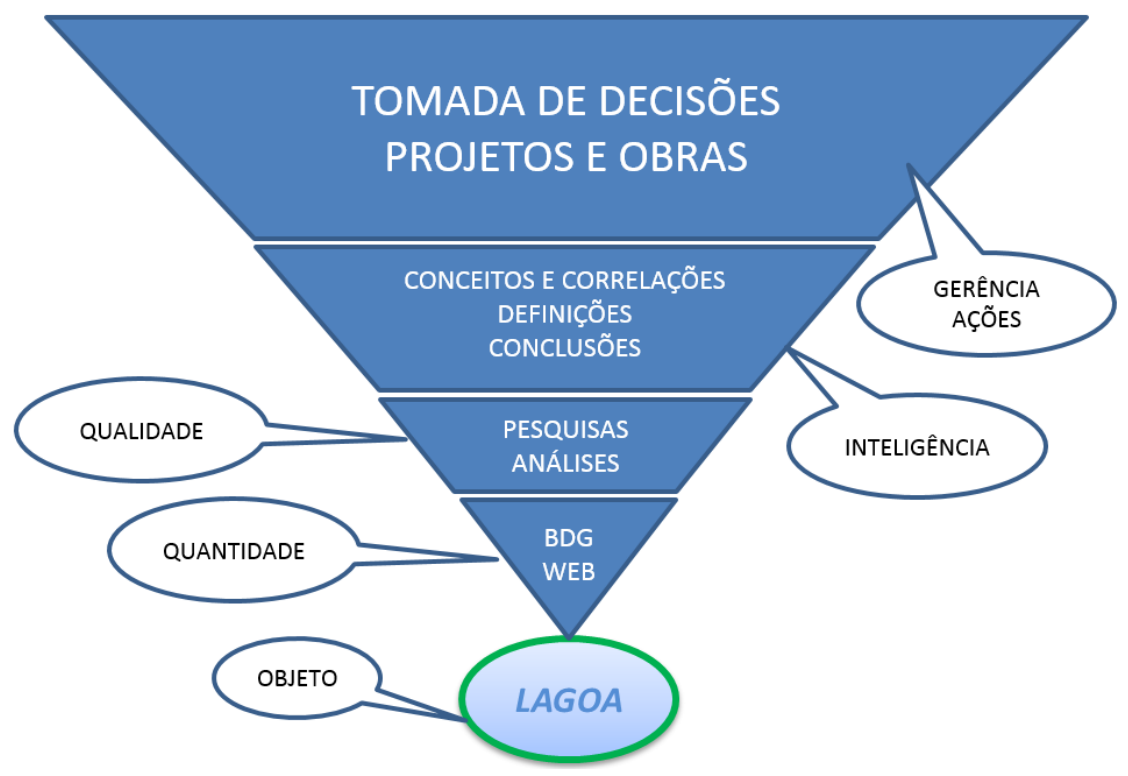

Gráfico 04 - Visualização da Evolução das Ações da Metodologia

Concluímos também, que a utilização das $\underline{\text { Tecnologias Digitais }}$ (CAD/SIG/WEB) se apresenta como uma realidade necessária, prática, eficaz e produtiva, já consolidada no meio técnico, e na maioria dos órgãos, entidades, empresas públicas e privadas, e nos grandes municípios. Apresentando-se como ferramentas padrão, deveriam ser também adotadas pelos demais municípios brasileiros, como um todo.

Entendemos que este estudo alcançou seus objetivos, experimentando uma linha de pesquisa e desenvolvimento, utilizando ferramentas modernas e atuais de obtenção e tratamento de dados e informações, de modo a determinar uma relação de escala de valores, capaz de sinalizar e mensurar os Fatores Condicionantes conceituados.

É fato conclusivo e evidente também, que no caso específico da Lagoa Rodrigo de Freitas, a determinação do "Tombamento Definitivo" do Espelho D’água, cujos limites estão definidos no PAA-9548 estudado, foi um marco fundamental para sua preservação, e evitar novas ocupações e perdas ambientais, por considerar constituir-se a Lagoa como um bem cultural de notável beleza paisagística, e de relevante significado cultural para a cidade do Rio de Janeiro (DM n. ${ }^{\circ} 9396$ de 13-06-1990). 
Mas mesmo com esta importante decisão eminentemente técnica e delimitadora, as atividades humanas e as ações urbanas já instaladas e consolidadas, bem como as transformações e modernizações que por ventura venham a ser realizadas, em conjunto com atividades constantes e cada vez mais intensas, continuam a ameaçar e interferir na saúde da Lagoa e suas condições ambientais.

Podemos observar na elaboração desta Dissertação, o alcance de diversos outros objetivos secundários, que agregaram constatações bastante interessantes, a saber:

1) Desburocratização e Democratização do acesso a informação pelo uso de Portais pelos Órgãos e Entidades Públicas;

2) Facilidade em obtenção de Mapas e Plantas Municipais com o uso de Tecnologias Digitais;

3) Comprovação da qualidade e confiabilidade das informações através da comparação dos dados obtidos em diversos níveis e locais;

4) Comprovação da consolidação e confiabilidade do uso das Tecnologias Digitais (CAD/SIG/BDG/WEB).

Encerramos, sugerindo para um melhor entendimento da relação e importância que cada um dos fatores condicionantes tem com o resultado final do Alinhamento das Lagoas Urbanas, a elaboração de um estudo e entendimento mais intrínseco e abrangente, naturalmente muito mais complexo, devendo ser desenvolvido com a adoção de uma escala de valores objetivando classificar cada um dos fatores condicionantes encontrados, de modo a analisar e mensurar a importância e/ou influência e correlação de cada um deles no resultado final. 


\section{Referências Bibliográficas}

BLASCHKE, Thomas / KUX Hermann. Livro: Sensoriamento Remoto e SIG Avançados - Novos sistemas Sensores - Métodos Inovadores Versão Brasileira atualizada e Organizada por. - Título Original: Fernerkundung und GIS - 2007 - Editora Oficina de Textos

BRITO, Jorge Nunes; COELHO, Luiz. e-book: Fotogrametria Digital $-1^{\underline{a}}$ Edição 2007 - Editora da Universidade do Estado do Rio de Janeiro Revisado em 2009.

CALIXTO, Robson José. Tese: Estabilidade Hidráulico-Sedimentológica de Embocaduras de Canais de Maré - O Caso da Lagoa Rodrigo de Freitas - RJ; Tese apresentada para Pós-Graduação de Mestre em Ciências em Engenharia Oceânica - UFRJ - 1990

CELU - Comitê Especial de Legado Urbano. Plano de Legado Urbano e Ambiental - Olimpíadas Rio 2016 - Prefeitura Rio - SMU - CGPU Coordenadoria Geral de Planejamento Urbano - GMP Gerência de Macroplanejamento.

CEMG - Comitê de Estruturação de Metadados Geoespaciais CONCAR. Norma: Perfil de Metadados Geoespaciais do Brasil (Perfil MGB) - Em Conformidade com a Norma ISSO 19115:2003 - Editora Biblioteca do IBGE

COMASTRI, José Anibal / TULER, José Claudio. Livro: TOPOGRAFIA Altimetria - 3를 Edição - 2010 - Editora UFV.

DNIT - Departamento Nacional de Infraestrutura de Transportes. Atlas Multimodal - UFPR - Universidade Federal do Paraná - 1를 Edição Curitiba - 2011.

DNIT - Departamento Nacional de Infraestrutura de Transportes. Glossário de Termos Técnicos Ambientais Rodoviários - Instituto de Pesquisas Rodoviárias - 2006.

DSG - Diretoria de Serviços Geográficos - Exército Brasileiro. Manual do Usuário BDGEx - Ministério da Defesa - 2012.

FILHO, Gilberto Milhomem Marinho; ANDRADE, Rui da Silva; JUNIOR, Joel Carlos Zukowski; e FILHO, Luiz Norberto Lacerda Magalhães. Publicação: MODELOS HIDROLÓGICOS: Conceitos e Aplicabilidades; Publicação: Revista de Ciências Ambientais - Canoas - 2012. 
FONSECA, Estefan Monteiro da / NETO, José Antonio Batista. Estudo: "Caracterização da Lagoa Rodrigo de Freitas - Aspectos Ambientais" Levantamento da Linha de Base da Lagoa Rodrigo de Freitas - Okeanos e EBX - Disponível no Portal da Lagoa Limpa - 2014.

FURTADO, André Luiz dos Santos e outros autores; TÔSTO, Sérgio Gomes, e outros Editores Técnicos. Livro "Geotecnologias e Geoinformação", EMBRAPA - "Coleção 500 Perguntas 500 Respostas: o produtor pergunta e a Embrapa responde" - 2014 - Editora EMBRAPA Min. Agric. Pec. E Abast.

GEOCIÊNCIAS, Diretoria - IBGE - Instituto Brasileiro de Geografia e Estatística. Manual Técnico de Geomorfologia - 2 $2^{\underline{a}}$ Edição - Rio de Janeiro - 2009.

GEOCIÊNCIAS, Diretoria - IBGE - Instituto Brasileiro de Geografia e Estatística. Atlas Geográfico das Zonas Costeiras e Oceânicas do Brasil Rio de Janeiro - 2011.

GONÇALVES, José Alberto / MADEIRA, Sérgio / SOUZA, J. João. Livro: Topografia - Conceitos e Aplicações - 2012 - Editora Lídel.

HEIZER, Alda / GASPAR, Cláudia Braga, Livro: Solar da Imperatriz 2011 - Jardim Botânico do Rio de Janeiro.

KJERFVE, Björn. Livro: Coastal Lagoon Processes - Editora Elsevier Science B. V. - 1994.

LOCH, Carlos / CORDINI, Jucilei. Livro: Topografia Contemporânea Planimetria - 1995 - Editora da UFSC.

MARTINELLI, Marcelo. Livro: Mapas, Gráficos e Redes - Editora Oficina de Textos - 2014.

MELLO, Flávio Miguez de. Livro: Episódios da Engenharia (e da política) no Brasil - 1ㄹ Edição - 2014 - Rio de Janeiro: CBDB - Comitê Brasileiro de Barragens

MIRANDA, E. E. de; (Coord.). Brasil em Relevo. Campinas: Embrapa Monitoramento por Satélite, 2005. Disponível em: <http://www.relevobr.cnpm.embrapa.br>. Acesso em: 13 set. 2014. 
ORLANDO, Marcos Tamoio César Seroa da Mota e SOARES NETO, Feliciano Leão Pedro Teixeira - IPHAN - Instituto do Patrimônio Histórico e Artístico Nacional. Decreto n. -130 , de 10/08/75 - Aprova o Projeto de Alinhamento 9.548, que Delimita o Espelho D’Água da Lagoa Rodrigo de Freitas - Publicado no "Diário Oficial" do Estado do Rio de Janeiro.

PINTO, Nelson L. de Sousa / HOLTZ, Antonio Carlos Tatit / MARTINS, José Augusto, GOMIDE, Francisco Luiz Sibut. Livro: Hidrologia Básica 2011 - Editora Edgard Blucher

PINHEIRO, Eliane Canedo de Freitas / PINHEIRO, Augusto Ivan de Freitas / RABHA, Nina Maria de Carvalho Elias / CORREA, Marcos Sá. Livro: Lagoa - Lagoa Rodrigo de Freitas - 2009 - Editora Andrea Jakobsson.

PONSONI, Flávio Jorge / SHIMABUKURO, Yosio Edemir. Livro: Sensoriamento Remoto no Estudo da Vegetação - São José dos Campos, SP - 2007 - Editora Parêntese.

Prefeito Municipal da Cidade do Rio de Janeiro. Decreto n.o 9396, de 13/06/1990 - Determina o Tombamento Definitivo da Lagoa Rodrigo de Freitas (PAA-9.548) e o seu Entorno - Prefeitura do Rio.

SERRA, M V / SERRA, Maria Teresa F. Livro: Guia da História Natural do Rio de Janeiro - 2012 - Editora CIDADE VIVA.

SIQUEIRA, Andréia Espinola de. Livro: Guia de Campo do Parque Nacional da Tijuca - Editora UERJ / IBRAG - 2013

SMU, Secretaria Municipal de Urbanismo - Prefeitura do Rio de Janeiro Legislação Urbana On-Line - Manual do Usuário - 2009.

SOUZA, Paulo Ferreira de. Livro: Terminologia Florestal - Glossário de Termos e Expressões Florestais - Editora Biblioteca do IBGE - 1973.

TUCCI, Carlos E. M.; MENDES, Carlos André. Publicação: Avaliação Ambiental Integrada de Bacia Hidrográfica; Publicação no âmbito do Projeto de Instrumentos de Gestão Ambiental - PROGESTÃO - MMA 2006.

VILLAÇA, Flávio. Livro: Espaço Intra-Urbano no Brasil - Editora Studio Nobel - Publicado em 2001 e Reimpresso em 2007. 


\title{
Portais Internet Consultados:
}

\author{
https://www.google.com/earth/ (Acesso em 12/07/14) \\ http://www.geoportal.eb.mil.br/ (Acesso em 25/06/14) \\ https://www.embrapa.br/home $\quad$ (Acesso em 09/07/14)
}

http://www.relevobr.cnpm.embrapa.br $\quad$ (Acesso em 23/07/14)

http://www.bdclima.cnpm.embrapa.br/ (Acesso em 23/07/14)

http://dnit.gov.br/ $\quad$ (Acesso em 01/07/14)

http://www.der.ri.gov.br/ $\quad$ (Acesso em 26/06/14)

http://www2.rio.ri.gov.br/smu/ (Acesso em 01/07/14)

http://mapas.rio.ri.gov.br/\# $\quad$ (Acesso em 01/07/14)

http://www.armazemdedados.rio.ri.gov.br/ $\quad$ (Acesso em 01/07/14)

http://www.urbanismobr.org/novosite/index.php?acao=pre cds dvds $\quad$ (Acesso em 25/06/14)

http://www.urbanismobr.org/bd/localizacoes.php?id=2 (Acesso em 25/06/14)

http://www.parquedatijuca.com.br// $\quad$ (Acesso em 03/07/14)

http://www.rioquepassou.com.br// $\quad$ (Acesso em 03/07/14)

http://abcd.jbrj.gov.br/site/php/index.php $\quad$ (Acesso em 19/07/14)

http://historia.jbri.gov.br/fotos/imagens.htm $\quad$ (Acesso em 19/07/14)

http://www.lagoalimpa.com.br/ $\quad$ (Acesso em 03/07/14)

http://www.rio.ri.gov.br/web/rio-aguas (Acesso em 25/06/14)

http://www.rio.ri.gov.br/web/smac/gestao-da-lagoa-rodrigo-de-freitas (Acesso em 25/06/14) 
http://www.ana.gov.br

(Acesso em 26/05/14)

http://hidroweb.ana.gov.br/ $\quad$ (Acesso em 26/05/14)

http://www.revistas.unilasalle.edu.br/ $\quad$ (Acesso em 24/06/14)

http://www.mma.gov.br/ $\quad$ (Acesso em 23/06/14)

http://www.ibge.gov.br/ $\quad$ (Acesso em 23/06/14)

http://www.oceanica.ufrj.br $\quad$ (Acesso em 23/06/14) 


\section{Anexos}

Anexo 01 - Banco de Dados Climáticos do Brasil - RJ.

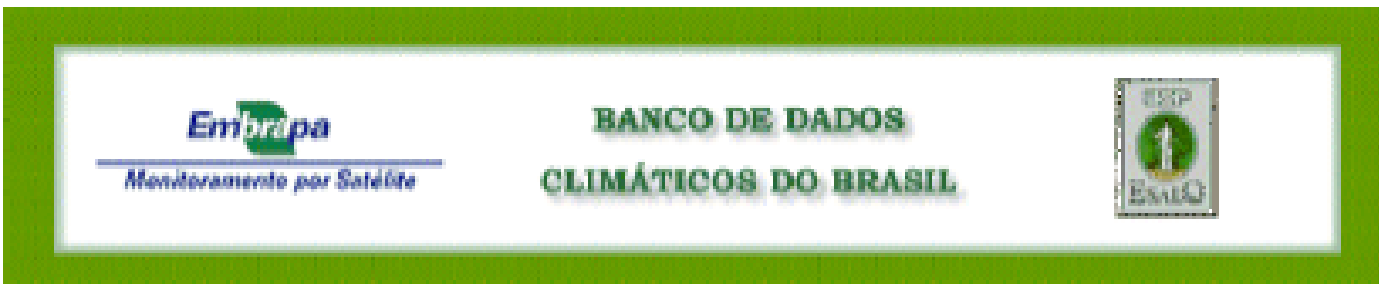

Municiple: Nio de Janeiro - RT

Latitude: 22,92 S Lengitude: 43,17 W Altitude: 5 m Periodo: 1973-1990

$\begin{array}{rrrrrr}\begin{array}{c}\text { P } \\ (\mathbf{m m})\end{array} & \text { ETP } & \begin{array}{r}\text { ARM } \\ (\mathbf{m m})\end{array} & \begin{array}{c}\text { ETR } \\ (\mathbf{m m})\end{array} & \begin{array}{c}\text { DEF } \\ (\mathbf{m m})\end{array} & \begin{array}{c}\text { EXC } \\ (\mathbf{m m})\end{array} \\ 105 & 147 & 72 & 142 & 5 & 0 \\ 103 & 139 & 51 & 125 & 13 & 0 \\ 137 & 139 & 36 & 119 & 21 & 0 \\ 86 & 107 & 66 & 107 & 0 & 0 \\ 80 & 87 & 65 & 87 & 0 & 0 \\ 56 & 66 & 79 & 66 & 0 & 0 \\ 50 & 66 & 72 & 64 & 2 & 0 \\ 87 & 73 & 57 & 65 & 8 & 0 \\ 88 & 74 & 70 & 74 & 0 & 0 \\ 96 & 93 & 66 & 91 & 2 & 0 \\ 169 & 112 & 56 & 106 & 6 & 0 \\ \mathbf{1 . 1 7 1} & 1.235 & 90 & 135 & 0 & 0 \\ 98 & 103 & 779 & 1.181 & 58 & 0 \\ & 1.23 & 98 & 5 & 0\end{array}$

Fente:TNMET

$$
\begin{array}{r}
T \\
(" \mathrm{C}) \\
26,2 \\
26,5 \\
26,0 \\
24,5 \\
23,0 \\
21,5 \\
21,3 \\
21,8 \\
21,8 \\
22,8 \\
24,2 \\
25,2 \\
284,8 \\
23,7
\end{array}
$$

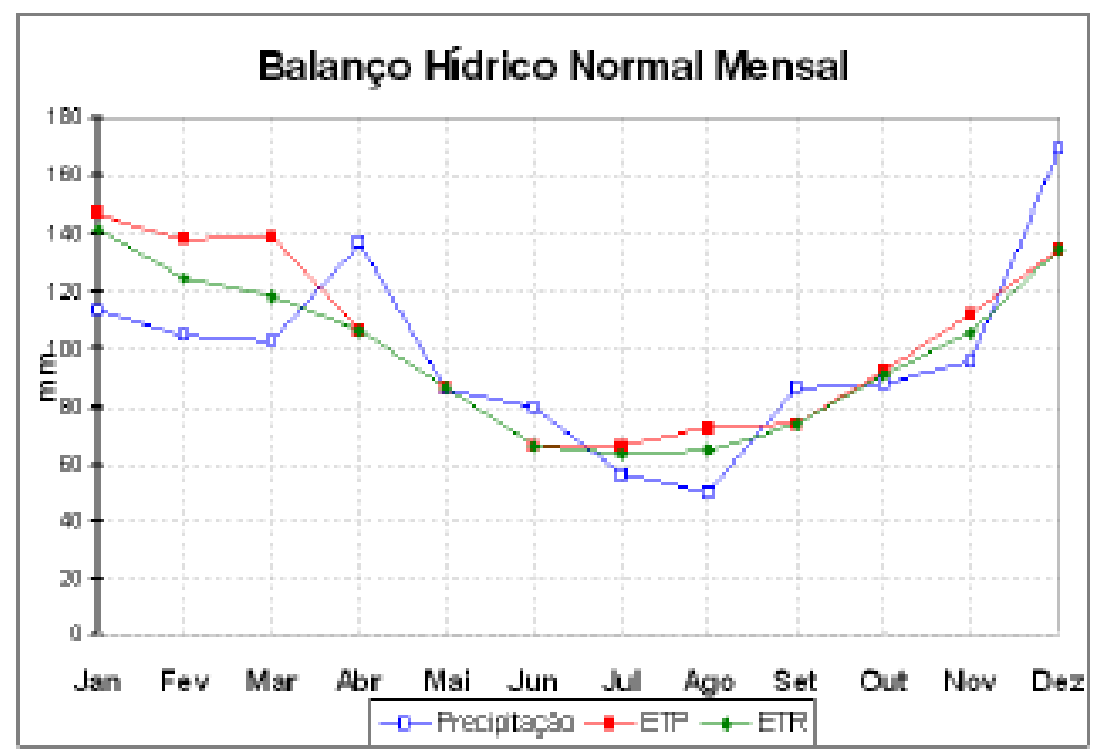



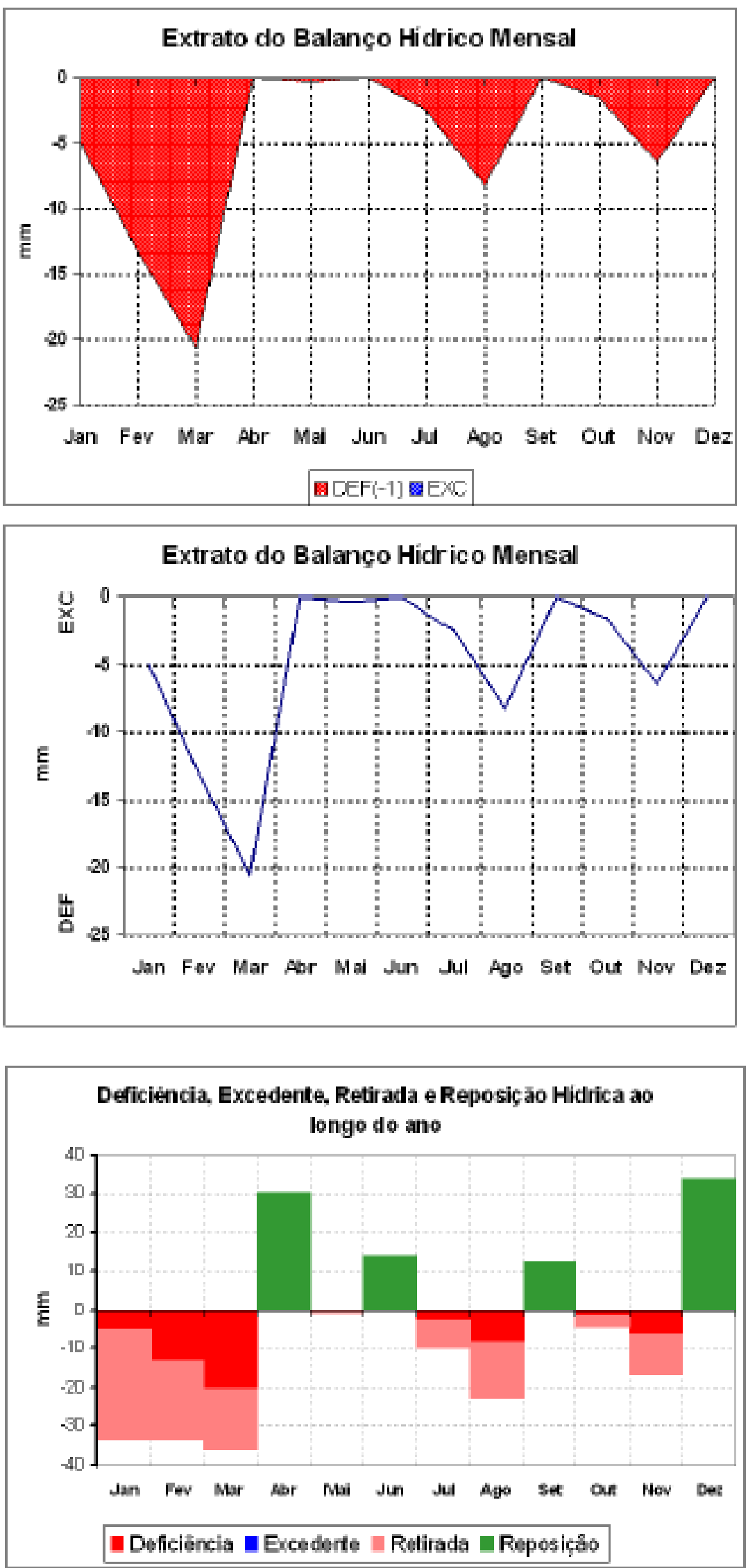
151

Anexo 02 - Manual Legislação Urbana On-Line

Legislação Urbana On-Line

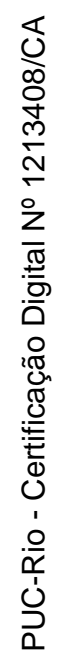

MANUAL DO USUÁRIO

MARÇO/2009 


\section{Uuizando o aplicanivo - conhecendo o sistema e suas informapoes}

Inicialmente, navegue pelo gistems para conhecer sa imagens e informag̨edes que vocé poderb́ obter. Em seguida, baive o Autodesk DWF Vewer, strakés do link indicado, para visualizar as plantas cacestrais doe trechos selecionacos.

Depols seleclone o trecho de logradouro de seu Interesse ou enderepo e ve|a as Informaçbes referentes a ele. Em algumas ocasides o sistema podera ficar lento em funçato, princlpalmente, do grande nümero de informaçbes (camadas) de que dlspbe e que tem que ser consutadas toda vez que uma pesqulsa e realzada. Outros fatores que tambem poderăo Influenclar a navegaçăo no sistema săo o horarlo de acesso, a velocldade da banda larga e o sistema operaclonal do usuarlo - que devera ser no minimo Windows XP e navegador Internet Explorer 7.

Pesquleando os dados

A tabela de dados (figura abalxo) apresenta as dversas "camadas" dos mapas e se compdem de dols grandes grupos de informaģbes utanisticas, alem da legenda:

1. Intomaçoses Disponlwels

2. Leglalacto de Uso e Ocupaça

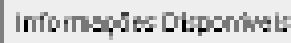

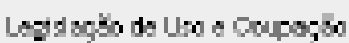

Leprots

O Item 1, Informaçoes Dleponivels (figura abalxo) apresenta:

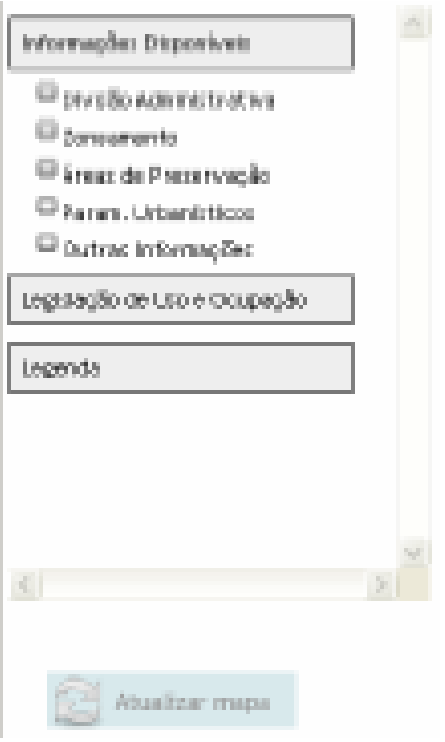




\section{Dlvlaso Administratlva}

Fepresenta a delimitaçấo da Dlvisấo Adminlstrativa do territorio do Municiplo do Filo de Janelro que se compdem por Areas de Planejamento, formadas por agrupamento de varlas Reglbes Admin/strattvas e estas por agrupamentos de balrros.

\section{Zoneamento}

Contem as macrozonas de restrlçấ a ocupaço urbana determinadas pela Lel complementar $n^{*} 16 / 92$ - Plano Diretor, que se consittuem por areas agricolas, areas com condlçbes f'islcas adversas a colpaçato, areas Improprias a urbanlzaçao e areas destinadas a proteça do melo amblente. Tambem estao definldas as macrozonas do Decreto $n^{2}$ 28.801107, que tem por objettvo orlentar a expansto da ocupaçato urbana, as açbes de planejamento urbano, a regulamentaçâo e a apllcaça dos Instrumentos da Politica Urbana, alem de lindlcar as proridades na dlstribulpho dos Investimentos. Apresenta tambem as zonas, centros de balmo e logradouros comerclas do Decreto $322 / 76$, o Regulamento de Zoneamento da cldade; as zonas dos Projetos de Estruturaça Urbana (PEUs), lintroduzldos no planejamento urbano da cldade pelo Plano Urbanistco Baslco da Cldade do Rlo de Janelro (PUBFiO), aprovado pelo Decreto n" 1.26977 ; as zonas amblentals crladas com as Areas de Preservacto e as Areas de Especlal Interesse (AEI), que se classiflcam contome sua destinaça, promulgadas por lels especifleas ou atraves dos PEUs. Este amplo conjunto de nomas compde o zoneamento da cldade.

\section{Areas de Pregervaço}

A partir da politica de melo amblente e de valorlzaģa do patrimonlo cultural do Municiplo, que visa a proteçâ, recuperaçấ e conservaçáo da memoria construlda, suas palsagens e seus recursos naturals, as areas de preservaço foram Implantadas em diversas regibes da cldade. Esta "camada" apresenta a dellmltaço das respectivas APAs, APACs e parques, que representam a proteçato e valorizaça do melo amblente e do patrimonilo cuitural.

\section{Parâmetros Urbaniaticos}

Contem o gabarto, que representam as dimensbes regulamentares pemitidas ou fxadas para uma edifcaço - altura maxima ejou o numero de pavimentos permilidos conslderando o posiclonamento da construço no lote (se afastada ou nto das dlvisas) e sua locallzaça no balmo. Na cldade o gabarito e dado pelo Decreto 322/76, pelos Projetos de Estruturaço Urbana (PEUs) e Projetos Aprowados de Loteamento (PALE).

\section{Outras Informaçoes}

Sâo "camadas" auxillares, que tratam de temas dlversos e visam compor os mapas e o conjunto de Informaçes escolhidos pelo usuario, de acordo com seu interesse.

Nunca se esqueça de aclonar o botäo apos a escolha de um ou mals temas de Interesse, na tabela de "camadas", para que a Informaça desejada seja processada e consequentemente visuallzada no mapa. 
O Item 2, Leglslaçăo de Uso e Ocupaçăo do solo (figura abalxo) reune as Informaçoes urbanisticas dlsponivels no slstema:

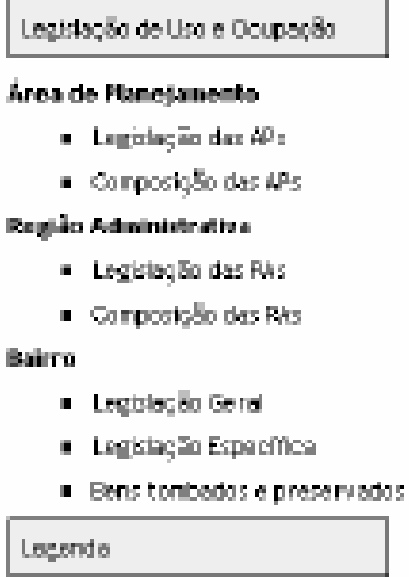

Conectado ao aplicativo Busca Facll, apresenta a leglslaçăo geral e especifica de todos os bairros da cldade. Alem dlsso, tambem estắo disponivels lels e decretos referentes as Aureas de Planejamento (A.P) e as Reg/Des Adminlstrativas (RA), assim como os quadros com a composiçăo de cada AP e RA. A Leglslaçăo Geral reùne os regulamentos gerals e a Leglslaçăo Especinca Indica as normas referentes a cada bairro. A llstagem de Bens Tombados e Preservados, Imovels ou năo, reune aqueles contemplados pelas normas municipals, estaduals e federals de preservaçáo.

O Item 3, Legenda (ngura abalxo), apresenta as formas e cores escolhidas para representar as "camadas" de informaçbes.

Intornacides Dtrponituet

Lovisapio de Usoe anupsebso

Lezende

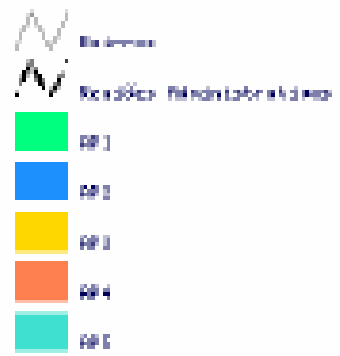




\section{Realizando a pesquisa}

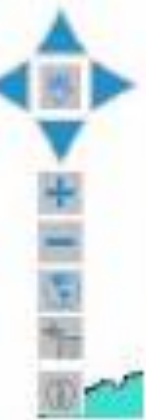

A pesquisa da legislaçăo de uma determinada area tera como refertencia sempre um trecho de logradouro e podera ser felta se utilizando a barra de ferramentas, atraves da dellmitaçalo de um trecho. A mesma pesquisa podera ser realzada na barra de menu uttllizando-se o endereço.

A Informaç5̆o solicitada sera capturada se utilzando o icone informaçaso da barra de ferramentas. As Informaçoes que aparecem no Resuitado da Pesquisa se referem ao trecho escolnido do logradouro ou ao endereço Indicado.
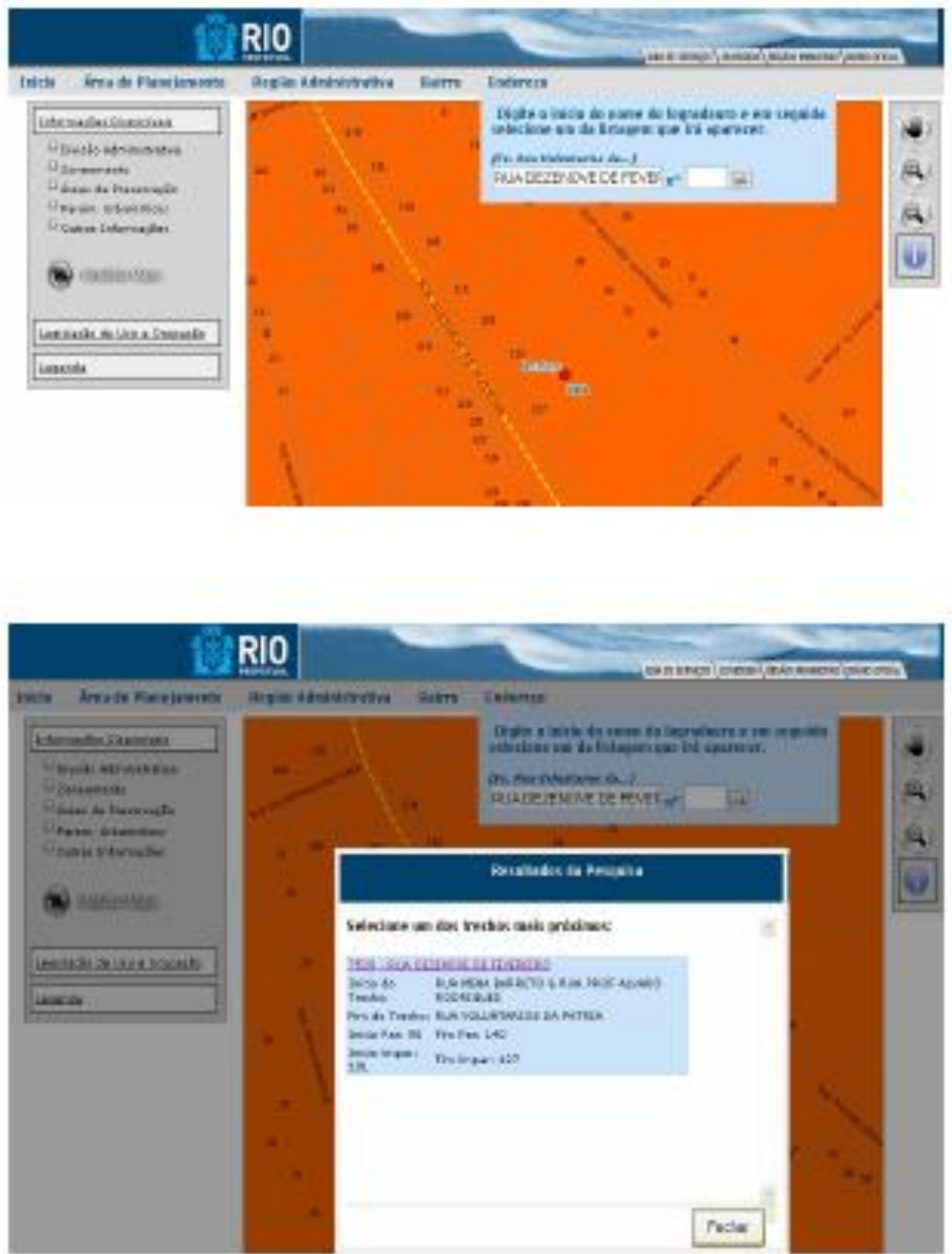
A planlliha "Informaçbes Detalhadas", Indlcando o trecho e as Informaçbes disponivels no sistema, sera gerada a partir da seleçăo de um trecho de logradouro ou endereço e podera ser Impressa. O nome da planta cadastral Indlcada, no resultado da pesqulsa, e um link para a Imagem do indice dos Projetos Aprovados de Allnhamento - PAAs em vigor. Para obter a Informaçáo especifica dos parametros definidos no PAA, do trecho ou endereço de seu Interesse, o usuario deve consultar o PAA original, disponivel no slte da SMU ou na Gerencla de Cadastro Tecnico da SMU - Rua Afonso Cavalcante 455/sala 1104 - Cldade Nova (ver no slte horario de atendimento).

A planlliha "Informaçbes Detalhadas" năo substitul a Certidăo de Informaçbes, documento oficlal emitido pela Secretarla Municipal de Urbanismo, que podera ser obtida junto as Gerenclas e Subgerenclas de Licenclamento e Flscalizaçăo - ver relaçăo e endereços na Pagina da SMU (www.rio.rl.gov.brismu).

\section{RIO}

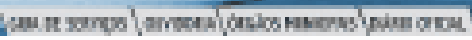

\section{Informações Detalhadas}

\section{1 - Localizaçăo}

\begin{tabular}{|c|c|}
\hline Lagradearec & CESID - RUA DEZENOUE DE FEVEREIO \\
\hline If Alla de Trecho: & FUL MENL BLARETO \& RUA PRCF ALWAKO ACCALCLES \\
\hline Fin do Trecho: & FUAA WOUNTKAIOS DA PRTRIA \\
\hline Inilcia Par: タI & Pin Par: 140 \\
\hline If Acla impari $10 t$ & Fin impan 127 \\
\hline Balirrec Batafe go & RA: $1 Y \quad$ AF $: 2$ \\
\hline Departarenta: & 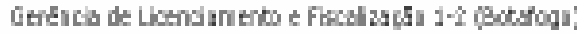 \\
\hline
\end{tabular}

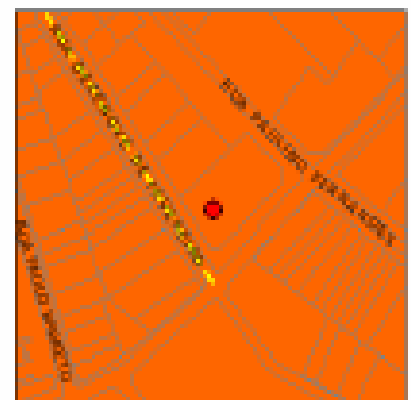

\section{2 - Dados Cadastrais do Logradouro}

planiar Cadartain

3 - Zoneamento
Plarta Codatral 207024 Dur

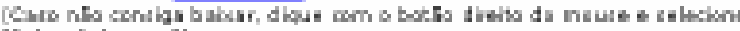
Yaka knk esmo'?

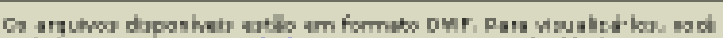

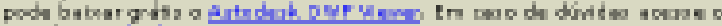
ite de Sulatist. 


\section{Anexo 03 - Cl Detalhadas - trecho Av Borges de Medeiros}

SMU - Informações Detalhadas

Página 1 de 2

ERIO

SECRETARIA MUNICIPAL DE URBANISMO

Informações Detalhadas

1 - Localização

\begin{tabular}{|c|c|}
\hline Logradouro: & 107276-AVN BORGES DE MEDEIROS \\
\hline Início Par: 0 & Fim Par: 0 \\
\hline Início impar: 0 & Fim impar: 0 \\
\hline Bairro: Lagoa & RA: VI \\
\hline Departamento: & 1 GLF Lagoa \\
\hline Endereço: & Avenida Bartolomeu Mitre, 1297 - Gávea \\
\hline Telefone(s): & Telefone: 22744098 \\
\hline
\end{tabular}

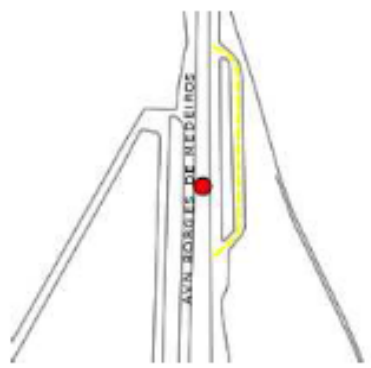

2 - Dados Cadastrais do Logradouro

\begin{tabular}{|c|c|}
\hline Plantas Cadastrais & Planta Cadastral 287 II 1 \\
\hline $\begin{array}{l}\text { Projetos Aprovados de Alinhamento (PAA) } \\
\text { Projetos Aprovados de Loteamento(PAL) }\end{array}$ & $\begin{array}{l}\text { Os arquivos disponiveis estāo em formato DWF. Para visualizdi-los, você pode baixar } \\
\text { grátis o Autodestk. DWF Viemar. Em caso de dúvidas acesse o site da Autodesti. }\end{array}$ \\
\hline $\begin{array}{l}\text { Plantas de Alinhamentos Projetados (PAP) } \\
3 \text { - Zoneamento }\end{array}$ & - \\
\hline MacroZona & Macrozona de Ocupaçăo Controlada - Plano Diretor_LC111/2011 \\
\hline Zona & Zona Turistica 1, consulte a(s) norma(s): Decrete 322/1976 \\
\hline SubZona & - \\
\hline Centro de Bairro & $\cdots$ \\
\hline Zona Ambiental & - \\
\hline Área de Especial Interesse (AEI) & - \\
\hline
\end{tabular}

ATENÇ̃̃o: quando se tratar de limite de zona, observar Artigo 115 e 121 do Regulamento de Zoneamento (RZ) Decreto $322 / 1976$ e
legislaçăo específica no caso de Projeto de Estruturaçŏo Urbana (PEU).

4 - Gabarito de Altura

Edificaçăo afastada das divisas

Decreto 9396/1990 Decreto 21191/2002 Decreto 130/1975 - setor E - 4m

Edificaçăo nb̆o afastada das divisas

Decreto 9390/1990 Decreto 21191/2002 Decreto 130/1975 - setor E - 4m

\section{5 - Áreas Protegidas}

\begin{tabular}{|c|c|c|c|c|}
\hline \multicolumn{2}{|c|}{ Área de Proteçăo do Entorno de Bem Tombado (APE) } & \multicolumn{3}{|c|}{ Lagoa Rodrigo de Freitas - Deacreto 939,6/1990 } \\
\hline \multicolumn{2}{|c|}{$\begin{array}{l}\text { Composiçăo Paisagistica e Ambiental } \\
\text { Proteç̧̄o Paisagistica e de Ambiência }\end{array}$} & \multicolumn{3}{|c|}{ Zona de Preservaçăo Paisagistica e Ambiental 1 - Decreto $35507 / 2012$} \\
\hline \multicolumn{5}{|c|}{ Desapropriaçöes = Clioue aoui nara ver/ocultar as Desaprooriacóes encontradas. } \\
\hline & Descri & & Legislaçăo & Assunto \\
\hline & LT.01 DA Q.07 DO PAL 44233 & & $\begin{array}{l}\text { DECRETO ESTADUAL No.23385 de } \\
01 / 00 / 1997\end{array}$ & DESAPROPRLAÇ̄ô \\
\hline & $\begin{array}{l}\text { ÄREA ENTRE O HELIPORTO DA LAGOA E O9 } \\
\text { FUNDO A LAGOA RODRTGO DE FRETIAS }\end{array}$ & DIO DE REMO DA LAGOA, TENDO AO & $\begin{array}{l}\text { DECRETO ESTADUAL No. } 8276 \text { de } \\
\text { 22/07/1985 }\end{array}$ & DESAPROPRIAÇ̄̃o \\
\hline
\end{tabular}

Tombamentos * Clioue aoui nara ver/ocultar os Tombamentos encontrados.

\begin{tabular}{|c|c|c|c|}
\hline $\begin{array}{c}\text { Número } \\
(\mathbf{s})\end{array}$ & Tipo & Legislaçăo & \multicolumn{1}{c|}{ Obs } \\
\hline S/N & DEFINITIVO & DECRETO 9396 & ESP. DAGUA LAGOA RODR. FREITAS \\
\hline & PRESERVADO & DECRETO 14898 & AREA DE ENTORNO, HIPODROMO DA GAVEA
\end{tabular}

http://mapas.rio.rj.gov.br/app2.2/ci.php?id=WRUE9XQ3\&x=682785.630521\&y=74588 $\ldots \quad$ 02/07/2014 


\section{Anexo 03a - Cl Detalhadas - Av Epitácio Pessoa - Av H Doosworth}

\section{RIO}

\section{SECRET ARIA MUNICIPAL DE URBANISMO}

Informações Detalhadas

\section{1 - Localização}

$\begin{array}{ll}\text { Logradouro: } & \text { 070854-AVN EPITACIO PESSOA } \\ \text { Inicio do Trecho: } & \text { AVN HENRIQUE DOOSWORTH } \\ \text { Inicio Part 0 } & \text { Fim Part 0 } \\ \text { Início impart 0 } & \text { Fim impart 0 } \\ \text { Bairro: Lagoa } & \text { RA: VI } \\ \text { Departamento: } & 1 \text { GUF Lagoa } \\ \text { Endereço: } & \text { Avenida Bartolomeu Mitre, 1297 - Gávea } \\ \text { Telefone(s): } & \text { Telefone: } 22744098\end{array}$

Telefone(s): Telefone: 22744098

AP: 2

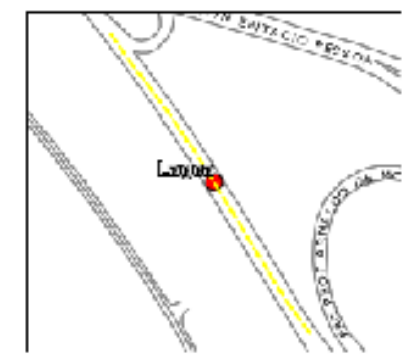

\section{2 - Dados Cadastrais do Logradouro}

\begin{tabular}{|c|c|}
\hline Plantas Cadastrais & Planta Cadastral 287E II 5 \\
\hline $\begin{array}{l}\text { Proietos Aprovados de Alinhamento (PAA) } \\
\text { Pmietos Aprovados de Loteamento(PAL) }\end{array}$ & $\begin{array}{l}\text { Os arquivos disponiveis est5o em formato DWF. Para visualizd-los, } \\
\text { pode balxar gratis o Autodesk. DWF Vlaver. Em caso de dúvidas aces } \\
\text { site da Autodesk. }\end{array}$ \\
\hline $\begin{array}{l}\text { Plantas de Alinhamentos Projetados (PAP) } \\
3 \text { - Zoneamento }\end{array}$ & - \\
\hline MacroZona & Macrozona de Ocupaçăo Controlada - Plano_Diretor_LC1111/2011 \\
\hline Zona & Zona Residencial 2, consulte a(s) norma(s): Decretn_322/1976 \\
\hline SubZona & - \\
\hline Centro de Bairro & - \\
\hline Zona Ambiental & - \\
\hline Área de Especial Interesse (AEI) & - \\
\hline
\end{tabular}

ATENÇ,̃̃o: quando se tratar de limite de zona, observar Artigo 115 e 121 do Regulamento de Zoneamento (RZ) Decretto $322 / 1976$ e legislaça especifica no caso de Projeto de Estruturaço Urbana (PEU).

\section{4 - Gabarito de Altura}

Edificaçao afastada das divisas

Decreto 9396/1990, Decreto 21191/2002, Decreto 130/1975 - setor E - 4m

Edificaçăo nåo afastada das divisas

Decreto 9390/1990, Decreto 21191/2002, Decreto 130/1975 - setor E - 4m

\section{5 - Áreas Protegidas}

Área de Protec\$o do Entomo de Bem Tombado (APE) Lagoa Rodrigo de Freitas - Decreto 9396/1990

Composiç̆o Paisagistica e Ambiental

Zona de Preservaçăo Palsagistica e Ambiental 1 - Decreto 3550712012

Protecto Pat

\section{6 - Informações Complementares}

\begin{tabular}{|c|c|c|c|}
\hline \multicolumn{4}{|c|}{ 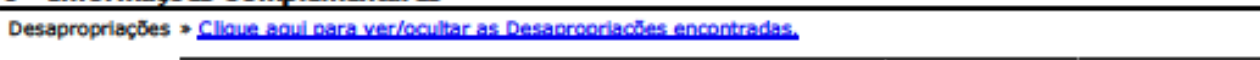 } \\
\hline & Descriçắo & Legislaçăo & Assunto \\
\hline & $\begin{array}{l}\text { AREA COM TESTADA DE } 100 \text { M ATÉ ENCONTRARA AV. BORGES DE } \\
\text { MEDEIROS, POR ONDE CONFRONTA PELO LADO ESQUERDO TENDO AOS } \\
\text { FUNDOSO CAMAL JARDIM DE ALLAH }\end{array}$ & $\begin{array}{l}\text { DECRETO } \\
\text { ESTADUAL No.8276 } \\
\text { de } 22 / 07 / 1985 \\
\end{array}$ & DESAPROPRIACẼO \\
\hline & ATENÇĀO: N॰2500 (Revogado pelo Dec.37036 de 15/04/13). & $\begin{array}{l}\text { DECRETO } \\
\text { MUNICIPAL } \\
\text { No.22678 de } \\
25 / 02 / 2003 \\
\end{array}$ & DESAPROPRIAÇÃO \\
\hline & $\begin{array}{l}\text { Revoga em swa totalidade o dec. } 22678 \text { de } 25 / 02 / 2003 \text {, Que des apropriou o no } \\
2500 \text {. }\end{array}$ & $\begin{array}{l}\text { DECRETO } \\
\text { MUNICIPAL } \\
\text { No.37039 de } \\
15 / 04 / 2013\end{array}$ & $\begin{array}{l}\text { REVOGAÇĀO } \\
\text { TOTALL DO } \\
\text { DISPOSITIVO } \\
\text { LEGAL. }\end{array}$ \\
\hline
\end{tabular}

Tombamentos * Clioue acul bara ver/ocultar os Tombamentos encontrados.

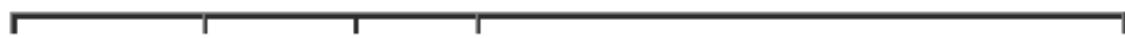




\section{Anexo 03b - Cl Detalhadas - Av Epitácio Pessoa - R Tabatinguera}

\section{RIO}

\section{SECRET ARIA MUNICIPAL DE URBANISMO}

Informações Detalhadas

\section{1 - Localização}

$\begin{array}{ll}\text { Logradouro: } & \text { 070854-AVN EPITACIO PESSOA } \\ \text { Inicio do Trecho: } & \text { RUA TABATINGUERA } \\ \text { Fim do Trecho: } & \text { RUA TABATINGUERA } \\ \text { Inicio Part 3666 } & \text { Fim Part 4120 } \\ \text { Inicio impart 0 } & \text { Fim impart 0 } \\ \text { Bairrot Lagoa } & \text { RA: VI } \\ \text { Departamento: } & 1 \text { GUF Lagoa } \\ \text { Endereç: } & \text { Avenida Bartolomeu Mitre, 1297 - Gávea } \\ \text { Telefone(s): } & \text { Telefone: } 22744098\end{array}$

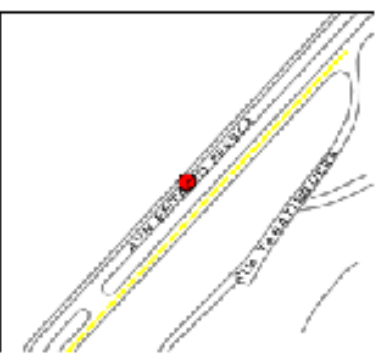

\section{2 - Dados Cadastrais do Logradouro}

Plantas Cadastrais
Proietos_Anrovados de_Alinhamento(PAA)
Proietos Aprovados de_Loteamento(PAL)

Planta Cadastral 287E II 5

Os arquivos disponiveis estäo em formato DWF. Para visualizd-los, voce pode balxar gratis o Autodesk DWF Viaver. Em caso de dúvidas acesse o

Loteamento(PAI) site da Autodesk.

Plantas de Alinhamentos Projetados (PAP)

\section{3 - Zoneamento}

\begin{tabular}{|c|c|}
\hline MacroZona & Macrozona de Ocupação Controlada - Plano Diretor LC111/2011 \\
\hline Zona & Zona Residencial 2, consulte a(s) norma(s): Decreto_ 322/1976 \\
\hline SubZona & - \\
\hline Centro de Bairro & $\cdots$ \\
\hline Zona Ambiental & $\cdots$ \\
\hline Área de Especial Interesse (AEI) & - \\
\hline
\end{tabular}
$322 / 1976$ e legislaçăo especifica no caso de Projeto de Estruturaça Urbana (PEU).

\section{4 - Gabarito de Altura}

Edificaçăo afastada das divisas

Decreto 9396/1990, Decreto 21191/2002 - setor B - 25m

Edificaçă nß̊ afastada das divisas

Lei $1654 / 1991$ - altura máxima $12 \mathrm{~m}$ observar artigo 80 do Decreto

\section{$\mathbf{5}$ - Áreas Protegidas}

Área de Proteç\$o do Entorno de Bem Tombado (APE) Lagoa Rodrigo de Freitas - Deacreto 93966/1990

Composiç̄o Paisagistica e Ambiental

Zona de Preservaçăo Paisagistica e Ambiental 1 - Decreto $355507 / 2012$

\section{6 - Informações Complementares}

Desapropriaçסes * Clloue_aoul nara ver/ocultar as Desaorooriaçbes encontradas.

\begin{tabular}{|c|c|c|}
\hline Descriçăo & Legislaçằ & Assunto \\
\hline $\begin{array}{l}\text { AREA COM TESTADA DE } 100 \text { M ATÉ ENCONTRARA AV. BORGES DE } \\
\text { MEDEIROS, POR ONDE CONFRONTA PELO LADO ESQUERDO TENDO AOS } \\
\text { FUNDOSO CAMAL JARDIM DE ALLAH }\end{array}$ & $\begin{array}{l}\text { DECRETO } \\
\text { ESTADUAL No.8276 } \\
\text { de } 22 / 07 / 1985\end{array}$ & DESAPROPRIAÇÃO \\
\hline ATENÇĀO : N* 2500 (Revogado pelo Dec.37036 de 15/04/13). & $\begin{array}{l}\text { DECRETO } \\
\text { MUNICIPAL } \\
\text { No.22678 de } \\
25 / 02 / 2003\end{array}$ & DESAPROPRIAÇÃO \\
\hline $\begin{array}{l}\text { Revoga em sua totalidade o dec. } 22678 \text { de } 25 / 02 / 2003 \text {, Que desaprepriou o no } \\
2500 \text {. }\end{array}$ & $\begin{array}{l}\text { DECRETO } \\
\text { MUNICIPAL } \\
\text { No.37039 de } \\
15 / 04 / 2013\end{array}$ & $\begin{array}{l}\text { REVOGAÇÁ } \\
\text { TOTAL DO } \\
\text { DISPOSITIVO } \\
\text { LEGAL. }\end{array}$ \\
\hline
\end{tabular}

Tombamentos * Clloue acul para ver/ocultar os Tombamentos encontrados. 
Anexo 04 - Decreto IPHAN 130 - PAA-9548_10-09-75

IPHAN

\section{Decreto n. ${ }^{\circ}$ 130, de 10 de setembro de 1975}

APRONA O PROJETO DE ALINHANENTO N.0 9.548, REFERENTE A DELIMTACÖO DA SUPERFICIE DE DOMINGO DO ESPELHO DE ÁGUA DA LAGOA ROCRIGO DE FRETTAS E DÁ CUTRAS PROVIDÊNCIAS.

Prefetura da Odade do Rio de Janeiro

O Prefeto do Municipio do Rio de Janeiro, no uso de suas atribuigöes legais, e tendo en vista as aspetos da defesa da paisagem e vistas panorämicas das margens da Lagoa Rodrigo de Freitas, decreta:

Artigo $1^{\circ}$ - Fica aprovado o projeto de alinhamento (PA) n.० 9.548, de delimitaçăo da superficie de dominio do espelho de agua da Logoa Rodrigo de Freitas, en substituiģäo ao anterior projeto de alinhamento (PA) n. ${ }^{\circ} 9.190$.

Artigo $2^{\circ}$ - A nǟo ser por rąz̃es de ordem técrica, impostas pelos órgäos responsłveis pelo saneamento daquela lagoa, a linha de limitaçäo de que trata o artigo $1^{\circ}$, incluidas as ilhas ali localizadas, näo poderá ser alterada por pesscas ou entidades de caráter público ou privado, ficando o infrator sujeito as penalidades previstas na legislaçäa.

Artigo $3^{\circ}$ - Ficam considerados espaços "non aedificandr" todas as breas livres incluidas na figura gecmetrica delimitada externamente pelos alinhamentos dos lotes de terreno existertes nas Avenidas Epitádio Pessoa e Barges de Medeiros, campreendendo a superficie de domínio do espelho de bgua, faiba de terras contiguas a este e logradouros evistentes ou que venham a se corstituir nesta faba. Parágrafo único - Nas ilhas existentes, as edificaç̄es terāo a altura máxima de $4 \mathrm{~m}$, respeitados a brea livre total corresponderte a $70 \%$ do terreno, a cota de respaldo das coberturas, que deverd ser de $6 \mathrm{~m}$ acima do nivel do mar, e o disposto nos artigos $1^{\circ}$ e $2^{\circ}$ deste decreto, sendo as edificaçōes evistertes toleradas com uso năo-conforme.

Artigo $4^{\circ}$ - Em consepjuéndia do dispceto no artigo $2^{\circ}$ deste decreto, fica terminantemente proibido o vazamento de low ou aterro de qualcuer espécie na orla da lagoa.

Artigo $5^{\circ}$ - A programasăo de ocupaçäo dos espaços a que se refere o artigo $3^{\circ}$ caberá exclusivamente a acministraç̧o muricipal, de forma a destina-los ao uso público e visando ds atividades de lazer e recreaçōo. 


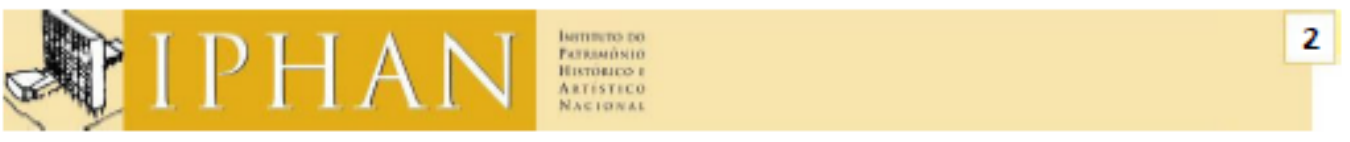

Artigo $6^{\circ}$ - Este decreto entrará em vigor na data da sua publicação, revogadas as disposições em contrário.

Rio de Janeiro, 10 de setembro de 1975

Marcos Tamoio César Seroa da Mota Orlando

Feliciano Leão Pedro Teixeira Soares Neto

Publicado no "Diário Oficial" do Estado do Rio de Janeiro, parte IV, de 11 de setembro de 1975 


\section{Anexo 05 - D9396M Tombamento Definitivo_PAA-9548_13-06-90}

\section{Decreto $n^{2} 9396$ de 13 de junho de 1990}

Determina o tombamento definitivo do bem cultural que mencionae dá outras providâncias.

O PREFEITO DA CIDADE DO RIO DE JANEIRO, no uso de suas atribuiçōes bgais, tendo em vista o que consta do processo $07 / 14.748 / 85$ e

Considerando que a Lagoa Rodrigo de Freitas se consttui em bem cultural de notável beleza paisagistica e de relevante significado cultural para a Cidade do Pio de Janeiro;

Considerando a necessidade de protegê-la, bem como o contorno dos morros que a circundam, e salvaguardé-la de açoes que prejudiquem sua ambiência;

Considerando os estudos elaborados pelo Departamento Geral de Patrimônio Cultural, da Secretaria Municipal de Cultura, Turismo e Esporles;

Considerando o parecer unânime do Conselho Municipal de Proteçao do Patrimônio Cultural do Pio de Janeiro,

\section{DECRETA:}

Art. $1^{2}$ - Fica tombado em caráter definitivo, nos termos do art. $1^{2}$ da Lei $n^{2} 166$, de 27 de maio de 1980, o espelho d'água da Lagoa Rodrigo de Freitas, cujos limiles estáo definidos no PA n 9548, aprovado no Decreto $n^{2} 130$, de 10 de setembro de 1975.

Art. $2^{2}$ - Fica criada a área de proteça do entorno da Lagoa Rodrigo de Freitas, delimitada no Anexo I deste decreto.

(O Decrefo 21.191 de 26 de março de 2002, republicado no Diário Oricial de 09 de outubro de 2002, deu ao arigo $3^{p}$ itens: $V, V I, V W$ e aos pa ágrafos $1^{q}, 3^{9}$ inciso $1,10^{2}, 11^{2}$, e $12^{2}$ a seguinte redaçao):

Art. $3^{2}$ - Para efeito de definiçao da altura das edificaços, a área a que se refere 0 art. $2 .^{2}$ fica dvidida em oito setores, delimitados no Anexo II deste Decreto:

I- Setor A - altura máxima: $8,00 \mathrm{~m}$ (oito metros);

II - Setor B - altura máxima: 25,00m (vinte e cinco metros);

III-Setor C- altura máxima: 14,00m (quatorze metros);

N - Setor D - alura fxada no Decreto $n^{2} 5251$, de 5 de agosto de 1985: 8,20m (oito metros e vinte œntimetros);

V-Setor E- altura e condiçoes fixadas no Decreto $n^{2}$ 130, de 10 de setembro de 1975: 4,00m (quatro matros).

Vi - Setor F- altura máxima: 14,00m (quatorze metros) e número máximo de pavimentos de qualquer natureza igual a 4 (quatro);

VII - Setor G - altura máxima: 17,00m (dezessete metros) e número máximo de pavimentos de qualquer natureza igual a 5 (cinco);

VIII - Setor H - altura máxima: 10,00m (dez metros).

$\S 1^{\mathrm{p}}$ - A atura máxima da edificaçăo inclui todos os elementos construtivos, com exœeçăo do disposto no $\$ 10$ deste artigo.

$\S 2^{2}$ - Nos terrenos em declive, a altura máxima fxada inclui a parte da edificaçao situada abaixo do nivel do meio fio dos logradouros.

$\S 3^{2}-\mathrm{O}$ pavimento de cobertura obedecerá às seguintes condiçøes:

I - será computado na Área Total da Edficaçäo - ATE;

II - a ocupaçao máxima da edificaçăo será de $50 \%$ (cinq0enta por cento) da área do pavimento imediatamente inferior;

III - terá afastamento minimo de $3,00 \mathrm{~m}$ (três metros) do plano da fachada voltada para o logradouro. 
§ $4^{2}$ - Nas edficaçoes residenciais mutiflamiliares e nas partes destinadas a unidades residenciais das edificap̧es mistas serăo permitidos, em um mesmo pavimento, os locais destinados ao estacionamento e guarda de veiculos e ao uso comum das edificaçoes, desde que isolados entre si e com acessos independentes.

$\S 5^{?}$ - Os pavimentos destinados a garagem, em subsolo, nâo serăo computados para efeto do número maximo de pavimentos.

$\S 6^{2}$ - O primeiro pavimento em subsolo poderá ser semi-enterrado desde que o piso do pavimento imediatamente superior náo fique acima da cota de $+1,50 \mathrm{~m}$.(mais um matro e cinq0enta centimetros) em relaça ao ponto mais baixo do meio-fio do logradouro correspondente à testada do lote.

\$ $7^{9}$ - No setor C, a área destinada a estacionamento e guarda de veículos só poderá se localizar no pavimento térreo ou em subsolo.

$\S 8^{2}$ - No Setor C, o número de vagas de estacionamento para veículos será de:

-1 (uma) vaga para cada unidade residencial mulifamilar com área útil alé $120 \mathrm{~m}^{2}$ (cento e vinte metros quadrados);

-2 (duas) vagas para cada unidade residencial multifamiliar com mais de $120 m^{2}$ (cento e vinte metros quadrados) de área útil;

$\$ g^{p}$ - No Setor C, é dispensada a obrigatoriedade do pavimento de uso comum, sem prejuizo das áreas de recreaça exigidas para as edificaços.

\$ 10. Do oômputo da altura máxima das edficaços stuadas nos logradouros integrantes dos setores $\mathrm{F}$ e $\mathrm{G}$ ficam excluidas as caxas dágua, caixas de escada e compartimentos destinados a equipamentos mecânicos.

\$ 11. A altura das edificaçes será medida a partir da cota de implantaçăo do pavimento de acesso, exceto no caso da existência de pavimento de subsolo semi-enterrado, cuja altura emergente na forma prevista no $\S 6 .^{2}$ será incluida para efeito do cálculo da altura total da edificaçao.

\$ 12. Nos terrenos em declive, o cálculo da altura das edificaçes inclui todos os pavimentos, inclusive os sîtuados abaixo do nivel do meio-fio, e será contada a partir do piso do pavimento mais baixo da edificaça.

Art. 4? - Nas margens da Lagoa Rodrigo de Fretas sao consideradas áreas "non aedificandi" todas as áreas livres incluidas na figura geométrica a que se refere 0 art. $3^{2}$ do Decreto $n^{2} 130$, de 10 de setembro de 1975 .

Art. $5^{2}$ - Somente instalaçes de apoio a atividade de lazer e recreaçao serao permitidas nas

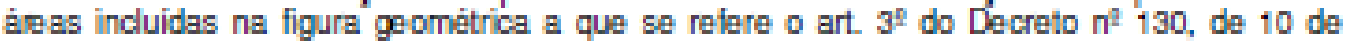
setembro de 1975.

Parágrafo único - As instalaçøes deverao obedecer aos seguintes parâmetros:

I - teráo, no máximo, $70 m^{2}$ (selenta metros quadrados) de área construida,

II - nao poderao ultrapassar a atura máxima de 4,00m (quatro metros),

III - manteráo o espaçamento de 500,00m (quinhentos metros) entre si,

IV - os projatos seráo aprovados, previamente, pelo Conselho Municipal de Proleça do Patrimônio Cultural do Pio de Janeiro.

Art. $6^{2}$ - A expediçá, ou a renovaçăo, de licença para o funcionamento de qualquer atividade, instalaçăo de equiparnentos e ocupaçao de áreas da figura geométrica referida no art. $5^{1}$ deste decreto, além de obedecer ao que dispoe o Decreto n $n^{2} 130$, de 10 de selembro de 1975, terá que ser previamente aprovada pelo Conselho Municipal de Proteçáo do Patrimônio Cuhtural do Pio de Janeiro.

Art. $7^{2}$ - Qualquer iniciativa que vise a alterar a estrutura viária na área de entorno da Lagoa Aodrigo de Fretas deverá ser previamente aprovada pelo Conselho Municipal de Proteçao do Patrimônio Cultural do Rio de Janeiro. 
Art. $8^{p}$ - Este decreto entrará em vigor na data de sua publicação, revogadas as disposiçoes em contrário.

Pio de Janeiro, 13 de junho de 1990 - $426^{9}$ de Fundaça da Cidade

MARCELLO ALENCAR

Gerardo Majella Melo Mourâo

DO RIO de $19 / 06 / 90$

\section{ANEXO I}

\section{LIMITE DA ÁREA DO ENTORNO}

Do entroncamento da Avenida Epitácio Pessoa com a Rua Prolessor Gastao Bahiana; seguindo por esta (incluida, incluindo a Rua Presidente Alfonso Lopes) até o seu ponto mais alto; dai, até o ponto mais alto; dai, alé o ponto mais alto da Avenida Henrique Dodsworth; subindo o espigalo do Morro dos Cabritos alé encontrar a curva de nivel de 50,00m (cinqDenta metros); seguindo por esta curva de nivel, na direçäo noroeste, ate encontrar a divisa laleral esquerda do Parque Carlos Lacerda; seguindo por esta dvisa, até encontrar o alinhamento da Avenida Epitácio Pessoa; seguindo por este alinhamento alé a divisa laleral direita do Parque Carlos Lacerda; seguindo por esta divisa até encontrar a curva de nivel de 50,00m (cinqDenta metros); por esta curva de nivel até encontrar a Rua " C (excluida); Rua Casuarina (excluida); Rua Engenheiro Marques Porto (excluida); Rua Humaitá (excluida); Rua Jardim Botânico (excluida) até a Rua Doutor Neves da Rocha; Rua Jardim Botânico (excluindo o lado par) até a Rua Oliveira Rocha; Rua Jardim Botânico (excluida) até a Rua General Garzon; Rua Jardim Botânico (excluido o lado par) alé a Rua Bartolomeu Mitre; por esta (excluido o lado impar) alé a Rua Mário Ribeiro; por esta (excluido o lado par) até a Rua Ministro Raul Machado; por esta (excluido o lado par): Rua Giberto Cardoso (excluido o lado par) alé a Avenida Afrânio de Melo Franco; por esta (excluido o lado impar) até a Rua Humberto de Campos; por esta (excluido o lado impar) alé a Avenida Borges de Medeiros; por esta (excluida) até o seu inicio; Avenida Epitácio Pessoa (excluida) do inicio alé a Rua Henrique Dumont; Jardim de Alah (incluido); Avenida Epitácio Pessoa (incluida) até o ponto de partida.

(O Decreto 21.191 de 26 de março de 2002, republicado no Diário Oficial de 09 de outubro de 2002, deu ao Anexo II a seguinte redaçao):

\section{ANEXO II}

\section{SETORES}

SETORA - altura máxima: $8,00 \mathrm{~m}$ (oito matros)

- Avenida Árânio de Melo Franco (lado par, da Rua Humberto de Campos ao seu final);

- Avenida Bartolomeu Mitre (lado par da Rua Mário Ribeiro até o seu final);

- Avenida Borges de Medeiros (lado impar da Rua Humberto de Campos alé a Rua General Garzon);

- Avenida Lineu de Paula Machado (da Rua Olveira da Rocha alé a Rua Doutor Neves da Aocha, excluindo os $n^{2} 137$ e 147);

- Rua Doutor Neves da Rocha (lado impar);

- Rua General Garzon (lado impar, incluindo o canal);

- Rua Gilberto Cardoso (lado impar, da Rua Ministro Paul Machado até o seu final);

- Rua Humberto de Campos (lado par, do seu inicio alé a Avenida Afránio de Melo Franco)

- Rua Jardim Botânico (lado impar, nos trechos entre a Rua Doutor Naves da Rocha e a Rua Oliveira Rocha e entre a Rua General Garzon e a Avenida Bartolomeu Mitre);

- Rua Mário Ribeiro (lado impar, entre a Avenida Bartolomeu Mitre e a Rua Ministro Raul

Machado);

- Rua Ministro Raul Machado;

- Rua Oliveira Rocha (lado par).

SETOR B - altura máxima: $25,00 \mathrm{~m}$ (vinte e cinco metros)

- Av. Borges de Medeiros (lado impar, da Rua General Garzon alé o seu final); 
- Av. Epitácio Pessoa (lado par, da Av. Henrique Dumont até o seu final, excluido o Parque Carlos Lacerda);

- Av. Henrique Dodsworth (da cota 14 alé o seu final);

- Av. Lineu de Paula Machado (excluida da Rua Oliveira da Rocha alé a Rua Doutor Naves da Pocha);

- Praça Senador Filinto Muller:

- Rua Presidente Alfonso Lopes;

- Rua Prolessor Gastäo Bahiana (da cota 14 até a Av. Epitácio Pessoa).

SETOR C - altura máxima: 14,00m (quatorze metros)

- Praça General Álcio Souto;

- Praça Henrique Brito e Cunha;

- Rua Baronesa de Poconé;

- Rua Carvalho de Azevedo

- Rua Cicero Góis Monte iro;

- Rua Frei Solano:

- Rua Frei Veloso;

- Rua Fonte da Saudade;

- Rua Vitor Maúrtua.

SETOR D - altura fixada pelo Decreto $n^{2} 5251$, de 5 de agosto de 1985: 8,20m (oito metros e vinte centimetros)

- Rua Tabatinguera.

SETOR E- altura fxxada no Decreto $n^{2} 130$, de 10 de setembro de 1975: 4,00m (quatro metros)

- Illha dos Caiçaras;

- llha Naval

- Margens da Lagoa Rodrigues de Freitas.

SETOR F - Atura máxima: 14,00m (quatorze metros), com no máximo 4 (quatro) pavimentos

- Praça Sagrada Famila;

- Rua Batista da Costa;

- Rua Carlos Esmeraldino;

- Rua Custódio Serrâa;

- Rua Doutor Naves da Rocha (lado par);

- Rua Frei Leandro;

- Rua General Garzon (lado par);

- Rua General Tasso Fragoso;

- Rua J. J. Seabra;

- Rua Maria Angélica (do início alé a Rua Jardim Botânico);

- Rua Oliveira Rocha (lado impar, do inicio até a Rua Jardim Botânico);

- Rua Prolessor Abelardo Lobo;

- Rua Prolessor Saldanha (do inicio até a Rua Jardim Botânico);

- Rua Saturnino de Brito.

SETOR G - Altura máxima: 17,00m (dezessete metros), com no máximo 5 (cinco) pavimentos

- Rua Alexandre Ferreira.

SETOR H - Atura máxima: 10,00m (dez metros)

- Rua Almeida Godinho;

- Rua Almirante Guillobel;

- Rua Bogari;

- Rua Conselheiro Macedo Soares;

- Rua Ferreira de Resende;

- Rua Ildefonso Simbes Lopes;

- Rua Ministro Armando de Alencar;

- Rua Negreiros Lobato;

- Rua Pesedá;

- Rua Sacopa (do seu inicio até a cota 50). 


\title{
Anexo 06 - Uso do Solo 2012 - Critérios de Mapeamento
}

USO DO SOLO 2012

CRITERIOS DE MAPEAMENTO

\begin{abstract}
O presente trabalho conslste na vetorlzaça das classificaçbes de uso e cobertura do solo da Cldade do Rlo de Janelro, realizadas a partir da Intepretaģo das ortofotos 1:10.000 do ano de 2012, em conjunto com experienclas acumuladas em trabahos de campo e vlstorlas.
\end{abstract}

A legenda apresentada refere-6e ao agrupamento final das clasces em 16 nlvels, dlvididos em dols grupos: areas urban|zadas e areas nấo urbanlzadas. Quanto as areas nấ urbanlzadas, fol utllzado um nivel de classiflcaça menor, compathel com a escala 1:50.000, princlpaimente no que se refere as areas de cobertura vegetal arborea e atustiva.

No processo de Interpretaça fol considerado o uso ou a cobertura predominante. Utillzou-se, alnda, o referenclal de 1 hectare $\left(10.000 \mathrm{~m}^{2}\right)$ como area minima a ser representada, embora eventualmente algumas areas Interlores tenham sldo wetorlzadas.

A Gerencla de Cartografla da DICIPP agradece a comunloapto de eventuals fal has ou omlssbes encontradas neste mapeamento.

\author{
LEGENDA \\ Ocupacto Predominante \\ Oe nivele abalxo devem ser coeservados em conjunto com se ortofotos de 2012.
}

\section{Grupo areas urbanlzadas}

Areas resildenclals - uso predominante residenclal, Inclulndo-se ruas, avenldas, estradas, cantelros, edificaples unifamillares e multiamillares, conjuntos habltaclonals (predominantemente de bakxa renda, construldos para fins soclals, e outros relevantes pela sua extensatoh e alnda pequenos espaços e edillcaçbes, tals como: comerclals, uso mlsto, comedores de comerclo, Industrlas, lotes, quadras vazlas, sede de fazendas, granjas ete.

Areas nao ediflcadas - areas lnserldas na malha utana, compreendendo grandes espaços vazlos ou subutll|zados, lloteamentos em Implantaço ou nto consolldados, E.F.A. [espapo flsloo alterado], com rulnas ou abandonados e movimentos de terta esparsos.

Areas Instituclonals e de infraestrutura publlca - areas e equlpamentos ocupados pela administraça publica, Institulçbes govemamentals, de pesqulsa, rellglosas, militares, presldlos, usinas de astalto, obras soclals, abrigos, quartels, prestadores de servlcos puolloos (agua, esgoto, Ilxo, energla, eletrca, Iumlnaça, gas, telefonla, comunicacto, correlos etc) tomes de telecomunlcaches, oleodutos, gasodutos, adutoras eto 
Areas de comerclo e aerviços - areas de uso predominantemente comerclal elou de serv/pos, Incilindo shoppings centers, centros de balmo, centro da Cldade, centrals de abastecimento, hotels e motels, bancos, empresas de onilbus, estidlos de gravacoes, depositos de container, de generos allmenticlos, de lojas de departamentos, cemiterios, empresas de onlous, bancos, hipermercados, estudlos de gravacto, Inclulndo as areas para estaclonamento correlaclonadas.

Favela - areas Identiflcadas e cadastradas como favelas no Sistema de Assentamento de Balka Renda do IPP (SABREN) atuallzadas ate 2012.

Areas de lazer - areas destinadas ao lazer, contemplativo, esportivo e cultural, como praças, parques, vllas olimplcas, clubes, complexos esportivos, tematlcos, estadlos, museus, blbilotecas, planeta io, observatorios, centros culturals etc.

Obs: as areas verdes expresslvas dentro de grandes parques pübllcos estâo representadas nos seus respectuos temas relatwos a vegetaça.

Areas de educaça a a aude - areas ocupadas por escolas, unlversidades, Institu/ples de ensino, hospltals, postos de saude, matemidades, creches, ambulatorlos etc.

Areas Industrlals - areas ocupadas por grandes equlpamentos e dlstrtos Industrials.

Areas de transportes - formados por aeroportos, teminals rodoularlos, ferovlartos, hidrovlarilos, llnha ferrea, oflchas femovarlasimetrovlarlas, estaçles de metro, estapjes de trem, barcas, hellpontos e grandes estaclonamentos.

Areas de exploraçato mineral - areas de exploraçăo mineral, em atlvidade ou nắo.

\section{Grupo areas nalo urbanlzadas}

Areas com cobertura vegatal arborea e arbustlva - floresta (ombroflla); restinga e mangue formaçbes plonelras capoelra em diferentes estaglos (vegetacto secundarla) e reflorestamentos.

Areas com cobertura vegetal gramineo-lenhosa (campo) - areas com vegetaça rastelra, graminoldes, situadas em planicles ou encostas, utllzadas ou năo para atlidades pastorls.

Areas agricolas - areas ccupadas por attvidades agricolas, Inclulndo hortculturas, frutlculturas etc.

Afloramentos rochosos e depostos sedlmentares - areas cobertas por afloramento rochoso natural (escarpas, pontbes, costbes, malacbes), e as ocupadas por areals, linclulindo pralas.

Corpos hidricos - areas fomadas por aguas continentals e amblentes estuarinos, lagoas, rlos, canals, açudes e represas.

Areas aujeltas a Inundaço - areas ccupadas por brejos, ba|x|os, com a vegetaça caracteristica desses amblentes. 
Mapa E01 - Folhas Vila Militar, Baía de Guanabara e TMR

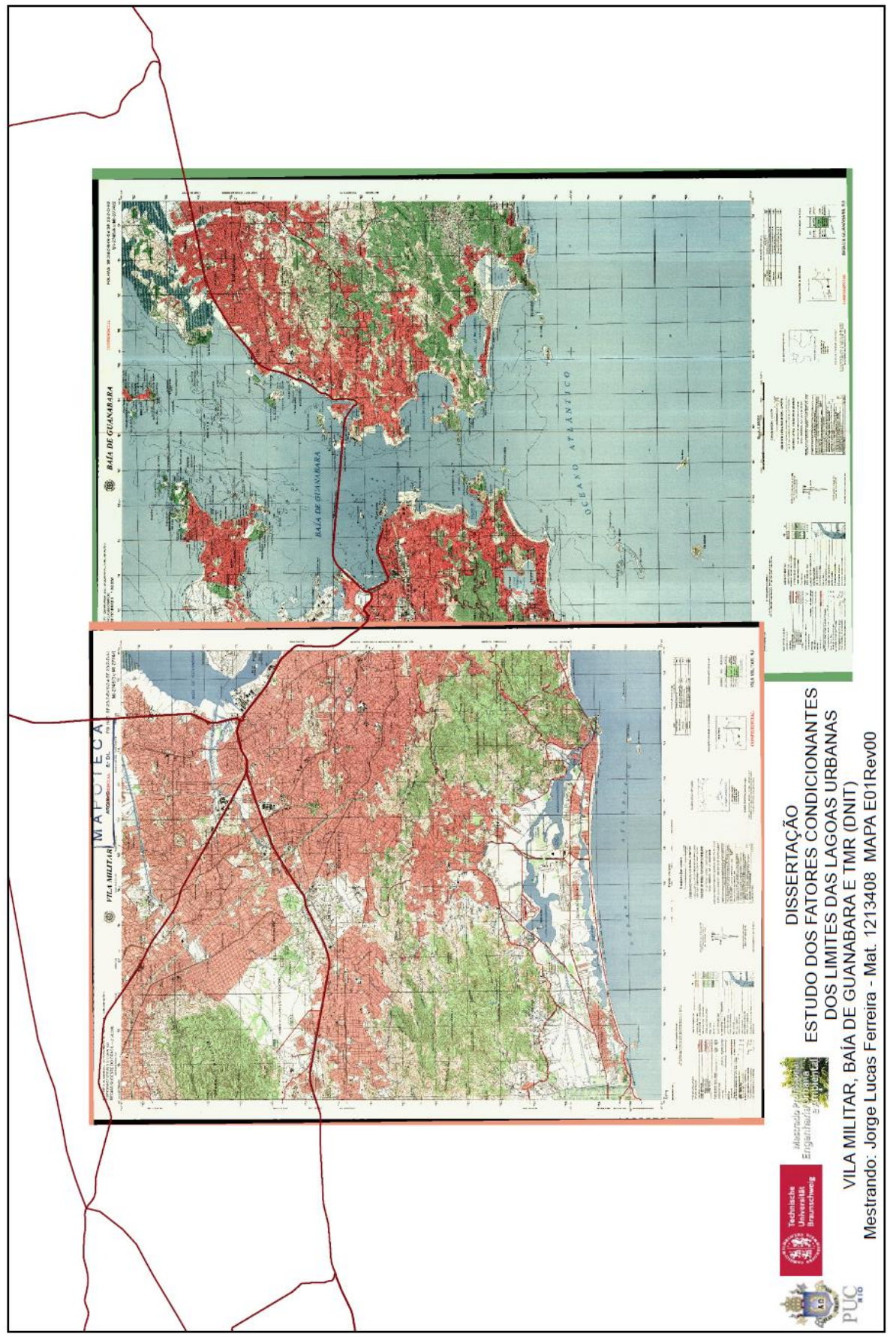


Mapa E02 - Extrato Mapa Rodoviário - Trecho RJ-071 - Orla LRF

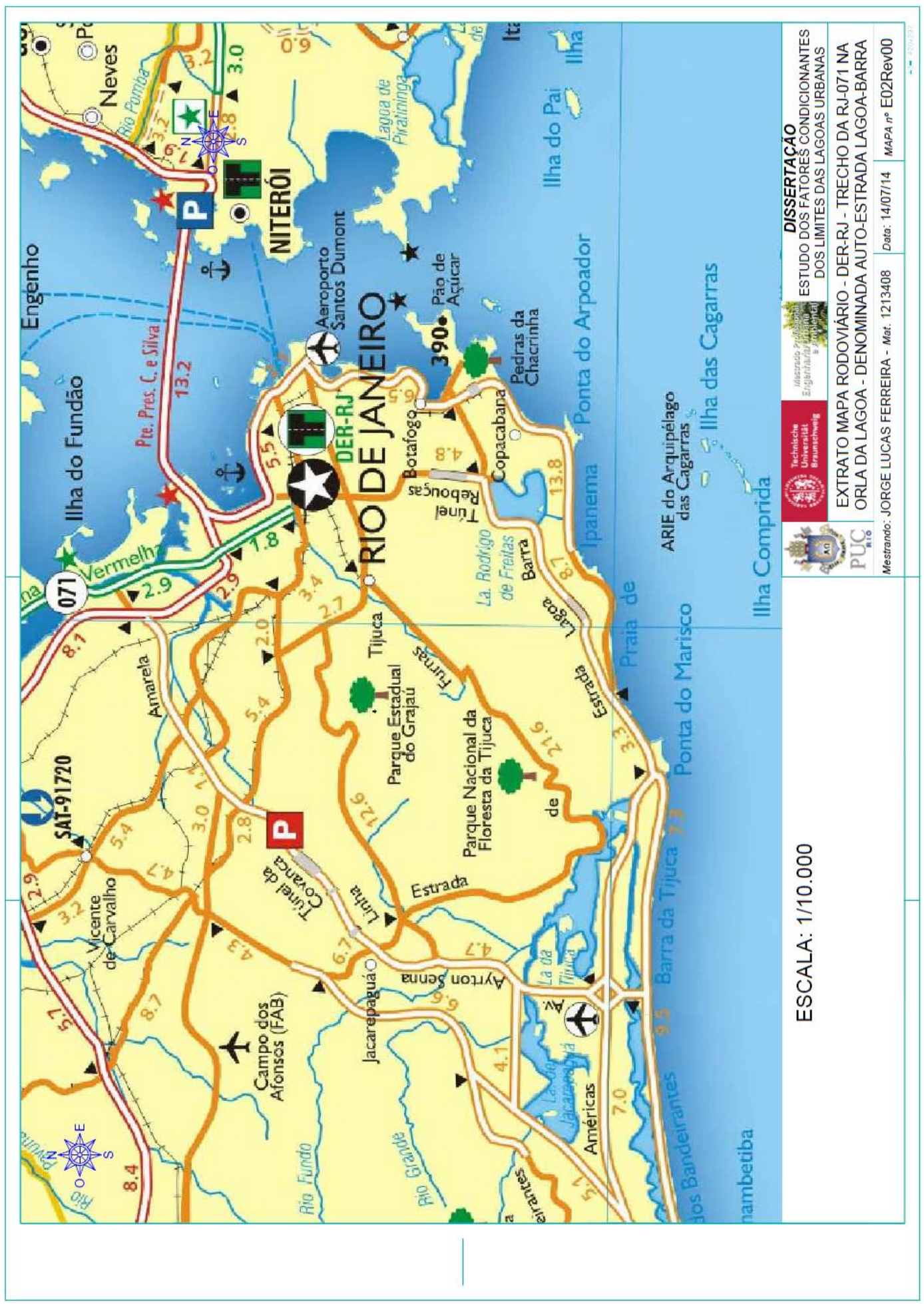


Mapa E03 - Planta da LRF, Extraída do Google Earth

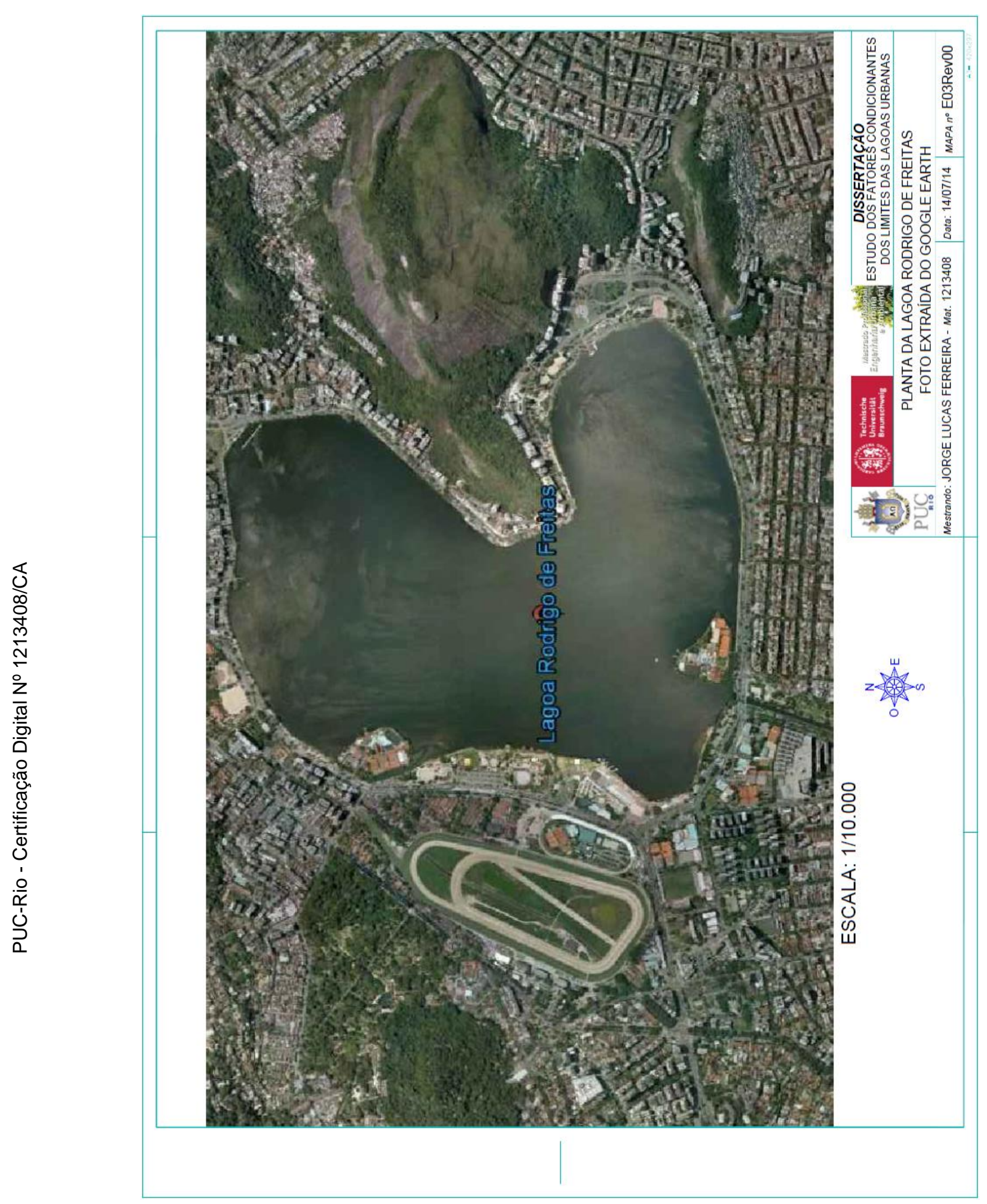


Mapa E04 - Planta Cadastral, Montagem 1/2000 - Detalhe Lagoa

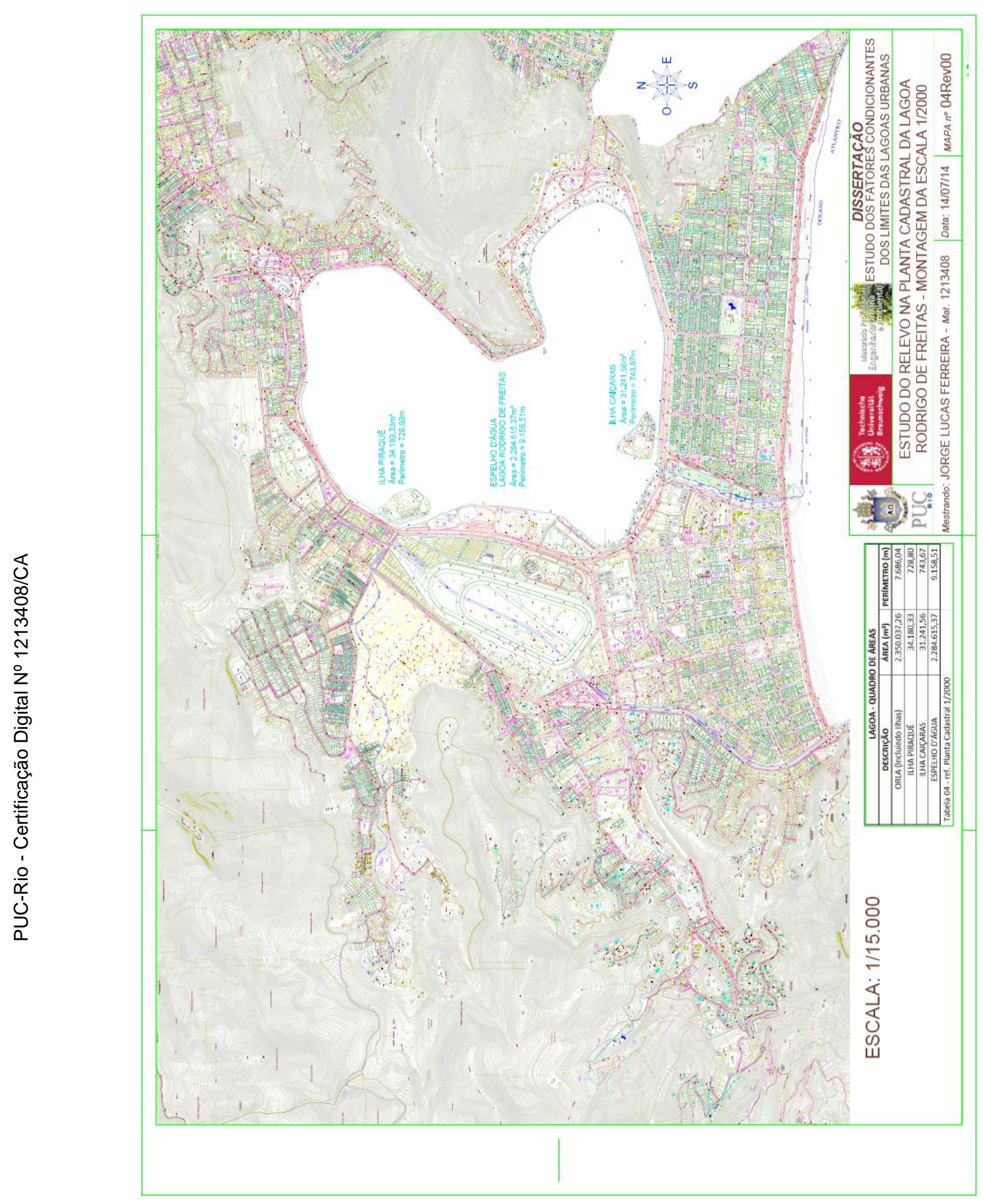


Mapa E05 - Estudo da Bacia e Malha Hidrográfica da Lagoa

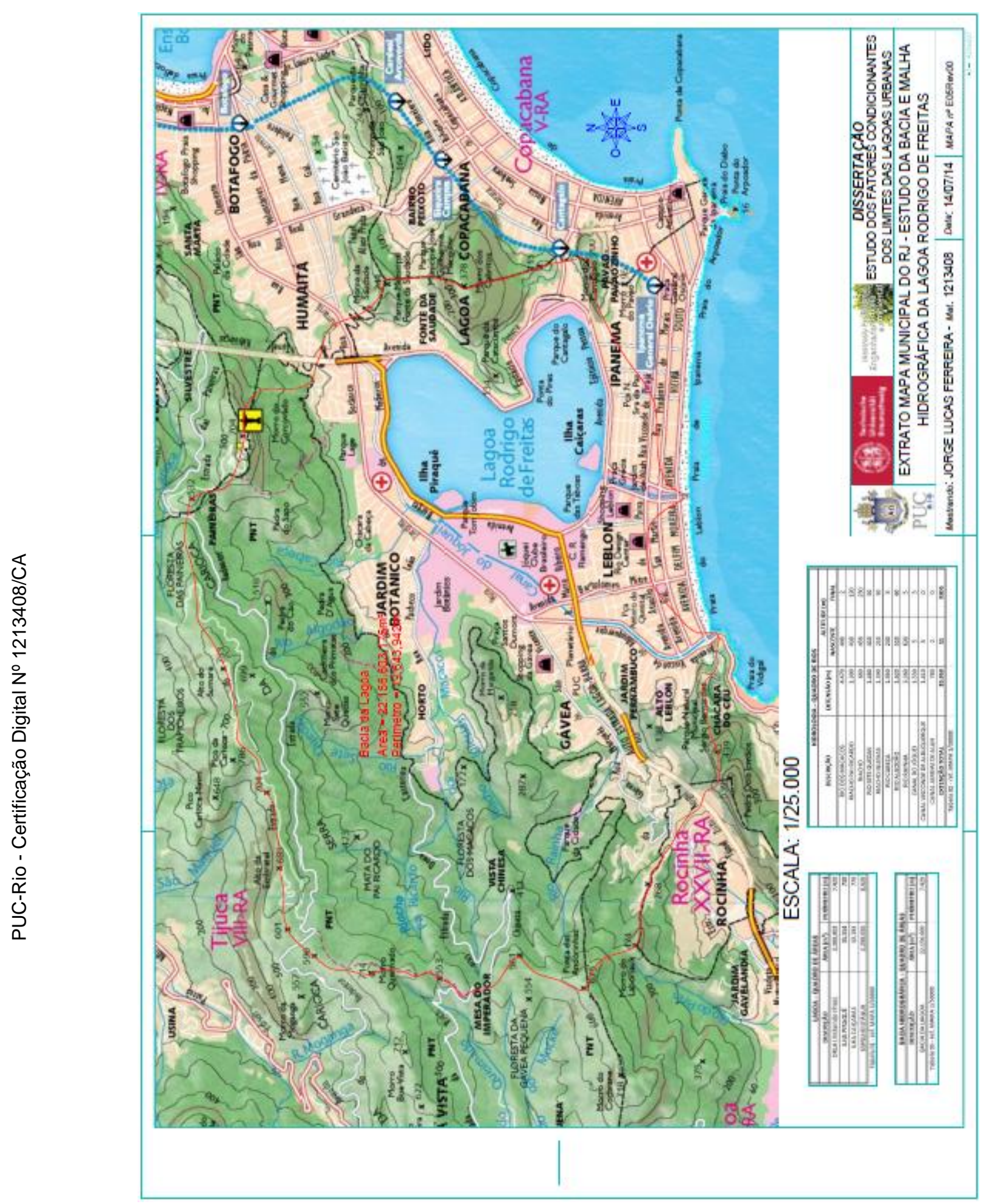


Mapa E06 - Espelho D’Água, Rios e Bacia Hidrográfica

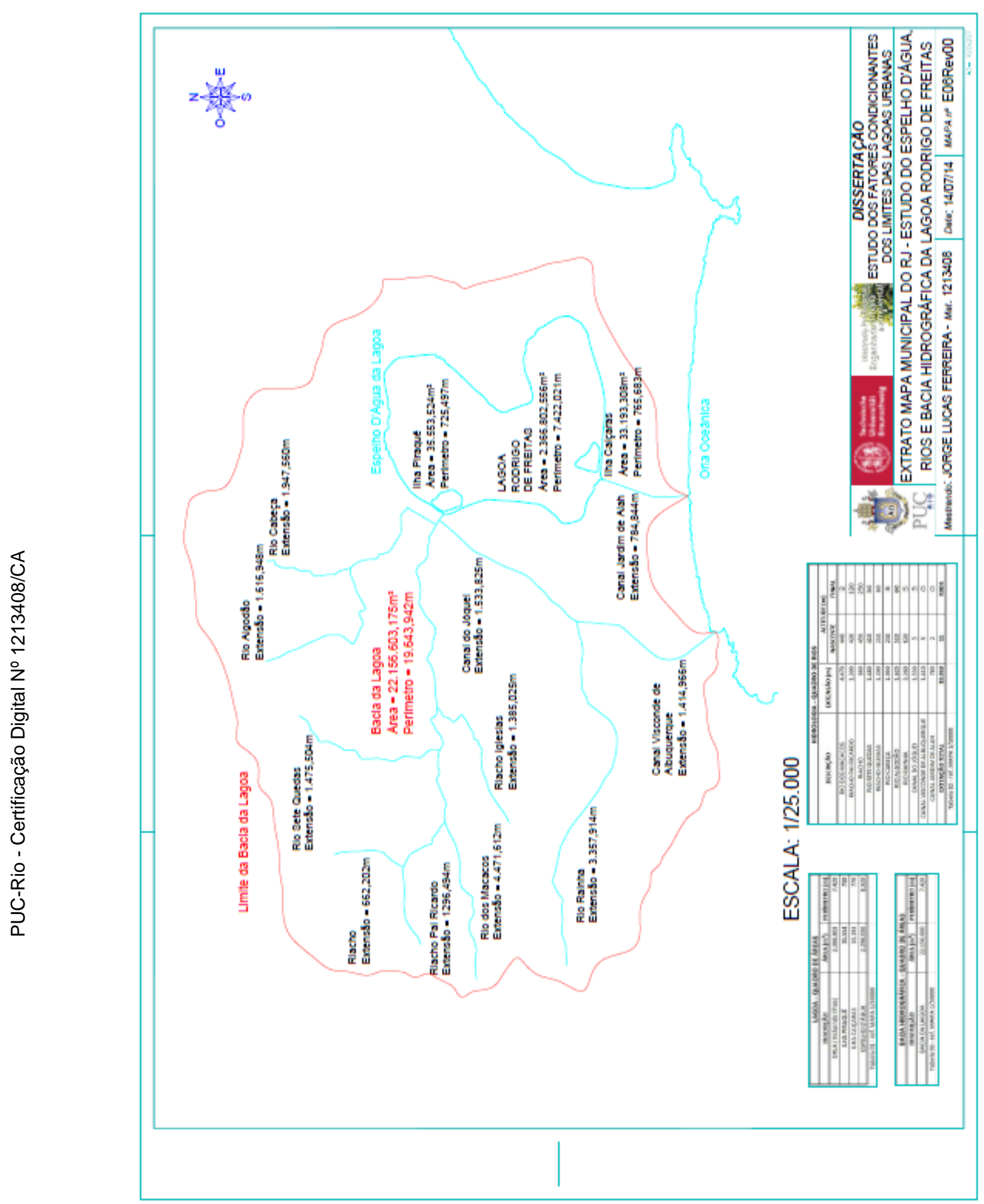


Mapa E07 - Projeto Alinhamento Aprovado - PAA-9548 - LRF

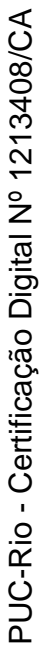

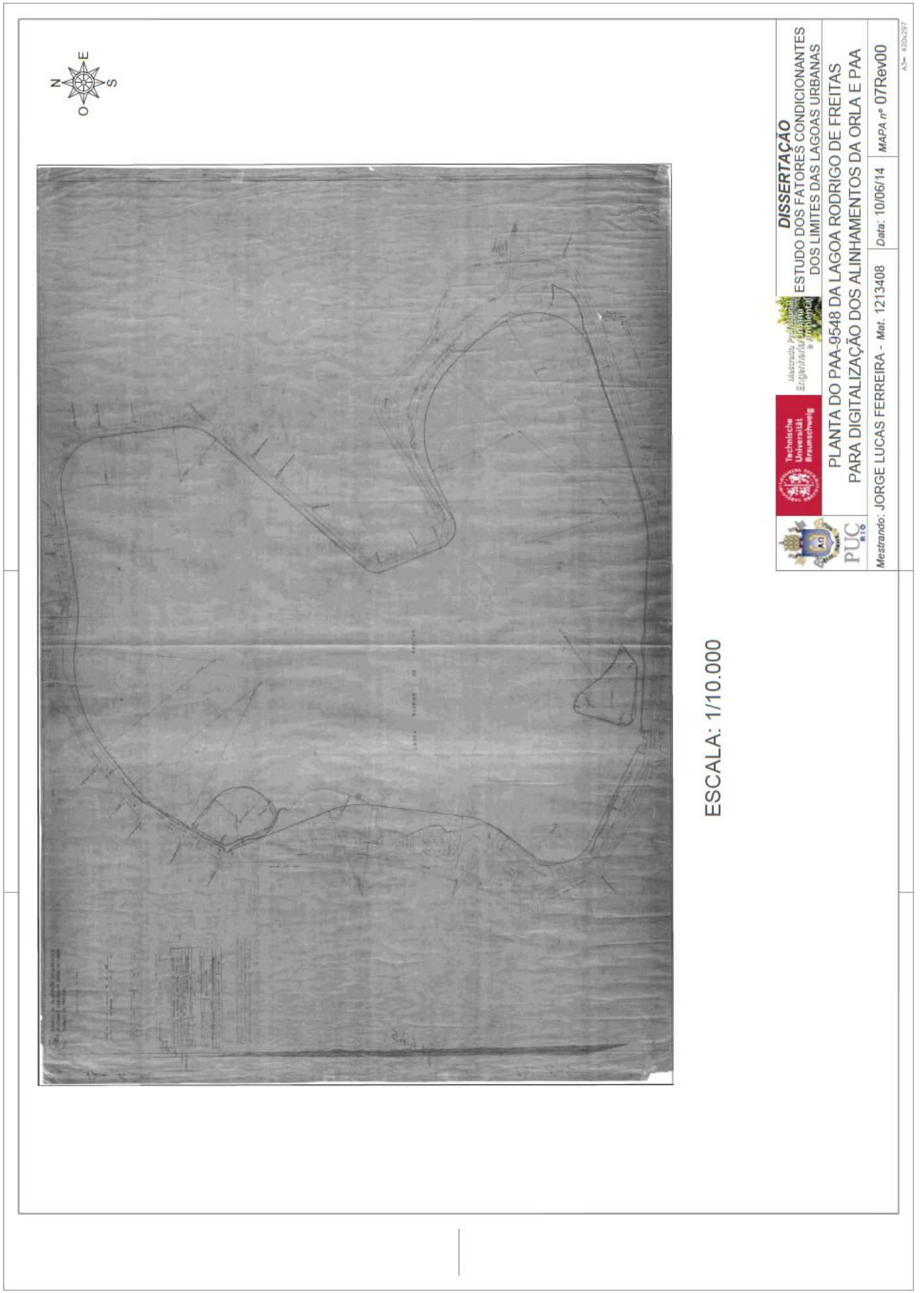


Mapa E08 - Mapa da Digitalização e Cálculo do PAA-9548

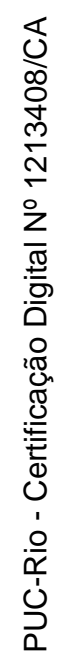

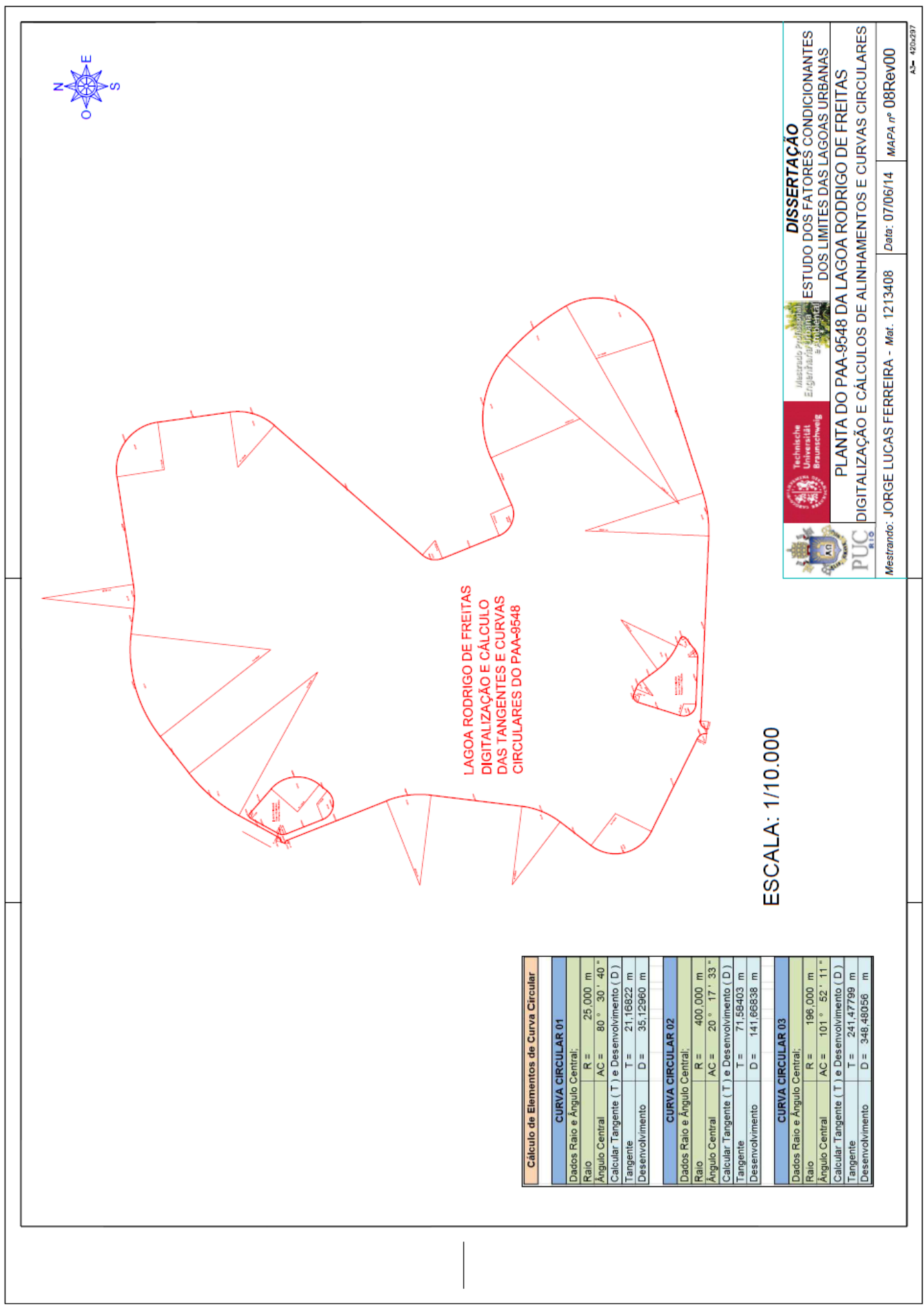


Mapa E09 - Mapa da Medição das Bordas - Natural e Projetada

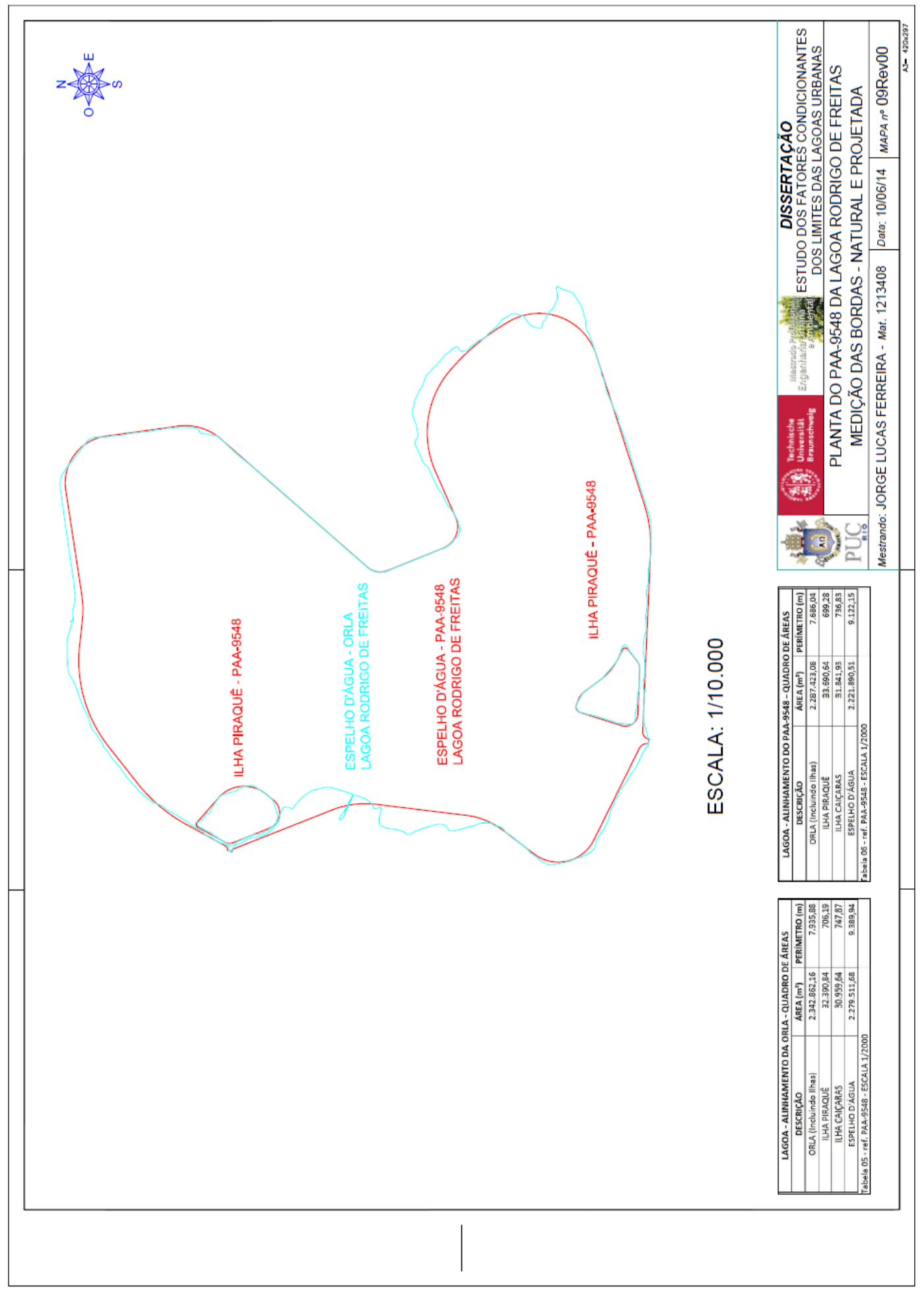


Mapa E10 - Áreas de Proteção Ambiental, Parques e Orla da LRF

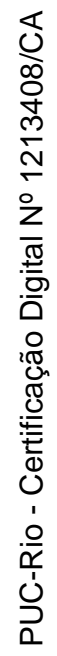

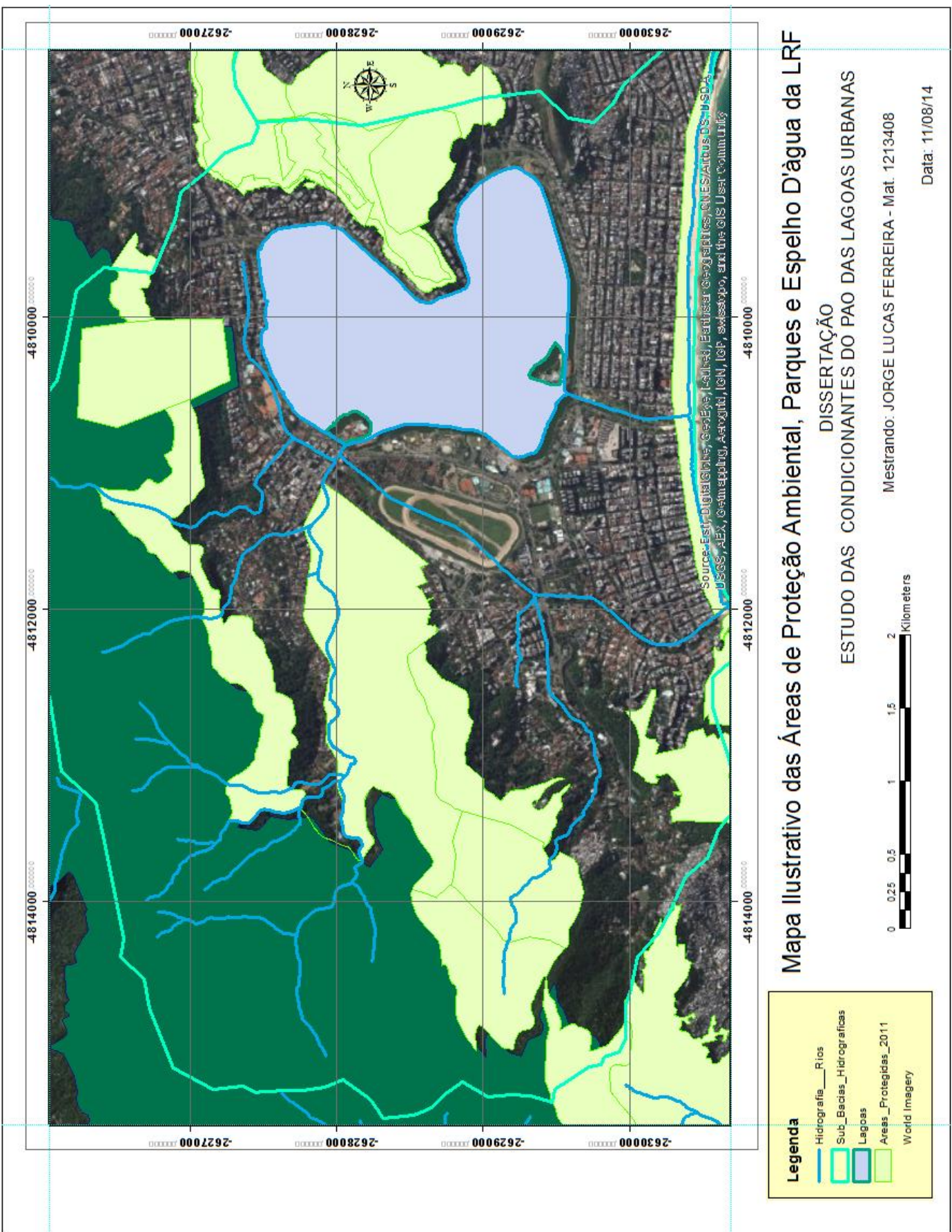




\section{Mapa E11 - Padrão Geomorfológico da Bacia da LRF}
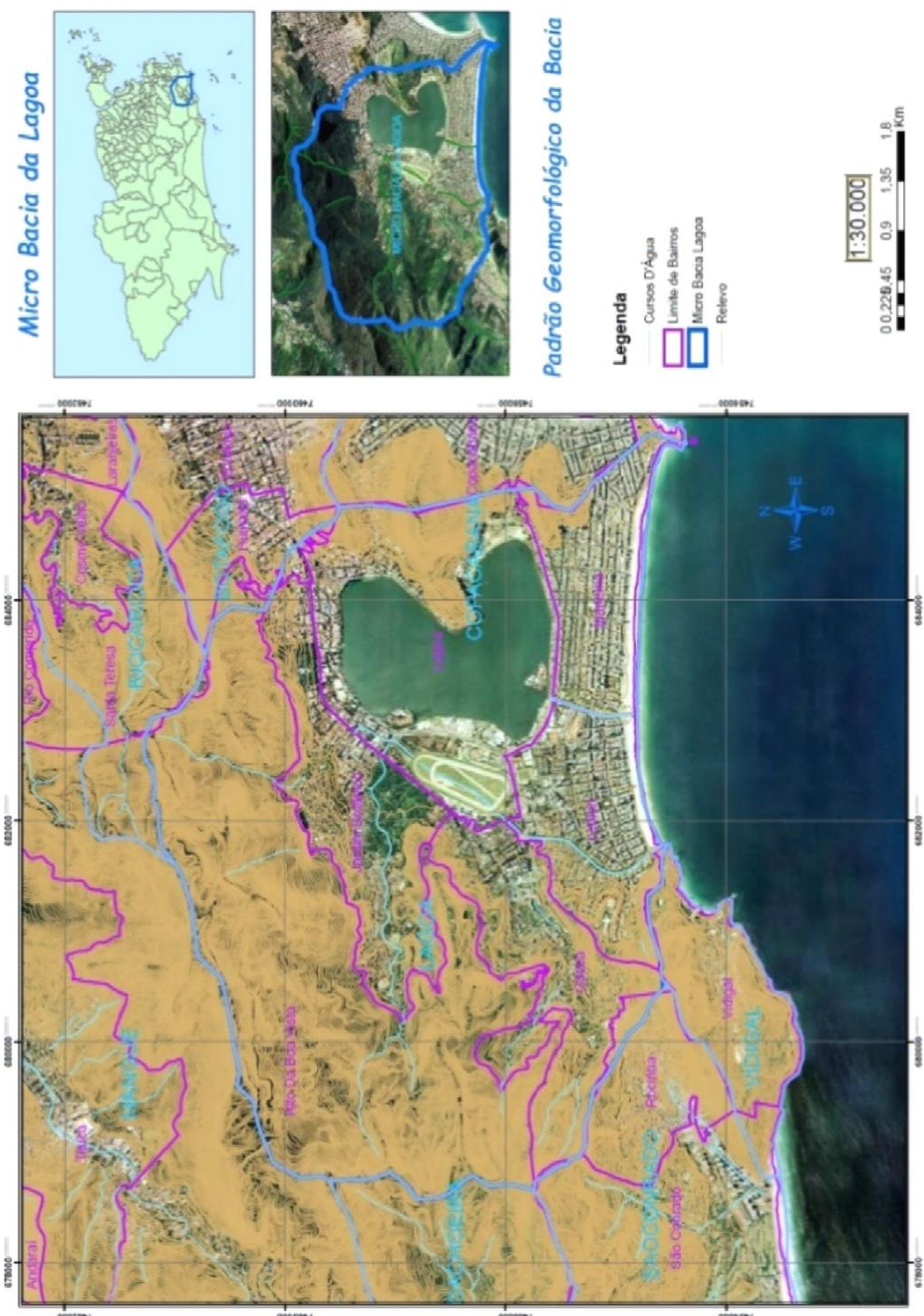
Mapa E12 - Padrão de Ocupação da Região da LRF

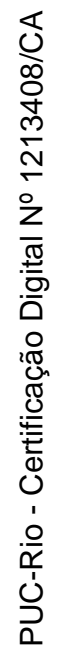

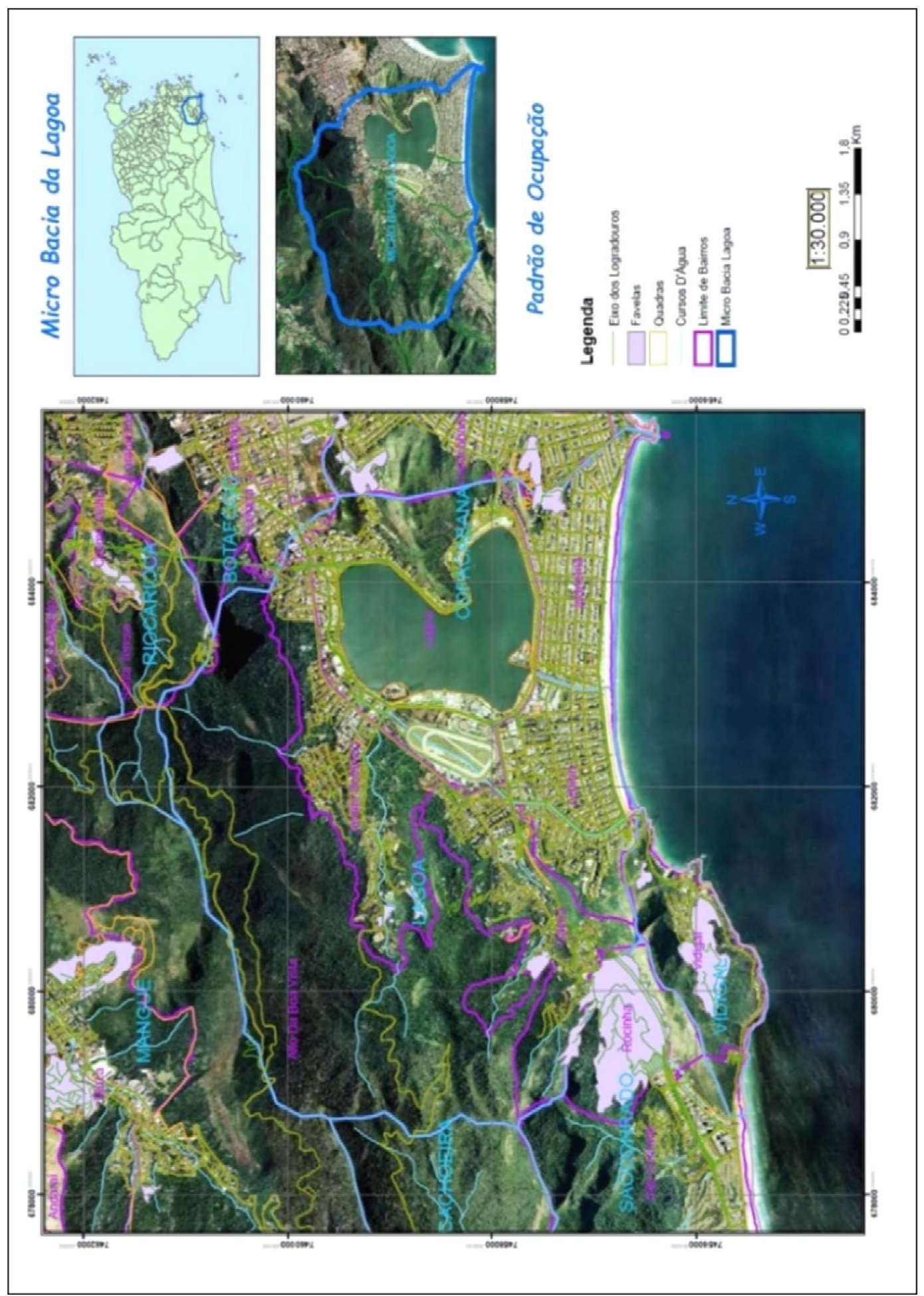


Mapa E13 - Condições da Cobertura Vegetal da Região da LRF

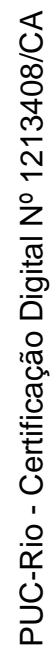

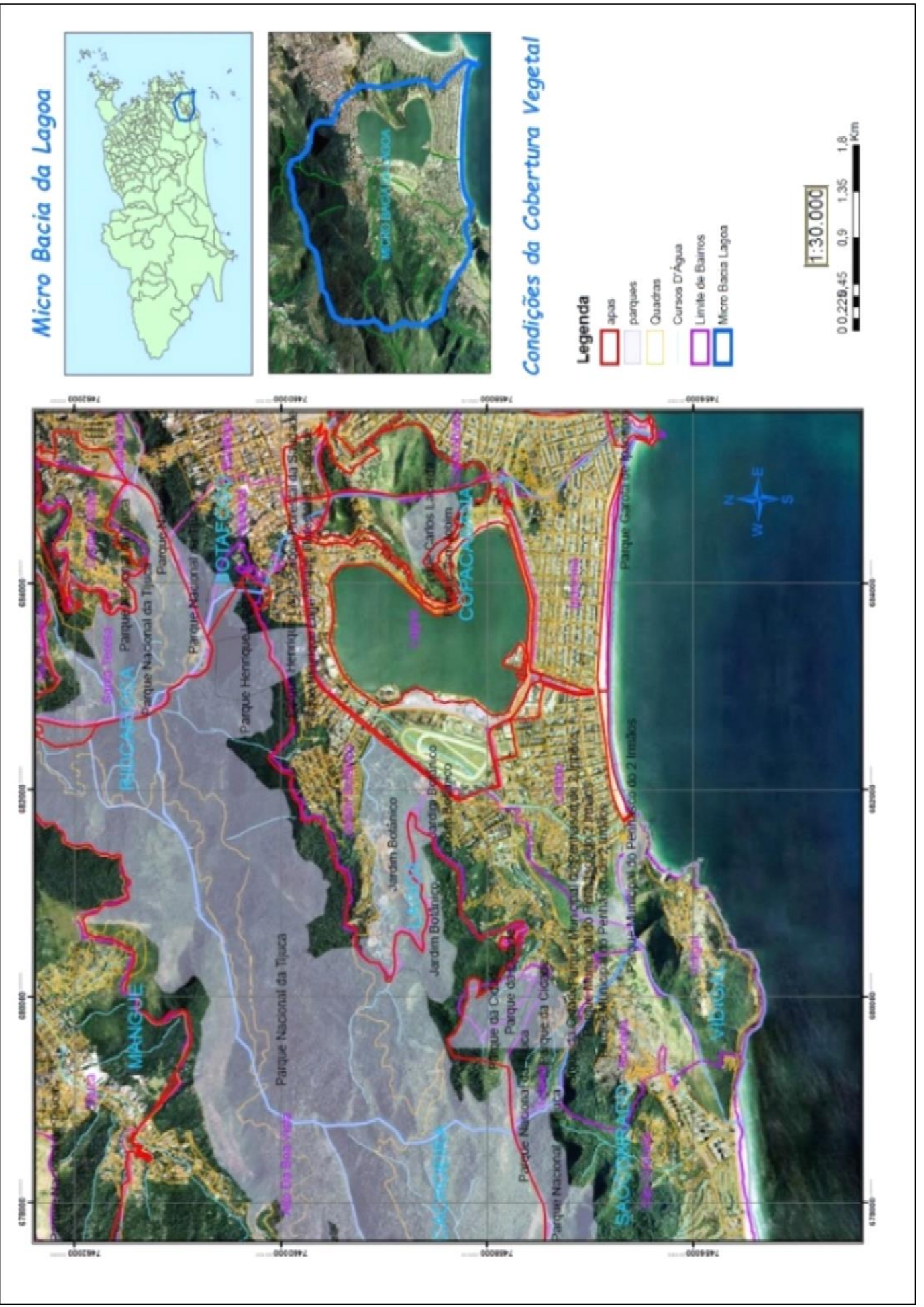


Mapa E14 - Caracterização/Relação c/ Distribuição de Serviços

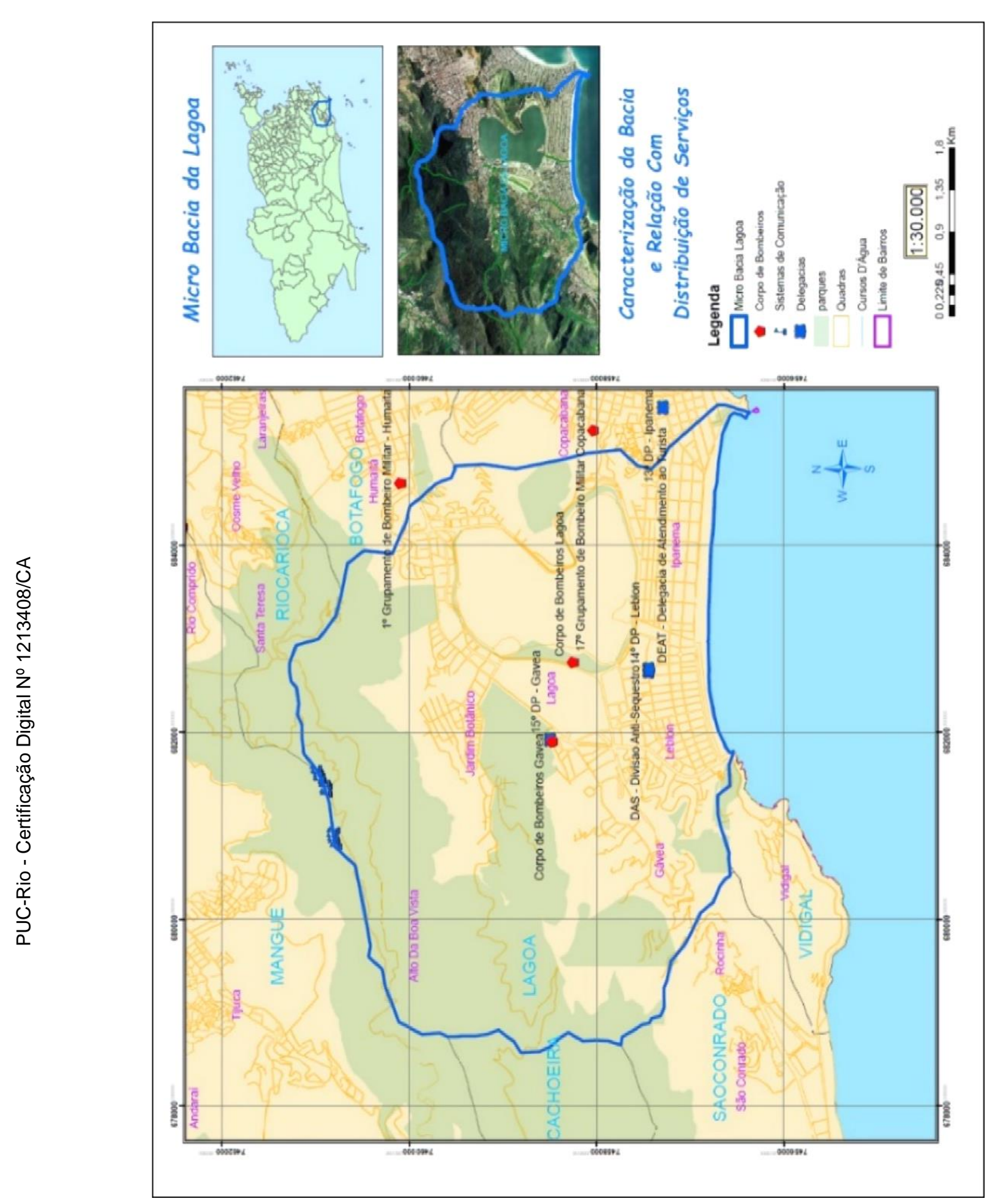

